NIST

PUBLICATIONS

\title{
AN EVALUATION OF KERMA IN CARBON AND THE CARBON CROSS SECTIONS
}

\section{E. J. Axton \\ Guest Researcher}

U.S. DEPARTMENT OF COMMERCE

Technology Administration

National Institute of Standards

and Technology

Gaithersburg, MD 20899

$-Q C$

100

.456

4838

1992

C. 2 



\section{AN EVALUATION OF KERMA IN CARBON AND THE CARBON CROSS SECTIONS}

\section{E, J. Axton \\ Guest Researcher}

U.S. DEPARTMENT OF COMMERCE Technology Administration National Institute of Standards and Technology

Gaithersburg, MD 20899

Current Address:

36 Hurst Road, East Molesey

Surrey, KT 8 9AF ENGLAND

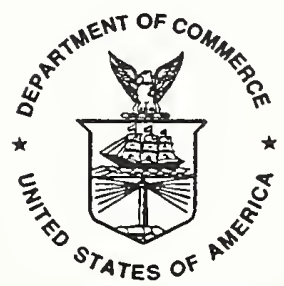

U.S. DEPARTMENT OF COMMERCE Baßbara Hackman Franklin, Secretary

TECHNOLOGY ADMINISTRATION Robert M. White, Under Secretary for Technology

NATIONAL INSTITUTE OF STANDARDS

AND TECHNOLOGY

John W. Lyons, Director 


\section{Introductory Statement}

This work was completed in 1988, and was a major input to the Evaluated Nuclear Data File ENDF/B-VI for carbon. There is continuing interest in this work. Therefore it is being issued as an NIST Internal Report (NISTIR). 


\section{ABSTRACT}

A preliminary simultaneous least squares fit to measurements of kerma in carbon, and carbon cross sections taken from the ENDF/B-V file was carried out. In this calculation the shapes of the total cross section and the various partial cross sections were rigid but their absolute values were allowed to float in the fit within the constraints of the ENDF/B-V uncertainties. The construction of the ENDF/B-V file imposed improbable shapes, particularly in the case of the ${ }^{12} \mathrm{C}\left(\mathrm{n}, \mathrm{n}^{\prime} 3 \alpha\right)$ reaction, which were incompatible with direct measurements of kerma and of the reaction cross sections. Consequently a new evaluation of the cross section data became necessary. Since the available time was limited the new evaluation concentrated particularly on those aspects of the ENDF/B-V carbon file which would have most impact on kerma calculations. Following the new evaluation of cross sections new tables of kerma factors were produced. Finally, the simultaneous least squares fit to measurements of kerma and the new cross section file was repeated. 


\section{CONTENTS}

List of Tables

List of Figures

1. Introduction $\ldots \ldots \ldots \ldots \ldots \ldots \ldots \ldots \ldots \ldots \ldots \ldots$

2. Preliminary Evaluation Based on ENDF/B-V Cross Section Data . . . . . . . 1

3. Evaluation of Cross Section Data . . . . . . . . . . . . . . . 3

3.1 Energy Range 5 to $20 \mathrm{MeV} \ldots \ldots \ldots \ldots \ldots \ldots \ldots \ldots$

3.2 Energy Range 20 to $32 \mathrm{MeV} \ldots \ldots \ldots \ldots \ldots \ldots \ldots \ldots$

3.3 Total Cross Sections . . . . . . . . . . . . . . . . . . 4

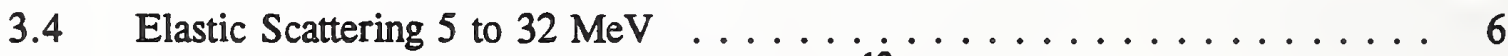

3.5 Inelastic Scatter to the $4.439 \mathrm{MeV}$ level of ${ }^{12} \mathrm{C} \ldots \ldots \ldots \ldots . \ldots 9$

3.6 The ${ }^{12} \mathrm{C}\left(\mathrm{n}, \alpha_{0}\right)^{9} \mathrm{Be}$ Reaction to the Ground State of ${ }^{9} \mathrm{Be} \ldots \ldots \ldots \ldots . \ldots 10$

3.7 The ${ }^{12} \mathrm{C}\left(\mathrm{n}, \mathrm{n}^{\prime} 3 \alpha\right)$ Reaction . . . . . . . . . . . . . . . . 11

3.8 The ${ }^{12} \mathrm{C}(\mathrm{n}, \mathrm{p})^{12} \mathrm{~B}$ Reaction Cross Section . . . . . . . . . . . . 13

3.9 The ${ }^{12} \mathrm{C}(\mathrm{n}, \mathrm{d})^{11} \mathrm{~B}$ Reaction Cross Section . . . . . . . . . . . . 13

3.10 The ${ }^{12} \mathrm{C}(\mathrm{n}, \gamma)^{13} \mathrm{C}$ Reaction Cross Section . . . . . . . . . . . 13

3.11 The ${ }^{12} \mathrm{C}(\mathrm{n}, 2 \mathrm{n})^{11} \mathrm{C}$ Reaction . . . . . . . . . . . . . . . . 13

3.12 Other Charged Particle Reactions with Thresholds Below $26.4 \mathrm{MeV}$. . . . 14

4. The Unification Procedure . . . . . . . . . . . . . . . . . . . 17

4.1 Correlations Between the Uncertainties of the Data . . . . . . . . . 17

4.2 Smoothing of Evaluated Cross Section Files . . . . . . . . . . 18

4.3 Energy Range from 5 to $6.174 \mathrm{MeV} \ldots \ldots \ldots \ldots \ldots \ldots 18$

4.4 Energy Range from 6.2 to $7.888 \mathrm{MeV} \ldots \ldots \ldots \ldots . \ldots . \ldots 19$

4.5 Energy Range from 7.89 to $10 \mathrm{MeV} \ldots \ldots \ldots \ldots \ldots$

4.6 Energy Range from 10.05 to $14.5 \mathrm{MeV} \ldots \ldots \ldots \ldots . \ldots . \ldots 19$

4.7 Energy Range from 14.55 to $15.25 \mathrm{MeV} \ldots \ldots \ldots \ldots . \ldots 20$

4.8 Energy Range from 15.45 to $17.3 \mathrm{MeV} \ldots \ldots \ldots \ldots . \ldots 20$

4.9 Energy Range from 17.3 to $20.5 \mathrm{MeV} \ldots \ldots \ldots \ldots . \ldots . \ldots 20$

4.10 Energy Range from 20.6 to $23.6 \mathrm{MeV} \ldots \ldots \ldots \ldots \ldots . \ldots . \ldots 20$

4.11 Energy Range from 23.7 to $24.6 \mathrm{MeV} \ldots \ldots \ldots \ldots \ldots . \ldots . \ldots 21$

4.12 Energy Range from 24.7 to $26.3 \mathrm{MeV} \ldots \ldots \ldots \ldots \ldots . \ldots \ldots$

4.13 Energy Range from 26.4 to $32 \mathrm{MeV} \ldots \ldots \ldots \ldots \ldots . \ldots . \ldots 21$

5. Unfolding the Components of the ${ }^{12} \mathrm{C}\left(\mathrm{n}, \mathrm{n}^{\prime} 3 \alpha\right)$ Cross Section . . . . . . . . . 21

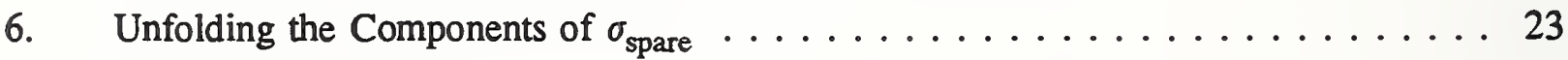

7. Angular Distributions . . . . . . . . . . . . . . . . . . . 24

8. Calculations of Mean Kinetic Energy Transfer and Kerma . . . . . . . . . . . 24

9. Simultaneous Fit to Carbon Cross Sections and Kerma . . . . . . . . . . . . . 26

10. Discussion . . . . . . . . . . . . . . . . . . . . 26

11. Conclusions .......................... 27

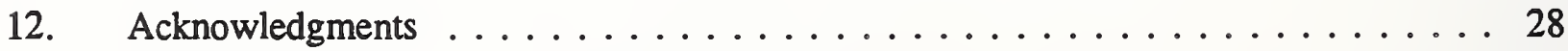

References . . . . . . . . . . . . . . . . . . . . . . . . 29

Appendix 1 Comments on the Least Squares Fitting Procedure . . . . . . . . . . . . . 34

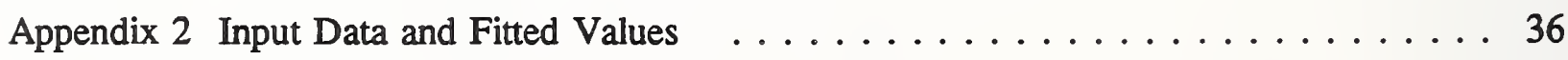

Appendix 3 Description of Functions Used in the Tables $\ldots \ldots \ldots \ldots \ldots$ 


\section{List of Tables}

Table 1. ENDF/B-V File Structure and Sources of Data . . . . . . . . . . . . 38

Table 2. Reactions with Thresholds Below $32 \mathrm{MeV} \ldots \ldots$. . . . . . . . . . . 39

Table 3. Total Cross Section Ratios of Various Data Sets to Ci78 . . . . . . . . . . . 40

Table 4. Total Cross Sections Reduced to ENDF/B-V Energy Grid . . . . . . . . . . 41

Table 5a. Input Data for Evaluation of Cross Section for Elastic Scattering . . . . . . 47

Table 5b. Evaluated Data for Cross Section for Elastic Scattering . . . . . . . . 48

Table 6a. Input Data for Evaluation of Cross Section for Inelastic Scattering . . . . . . 51

Table $6 \mathrm{~b} . \quad$ Evaluated Cross Section for Inelastic Scattering $\ldots \ldots \ldots \ldots \ldots \ldots$

Table 7a. Input Data for Evaluation of the ${ }^{12} \mathrm{C}\left(\mathrm{n}, \alpha_{0}\right)^{9} \mathrm{Be}$ Cross Section $\ldots \ldots \ldots . . .55$

Table 7b. Evaluated Cross Section for the Reaction ${ }^{12} \mathrm{C}\left(\mathrm{n}, \alpha_{0}\right)^{9} \mathrm{Be} \ldots \ldots \ldots \ldots \ldots$

Table 8a. Input Data for the Evaluation of the ${ }^{12} \mathrm{C}\left(\mathrm{n}, \mathrm{n}^{\prime} 3 \alpha\right)$ Reaction . . . . . . . . 59

Table $8 \mathrm{~b}$. Evaluated Cross Section for the ${ }^{12} \mathrm{C}\left(\mathrm{n}, \mathrm{n}^{\prime} 3 \alpha\right)$ Reaction $\ldots \ldots \ldots \ldots \ldots$

Table 9. Evaluated Data for the ${ }^{12} \mathrm{C}(\mathrm{n}, \mathrm{p})^{12} \mathrm{~B}$ Reaction $\ldots \ldots \ldots \ldots \ldots \ldots$

Table 10. Evaluated Data for the ${ }^{12} \mathrm{C}(\mathrm{n}, \mathrm{d})^{11} \mathrm{~B}$ Reaction $\ldots \ldots \ldots \ldots \ldots \ldots$

Table 11. Evaluated Data for the ${ }^{12} \mathrm{C}(\mathrm{n}, 2 \mathrm{n})^{11} \mathrm{C}$ Reaction $\ldots \ldots \ldots \ldots \ldots \ldots$

Table 12. Integrals of Double Differential Charged Particle Production Data . . . . . . 64

Table 13. Evaluated Cross Sections for the Reactions ${ }^{12} \mathrm{C}(\mathrm{n}, \mathrm{np}){ }^{11} \mathrm{~B},{ }^{12} \mathrm{C}(\mathrm{n}, \mathrm{t}){ }^{10} \mathrm{~B}$, ${ }^{12} \mathrm{C}(\mathrm{n}, \mathrm{d} \alpha){ }^{7} \mathrm{Li},{ }^{12} \mathrm{C}(\mathrm{n}, \mathrm{p} \alpha){ }^{8} \mathrm{Li}$, and ${ }^{12} \mathrm{C}\left(\mathrm{n},{ }^{6} \mathrm{Li}\right){ }^{7} \mathrm{Li} \ldots \ldots 65$

Table 14. Blanket Cross Sections for the Remaining 17 Reactions in Table $2\left(\sigma_{\text {spare }}\right) \ldots 66$

Table 15a. Unified Cross Sections and Uncertainties from 5 to $6.174 \mathrm{MeV}$. . . . . . . 67

Table 15b. Average Correlation Matrix for Total and Partial Cross Sections from 5 to

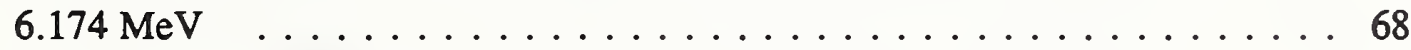

Table 16a. Unified Cross Sections and Uncertainties from 6.18 to $7.888 \mathrm{MeV}$. . . . . . 69

Table 16b. Average Correlation Matrix for Total and Partial Cross Sections from 6.18 to

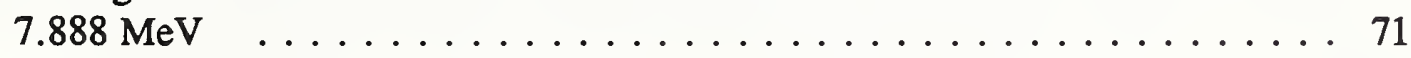

Table 17a. Unified Cross Sections and Uncertainties from 7.897 to $10 \mathrm{MeV}$. . . . . . 72

Table 17b. Average Correlation Matrix for Total and Partial Cross Sections from 7.897 to

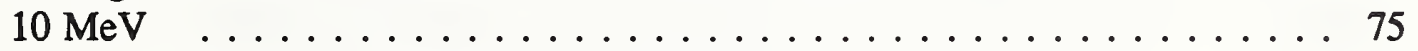

Table 18a. Unified Cross Sections and Uncertainties from 10.05 to $14.5 \mathrm{MeV}$. . . . . 76

Table 18b. Average Correlation Matrix for Total and Partial Cross Sections from 10.05 to

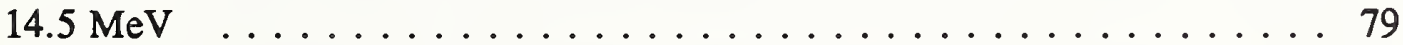

Table 19a. Unified Cross Sections and Uncertainties from 14.553 to $15.25 \mathrm{MeV}$. . . . 80

Table 19b. Average Correlation Matrix for Total and Partial Cross Sections from 14.553 to

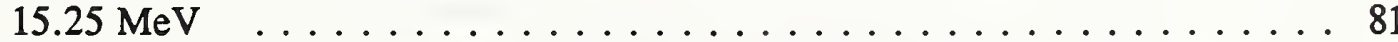


Table 20a. Unified Cross Sections and Uncertainties from 15.448 to $17.3 \mathrm{MeV}$

Table 20b. Average Correlation Matrix for Total and Partial Cross Sections from 15.448 to $17.3 \mathrm{MeV}$

Table 21a. Unified Cross Sections and Uncertainties from 17.301 to $20.5 \mathrm{MeV}$

Table 21b. Average Correlation Matrix of Total and Partial Cross Sections from 17.301 to $20.5 \mathrm{MeV}$

Table 22a. Unified Cross Sections and Uncertainties from 20.6 to $23.6 \mathrm{MeV}$

Table 22b. Average Correlation Matrix of Total and Partial Cross Sections from 20.6 to $23.6 \mathrm{MeV}$

Table 23a. Unified Cross Sections and Uncertainties from 23.7 to $24.6 \mathrm{MeV}$

Table 23b. Average Correlation Matrix of Total and Partial Cross Sections from 23.7 to 24.6 MeV

Table 24a. Unified Cross Sections and Uncertainties from 24.7 to $26.3 \mathrm{MeV}$

Table 24b. Average Correlation Matrix of Total and Partial Cross Sections from 24.7 to $26.3 \mathrm{MeV}$

Table 25a. Unified Cross Sections and Uncertainties from 26.4 to $29.2 \mathrm{MeV}$

Table 25b. Average Correlation Matrix of Total and Partial Cross Sections from 26.4 to $29.2 \mathrm{MeV}$

Table 26a. Unified Cross Sections and Uncertainties from 29.3 to $32 \mathrm{MeV}$

Table 26b. Average Correlation Matrix of Total and Partial Cross Sections from 29.3 to $32 \mathrm{MeV}$

Table 27. Normalized Components of the ${ }^{12} \mathrm{C}\left(\mathrm{n}, \mathrm{n}^{\prime} 3 \alpha\right)$ Reaction 101

Table 28. Cross Sections Unfolded from the Cross Section $\sigma_{\text {spare }}$ in Tables 25a and 26a . 105 Table 29. Extension to $32 \mathrm{MeV}$ of ENDF/B-V Files for $\mathrm{fl} \ldots \ldots \ldots \ldots$

Table 30. Kerma Factors and Uncertainties from 5 to $6.174 \mathrm{MeV}$. . . . . . . . . . 108

Table 31. Kerma Factors and Uncertainties from 6.18 to $7.888 \mathrm{MeV}$. . . . . . . . 109

Table 32. Kerma Factors and Uncertainties from 7.897 to $10 \mathrm{MeV}$. . . . . . . . . . 111

Table 33. Kerma Factors and Uncertainties from 10.05 to $14.5 \mathrm{MeV} \ldots \ldots \ldots \ldots 13$

Table 34. Kerma Factors and Uncertainties from 14.553 to $15.25 \mathrm{MeV}$. . . . . . . . 115

Table 35. Kerma Factors and Uncertainties from 15.448 to $17.3 \mathrm{MeV} \ldots \ldots \ldots \ldots . . .116$

Table 36. Kerma Factors and Uncertainties from 17.301 to $20.5 \mathrm{MeV}$. . . . . . . . . 117

Table 37. Kerma Factors and Uncertainties from 20.6 to $23.6 \mathrm{MeV}$. . . . . . . . . 118

Table 38. Kerma Factors and Uncertainties from 23.7 to $24.6 \mathrm{MeV}$. . . . . . . . . . 119

Table 39. Kerma Factors and Uncertainties from 24.7 to $26.3 \mathrm{MeV} \ldots \ldots \ldots \ldots$. . . . 120

Table 40. Kerma Factors and Uncertainties from 26.4 to $29.2 \mathrm{MeV}$. . . . . . . . . 121

Table 41. Kerma Factors and Uncertainties from 29.3 to $32 \mathrm{MeV} \ldots \ldots \ldots \ldots . \ldots 122$

Table 42. Input Data and Fitted Values for Simultaneous Fit . . . . . . . . . 123

Table 43. Kerma Factors from Simultaneous Fit . . . . . . . . . . . . . 124 


\section{List of Figures}

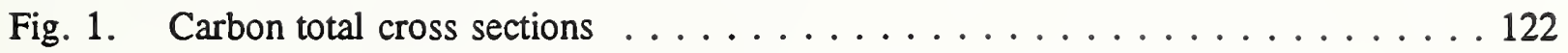

Fig. 2. Cross sections for carbon elastic scattering $\ldots \ldots \ldots \ldots \ldots \ldots \ldots \ldots$

Fig. 3. Cross sections for inelastic scattering to $4.43 \mathrm{MeV}$ state of ${ }^{12} \mathrm{C} \ldots \ldots \ldots \ldots 124$

Fig. 4. Cross section for ${ }^{12} \mathrm{C}\left(\mathrm{n}, \alpha_{0}\right)^{9} \mathrm{Be}$ reaction $\ldots \ldots \ldots \ldots \ldots \ldots \ldots \ldots$

Fig. 5. Cross section for ${ }^{12} \mathrm{C}\left(\mathrm{n}, \mathrm{n}^{\prime} 3 \alpha\right)$ reaction $\ldots \ldots \ldots \ldots \ldots \ldots \ldots$

Fig. 6. Cross section for ${ }^{12} \mathrm{C}(\mathrm{n}, \mathrm{p}){ }^{12} \mathrm{~B}$ and ${ }^{12} \mathrm{C}(\mathrm{n}, \mathrm{d})^{11} \mathrm{~B}$ reactions $\ldots \ldots \ldots \ldots \ldots$

Fig. 7. Carbon total kerma factors, $f G y \cdot m^{2} \ldots \ldots \ldots \ldots \ldots \ldots$

Fig. 8. Kerma from carbon elastic and inelastic scattering $\mathrm{fGy} \cdot \mathrm{m}^{2} \ldots \ldots \ldots$. . . . 129

Fig. 9. Kerma from ${ }^{12} \mathrm{C}(\mathrm{n}, \mathrm{p}){ }^{12} \mathrm{~B},{ }^{12} \mathrm{C}(\mathrm{n}, \mathrm{d}){ }^{11} \mathrm{~B}$, and ${ }^{12} \mathrm{C}(\mathrm{n}, \mathrm{np}){ }^{11} \mathrm{~B}$ reactions $\ldots \ldots \ldots 130$

Fig. 10. Kerma from ${ }^{12} \mathrm{C}(\mathrm{n}, 2 \mathrm{n}){ }^{11} \mathrm{C},{ }^{12} \mathrm{C}(\mathrm{n}, \mathrm{t})^{10} \mathrm{~B}$, and ${ }^{12} \mathrm{C}(\mathrm{n}, \mathrm{d} \alpha)^{7} \mathrm{Li}$ reactions $\ldots \ldots \ldots 131$

Fig. 11. Kerma from ${ }^{12} \mathrm{C}\left(\mathrm{n},{ }^{6} \mathrm{Li}\right){ }^{7} \mathrm{Li},{ }^{12} \mathrm{C}(\mathrm{n}, \mathrm{p} \alpha){ }^{8} \mathrm{Li}$ reactions, and from the reactions

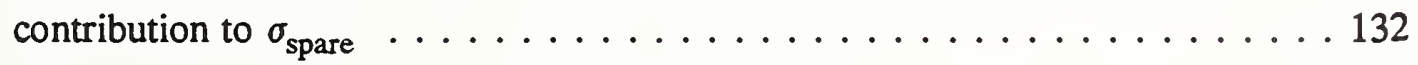

Fig. 12. Kerma from ${ }^{12} \mathrm{C}\left(\mathrm{n}, \alpha_{0}\right){ }^{9} \mathrm{Be}$ and ${ }^{12} \mathrm{C}\left(\mathrm{n}, \mathrm{n}^{\prime} 3 \alpha\right)$ reactions $\ldots \ldots \ldots \ldots \ldots$

Fig. 13. Shapes of cross sections for inelastic scattering to higher excited states of ${ }^{12} \mathrm{C} \ldots 134$

Fig. 14. Shapes of cross sections for inelastic scattering to pseudo-states of ${ }^{12} \mathrm{C} \ldots \ldots 135$ 



\section{INTRODUCTION}

Recent measurements of kerma (mnemonic for kinetic energy released in matter) in carbon indicate that values of this quantity calculated on the basis of cross sections taken from the ENDF/B-V file ( $\mathrm{Ca} 80$ ) are probably too high, particularly in the energy range from 15 to $20 \mathrm{MeV}$. Measurements of the inelastic scattering cross section to the first excited state of ${ }^{12} \mathrm{C}$, and of the ${ }^{12} C\left(n, n^{\prime} 3 \alpha\right)$ cross section in this energy range which have appeared since the establishment of ENDF/B-V suggest that the former should be higher, and the latter lower.

A preliminary exercise is to perform a least squares fit to the available data for kerma and the cross sections in order to find best values for these parameters. The basis of the fitting procedure has been described elsewhere, (Ax86) and a brief description is given in Appendix 1.

The calculation is programmed on a SAGE computer in APL ("A Programming Language"), which is specially suitable for matrix manipulations and has many other advantages over the traditional FORTRAN-type languages.

\section{PRELIMINARY EVALUATION BASED ON ENDF/B-V CROSS SECTION DATA}

The initial problem is the definition of a suitable model, which must be capable of representing all cross sections and partial cross sections, and kerma and partial kerma analytically in terms of a limited number of parameters whose values can be changed in the fitting process.

A full representation of all the cross-section data in the ENDF/B-V files including the covariance files would introduce too many variables and the covariance matrix alone would occupy more than the available capacity of most computers. Moreover, the limited amount of information in the covariance files of ENDF/B-V is in a very condensed form, and is considered to grossly overestimate the correlations between individual partial cross sections at different neutron energies whilst ignoring completely the important correlations between the partial cross sections at the same energy. This subject will be discussed in more detail in a later section.

This preliminary calculation has been carried out with a very simple model in which the cross sections are taken from ENDF/B-V and multiplied by various factors which are initially unity, but which are allowed to float in the least squares fit within the constraints of their uncertainties. Thus, the absolute values of the cross sections can change, but not their shapes as a function of energy, which is another way of saying that there is $100 \%$ correlation between cross sections at different energies. This procedure comes fairly close to representing the status of the ENDF/B-V covariance files.

The first six floating parameters in the fit are multiplying factors for the total, elastic, inelastic, $(n-\alpha),(n-p)$, and $(n-d)$ reactions. The $\left(n, n^{\prime} 3 \alpha\right)$ reaction is represented as the total cross section minus the sum of the remaining partial cross sections. There are ten floating parameters altogether, the remaining four being the multiplying factors applicable to the first Legendre coefficients in the angular distributions for the elastic scattering reaction, and the ENDF/B-V reactions MT51; MT52, and MT53, which 
represent inelastic scattering to the first three excited states of ${ }^{12} \mathrm{C}$. These coefficients are known as $f 1$ values. The only departure from ENDF/B-V at this stage is that $f 1$ for ENDF/B-V reaction MT53 is applied to all reactions leading to higher excited states of ${ }^{12} \mathrm{C}$, in order to introduce some variability into the mean kinetic energy imparted in the $\left(n, n^{\prime} 3 \alpha\right)$ reaction.

Any measurement of a cross section, partial cross section, or total or partial kerma can then be entered into the system as an APL language function of these ten floating parameters, as seen in Appendix 2. Total carbon kerma is represented by $\mathrm{fk}$, and $\mathrm{fka}$ and $\mathrm{fk} 3 \mathrm{a}$ represent partial kerma for the $(\mathrm{n}, \alpha)$ and $\left(n, n^{\prime} 3 \alpha\right)$ reactions. Similarly, csa and cs3a are the cross sections for these reactions. feb3a is the average energy, imparted in the (n, n' $3 \alpha$ ) reaction. Representative definitions of some of these functions are given in Appendix 3 .

These representations are not merely identifiers. They are executable APL functions, and when called, they evaluate the appropriate quantity using the current values of the variable parameters.

Appendix 2 shows author or source, date, measured function, measured value, uncertainty, fitted value, residual, and weighted residual, the sum of squares of which is $\chi^{2}$.

Any number of derived functions of the fitted parameters can be calculated.

The data set may not be complete, but it probably gives a reasonable initial estimate of the eventual outcome. The calculation covers the energy range from 11 to $20 \mathrm{MeV}$. The total kerma at $14.1 \mathrm{MeV}$ is reduced by $16 \%$ from the initial value. The $\left(n, n^{\prime} 3 \alpha\right)$ cross section is reduced by between $10 \%$ and $17 \%$ over the range considered. This is achieved by reducing the total, elastic, $(n, \alpha)$, and $(n, d)$ cross sections by $6,5.5,11$, and $5.3 \%$ respectively, and increasing the inelastic by 7.98 . This latter increase is supported by inelastic angular distribution measurements which appeared after ENDF/B-V was established.

The fitted values of the floating parameters gp[1] through gp[10] can be used in conjunction with the ENDF/B-V cross section file to calculate, as derived functions, for any energy grid, both the total kerma and the partial kerma from the individual reactions. The value of $x^{2}$ for 37 degrees of freedom is 46 , which is not unreasonable.

Probably the main defect in the simple model described above is the rather improbable shape of the $\left(n, n^{\prime} 3 \alpha\right)$ cross section derived as represented in ENDF/B-V and which cannot change appreciably using this simple model. There have been some important new measurements of carbon cross sections since the establishment of ENDF/B-V, and it is concluded that a re-evaluation of the carbon cross sections is necessary. It is also necessary to design a new model which will allow a more realistic shape to the cross section for the $\left(n, n^{\prime} 3 \alpha\right.$ ) reaction which in turn requires a revised structure for the carbon cross section file. 


\section{EVALUATION OF CROSS SECTION DATA}

\subsection{Energy Range $5 \mathrm{MeV}$ to $20 \mathrm{MeV}$}

The intention is to re-evaluate the cross section data from $5 \mathrm{MeV}$ to $20 \mathrm{MeV}$, and to extend the energy range up to $32 \mathrm{MeV}$. The ENDF/B-V file will be retained except where new data renders it obsolete, or where there is a need to change the structure. The structure and data sources for ENDF/B-V are shown in table 1. In this file the requirement that the sum of all the partial cross sections should equal the total cross section is met, approximately by designating a selected partial cross section as equal to the total cross section less the sum of the remaining partial cross sections. The approximation arises because the equality can only be exact if the total and elastic cross sections are quoted to seven significant figures in order to retain only two significant figures for the $(n, \gamma)$ reaction.

From $5 \mathrm{MeV}$ to the threshold of the $\left(n, n^{\prime} 3 \alpha\right)$ reaction at $7.887 \mathrm{MeV}$ the selected cross section is that of inelastic scatter to the first excited state of ${ }^{12} \mathrm{C}$, and above this energy is that of the $\left(n, n^{\prime} 3 \alpha\right)$ cross section. In both cases the selected partial cross sections are small, and consequently they finish up with undesirable shapes over at least part of the energy range. An example is the lone peak in the inelastic cross section ${ }^{1}$ at $14.86 \mathrm{MeV}$. Of far more importance, however, is the shape of the $\left(n, n^{\prime} 3 \alpha\right)$ cross section, which is not supported by now available measurements and which leads to kerma values considerably higher than the measured values.

The total and partial cross section values at a given energy form an overdetermined set of which none is known exactly. The requirement that the total cross sections should equal the sum of the partial cross sections can therefore be met by a weighted least squares minimization procedure ${ }^{2}$ to determine the partial cross sections, with the total cross section entered as their sum. In this way all the data carries its true weight, and the resulting correlation matrix more correctly describes correlations between the partial cross sections, and between them and the total. This information is needed to determine the uncertainties of calculated kerma values. ENDF/B-V does not mention correlations between partial cross sections, but nevertheless they exist in a distorted form due to the method used to obtain congruity. Correlations will be discussed in more detail later.

A consequence of this difference in procedure provokes the need to evaluate the cross sections for inelastic scatter and the $\left(n, n^{\prime} 3 \alpha\right)$ reaction in their entirety.

\footnotetext{
${ }^{1}$ Because all higher states are presumed to decay by the break-up reaction to 3 alpha particles, this term will, henceforth in this report refer only to inelastic scatter to the first excited state of ${ }^{12} \mathrm{C}$ unless otherwise stated.

${ }^{2}$ This procedure will be referred to henceforth as the unification procedure. It treats all partial cross sections equally. This is in contradistinction to the evaluation procedure used in ENDF/B-V where all but one of the partial cross sections were evaluated and the remaining cross section was determined by subtracting the evaluated partial cross sections from the total.
} 
The sections of ENDF/B-V which will be retained are listed below. However, this does not mean that they will remain unchanged in the final evaluation because the cross section data will change in the unification procedure.

(1) All data below $5 \mathrm{MeV}$

(2) Elastic scattering cross sections below $8 \mathrm{MeV}$

(3) ( $n, p)$ cross sections

(4) $(n, d)$ cross sections

(5) All angular distribution data

(6) $(n, \gamma)$ cross sections.

Some of the above items are retained because there is no time available to review them. The $(n, p)$ reaction cross section, and the angular distribution data for elastic and inelastic scattering would benefit from consideration of new measurements.

Of the Legendre coefficients given in file 4 of ENDF/B-V, only the first quoted, $f 1$, is important to kerma calculations. A review of $f 1$ for elastic scattering and for inelastic scattering to the first three excited states of ${ }^{12} \mathrm{C}$ in isolation would tend to be misleading and might produce unacceptable angular distributions.

\subsection{Energy Range $20 \mathrm{MeV}$ to $32 \mathrm{MeV}$}

In this energy range the total cross section and those for elastic and inelastic scatter and for the $\left(n, n^{\prime} 3 \alpha\right)$ reaction are evaluated to $32 \mathrm{MeV}$, and plausible assumptions are made which enable the cross sections for the $(n, \alpha)$, $(n, p)$, and $(n, d)$ reactions to be extended to $32 \mathrm{MeV}$. However, over this energy range numerous other reactions become energetically possible for which little cross section data is available. Possible reactions below $32 \mathrm{MeV}$ are listed in table 2 .

\subsection{Total Cross Section. $5 \mathrm{MeV}$ to $32 \mathrm{MeV}$}

The experimental data obtained in several experimental determinations of the carbon total cross section were obtained from the Brookhaven Data Center. of particular interest were the data sets for experiments done since ENDF/ $\mathrm{V}-\mathrm{B}$ was issued. Three data sets fell into this category. They are:

1. Cierjacks et al. from Karlsruhe (Ci78)

2. Auchampaugh from Los Alamos (Au79)

3. Kellie et al. from NBS (Ke79).

In addition the earlier work from NBS by (Sc67) was examined. Other recent measurements were found to have inadequate resolution.

To make a point by point comparison of the different experimental results it was decided to reduce all data to a common energy grid. The ENDF/B-V energy grid was chosen. This grid has the virtue that the energy values used are such that linear interpolation of the cross section between any two successive points will not induce an interpolation error greater than 18. 
The spacing of data points in energy varied greatly. The Karlsruhe data had the finest energy grid, having on average ten data values between each set of ENDF/B-V energy values. At the other extreme the NBS data had as few as one data value for every 3 ENDF/B-V values.

The large amount of data in the Karlsruhe and Los Alamos data was combined into sets with the same energy grid as ENDF/B-V by linear least squares fitting. The experimental data points lying between two ENDF/B-V points were fitted and values defined by this fit were calculated for each ENDF/B-V end point. This produced two values of calculated cross sections with associated uncertainties for each ENDF/B-V energy grid point; one value determined by the set with lower energies, and the other by the set with higher energies. The weighted mean of these two calculated values was then taken as the "experimental" value associated with the ENDF/B-V energy grid point. An estimated uncertainty of 1.58 was added to the uncertainties of these weighted means to cover uncertainties which would not be expected to be reduced in the fitting procedure.

For the NBS data a simple linear interpolation between experimental data points was used to define the values associated with the ENDF/B-V energy grid point.

The values obtained using the procedure described were then plotted and compared visually. It could be seen that the Karlsruhe data set was clearly superior in resolution to the other three sets of data.

Any technique that would combine the data sets would produce a data set with lower resolution than the Karlsruhe data. A procedure was developed to preserve the resolution of the Karlsruhe data and yet take advantage of any additional information the other data sets might provide.

The point by point ratios of the Los Alamos and NBS data to the Karlsruhe data were taken. If the data sets differed only in resolution and statistical precision then the ratio values have an average value of a reduced $\chi^{2}$ of unity. The unweighted and weighted means of the ratio was calculated for each set of data together with its standard deviation and the standard error of the mean.

The results of this procedure are shown in table 3 . Ratio tests were made over the energy ranges 5 to $8 \mathrm{MeV}, 8$ to $10 \mathrm{MeV}, 10$ to $14.8 \mathrm{MeV}$ and 14.8 to $20 \mathrm{MeV}$. Similar tests were made to compare the Ci78 data with the ENDF/B-V file. As would be expected the ratios tend to be high at the energies of cross section peaks and lower in valleys, due to the superior resolution of the Ci78 data.

The results show that the normalization of the Ci78 data is not contested by the alternatives, and in view of their better resolution and accuracy, these data reduced to the ENDF/B-V energy grid are accepted for this evaluation. The total cross sections and uncertainties are shown in table 4, and compared with the ENDF/B-V version in figure 1. 


\subsection{Elastic Scattering $5 \mathrm{MeV}$ to $32 \mathrm{MeV}$}

Elastic scattering cross sections are invariably obtained by integration of measured angular distributions of scattered neutrons. The amount of detail in the reporting of results varies considerably. In some cases only the angular distributions themselves are given. In others, Legendre coefficients and/or integrated cross sections are given as well as, or instead of, angular distributions. Similarly, there is considerable variation in the amount of information available on the uncertainties. In some cases relative uncertainties are given for each angle together with an overall normalization uncertainty which is quoted individually for each incident neutron energy. Sometimes only relative uncertainties or only total uncertainties are quoted and it is necessary to guess the normalization uncertainty. None of the authors considered provided any information regarding the degree of correlation between the normalization uncertainties for different neutron energies.

For each measurement energy by each author varying degrees of Legendre polynomial fitting were performed to test for stability, meaning that the addition of one extra coefficient does not produce a significantly different cross section. Also, the fitted coefficients were used to test for negative cross sections at zero and 180 degrees. Measurements which failed either of these tests were rejected. The degree of agreement with the authors' own integrated cross sections varied with the degree of detail in the uncertainty statements. For the evaluation the authors integrated cross sections are adopted if provided. Failing that, the authors fitted Legendre coefficients are used if provided. Otherwise, integrations as described above are used.

For evaluation purposes the energy range from $5 \mathrm{MeV}$ to $32 \mathrm{MeV}$ is divided into suitable sections, each section being evaluated separately using a method based on that described by Ha70. For each section the main, or most prolific author is selected, being the author covering the largest section of the range with measurements at the most energies. These data are then interpolated at any energy at which another author or other authors have made measurements. In some cases the second most prolific author is interpolated as well. Each author is regarded as having a bias factor which is initially unity with an uncertainty equal to the authors normalization uncertainty. If the latter varies with neutron energy an average is used. A weighted least squares fit is then performed in which the floating parameters are the cross section at each neutron energy and the author bias factors. This is a non-linear least squares problem and therefore it is necessary to choose starter values for the unknown. parameters, which are usually the main author's values for the cross sections and unity for the authors' bias factors. The output consists of the best values for the cross sections at each energy at which there is a measurement available, and the best values of the author bias factors. At interpolated energies the cross sections are weighted averages of two or more measurements, and at other energies they are the main author's measurements divided by his bias factor. Some consideration has to be given to the input covariance matrix. Consideration of the cross section shapes as a function of neutron energy for different authors and the same energy range tend to suggest that the normalization uncertainties are not very strongly correlated. These correlations are certainly unknown, and under these circumstances it is considered more accurate to ignore them than to guess them. Input covariance matrices for these fits therefore have no non-zero off-diagonal elements, and are constructed from the total uncertainties of the cross sections. 
Output covariance matrices for the cross sections and author bias factors are generated. These will be discussed later in section 4.1

\subsubsection{Energy Range 5-7.936 MeV}

Over this energy range the cross sections of ENDF/B-V are adopted. The region was very carefully evaluated for ENDF/B-V and there are no new measurements to be considered. The covariance files of ENDF/B-V give the total uncertainty of 2.298 at each energy. 1008 correlation is given within the three energy ranges 5-6 MeV, 6-7 MeV, and 7-8 MeV with approximately 248 correlation between the three ranges. However, it was found when operating the unification procedure described in section 3.1 that these total uncertainties were too small and produced undesirable aberrations in the total and other partial cross sections and abnormal distributions of residuals in the unification fits. The elastic scatter data were therefore down-weighted by increasing the uncertainties to 58 and discarding the correlations. The justification for this procedure is as follows.

In section 3.1 it was observed that the ENDF/B-V definition of the cross sections for inelastic scattering and the $\left(n, n^{\prime} 3 \alpha\right)$ reaction as the total cross section less the sum of the remaining partial cross sections over two different energy ranges led to undesirable features in the shapes of these cross sections. At a meeting with Dr. F. G. Perey and Dr. C. Y. Fu at Oak Ridge National Laboratory in October 1986 these problems were discussed, and it was concluded that it was wrong to define a small cross section as effectively the difference between two large ones, and that less disturbance would occur if the elastic cross section was defined as the total less the remainder. Since this would be equivalent to giving zero weight to the evaluated elastic scattering cross section data the downweighting described above does not seem unreasonable.

\subsubsection{Energy Range 8.04 to $8.69 \mathrm{MeV}$}

The available measurements are those of Ve73, $\mathrm{Ha} 75, \mathrm{Pe} 69$, and $\mathrm{Pe} 71$ where the measurements of the main author, Pe71, are interpolated at the energies of the other authors for the least squares calculation designated FIT1. The output author bias factors are $0.985 \pm 0.071,0.994 \pm 0.060,1.068 \pm 0.071$, and $1.029 \pm 0.063$ for $\mathrm{Ve} 73, \mathrm{Ha} 75, \mathrm{Pe} 69$, and $\mathrm{Pe} 71$, respectively. The value of $\chi^{2}$ is 53.6 for 8 degrees of freedom so the agreement cannot be regarded as good. Consequently external rather than internal uncertainties are propagated.

\subsubsection{Energy Range 8.98 to $11.96 \mathrm{MeV}$}

The available measurements are those of Ve73, Ha75, Gl76, and Sa81, where the main author G176 is interpolated at the energies of the other authors for the calculation designated FIT2. The output author bias factors are $1.012 \pm 0.098,1.009 \pm 0.064,0.985 \pm 0.062$, and $1.008 \pm 0.140$ in the above order, respectively. Again, the agreement is poor, with a $\chi^{2}$ value of 94 for 8 degrees of freedom. External uncertainties are propagated. 


\subsubsection{Energy Range 12 to $14.43 \mathrm{MeV}$}

The available measurements are those of $\mathrm{Ha} 75, \mathrm{Gl76}, \mathrm{Ba} 85$, and $\mathrm{Bo68}$, where the author Gl76 is interpolated at the energies of $\mathrm{Ha} 75$ and $\mathrm{Ba} 85$, and $\mathrm{Bo6} 8$ is interpolated at these energies and those of Gl76. The calculation is designated FIT3 and the author bias factors become $0.968 \pm 0.019$, $1.017 \pm 0.019,1.008 \pm 0.036$, and $0.990 \pm 0.027$ for the authors Ha75, G176, $\mathrm{Ba} 85$, and Bo68, respectively. The value of $\chi^{2}$ is 34.1 for 9 degrees of freedom. As before, external uncertainties are propagated.

\subsubsection{Energy Range 14.43 to $16 \mathrm{MeV}$}

The available measurements are those of Ha75, Gu81, Ar71, G176, and Bo68 where the authors G176 and Bo68 are interpolated at the energies of the others. The calculation is referenced FIT4 and the author bias factors become, in the order listed above, $0.952 \pm 0.029,0.952 \pm 0.034,0.873 \pm 0.045,1.034 \pm 0.022$, and $0.986 \pm 0.029$. The value of $\chi^{2}$ is 12.9 for 6 degrees of freedom, and external uncertainties are propagated.

\subsubsection{Energy Range 16 to $26 \mathrm{MeV}$}

The available measurements are those of $\mathrm{Ba} 85, \mathrm{Me} 84, \mathrm{De} 70$, and Bo68, where the author Bo68 is interpolated at the energies of the others. The calculation is referenced FIT5 and the author bias factors, in the order listed above, are respectively, $1.000 \pm 0.045,1.002 \pm 0.024,1.009 \pm 0.026$, and $0.901 \pm 0.022$. The value of $\chi^{2}$ is 28.2 for 7 degrees of freedom, so external uncertainties are propagated. Unfortunately, the data of Bo68 are available only in graphical form. Nevertheless it is possible to read the cross section data to approximately \pm 2.58 accuracy, and a further uncertainty of \pm 108 was added. Although the data looks highly correlated between different energies the shapes of the cross sections as a function of neutron energy of Bo68 and Me84 are quite different and therefore both set of data are regarded as uncorrelated at different energies.

\subsubsection{Energy Range 26 to $32 \mathrm{MeV}$}

This range is covered by interpolating a straight line between the $26 \mathrm{MeV}$ cross section of $\mathrm{Me} 84$ and the $40 \mathrm{MeV}$ cross section of Wi86.

The Wi86 data are given as angular distributions covering the angular range to $95^{\circ}$ (CM), beyond which angle the differential cross section was too low to measure. In order to obtain an integrated cross section it was assumed that the differential cross section continued to fall at the same rate per 10 degree interval. The integration was obtained both trapezoidally and by Legendre polynomial fitting, with similar results. The latter is preferred because it also produces an $f 1$ value (for kerma calculations) which does not look out of place with regard to the values in the energy range $20-26 \mathrm{MeV}$. Thirteen Legendre coefficients were required.

The input data for the elastic cross section evaluation are shown in table 5a, and the evaluated data in table 5b. The I following a reference signifies an interpolated value. The fit references in the first column refer to the least-squares calculation described in section 3.4 above. The $B$ following author references indicate that the authors measured value has been 
divided by the appropriate bias factor. The unified (see section 4) elastic cross section is compared with the evaluated and ENDF/B-V versions in figure 2.

3.5 Inelastic Scatter to the $4.439 \mathrm{MeV}$ Level of ${ }^{12} \mathrm{C}$.

The evaluation of this cross section follows in general the procedures described in the previous section. The ENDF/B-V file does not contain an independent evaluation of this cross section in the energy range from the threshold at $4.812 \mathrm{MeV}$ to the threshold of the $\left(n, n^{\prime} 3 \alpha\right.$ ) reaction at $7.887 \mathrm{MeV}$, it being equated to the total cross section minus the sum of the elastic and the $(n, \gamma)$ cross sections.

\subsubsection{Energy Range 5.0 to $6.5 \mathrm{MeV}$}

For this evaluation, from 5.0 to $5.306 \mathrm{MeV}$, the values were taken from the $\gamma$-ray production data of Mo72. In using this data it is assumed that the measurement made at $125^{\circ}$ can also be used to obtain the total $\gamma$-ray production cross section since this angle is a zero of the second Legendre polynomial, and the fourth Legendre polynomial coefficient is assumed to be negligible (see La75). From 5.32 to $6.5 \mathrm{MeV}$ the data of Pe71 are used.

\subsubsection{Energy Range 6.508 to $8.69 \mathrm{MeV}$}

The available measurements are those of Ha75, Mc72, Pe71, Pe69, Ve73, and Mo72, where the latter was interpolated at the energies of the other authors for input to the least squares calculation designated FIT6. The author bias factors listed in the above order are $0.987 \pm 0.055,0.932 \pm 0.078$, $0.950 \pm 0.056,0.953 \pm 0.058,1.046 \pm 0.061$, and $0.975 \pm 0.056$. External uncertainties are quoted because the value of $\chi^{2}$ is 140 for 29 degrees of freedom.

\subsubsection{Energy Range 8.69 to $19.09 \mathrm{MeV}$}

The available measurements are those of Ha75, Ad80, Gu81, Ba85, Ve73, Sa81, G176, and Mo72. For the least squares calculation designated FIT7 both G176 and Mo72 were interpolated at the energies of the other authors and Mo72 was interpolated at the energies of G176. As in the previous fits of this type the residuals are high compared with the uncertainties, and a high value of $\chi^{2}$ (635 for 49 degrees of freedom) is obtained. Consequently external uncertainties are propagated. The author bias factors, in the order of the references listed above are $0.953 \pm 0.050,1.056 \pm 0.123,1.008 \pm 0.238$, $1.019 \pm 0.153,0.914 \pm 0.061,0.996 \pm 0.229,1.027 \pm 0.056$, and $0.894 \pm 0.048$, respectively.

\subsubsection{Energy Range 20.8 to $35 \mathrm{MeV}$}

The angular distribution measurements of Me84 are used for the range 20.8 to $26 \mathrm{MeV}$. The fitted Legendre coefficients are to be found in table 3 of the thesis. The extension to $35 \mathrm{MeV}$ is achieved by using the deformed optical model calculation, in the absence of reported measurements, in this energy range. Over the energy range 20 to $25 \mathrm{MeV}$ the optical model calculations are in good agreement with cross sections calculated from the Legendre coefficients in the overlap region 20 to $25 \mathrm{MeV}$. Similar optical model calculations are available for the elastic cross sections, but the agreement with the measured 
cross sections calculated from the Legendre coefficients was not so good in the overlap region. Consequently the $40 \mathrm{MeV}$ measurement of Wi86 was preferred. Use of the optical model calculation for $30 \mathrm{MeV}$ would lead to an increase in the elastic scattering cross section varying between zero and about 50 mb over the energy range from 26 to $32 \mathrm{MeV}$. The effect of this alternative on the calculation of kerma will be considered later.

The input data for the evaluation of the inelastic scattering to the first excited state of ${ }^{12} \mathrm{C}$ are shown in table $6 \mathrm{a}$, and the evaluated data in table $6 \mathrm{~b}$. In the reference column the letters $B$ and $I$ have the same significance as before. The letter 0 distinguishes the optical model calculations from measured values. The unified inelastic scattering cross section is compared with the evaluated and ENDF/B-V versions in figure 3.

\subsection{The ${ }^{12} \mathrm{C}\left(\mathrm{n}, \alpha_{0}\right)^{9} \mathrm{Be}$ Reaction to the Ground state of ${ }^{9} \mathrm{Be}$}

Most of the data contributing to the ENDF/B-V evaluation of this reaction is based on the reciprocity theorem as applied to cross section measurements of the inverse reaction ${ }^{9} \mathrm{Be}(\alpha, n)^{12} \mathrm{C}$. In their description of the evaluation Lachkar ( $L$ 75) considered, in addition to the references listed in table 1 , the ${ }^{12} \mathrm{C}\left(\mathrm{n}, \alpha_{0}\right)^{9} \mathrm{Be}$ measurements of $\mathrm{Br} 68, \mathrm{Al63}, \mathrm{Ki} 69, \mathrm{Ch} 64, \mathrm{Ko67}, \mathrm{Sa} 71$, and Hu66, as well as the ${ }^{9} \mathrm{Be}(\alpha, n)^{12} \mathrm{C}$ measurements of $\mathrm{Ri57}$, De70, and $\mathrm{Ni62}$. The references for ${ }^{9} \mathrm{Be}(\alpha, n)^{12} \mathrm{C}$ measurements do not usually contain reciprocity calculations for the inverse reaction so it has not been possible to locate all of the data. The data for Re60 and $0 b 72$ are available in graphical form in $0 b 72$. Those of De70 and Ni62 have not been located, but reciprocity calculations of Va70 were reported in Ge76, and are quoted without uncertainties in Di87.

\subsubsection{Energy Range from Threshold to $11.04 \mathrm{MeV}$}

Some new ${ }^{12} \mathrm{C}\left(\mathrm{n}, \alpha_{\mathrm{o}}\right)^{9} \mathrm{Be}$ measurements at PTB (Di87) have become available, although as yet only in graphical form, but it is possible to extract ${ }^{3}$ the data to an accuracy of $\pm 0.6 \mathrm{mb}$. In this energy range the data of $\operatorname{Re} 60$ and $0 b 72$ are also available graphically. The Di87 data are in general, lower than those of the other authors, but not catastrophically so. As reported in La75, the data of Da63 are approximately a factor of two lower, and have not been included. The data of Ge76 are taken from Di87. Following the procedure adopted for the elastic cross section, the PTB data up to $10.03 \mathrm{MeV}$ have been interpolated at the energies of the other three authors for the least squares fit designated FIT8 from which the author bias factors emerge as $1.043 \pm 0.098,1.165 \pm 0.126$, $1.003 \pm 0.112$, and $0.982 \pm 0.080$ for the authors Re60, Ob72, Ge76, and Di87, respectively. In view of the large disparity in values and uncertainties the author bias factor starter values were entered as $1 \pm 0.2,1 \pm 0.2,1 \pm 0.2$, and $1 \pm 0.05$, respectively. The value of $\chi^{2}$ is 96.9 for 31 degrees of freedom, and as for the previous two reactions, external uncertainties are propagated. The Di87 data above $10.03 \mathrm{MeV}$ are not used because they exhibit a sharp rise which is attributed to the on-set of the $\left(n, n^{\prime} 3 \alpha\right)$ reaction. Consequently the energy range from 10.03 to $11.04 \mathrm{MeV}$ is satisfied by the Re60 and the $0 b 72$ data divided by their appropriate author bias factors. From the threshold to $7.34 \mathrm{MeV}$ the ENDF/B-V evaluation is used with uncertainties of \pm 208 .

\footnotetext{
${ }^{3}$ Subsequent comparison of the extracted data with revised values in K187 showed agreement of the order of 18 .
} 


\subsubsection{Energy Range 11.3 to $14.5 \mathrm{MeV}$}

The only data available from 11.333 to $13.6 \mathrm{MeV}$ are those of Ve68, which are in harmony with those of $0 \mathrm{~b} 72$ at $11.04 \mathrm{MeV}$, and with the average of the three measurements at $14.1 \mathrm{MeV}$. This energy range is therefore covered by the data of Ve68.

The cross section at $14.1 \mathrm{MeV}$ is derived from a weighted least squares fit to the data of $\mathrm{Ki} 69, \mathrm{Ha} 84$, and Gr55 (FIT9). The cross section at this point emerges as $75.3 \pm 11.5 \mathrm{mb}$ with a value of 0.072 for $\chi^{2}$ indicating good agreement within the rather large quoted uncertainties.

At $14.5 \mathrm{MeV}$ the data of $\mathrm{Ch} 64$ is used, and at $14.0 \mathrm{MeV}$, that of Al63.

\subsubsection{Energy Range 15.6 to $21.46 \mathrm{MeV}$}

This energy range is spanned by the data of Sa71 to $18.65 \mathrm{MeV}$ at which energy they are overlapped by those of St76 which extend to $21.7 \mathrm{MeV}$.

In La75 the data of Sa71 and De63 were not accepted because they were approximately a factor of two lower than those of Br68, Hu66, and Ni62 in the overlapping range 15 to $17 \mathrm{MeV}$. It has not been possible to locate the $(n, \alpha)$ data of De63 and $\mathrm{Ni62}$, but $\mathrm{Sa71}$ is supported by St76 at the overlap energy of $18.65 \mathrm{MeV}$. The range 15.8 to $18.65 \mathrm{MeV}$ is therefore covered by a least squares calculation (FIT10) comprising the data of St76, Br68, Hu66, and Sa71 with Sa71 interpolated at the energies of the other authors. The data of Hu66 is renormalized to the cross section at $14.1 \mathrm{MeV}$ obtained in 3.6 .2 above. A $\chi^{2}$ value of 4.45 is obtained with 4 degrees of freedom, so the external and internal uncertainties are not significantly different. Sa71 data at other energies are included, divided by the appropriate bias factor. The bias factors are $0.857 \pm 0.176,1.106 \pm 0.170,1.081 \pm 0.176$, and $0.850 \pm 0.146$ for St76, Br68, Hu66, and Sa71, respectively. The energy range from 18.92 to $21.46 \mathrm{MeV}$ is covered by the data of $\mathrm{St76}$ divided by the appropriate bias factor.

\subsubsection{Energy Range 22-32 MeV}

To cover this energy range an exponential tail was added. The exponent (5.640 $\mathrm{MeV}^{-1}$ ) was obtained by fitting an exponential curve to the evaluated data from 16 to $21.46 \mathrm{MeV}$. Twenty-five percent uncertainty is attributed to the extension. This exponential curve appears to give a reasonable approximation to the $\left(n, \alpha_{0}\right)$ cross section even down to $12 \mathrm{MeV}$.

The input data selected for the evaluation of the ${ }^{12} \mathrm{C}\left(n, \alpha_{0}\right){ }^{9} \mathrm{Be}$ reaction is listed in table $7 \mathrm{a}$, and the evaluated data in table $7 \mathrm{~b}$. The latter is compared with the unified and ENDF/B-V versions in figure 4.

\subsection{The ${ }^{12} C\left(n, n^{\prime} 3 \alpha\right)$ Reaction}

The cross section for this reaction was not evaluated in ENDF/B-V. From its threshold at $7.887 \mathrm{MeV}$ to $20 \mathrm{MeV}$ the cross section is determined as the total cross section less the sum of all remaining partial cross section. All 
inelastic scattering reactions to states higher than the $4.439 \mathrm{MeV}$ level in ${ }^{12} \mathrm{C}$ are deemed to contribute to the $\left(n, n^{\prime} 3 \alpha\right.$ ) reaction (as discussed in La75) and they are represented in ENDF/B-V as reactions MT52 through MT68. Of these the first four represent inelastic scattering to the $7.563,9.638,10.3$, and $10.84 \mathrm{MeV}$ states of ${ }^{12} \mathrm{C}$ and the remainder represent scattering to pseudo-states at $0.5 \mathrm{MeV}$ intervals up to $17.25 \mathrm{MeV}$. In addition the reaction

${ }^{12} \mathrm{C}(\mathrm{n}, \alpha)^{9} \mathrm{Be} * \rightarrow 2 \alpha+n$, represented in ENDF/B-V by reaction MT91, contributes $10-128$ to the $\left(n, n^{\prime} 3 \alpha\right)$ reaction cross section. The sum of the reactions MT52 to MT68 and MT91 is normalized to the total $\left(n, n^{\prime} 3 \alpha\right.$ ) cross section determined as described above.

In this evaluation the ${ }^{12} \mathrm{C}\left(\mathrm{n}, \mathrm{n}^{\prime} 3 \alpha\right)$ reaction cross section is evaluated from available measured values. The reactions MT52 to MT68 and MT91 are, replaced by MT52-MT73 and MT91 as evaluated later in section 5, and the sum of the partial cross sections is normalized to the new unified total ${ }^{12} \mathrm{C}\left(\mathrm{n}, \mathrm{n}^{\prime} 3 \alpha\right)$ reaction cross section.

\subsubsection{Evaluation of the ${ }^{12} \mathrm{C}\left(\mathrm{n}, \mathrm{n}^{\prime} 3 \alpha\right)$ Cross Section}

The available data are those of Fr55, Br84, Va58, Co76, Gr69, Fa71, An84, and An86. The An84 measurements spanning the energy range 11-35 MeV are studies of kinematically complete events in nuclear emulsions exposed in a white spectrum of neutrons. The results were subsequently revised downwards significantly by several corrections by Br84, the most important of which was the subtraction of three-pronged events produced by reactions other than $\left(n, n^{\prime} 3 \alpha\right)$ which become significant above $16 \mathrm{MeV}$. Similar measurements using monoenergetic neutrons were reported in An76. The data set as a whole shows wide variations in the value of the cross section and no single set of data can be used for the interpolation technique used for the previous partial cross sections. Least squares fitting of the data to an arbitrary shape can be dangerous because it involves addition of information which does not really exist, namely the shape, and it invariably leads to output uncertainties which are much too low. However, in this case there appears to be no viable alternative. Consequently, a quadratic has been fitted to the data of Fr55, Fa71, Va58, Co76, An86, Gr69, and Br84 over the energy range from 11 to $20 \mathrm{MeV}$.

The data of An84 as corrected above $15 \mathrm{MeV}$ in $\mathrm{Br} 84$ were included. The An84 data at 14 and $15 \mathrm{MeV}$ are disproportionately high, and at 11-13 MeV considerably lower than the fitted curve, and have not been included.

Likewise, the data of St76 is not included because it is an average 408 low and shows wild fluctuations. Also $\mathrm{Ha} 84$ at $14 \mathrm{MeV}$ is excluded being considerably lower than all the other measurements in the neighborhood of $14 \mathrm{MeV}$.

The fitted curve for $(11<E<20 \mathrm{MeV})$ is

$$
\sigma=(-0.7537)+(0.1062 E)-\left(0.002674 E^{2}\right) b .
$$

A second quadratic was fitted to the data of Br84 from $20 \mathrm{MeV}$ to $35 \mathrm{MeV}$. Giving for $(21<\mathrm{E}<35 \mathrm{MeV})$

$$
\sigma=(-0.5165)-(0.01215 E)+\left(0.0000899 E^{2}\right) \quad b .
$$


The two curves join smoothly at $0.301 \mathrm{~b}(20 \mathrm{MeV})$ for the first, and $0.301 \mathrm{~b}$ (21 MeV) for the second. From threshold to $10.5 \mathrm{MeV}$ the sum of the reactions MT91 and MT52 is used, with a very small contribution from reaction MT53.

The uncertainties derived from FIT11 and FIT12 are, as expected, too small. More realistic uncertainties attributed to the evaluated curve are $20 \%$ for $\mathrm{E}<12 \mathrm{MeV}, 15$ f for $(12<\mathrm{E}<20 \mathrm{MeV})$ and 20 of for $20<\mathrm{E}<35 \mathrm{MeV}$. It should be emphasized that if the $\left(n, n^{\prime} 3 \alpha\right)$ reaction cross section evaluation were either significantly lower or higher it would cause problems with the unification procedure described in the following section over the energy range $12-20 \mathrm{MeV}$.

The consideration of inelastic scattering to the higher excited states of ${ }^{12} \mathrm{C}$ will be described in section 5 . The input data for the ( $\mathrm{n}, \mathrm{n}^{\prime} 3 \alpha$ ) reaction are listed in table $8 \mathrm{a}$ and the evaluated data in table $8 \mathrm{~b}$. The latter are compared with the unified and $E N D F / B-V$ versions in figure 5.

\subsection{The ${ }^{12} \mathrm{C}(\mathrm{n}, \mathrm{p})^{12} \mathrm{~B}$ Reaction Cross Section}

The ENDF/B-V evaluation is based on the data of Ri68, which are supported by that of $\mathrm{Kr} 57$ up to $16 \mathrm{MeV}$, but the latter are considerably higher above that energy. There are no new measurements. The Ri68 extends to $21.56 \mathrm{MeV}$ and is therefore used for this evaluation. The energy range from $21.56 \mathrm{MeV}$ to $32 \mathrm{MeV}$ is covered, as in the $\left(n, \alpha_{0}\right)$ reaction, by adding an exponential tail which is derived by fitting an exponential curve to the Ri68 data from 18.5 to $21.56 \mathrm{MeV}$. The exponent is $2.992 \mathrm{MeV}^{-1}$. The uncertainties are estimated for $(20<\mathrm{E}<32 \mathrm{MeV})$ as \pm 308 . The evaluated data for the ${ }^{12} \mathrm{C}(\mathrm{n}, \mathrm{p})^{12} \mathrm{~B}$ cross section appear in table 9. The unified cross section is shown in figure 6.

\subsection{The ${ }^{12} \mathrm{C}(\mathrm{n}, \mathrm{d})^{11} \mathrm{~B}$ Reaction Cross Section}

The ENDF/B-V evaluation is based on the reciprocity theorem applied to the Am57 measurements of the ${ }^{11} B(d, n)^{12} C$ reaction. The $(n, d)$ reaction to excited states of ${ }^{11} \mathrm{~B}$, and the ${ }^{12} \mathrm{C}(\mathrm{n}, \mathrm{np})$ cross sections were considered to be small and were ignored. There appear to be no new measurements. For this evaluation, the $(n, d)$ reaction to excited states of ${ }^{11} B$ is ignored, but it is discussed in section 8 . The ( $\mathrm{n}, \mathrm{np})$ reaction is considered in section 3.12. The extension of the ENDF/B-V file to $32 \mathrm{MeV}$ is achieved by adding an exponential tail derived by fitting an exponential curve to the data from 19 to $20 \mathrm{MeV}$. The exponent is $3.881 \mathrm{MeV}^{-1}$. The estimates of uncertainty are the same as in section 3.8 above. The evaluated data for the ${ }^{12} \mathrm{C}(n, d)^{11} \mathrm{~B}$ cross section appear in table 10. The unified cross section is shown in figure 6.

3.10 The ${ }^{12} \mathrm{C}(\mathrm{n}, \gamma)^{13} \mathrm{C}$ Reaction Cross Section

This cross section is taken directly from ENDF/B-V. Since this cross section is constant from 16 to $20 \mathrm{MeV}$ it is assumed to remain constant (at $0.21 \mathrm{~b})$ to $32 \mathrm{MeV}$ with an uncertainty of $\pm 10 \%$.

3.11 The ${ }^{12} \mathrm{C}(\mathrm{n}, 2 \mathrm{n})^{11} \mathrm{C}$ Reaction

This reaction has a threshold at $20.296 \mathrm{MeV}$. The data of An81 which are quoted with an uncertainty of 108 are used for this evaluation. The measurements of We81 which extend to $26 \mathrm{MeV}$ and are quoted to 148, are in reasonable 
agreement. Both sets of data are based on neutron activation to produce ${ }^{11} \mathrm{C}$ and therefore do not include contributions from other reactions in which two neutrons are emitted. The cross sections for the ${ }^{12} C(n, 2 n)^{11} c$ reaction are presented in table 11 .

\subsection{Other Charged Particle Reactions With Thresholds Below $26.4 \mathrm{MeV}$}

A further six charged particle reactions have thresholds below $26.4 \mathrm{MeV}$, for which little experimental evidence is available. However, it is possible to make rough estimates of the probable shapes of these cross sections as a function of neutron energy and approximate estimates of their size. The reactions concerned are ${ }^{12} \mathrm{C}(\mathrm{n}, \mathrm{np})^{11} \mathrm{~B},{ }^{12} \mathrm{C}(\mathrm{n}, \mathrm{t})^{10} \mathrm{~B},{ }^{12} \mathrm{C}\left(\mathrm{n},{ }^{3} \mathrm{He}\right)^{10} \mathrm{Be}$, ${ }^{12} \mathrm{C}\left(\mathrm{n},{ }^{6} \mathrm{Li}\right){ }^{7} \mathrm{Li},{ }^{12} \mathrm{C}(\mathrm{n}, \mathrm{d} \alpha)^{7} \mathrm{Li}$, and ${ }^{12} \mathrm{C}(\mathrm{n}, \mathrm{p} \alpha)^{8} \mathrm{Li}$. Of the reaction products ${ }^{6} \mathrm{Li}$, ${ }^{7} \mathrm{Li},{ }^{10} \mathrm{~B}$, and ${ }^{11} \mathrm{~B}$ are stable. ${ }^{8} \mathrm{Li}$ decays by $\beta$ emission to ${ }^{8} \mathrm{Be} \rightarrow 2 \alpha$ with a half-life of $0.84 \mathrm{~s} .{ }^{10} \mathrm{Be}$ is effectively stable since it has a half-life of $2.5 \times 10^{6} \mathrm{y}$. The Q-values and the threshold energies of the reactions are given in table 2 .

\subsubsection{Shape Information}

The shapes of the cross sections for the reactions ${ }^{12} \mathrm{C}\left(\mathrm{n}, \alpha_{0}\right)^{9} \mathrm{Be}$, ${ }^{12} \mathrm{C}(\mathrm{n}, \mathrm{p})^{12} \mathrm{~B}$, and ${ }^{12} \mathrm{C}(\mathrm{n}, \mathrm{d})^{11} \mathrm{~B}$ have certain characteristics in common. Coulomb barrier considerations prevent the cross sections from rising significantly until the Coulomb threshold is reached. The difference between the Coulomb threshold and the energetic threshold has been assessed in Ca80 as $0.1 \mathrm{zZ}$ where $z$ is the atomic number of the lighter emitted particle and $Z$ is the atomic number of the residual nucleus after particle emission. When three or more charged particles are emitted an averaging process is used. Each reaction cross section exhibits a peak at 3 or $4 \mathrm{MeV}$ above the threshold and then reduces more or less exponentially. The exponents given in sections $3.6,3.8$, and 3.9 for the $\left(n, \alpha_{0}\right),(n, p)$, and $(n, d)$ reactions appear to lie on a straight line as a function of the mass of the emitted particle. Whilst there is no theoretical basis for this relationship, in the absence of better information it has been used to estimate the cross section shapes for other reactions.

\subsubsection{Normalization Information}

A limited amount of information is available from the work of Su83 which presents double differential angular dependent energy spectra $\left(\mathrm{mb} \cdot \mathrm{sr}^{-1} \cdot \mathrm{MeV}^{-1}\right.$ ) for protons, deuterons, tritons, ${ }^{3} \mathrm{He}$, and $\alpha$-particles for neutron energies of $27.4,39.7$, and $60.9 \mathrm{MeV}$. Double integrals were performed trapezoidally to provide both charged particle production cross sections and charged particle kerma for the particles and neutron energies above. Firstly, the spectra were integrated at each angle and neutron energy to give $\mathrm{mb} \cdot \mathrm{sr}^{-1}$ and $\mathrm{mb} \cdot \mathrm{MeV} \cdot \mathrm{sr}^{-1}$. It was assumed that the spectra terminated at the highest particle energy listed, and that the intensity at zero energy was equal to the intensity at the first listed energy. Secondly, the results of the first integration were integrated over the range 0 to $180^{\circ}$. Here it was assumed that the intensity at zero degrees was equal to that at the first listed angle, and that the intensity fell to zero at $180^{\circ}$ or at the first measurement angle at which no measurements were recorded. The results of these integrations are shown in table 12. It is the measurements at $27.4 \mathrm{MeV}$ that are of particular interest for this evaluation, since they provide almost the only information on the reactions discussed in this section. 
Compared with this evaluation the cross section of $431 \mathrm{mb}$ for the total production of $\alpha$-particles appears to be very low. From tables 7 and 8 the total cross section for $\alpha$-particle production $\left(3 \times \sigma_{n, n} ; \alpha+\sigma_{n, \alpha}\right)$ is 760 excluding any allowance for the ${ }^{12} \mathrm{C}(\mathrm{n}, \mathrm{p} \alpha)^{8} \mathrm{Li},{ }^{12} \mathrm{C}(\mathrm{n}, \mathrm{d} \alpha)^{7} \mathrm{Li}^{3}$, and ${ }^{1}{ }^{3} \mathrm{C}(\mathrm{n}, \mathrm{t \alpha})^{6} \mathrm{Li}$ reactions. After making a modest allowance for these reactions it would be necessary to reduce $\sigma_{n, n} \cdot 3 \alpha$ by between $110 \mathrm{mb}$ and $140 \mathrm{mb}$, in order to produce agreement with the integrals of Su83. Such a low value would be in disagreement with the evaluation in table 8 . Furthermore, in order to maintain unification with the total cross section, a further $110 \mathrm{mb}$ - $140 \mathrm{mb}$ would have to be re-allocated to the other partial cross sections, of which the majority would be taken by the elastic cross section, thereby producing disagreement with the value from table $5 \mathrm{~b}$ based on Me84 and Wi86. Nevertheless, the cross sections for the production of $p, d, t$, and ${ }^{3} \mathrm{He}$ can be used as a guide to the probable strengths of the reactions discussed in this section.

Other evidence considered is the deficiency in the sum of the cross sections for the reactions already evaluated, relative to the total cross section over the energy range from $17.3 \mathrm{MeV}$ to $26.4 \mathrm{MeV}$.

\subsubsection{The ${ }^{12} \mathrm{C}(\mathrm{n}, \mathrm{np})^{11} \mathrm{~B}$ Reaction}

Since there are no measurements available for this reaction, the cross section is assumed to be similar in shape to that of the ${ }^{12} \mathrm{C}(n, d)^{11} B$ reaction, with a threshold of $17.3 \mathrm{MeV}$, a Coulomb threshold of $17.8 \mathrm{MeV}$, a peak value of $35 \mathrm{mb}$ at $20.9 \mathrm{MeV}$, and a "decay exponent" of $3.881 \mathrm{MeV}^{-1}$. The peak value was initailly chosen as equal to that of the $(n, d)$ reaction, and then halved after considering the cross-section deficiency at that energy. In retrospect it might have been better to retain the initial value in order to take up more of the Su83 proton production at $27.4 \mathrm{MeV}$.

\subsubsection{The ${ }^{12} \mathrm{C}(\mathrm{n}, \mathrm{t})^{10} \mathrm{~B}$ Reaction}

The cross section for this reaction has a threshold at $20.522 \mathrm{MeV}$, a Coulomb threshold at $21.02 \mathrm{MeV}$, and it is allocated a peak value of $12 \mathrm{mb}$ at 23.8 and an exponent of $3.881 \mathrm{MeV}^{-1}$. The shape was normalized to the single measurement, $8.6 \pm 2.4 \mathrm{mb}$ at $22.5 \mathrm{MeV}$, of Qa78. It absorbs $6 \mathrm{mb}$ at $27.4 \mathrm{MeV}$ which is most of the Su83 cross section for charged particle production at this energy. The exponent was derived by interpolation as described in Section 3.12.1.

\subsubsection{The ${ }^{12} \mathrm{C}\left(\mathrm{n},{ }^{3} \mathrm{He}\right){ }^{10} \mathrm{Be}$ Reaction}

This reaction has a threshold at $21.102 \mathrm{MeV}$. Since no ${ }^{3} \mathrm{He}$ particles were observed by Su83 at $27.4 \mathrm{MeV}$ this reaction is presumed to have a negligible cross section.

\subsubsection{The ${ }^{12} \mathrm{C}(\mathrm{n}, \mathrm{d} \alpha)^{7} \mathrm{Li}$ Reaction}

This reaction has a threshold at $24.281 \mathrm{MeV}$, an estimated Coulomb threshold at $25.0 \mathrm{MeV}$, and is allocated a peak value of $28 \mathrm{mb}$ at $27.3 \mathrm{MeV}$. The exponent $4.76 \mathrm{MeV}^{-1}$ is a compromise between the values for $\alpha$-particles and deuterons. The cross section at $27.4 \mathrm{MeV}$ is $27.8 \mathrm{mb}$ giving a total cross 
section at this energy for the production of deuterons of $35.9 \mathrm{mb}$ in comparison with the Su83 value of $34.7 \mathrm{mb}$.

\subsubsection{The ${ }^{12} \mathrm{C}(\mathrm{n}, \mathrm{p} \alpha)^{8} \mathrm{Li}$ Reaction}

This reaction has a threshold of $24.489 \mathrm{MeV}$, an estimated Coulomb threshold at $25.2 \mathrm{MeV}$, and is allocated a peak value of $38 \mathrm{mb}$ at $27.5 \mathrm{MeV}$. With an exponent of $3.9 \mathrm{MeV}^{-1}$ the cross section at $27.4 \mathrm{MeV}$ is $37.1 \mathrm{mb}$, giving a total cross section for the production of protons at $27.4 \mathrm{MeV}$ of $45.9 \mathrm{mb}$ in comparison with the Su83 value of $51.9 \mathrm{mb}$.

\subsubsection{The ${ }^{12} \mathrm{C}\left(\mathrm{n},{ }^{6} \mathrm{Li}\right)^{7} \mathrm{Li}$ Reaction}

All the partial cross sections considered in the previous sections have been evaluated without reference to the discrepancy between the total cross section and the aggregate of the partial cross sections. For this reaction, and for the seventeen additional reactions considered in the following sections, this is not possible. The discrepancy is the only evidence available for the determination of the magnitudes of the individual reaction cross sections.

Based on the shape information of section 3.12 .1 the cross section for the ${ }^{12} \mathrm{C}\left(\mathrm{n},{ }^{6} \mathrm{Li}\right)^{7} \mathrm{Li}$ reaction has a threshold at $22.683 \mathrm{MeV}$, a Coulomb threshold at $23.6 \mathrm{MeV}$, a peak value at $26.3 \mathrm{MeV}$. In the following section a cross section $\sigma_{\text {spare }}$ is defined as the sum of the remaining partial cross sections which become energetically possible between $26.4 \mathrm{MeV}$ and $32 \mathrm{MeV}$. The individual cross sections are then unfolded from the unified $\sigma_{\text {spare }}$. The magnitude of $\sigma_{\text {spare }}$ is determined by reference to the discrepancy between the total cross sections and the sum of the partial cross sections. For the unfolding technique to be viable it is necessary that the discrepancy should be approximately zero at $26.4 \mathrm{MeV}$. This condition is met by allocating to the ${ }^{12} \mathrm{C}\left(\mathrm{n},{ }^{6} \mathrm{Li}\right)^{7} \mathrm{Li}$ cross section a peak value of $100 \mathrm{mb}$. Although this value seems inordinately high there does not seem to be any alternative. The consequences of ignoring this reaction completely will be discussed at a later stage:

Evaluated cross sections for the reactions discussed in section 3.12 are presented in table 13.

\subsubsection{Other Reactions Which Become Energetically Possible Below $32 \mathrm{MeV}$}

Reference to table 2 shows a further seventeen reactions which are energetically possible below $32 \mathrm{MeV}$. There is no experimental evidence regarding their cross sections. For the purposes of the unification procedure described in the next section a cross section $\sigma_{\text {spare }}$ is defined as the sum of these cross sections and its magnitude is derived by smoothing the discrepancy between the total cross section and the sum of all remaining cross sections. In a later section $\sigma_{\text {spare }}$ is unfolded to give cross section curves for the individual reactions. The values adopted for $\sigma_{\text {spare }}$ are shown in table 14. 


\section{THE UNIFICATION PROCEDURE}

This is the procedure by which the requirement that the total cross section is equal to the sum of all the partial cross sections is met. It consists of a least squares fit to the over determined set of evaluated cross sections consisting of the total cross section and all the partial cross sections.

\subsection{Correlations Between the Uncertainties of the Data}

In the process of evaluating the cross sections for elastic scattering, inelastic scattering, the $\left(n, \alpha_{0}\right)$ reaction and the $\left(n, n^{\prime} 3 \alpha\right)$ reaction it was observed that measurements by different authors had quite different shapes as a function of energy, leading to the conclusion that errors in measurements at different energies are uncorrelated. In the cases of the scattering reactions this implies that the normalization uncertainties given for each energy, although in many cases equal, are at most only weakly correlated. No author has made any comment on this degree of correlation. Hence there is no evidence of correlations of the type given in ENDF/B-V file 33.

However, the least squares fitting process used for FIT1 to FIT10 produces correlation matrices between the uncertainties of the fitted cross section values at each neutron energy involved in the fit, and the various author bias factors. The evaluated cross section tables contain fitted cross sections intermingled on the energy scale with authors measurements divided by their appropriate bias factors. The correlations can only be preserved in a full covariance matrix. The unification procedure is carried out at each energy of the ENDF/B-V energy grid for the total cross section, and each partial cross section is interpolated at each of these energies. In order to preserve the correlations described it would be necessary to carry out the unification simultaneously at least over the energy range of a singe FIT. The input correlation matrix would be enormous. The output correlation matrix would be almost as large, and would probably never be used.

It was decided, therefore, that since these correlations are relatively unimportant, and in fact non-existent except within the energy range of a particular fit to a particular partial cross section, that correlations between uncertainties at different energies should be ignored.

The unification procedure can then be carried out separately at each energy. It is necessary to do so at all energies of the ENDF/B-V grid in order to ensure that linear interpolation is valid for all output files.

On the other hand, each operation of the unification procedure produces a correlation matrix for the uncertainties of the total and all the partial cross sections. The correlations cannot be ignored. They are important to the calculation of derived functions of the cross sections, such as kerma, or the response of a neutron detector. Fortunately this information can be preserved with reasonable accuracy in a fairly compact form. Although unification produces of the order of 500 such correlation matrices, they do not change very much except when the threshold of a new reaction is reached. The unification procedure described in the following sections is therefore separated into various energy bands within which the number of partial cross sections remains the same. 


\subsection{Smoothing of Evaluated Cross Section Files}

In most evaluations the evaluated data are smoothed. Fluctuations in data are smoothed out either by fitting a curve or by eye-line drawing. For example, the higher energy parts of the evaluations of the $\left(n, \alpha_{0}\right),(n, p)$ and $(n, d)$ reactions would look better if replaced by their respective exponentials. The reason for such artificial smoothing is obscure, because no new information has been contributed. In the present evaluation, although the correlations have been dropped, the total uncertainties from the fits have been preserved, and would be lost if artificial smoothing were to be applied at this stage. Moreover, the curves could become unsmoothed again during the unification procedure. If artificial smoothing is applied after the unification procedure, the sum of the partial cross sections would cease to be equal to the total cross section. Consequently the cross section shapes will remain jagged in this evaluation.

\subsection{Energy Range from 5 to $6.174 \mathrm{MeV}$}

In this energy range the data set consists only of the total cross section and the partial cross sections for the reactions $(n, \gamma)$, elastic scattering and inelastic scattering. The floating parameters are the partial cross sections. Values for these are interpolated from the evaluated files of section 3 , and the total cross section is entered as the sum of the partial cross sections. Output tables from the procedure list, for each energy, the input cross sections and their uncertainties, the output cross sections and their uncertainties, the fractional changes in the cross sections, and the ratio of the change to the uncertainty. A study of these ratios provides insight into the consistency of the data. For example, ideally they should be equally distributed between positive and negative, and equally distributed between reactions. The absolute values should be less than unity in 688 of the cases, and so on.

Some larger ratios might be expected to appear near sharp resonances, indicating slight differences in energy scale or in energy resolution, for example, between the total and elastic scattering cross sections. Larger ratios would appear at peaks and valleys if the resolution of partial cross sections is inferior to that of the total cross section. These would tend to distort the normality of the distribution.

The procedure also calculates a quantity called the discrepancy, which is the total cross section less the sum of the partial cross sections. The unification procedure dissipates this discrepancy among the total and partial cross sections according to their variances. In this energy range there are 42 ENDF/B-V energies, and therefore 42 least squares fits, which produce an average value of $\chi^{2}$ of 0.49 for one degree of freedom. Only five cross sections changed by more than their uncertainty, and two by more than twice that amount. All were elastic, in the region of the peaks in the total and the elastic cross sections at $5.371 \mathrm{MeV}$, where the peaks were displaced by about $1 \mathrm{keV}$. Unified cross sections from 5 to $6.174 \mathrm{MeV}$ are shown in table $15 a$, and an average correlation matrix in table 15b, which shows $50 \%$ correlation between elastic and inelastic cross sections. 


\subsection{Energy Range from 6.2 to $7.888 \mathrm{MeV}$}

In this energy range, which includes also a contribution from the ${ }^{12} \mathrm{C}\left(\mathrm{n}, \alpha_{0}\right)$ reaction, there are $82 \mathrm{ENDF} / \mathrm{B}-\mathrm{V}$ energies. The 82 least squares fits produce an average value of $\chi^{2}$ of 1.11 for 1 degree of freedom. The discrepancies are commensurate with their uncertainties. One total cross section and thirteen elastic cross sections change by more than their uncertainty, four of which change by more than twice that amount. All are associated with total cross section peaks at $6.295,6.36$, and $6.658 \mathrm{MeV}$; reflecting the superior resolution of the total cross section data. The unification procedure reduces the uncertainties of all the cross sections. For example the uncertainty in the elastic cross section is reduced from 5 to 28 in this energy range and in the previous one. Unified cross sections from 6.2 to $7.888 \mathrm{MeV}$ are shown in table $16 \mathrm{a}$, with an average correlation matrix in table $16 \mathrm{~b}$.

\subsection{Energy Range from 7.89 to $10 \mathrm{MeV}$}

In this energy range, which also includes a contribution from the ${ }^{12} \mathrm{C}\left(\mathrm{n}, \mathrm{n}^{\prime} 3 \alpha\right)$ reaction, there are 95 energy points. Twenty-six cross sections (all elastic) change by more than their uncertainty, but none more than twice that amount. Most of these changes are associated with improvement of the resolution of the peak in the elastic cross section at $8.101 \mathrm{MeV}$ and the subsequent valley at $8.92 \mathrm{MeV}$. The average value of $\chi^{2}$ over this energy range is 1.0 for one degree of freedom. As an illustration of the effect of the unification procedure, the peak total cross section at $8.101 \mathrm{MeV}$ is $1919.40 \mathrm{mb}$, and the interpolated evaluated partial cross sections for the $(n, \gamma)$, elastic scattering, inelastic scattering, $\left(n, \alpha_{0}\right)$, and $\left(n, n^{\prime} 3 \alpha\right)$ reactions are $0.11 \mathrm{mb}$, $1240.54 \mathrm{mb}, 442.49 \mathrm{mb}, 110.21 \mathrm{mb}$, and $0.30 \mathrm{mb}$, respectively. The discrepancy is $125.66 \mathrm{mb}$, which is disposed of by decreasing the total cross section by $15.57 \mathrm{mb}$ and increasing the partial cross sections by $0.00 \mathrm{mb}, 491.32 \mathrm{mb}$, $15.87 \mathrm{mb}, 2.89 \mathrm{mb}$, and $0.01 \mathrm{mb}$, respectively. The elastic cross section takes up most of the discrepancy because it has the greatest uncertainty in absolute terms.

Unified cross sections from 7.89 to $10 \mathrm{MeV}$ are shown in table 17a, with an average correlation matrix of partial cross sections in table $17 \mathrm{~b}$.

\subsection{Energy Range from 10.05 to $14.5 \mathrm{MeV}$}

Agreement between the total cross section and the sum of the partial cross section is generally poor in this energy range, which comprises 84 ENDF/B-V energy points. The average value of $\chi^{2}$ is 2.25 . Thirty-eight cross sections change by more than their uncertainty, of which 26 are elastic cross sections and the remainder are distributed between the total, inelastic, $\left(n, \alpha_{0}\right)$, and $\left(n, n^{\prime} 3 \alpha\right)$ cross sections. The discrepancies are caused by the conflict between the elastic scattering measurements of 6176 and Ha75. Compared with the unified elastic cross section shape the measurements of Ha75 appear to be low at 11 and $12 \mathrm{MeV}$ whilst those of Gl76 appear to be too low at $10.69 \mathrm{MeV}$ and too high at $13.94 \mathrm{MeV}$. These observations indicate that there is little

\footnotetext{
${ }^{4}$ There is an increase in the $(n, \gamma)$ cross section which is insignificant to two decimal places.
} 
correlation between measurements at different energies by the same author. The maximum value of $\chi^{2}, 14.8$ at $12.1 \mathrm{MeV}$, suggests under-estimation of error by a factor approaching 4 at this energy. Unified cross sections from 10.05 to $14.5 \mathrm{MeV}$ are shown in table 18a, with an average correlation matrix in table $18 \mathrm{~b}$.

\subsection{Energy Range from 14.55 to $15.25 \mathrm{MeV}$}

This range comprises 25 ENDF/B-V energies and also includes a contribution from the ${ }^{12} C(n, p)^{12} B$ reaction. The average value of $\chi^{2}$ is 1.0 , and no cross section is changed by more than its uncertainty. Unified cross sections from 14.55 to $15.25 \mathrm{MeV}$ are shown in table $19 \mathrm{a}$, with an average correlation matrix in table $19 b$.

\subsection{Energy Range from 15.45 to $17.3 \mathrm{MeV}$}

This range comprises 23 ENDF/B-V energies and also includes a contribution from the ${ }^{12} \mathrm{C}(\mathrm{n}, \mathrm{d})^{11} \mathrm{~B}$ reaction. As in section 4.7 , the sum of the partial cross sections follows reasonably closely the total cross section. No cross sections are changed significantly by the unification procedure, which gives an average of 0.38 for the 23 values of $\chi^{2}$. As usual, the uncertainties of the output cross sections are reduced, those with the larger absolute uncertainties benefitting the most.

In this energy range the uncertainty of the elastic cross section is reduced from 58 to 3.48 , and that of the ${ }^{12} \mathrm{C}\left(n, n^{\prime} 3 \alpha\right)$ reaction is reduced from 158 to $12 \%$. Unified cross sections from 15.45 to $17.3 \mathrm{MeV}$ are shown in table $20 \mathrm{a}$, with an average correlation matrix in table $20 \mathrm{~b}$.

\subsection{Energy Range from 17.3 to $20.5 \mathrm{MeV}$}

This energy range comprises 29 energies, and includes a contribution from

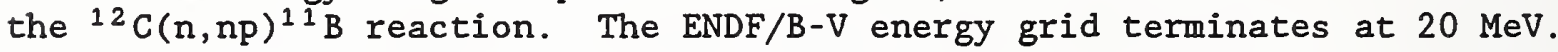
Above this energy, cross sections are evaluated at $0.1 \mathrm{MeV}$ intervals. This is another region in which the sum of the partial cross sections follows closely the total cross section. No cross sections are changed significantly in the unification procedure. The average of the 29 values of $\chi^{2}$ is 0.10 . Unified cross sections from 17.3 to $20.5 \mathrm{MeV}$ are shown in table $21 \mathrm{a}$, with an average correlation matrix in table $21 \mathrm{~b}$.

\subsection{Energy Range from 20.6 to $23.6 \mathrm{MeV}$}

This energy range covers 31 energies, and it includes contributions from the ${ }^{12} \mathrm{C}(n, 2 n)^{1{ }^{1} \mathrm{C} \text { and }}{ }^{12} \mathrm{C}(\mathrm{n}, \mathrm{t})^{10} \mathrm{~B}$ reactions, which have similar threshold energies. Over most of this energy range the sum of partial cross sections is deficient, the discrepancy rising from zero at $21 \mathrm{MeV}$ to about $170 \mathrm{mb}$ at $26.4 \mathrm{MeV}$. At this energy $136 \mathrm{mb}$ is transferred to the elastic cross section, which thus rises slightly more than its uncertainty of 158 . The fall in the elastic cross section observed by Me 84 and Bo68 is thus over-ridden by the unification procedure. The other partial cross sections are also raised, but less significantly. The average of the 31 values of $\chi^{2}$ is 0.45 but values above 23.2 MeV are between 1 and 1.5 . 
Unified cross sections from 20.6 to $23.6 \mathrm{MeV}$ are shown in table 22a, with an average correlation matrix in table $22 \mathrm{~b}$.

\subsection{Energy Range from 23.7 to $24.6 \mathrm{MeV}$}

This energy range has 10 energies, and witnesses the onset of the ${ }^{12} \mathrm{C}\left(\mathrm{n},{ }^{6} \mathrm{Li}\right)^{7} \mathrm{Li}$ reaction. The discrepancy is still of the order of $110-160 \mathrm{mb}$ and the elastic cross section is still raised above the level of the observations of Me84 and Bo68, although the situation is alleviated by the relatively large contribution of the lithium production reaction. If the latter were omitted the other cross sections would have to rise even more. The average value of $\chi^{2}$ is 0.98 .

Unified cross sections from 23.7 to $24.6 \mathrm{MeV}$ are shown in table 23a, with an average correlation matrix in table $23 \mathrm{~b}$.

\subsection{Energy Range from 24.7 to $26.3 \mathrm{MeV}$}

Two more reactions contribute to this energy range which comprises 17 energies. They are the ${ }^{12} \mathrm{C}(\mathrm{n}, \mathrm{d} \alpha)^{7} \mathrm{Li}$ and ${ }^{12} \mathrm{C}(\mathrm{n}, \mathrm{p} \alpha)^{8} \mathrm{Li}$ reactions. The discrepancy falls from $120 \mathrm{mb}$ to zero over this energy range. These values are less than the relevant uncertainties, so that no individual cross section changes by more than its uncertainty. The average value of $\chi^{2}$ is 0.25 . However, it should be remembered that the ${ }^{12} \mathrm{C}\left(\mathrm{n},{ }^{6} \mathrm{Li}\right)^{7} \mathrm{Li}$ cross section was not evaluated independently, but was chosen to bring the discrepancy close to zero at $26.3 \mathrm{MeV}$. Consequently the value of $\chi^{2}$ has no real meaning.

Unified cross sections for 24.7 to $26.3 \mathrm{MeV}$ are shown in table $24 \mathrm{a}$, with an average correlation matrix in table $24 \mathrm{~b}$.

\subsection{Energy Range from 26.4 to $32 \mathrm{MeV}$}

This is the energy range in which the cross section $\sigma_{\text {spare }}$ represents the sum of the cross sections of the final 17 reactions in table 2. Since $\sigma_{\text {spare }}$ is a smoothed version of the difference between the total cross section and the sum of the evaluated partial cross sections the discrepancies in this energy range are simply a reflection of the "noise" in the total cross section, all partial cross sections being smooth. The operation of the unification procedure therefore only disperses this noise amongst the evaluated partial cross sections according to their variances. $\chi^{2}$ in this situation is a meaningless quantity. Unified cross sections from 26.4 to $32 \mathrm{MeV}$ are shown in tables 25a and 26a, with an average correlation matrices in tables $25 \mathrm{~b}$ and $26 \mathrm{~b}$.

\section{UNFOLDING THE COMPONENTS OF THE ${ }^{12} \mathrm{C}\left(\mathbf{n}, \mathbf{n}^{\prime} 3 \alpha\right)$ CROSS SECTION}

The components of the ${ }^{12} \mathrm{C}\left(\mathrm{n}, \mathrm{n}^{\prime} 3 \alpha\right)$ reaction were discussed in $\mathrm{La} 75$ from which most of the carbon cross section data for ENDF/B-V was taken. From a study of the products of neutron reactions on carbon La75 concluded that:

(1) the $\left(n, n^{\prime} 3 \alpha\right)$ reaction proceeds through sequential processes involving intermediate nuclei in particle-unstable states, and that no evidence has been reported for the simultaneous break-up of the carbon nucleus below $20 \mathrm{MeV}$. 
(2) the low value of the separation energy for secondary particle emission is the main reason why only the $4.439 \mathrm{MeV} \gamma$-ray is produced by inelastic scattering. It was deduced that the largest contribution to the $\left(n, n^{\prime} 3 \alpha\right)$ reaction comes from inelastic scattering with the ${ }^{12} \mathrm{C}$ nucleus excited above the $7.653 \mathrm{MeV}$ level. The remaining small amount comes from the ${ }^{12} \mathrm{C}(\mathrm{n}, \alpha)^{9} \mathrm{Be} *$ reaction with the ${ }^{9} \mathrm{Be}$ nucleus excited to the $2.4 \mathrm{MeV}$ level which breaks up into $n+2 \alpha$.

(3) the spectrum of emitted neutrons is therefore assumed to consist of a sum of Gaussian distributions associated with the excited states of ${ }^{12} \mathrm{C}$, plus an evaporation spectrum due to the ${ }^{12} \mathrm{C}(\mathrm{n}, \alpha){ }^{9} \mathrm{Be} *$ reaction.

Table 15 of La75 shows the total ${ }^{12} \mathrm{C}\left(\mathrm{n}, \mathrm{n}^{\prime} 3 \alpha\right)$ cross section evaluated as the total cross section less the sum of the remaining partial cross sections, and this total is subdivided into contributions from the ${ }^{12} \mathrm{C}(\mathrm{n}, \alpha){ }^{9}$ Be* reaction, and from inelastic scattering to excited states of ${ }^{12} \mathrm{C}$ at $7.653,9.638,10.3$, $10.84,11.83,12.71$, and $13.35 \mathrm{MeV}$.

ENDF/B-V retained the total $\left(n, n^{\prime} 3 \alpha\right)$ cross section of La75, but changed considerably the way that it was subdivided into the various contributing components. The share allocated to the ${ }^{12} \mathrm{C}(\mathrm{n}, \alpha)^{9}$ Be* reaction above $10 \mathrm{MeV}$ is a straight 108 of the total, a large reduction on the La75 allocation (a factor of 4.5 at $12 \mathrm{MeV}$ ). Allocations for inelastic scattering to the excited states of ${ }^{12} \mathrm{C}$ at $7.653,9.638,10.3$, and $10.84 \mathrm{MeV}$ became corresponding larger, they peaked at lower energies, and reduced more rapidly with increasing neutron energies.

Instead of the excited states at $11.83,12.71$, and $13.85 \mathrm{MeV}$, a series of 23 pseudo-states were introduced at $0.5 \mathrm{MeV}$ intervals starting at $11.25 \mathrm{MeV}$ and terminating at $17.75 \mathrm{MeV}$. These 23 inelastic scattering cross sections were allocated characteristic shapes as a function of neutron energy above the individual threshold energies, and given amplitudes such that the sum of the contributing reactions equaled the total ${ }^{12} \mathrm{C}\left(\mathrm{n}, \mathrm{n}^{\prime} 3 \alpha\right)$ reaction cross section. The departures from table 17 of La75 do not appear to be documented anywhere.

The cross sections for inelastic scattering to the $7.65 \mathrm{MeV}$ and all higher states (ENDF/B-V reactions MT52-MT68) all have the same general shape, rising to a peak a few $\mathrm{MeV}$ above threshold, and becoming exponential a few $\mathrm{MeV}$ above the peak. For this evaluation the same general shape is assumed, but modified in the light of the new measurements now available.

Cross sections for inelastic scattering to the 7.655 and $9.84 \mathrm{MeV}$ levels of ${ }^{12} \mathrm{C}$ (reactions MT52 and MT53) are derived from the measurements of Ba85, Gu81, Me84, and 0187. Exponential shapes were fitted to the available data at neutron energies greater than $7.65 \mathrm{MeV}$ above the reaction thresholds, yielding exponents of $7.874 \mathrm{MeV}^{-1}$ and $9.285 \mathrm{MeV}^{-1}$, respectively. At lower energies smooth curves were drawn which exhibited peaks 4-5 MeV above the thresholds.

For the $10.8 \mathrm{MeV}, 11.8 \mathrm{MeV}, 12.7 \mathrm{MeV}, 13.35 \mathrm{MeV}$, and $14.08 \mathrm{MeV}$ levels of ${ }^{12} \mathrm{C}$ (MT54-MT58) only the data of Me84 are available, at neutron energies of $22 \mathrm{MeV}$ and $24 \mathrm{MeV}$. In view of the large uncertainties of the data, and the wide spread of apparent exponents, it was assumed that these five cross sections would exhibit the exponential shape in this energy region, and that the exponent would be the same for all five reactions. Accordingly, a least 
squares calculation was used to determine the common exponent ( $3.587 \mathrm{MeV}^{-1}$ ), and individual amplitudes for each reaction. It was further assumed that the cross sections would peak at about $4 \mathrm{MeV}$ above the thresholds.

Following ENDF/B-V, pseudo states were introduced at $1 \mathrm{MeV}$ intervals with thresholds from $15.08 \mathrm{MeV}$ to $29.08 \mathrm{MeV}$ with similar cross section shapes. These are designated as reactions MT59-MT73.

In the absence of any information for the ${ }^{12} \mathrm{C}(n, \alpha){ }^{9}$ Be* reaction (MT91) the cross section was evaluated as the difference between the unified ${ }^{12} \mathrm{C}\left(n, n^{\prime} 3 \alpha\right)$ cross section and the sum of the cross sections for MT52-MT73. The amplitudes of the cross sections for the latter were then adjusted arbitrarily in order to produce a plausible shape for the cross section of MT91. The somewhat jagged shape of the latter is simply a reflection of the noise in the total cross section which is introduced into the ${ }^{12} \mathrm{C}\left(n, \mathrm{n}^{\prime} 3 \alpha\right)$ cross section by the unification procedure.

Evidence for the existance of high level states in ${ }^{12} \mathrm{C}$ is summarized in Aj85, where 37 such states are identified below $28 \mathrm{MeV}$. The cross sections derived here, which appear in Table 27, are necessarily rather speculative. Their purpose in the context of kerma calculations is to provide a basis for the estimation of kinetic energy transfer in the ${ }^{12} \mathrm{C}\left(n, n^{\prime} 3 \alpha\right)$ reaction.

\section{UNFOLDING THE COMPONENTS OF $\sigma_{\text {s pare }}$}

It is necessary to allocate cross section values to the 17 components of $\sigma_{\text {spare }}$, which represent the last 17 reactions listed in table 2 , in order to determine a reasonable estimate of the average energy transfer per event for these reactions. In order to do this it is necessary to make some assumptions. It is assumed that these cross sections have the same general shape characteristics as those for the reactions discussed in section 3.12 . Thus it is possible to calculate Q-values, reaction thresholds, Coulomb thresholds, positions of cross section peaks on the energy scale, and "decay" exponents. Armed with this information it is a simple matter to generate, by trial and error, a set of cross sections which follow the general shape characteristics, and which can then be normalized to the total unified $\sigma_{\text {spare }}$. The results of this exercise is shown in table 28.

It is important to realize that these cross sections are highly speculative, because apart from the uncertainty of the unfolding process, the value of the total unified $\sigma_{\mathrm{spar}}$ is dependent on the validity of all previously evaluated partial cross sections. Many of these are themselves highly speculative, and furthermore small errors in the large cross sections, such as the total, the elastic, and the $\left(n, n^{\prime} 3 \alpha\right)$ have a profound effect on these results.

The total cross sections for the production of $p, d, t,{ }^{3} \mathrm{He}$ and $\alpha$-particles at $32 \mathrm{MeV}$ can be calculated by summing the contributions from all of the reactions involved, and are $88 \mathrm{mb}, 41 \mathrm{mb}, 56 \mathrm{mb}, 10 \mathrm{mb}$, and $751 \mathrm{mb}$, respectively. Those for $\mathrm{p}$ and $\mathrm{d}$ are in reasonable agreement with values from table 12 interpolated at $32 \mathrm{MeV}$, but those for the heavier particles are considerably higher than the interpolated values. 


\section{ANGULAR DISTRIBUTIONS}

Angular distributions of secondary neutrons produced by elastic and inelastic scattering are expressed in terms of coefficients derived from the fitting of Legendre polynomials to experimental data. In ENDF/B-V format the coefficients are expressed in terms of parameters $f$, which represent the Legendre coefficients normalized so that $f_{0}=1$. Thus, $f_{i}=\left(P(i) l_{0}\right) /\left(P(0) l_{i}\right)$. In Ca80 it was shown that, for the purposes of kerma calculations, only $f_{1}$ is required. For the calculation of mean energy transfer per event, $\bar{E}$, only the average energy of the scattered neutrons is required, not their angular distribution. Hence, in their expressions for $\bar{E}$ the terms containing other $f$ factors cancel out. Time did not permit a new evaluation of $f$ factors based on all the scattering data considered in the cross section evaluation. An evaluation of $f_{1}$ in isolation would serve no useful purpose because it might well lead to unacceptable angular distributions. It was therefore decided that, for the purposes of the present calculations of kerma, the ENDF/B-V values should be adopted. However, since the ENDF/B-V covariance files give no information regarding the uncertainties of $f_{1}$ it was necessary to allocate uncertainties based on those obtained in Legendre polynomial fitting processes mentioned in section 3.4. ENDF/B-V provides $f$ values only for inelastic scattering to the first three excited states of ${ }^{12} \mathrm{C}$, scattering to higher states and pseudo-states being assumed to be isotropic. There remains the problem of extending the ENDF/B-V data to $32 \mathrm{MeV}$.

For elastic scattering a survey of results from the Legendre polynomial fitting processes indicated an uncertainty of $5 \%$ for $f_{1}$ values up to $20 \mathrm{MeV}$. Uncertainties for individual results were in general much smaller, but the scatter of values from different authors suggested that $5 \%$ would be reasonable. The Legendre coefficients relating to the measurements of Me84 and Wi86 demonstrated clearly that $f_{1}$ for elastic scattering continues to rise over the range from 20 to $32 \mathrm{MeV}$. The $f_{1}$ file was extended through values obtained from the Legendre coefficients of Me84 and Wi86, with uncertainties of 28 . For inelastic scattering to the $4.439 \mathrm{MeV}$ level of ${ }^{12} \mathrm{C}$ also, the $f_{1}$ values continue to rise. The curve was extended by means of a straight line from the $20 \mathrm{MeV}$ point through the values based on Legendre coefficients of Me84, representing an increase of about $15 \%$ at $32 \mathrm{MeV}$. The $f_{1}$ curve shows structure up to about $15 \mathrm{MeV}$ and has many negative values and values close to zero, so relative uncertainties are rather meaningless. Uncertainties of \pm 0.03 were used for energies up to $15 \mathrm{MeV}$, and above that energy, where the scatter of individual values is greater, the uncertainty was increased to \pm 0.06 . For inelastic scatter to the $7.563 \mathrm{MeV}$ and $9.638 \mathrm{MeV}$ levels of ${ }^{12} \mathrm{C}$ the $f_{1}$ values were assumed to remain constant at their $20 \mathrm{MeV}$ values.

\section{CALCULATIONS OF MEAN RINETIC ENERGY TRANSFER AND KERMA}

For calculations of $\overline{\mathrm{E}}$, the average amount of energy transferred to kinetic energy of charged particles in each reaction, the non-relativistic equations of $\mathrm{Ca} 80$ are used. These equations are stated to be accurate to 18 for neutron energies up to $30 \mathrm{MeV}$ incident upon target nuclei up to mass 55, and must therefore be accurate to better than 18 for $32 \mathrm{MeV}$ neutrons incident upon carbon. Natural carbon consists of $99.8928{ }^{12} \mathrm{C}$ and $1.108 \%{ }^{13} \mathrm{C}$. For most cross section measurements pure natural carbon is used unless isotopic ${ }^{13} \mathrm{C}$ is specifically stated. However, in the application of the equations to determine 
$\bar{E}$, for the determination of Q-values and threshold energies in table 2, and in the subsequent discussions of charged particle reactions, it is assumed that natural carbon is ${ }^{12} \mathrm{C}$.

Examples of thresholds of similar reactions in ${ }^{13} \mathrm{C}$ are $(n, \alpha) 4.198 \mathrm{MeV}$, $(n, t) 13.385 \mathrm{MeV},(n, p) 13.636 \mathrm{MeV},(n, d) 14.887 \mathrm{MeV}$, and $(n, 2 n) 5.330 \mathrm{MeV}$. Experiments in which charged particles are detected would presumably record charged particle reactions from ${ }^{13} \mathrm{C}$ as well as from ${ }^{12} \mathrm{C}$, but wrong $\overline{\mathrm{E}}$ values would be attributed to them. Measurements of ${ }^{12} \mathrm{C}(n, 2 n)$ by activation would not record ${ }^{13} \mathrm{C}(\mathrm{n}, 2 \mathrm{n})$, but would record ${ }^{13} \mathrm{C}(\mathrm{n}, 3 \mathrm{n})$ with a threshold of $25.5 \mathrm{MeV}$.

Thresholds of some possible mechanisms for the ${ }^{13} C(n, 2 n 3 \alpha)$ break-up reaction are

$$
\begin{array}{ll}
\mathrm{n}+{ }^{13} \mathrm{C} \rightarrow\left({ }^{8} \mathrm{Be} \rightarrow 2 \alpha\right)+{ }^{6} \mathrm{He}^{*}(1.8 \mathrm{MeV}) \rightarrow 2 \mathrm{n}+\alpha & 14.162 \mathrm{MeV} \\
\mathrm{n}+{ }^{13} \mathrm{C} \rightarrow 2 \mathrm{n}+3 \alpha & 13.169 \mathrm{MeV} \\
\mathrm{n}+{ }^{13} \mathrm{C} \rightarrow 2 \mathrm{n}+{ }^{12} \mathrm{C}^{*}(7.653 \mathrm{MeV}) \rightarrow 3 \alpha & 13.577 \mathrm{MeV} \\
\mathrm{n}+{ }^{13} \mathrm{C} \rightarrow \mathrm{n}+\alpha+{ }^{9} \mathrm{Be}^{*}(2.429 \mathrm{MeV}) \rightarrow \mathrm{n}+2 \alpha & 14.091 \mathrm{MeV}
\end{array}
$$

Such possibilities have been ignored in this evaluation because of the low abundance of ${ }^{13} \mathrm{C}$.

The product of cross section in units of $\mathrm{mb}$, and $\bar{E}$ in units of $\mathrm{MeV}$, produces kerma factors in units of $\mathrm{mb} \cdot \mathrm{MeV} \cdot \mathrm{atom}^{-1}$. Conversion to the SI unit $\mathrm{Gy} \cdot \mathrm{m}^{2}$ is achieved by multiplication by the factor $8.04044 \times 10^{-19}$, which is the product of the three factors atoms per $\mathrm{kg}$ of ${ }^{12} \mathrm{C}(6.0221367 \div 12) \times 10^{26}$, $\mathrm{J} \cdot \mathrm{MeV}^{-1}\left(1.60217733 \times 10^{-13}\right)$, and $\mathrm{m}^{2} \cdot \mathrm{mb}^{-1}\left(10^{-31}\right)$.

In calculating $\overline{\mathrm{E}}$ it is assumed that all final nuclei are at ground-state levels. Cases where final states are above the level at which charged particle emission becomes possible are catered for by the introduction of the appropriate multi-body reactions. However, intermediate states are possible which are above the ground state but below the level for charged particle emission, and which decay by $\gamma$-ray emission which does not contribute to the kerma factor. Ca80 took the view that if these intermediate states are energetically possible they will occur to some extent. Where cross section data was not available, they used a simple algorithm, called "energy averaging," which assumed that the probability of excitation of the intermediate levels increases linearly from zero at the Coulomb threshold to free (equally probable) excitation at $2 \mathrm{MeV}$ above the threshold. This energy averaging procedure is not used in this evaluation, but a rough estimate is made of the consequences of including it. Energy-averaging would have a noticeable effect in the calculation of $\overline{\mathrm{E}}$ if applied to the intermediate (i.e., above ground state and below charged particle emission level) states of ${ }^{11} \mathrm{C}$, ${ }^{12} \mathrm{~B},{ }^{11} \mathrm{~B},{ }^{10} \mathrm{~B},{ }^{8} \mathrm{Li}$, and ${ }^{7} \mathrm{Li}$. At $19 \mathrm{MeV}$ there would be a reduction of 4.88 in total kerma, principally due to the $(n, d)$ and $(n, n p)$ reactions. At $28 \mathrm{MeV}$ the reduction would be 2.458 of total kerma mainly due to the $(n, d)$, (n, np), $(n, d \alpha)$, and $(n, 2 n)$ reactions. At $32 \mathrm{MeV}$ the reduction would be about 1.48 . Uncertainties due to these effects are not included in the uncertainties quoted for kerma factors, the latter being derived only from propagation of the uncertainties in cross sections and $f_{1}$ values. The unification procedure, which contributes the information that the sum of the partial cross sections is 
equal to the total cross section, has a reducing effect on the uncertainties of the cross sections, and the negative correlation between pairs of partial cross sections further reduces the uncertainties in the kerma factors.

Kerma factors, partial kerma factors, and uncertainties, in units of $\mathrm{fGy} \cdot \mathrm{m}^{2}$ are presented in tables 30 through 41.

\section{SIMULTANEOUS FIT TO CARBON CROSS SECTIONS AND RERMA}

The kerma factors presented in tables 30 through 41 are calculated from unified cross sections and calculated $\bar{E}$ values only. Measured kerma values were not considered. It is therefore of interest to repeat the simultaneous evaluation of cross sections and kerma described in section 2 and Appendices 1 through 3. The problem of finding a model with sufficient simplicity and flexibility remains, so it is necessary to retain the same model with all its faults, because no better one has been devised. The assumption of rigidity for all cross section shapes is less true now than at the beginning, and as before, the cross section for the $\left(n, n^{\prime} 3 \alpha\right)$ reaction cannot float independently without disturbing the equality between the total cross sections and the sum of the partial cross sections. The input data set needs editing because it is necessary to delete all cross section measurements which were used in the cross section evaluation, leaving only kerma and partial-kerma measurements, $\overline{\mathbf{E}}$ measurements, and measurements of the total $\alpha$-particle production between 14 and $15 \mathrm{MeV}$. The kerma measurement of $\mathrm{Mc} 87$ was also deleted following criticism of the interpretation of this experiment by Go87. The input data and fitted values for this calculation are shown in table 42. The fitted values demonstrate that the unified cross sections are much more in harmony with the available measurements of kerma than are the ENDF/B-V cross sections. This is demonstrated by the low value of $\chi^{2}$ which is 14 for 29 degrees of freedom. The total, elastic, $(n, p)$, and $(n, d)$ cross sections are reduced by only $0.38,0.18$, $0.3 \%$, and $0.5 \%$, respectively. The inelastic and $(n, \alpha)$ cross sections rise by 3.18 and 1.38 , respectively.

Kerma factors calculated from the simultaneous fit are presented in table 43. They are approximately 48 lower than those of tables 30 through 41. Uncertainties for the values in table 43 are not quoted because they are unrealistically small, being a by-product of the over-simplified model which assumes that all cross section data are exact apart from the errors in the normalizing factors. Nevertheless, the fitting exercise demonstrates clearly the improved agreement between measured and calculated kerma factors.

Total kerma factors from the simultaneous fit are compared with those in tables 30 through 41, and with calculations by other authors in figure 7. Partial kerma factors appear in figures 8 through 12.

\section{DISCUSSION}

The evaluated data for the partial cross sections form a consistent set, the sum of which is equal to the total cross section. If any partial cross section is reduced substantially, for example the cross sections which yield high kerma in the energy range from $20 \mathrm{MeV}$ to $32 \mathrm{MeV}$, the defect would have to be rectified by increasing other partial cross sections. The weighting would 
ensure that most of this defect would be allocated to the elastic scattering reaction. The unified elastic scattering cross section is already raised substantially above the evaluated curve of table 5b, and above the Me84 optical model calculations, and to cause it to be raised further would contradict the available evidence. The controversial ${ }^{12} \mathrm{C}\left(\mathrm{n},{ }^{6} \mathrm{Li}\right)^{7} \mathrm{Li}$ reaction, with its $100 \mathrm{mb}$ peak cross section, is a case in point. If the reaction is eliminated, another home has to be found for this $100 \mathrm{mb}$ at $26 \mathrm{MeV}$. There appears to be nowhere for it to go without conflicting with the available evidence upon which the evaluated cross sections are based.

The calculated kerma factors are lower than those of Ca80 above $13 \mathrm{MeV}$ as a result of the reduction in the $\left(n, n^{\prime} 3 \alpha\right)$ cross section from the ENDF/B-V curve and the redistribution of the components of this reaction. From $20 \mathrm{MeV}$ to $32 \mathrm{MeV}$ the calculated values of Br83, Dy82, Be81, and We79 are 158 to 258 lower. It is not easy to see how the present kerma factors could be reduced by such large amounts. Significant re-arrangement of the values of partial cross sections would conflict with available evidence.

Kerma calculations based on ENDF/B-V shapes for the MT52-MT73 would be about 108 higher above $20 \mathrm{MeV}$, and therefore even more in disagreement with the other authors in figure 7. The new shape is compared with the ENDF/B-V shape in figure 13 where all available data is shown for inelastic scattering to the $7.65 \mathrm{MeV}, 9.63 \mathrm{MeV}, 10.8 \mathrm{MeV}, 11.8 \mathrm{MeV}, 12.7 \mathrm{MeV}, 13.55 \mathrm{MeV}$, and $14.08 \mathrm{MeV}$ states of ${ }^{12} \mathrm{C}$. In order to display these on a single graph, they are plotted on a horizontal scale of $E_{n}-E_{t h}$, and normalized to a scale of arbitrary units by least squares fitting. The decay exponent is $7.71 \mathrm{MeV}$. Figure 14 is similar to figure 13, but only the top five of the above states are included, and the decay exponent is $3.71 \mathrm{MeV}$.

The tabulated kerma factors could be reduced by perhaps $5 \%$ to 28 over the energy range from $19 \mathrm{MeV}$ to $32 \mathrm{MeV}$ by taking into consideration the energyaveraging procedure described in section 8 , but this would be insufficient agreement with the other authors in figure 7 .

\section{CONCLUSIONS}

The parts of the carbon cross section file which have been evaluated are a considerable improvement on the ENDF/B-V version, partly as a result of the inclusion of modern data and partly as a result of the unification procedure used to dissipate more fairly the discrepancies between total and partial cross sections. In addition important correlations between partial cross sections are provided. Aspects which should receive high priority in any further work would be the evaluation of angular distributions and the inclusion of new data such as the scattering measurements from PTB and revised values from the TUNL University group. To facilitate ease of access, the data should be transformed into ENDF/B-V format. Calculated values of kerma could possibly be reduced by as much as $5 \%$ above $20 \mathrm{MeV}$, but not enough to create agreement with some of the other calculations. 


\section{ACKNOWLERGEIENTS}

It is a pleasure to acknowledge the valuable assistance provided by various individuals and laboratories. R. S. Caswell initiated the project, and gave it enthusiastic support throughout. J. J. Coyne provided much valuable advice and discussion. R. A. Schrack kindly performed the data reduction of the total cross sections. A. D. Carlson obtained the necessary data files from the National Nuclear Data Centre, and G. Cooper rendered them digestible to the Sage computer which was kindly provided by $P$. Christmas, and maintained by J. K. Whittaker and N. D. Wilkin. The Physikalisch Technische Bundesanstalt in Germany generously provided facilities for the completion of the manuscript. The project was funded by Defense Nuclear Agency, Armed Forces Radiobiology Research Institute, Order No. N87005I. 


\section{REFERENCES}

Ad80 M. Adel-Fawzy, H. Foertsch, S. Mittag, D. Schmidt, D. Seeliger, and T. Streil (32001), Nucl. Instr. Meth. 169, 533 (1980).

Aj85 F. Ajzenberg-Selove, Nucl. Phys. A433, 1-157 (1985).

Al63 R. A. Al-Kital and R. A. Peck (11332), Phys. Rev. 1301500 (1963).

Am57 0. Ames, G. E. Owen, and C. D. Swartz, Phys. Rev. 106, 775 (1957).

An75 B. Antolkovic and Z. Dolenec, Nucl. Phys. A237, 235 (1975).

An81 B. Anders, P. Herges, and W. Scobel (20348), Z. Phys. 301, 353 (1981).

An83 B. Antolkovic (30635), Nucl. Phys. A394, 87 (1983).

An84 B. Antolkovic, I. Slaus, and D. Plenkovic, Rad. Res. 97, 253 (1984).

An86 B. Antolkovic, G. Dietze, and H. Klein, Proc. Int. Conf. Fast Neutron Physics, Dubrovnik, Yugoslavia May 26-31, 1986, Ruder Boskovic Institute, Zagreb, Yugoslavia (1986), p. 137.

Ar71 E. Arai (20265) (1971), private communication.

Au79 G. F. Auchampaugh, et al. (10884), Nucl. Sci. Eng. 69, 30 (1979).

Ax86 E. J. Axton, Metrologia. 23, 129-144 (1986/87).

Ba85 M. Baba, M. Ono, N. Yabuta, T. Kikuti, and N. Hirakawa (21984), Int. Conf. Nucl. Data. Basic and Applied Science, Santa Fe, New Mexico (1985), p. 223.

Be81 M. A. Behrooz and D. Watt, Rad. Prot. Dosim. 1, 291 (1981).

Bo68 F. Boreli, B. B. Kinsey, and P. N. Shrivastava, Phys. Rev. 174, 1147 (1968).

Br68 M. Brendle, M. Moricke, G. Staudt, and G. Steidel, Z. Naturforch. A23, 1229 (1968).

Br79 F. P. Brady, J. L. Romero, Neutron Induced Reactions in Tissue Resident Elements, Final Report to National Cancer Institute, Grant No. 1RO1

CA16261, Technical Report, Univ. of California-Davis, Davis, CA (1979).

Br83 D. J. Brenner, Phys. Med. Biol. 29, 437 (1983).

Br84 D. J. Brenner and R. E. Prael, Nucl. Sci. Eng. 88, 97 (1984).

Bu85 G. Buhler, H. G. Menzel, H. Schuhmacher, and S. Guldbakke, Proc. 5th Symp. on Neutron Dosimetry, Munich/Neuherburg. FRG (CEC. Luxembourg) Report EUR9762 (1985), p. 62.

Ca80 R. S. Caswell and J. J. Coyne. Radiat. Res. 83, 217 (1980). 
Ca82 R. S. Caswell, J. J. Coyne, and M. I. Randolph, Int. J. Appl. Radiat. Isot. $\underline{33}, 1237$ (1982).

Ch64 M. L. Chatterjee and B. Sen, Nucl. Phys. $\underline{51}, 583$ (1964).

Ci69 S. Cierjacks, P. Forti, D. Kopsch, L. Kropp, J. Nebe, and H. Unseld (20010), Karlsruhe Report KFK 1000 and private communication, Gesellschaft für Kernforschung, Karlsruhe, Germany.

Ci78 S. Cierjacks, F. Hinterberger, G. Schmalz, and D. Erbe (20742), Nucl. Inst. Meth. 169, 185 (1980). Nucl. Phys. A352, 93 (1981).

C165 C. M. Class, J. E. Price, and J. R. Risser, Nucl. Phys. 71, 433 (1968).

Co57 B. C. Cook, Phys. Rev. 106, 300 (1957).

Co76 F. Cocu, G. Haouat, J. Lachkar, Y. Patin, J. Sigaud, and G. Dalbera, CEN Saclay, Report CEA-R-4746, Saclay, France (1976).

Da63 E. A. Davis, T. W. Bonner, D. W. Worley, and R. Bass, Nucl. Phys. 48, 169 (1963).

De63 G. Deconninck, M. deVroey, J. P. Meulders, and J. Simonet, Nucl. Phys. 49 , 424 (1963).

De70 G. Deconninck and J. P. Meulders (20240), Phys. Rev. C1, 1326 (1970).

De84 P. M. Deluca, Jr., H. H. Barschall, R. C. Haight, and J. C. McDonald, Radiat. Res. 100, 78 (1984).

De85 P. M. Deluca, Jr., H. H. Barschall, and R. C. Haight, Proc. 5th Symp. Neutron Dosimetry, Munich/Neuherburg, Germany, CEC Luxembourg EUR-9762 (1985), p. 193.

De86 P. M. Deluca, Jr., H. H. Barschall, M. Burhoe, and R. C. Haight, Nucl. Sci. Eng. 94, 192 (1986).

Di87 G. Dietze, РTB, Braunschweig, private communication (1987).

Dy82 P. J. Dimbylow, Phys. Med. Biol. 27, 989 (1982).

Fa71 H. U. Fabian (20895), Z. Naturforsch. A26, 317 (1971).

Fa78 H. F. Farrar, IV, and D. W. Kneff, Trans. Am. Nucl. Soc. 28, 197 (1978).

Fr55 G. M. Frye, Jr., L. Rosen, and L. Stewart, Phys. Rev. 99, 1375 (1955).

Ga72 W. Galati, Phys. Rev. C5, 1508 (1972).

Ge76 K. W. Geiger and L. Van der Zwan, Nuclear Research Council (Canada), Report NRCC 15303 (1976). 
G176 D. W. Glasgow, F. O. Purser, H. Hogue, G. Mack, J. R. Boyce,

D. H. Epperson, S. G. Buccino, P. W. Lisowski, S. G. Glendinning,

E. G. Bilpuch, H. W. Newsome, and C. R. Gould. (12890) Nucl. Sci. Eng. $\underline{61}, 521,1976$.

Go87 L. J. Goodman, Radiat. Res. 113, 396-397 (1988).

Gr55 E. R. Graves and R. W. Davis, Phys. Rev. 97, 1205 (1955).

Gr69 G. A. Grin, B. Vaucher, J. C. Adler, and C. Joseph, Helv. Phys. Acta 42 , 990 (1969).

Gu81 K. Gul, M. Anwar, M. Ahmed, S. M. Saleem, and N. A. Khan (30593) Phys. Rev. C24, 2458 (1981).

Ha70 J. G. Hayes and E. J. Axton, Metrologia 6, 21 (1970).

Ha75 G. Haouat, J. Lachkar, J. Sigaud, Y. Patin, F. Cocu, CEN Saclay Report CEA-R 4641 (1975), Saclay, France.

Ha84 R. C. Haight, S. M. Grimes, R. G. Johnson, and H. H. Barschall, (12899) Nucl. Sci. Eng. 87, 41 (1984).

Ho76 J. B. Holt, M. W. Guinan, D. W. Hosmer, R. H. Condit, and R. J. Borg, Proc. Tech. of Controlled Fusion, Richland, Washington, Sept. 21-23, 1976. Conf-760935 USERD (1976), p. 1565.

Hu66 A. Huck, G. Walter, and A. Coche, (20923) J. Phys. (Paris) 27, 88 (1966).

Ke79 J. D. Kellie, G. P. Lamaze, and R. B. Schwartz (10888), Int. Conf. Nuclear Cross Sections for Technology, Univ. Tenn, Knoxville, TN, (1979), p. 48.

Ki69 H. Kitazawa and N. Yamamuro, (20919) J. Phys. Soc. Japan 26, 600 (1969).

Kl87 H. Klein (1987), private communication. To be published by G. Dietze, H.J. Brede, H. Klein, and H. Schölermann.

Kn86 D. W. Kneff, B. M. Oliver, and H. Farrar. Nucl. Sci. Eng. 92, 491 (1986).

Ko67 D. Kopsch and S. Cierjacks, Nucl. Instr. Meth. 54, 277 (1967).

Kr57 W. E. Kreger and B. D. Kern (11324), Phys. Rev. 113, 890 (1959).

La75 J. Lachkar, F. Cocu, G. Haouat, P. Le Foch, Y. Patin, and J. Sigaud, NEA Nucl. Data Committee Reports, NEANDC(E) 168L and Int. Nucl Data Committee Reports, INDC(FR) - 7/L (1975).

Mc72 F. D. McDaniel, M. W. McDonald, M. F. Steuer, and R. M. Wood (10819), Phys. Rev. $\underline{\text { 66, }} 1181$ (1972).

Mc87 J. C. McDonald, Radiat. Res. 109, 28 (1987). 
Me84 A. S. Meigooni, J. S. Petler, and R. W. Finlay, Phys. Med. Biol. 29, 643-659 (1984); also, Nucleon-Induced Excitation of Collective Bands in ${ }^{12} \mathrm{C}$ and the Application to Neutron Dosimetry at $\mathrm{E}_{\mathrm{n}}>20 \mathrm{MeV}$. Thesis, Ohio University, Athens, OH (1984).

Mo72 G. L. Morgan, T. A. Love, J. K. Dickens, F. G. Perey, Report ORNL TM-3702 (1972). Nucl. Sci. Eng. 62, 515-531 (1977).

Ni62 A. Nilsson and J. Kjellman, Nucl. Phys. 32, 177 (1962).

Ob72 A. W. Obst, T. B. Grandy, and J. L. Weil, Phys. Rev. C5, 738 (1972).

0187 N. Olsson, private communication (1987).

Pe69 F. G. Perey and W. E. Kinney, Oak Ridge National Laboratory Report ORNL-4441 (1969).

Pe71 F. G. Perey and W. E. Kinney, Reports to the AEC Nuclear Cross Section Advisory Committee, 42, 190 (1971), and private communication.

Pe72 F. G. Perey, T. A. Love, and W. E. Kinney, Oak Ridge National Laboratory Report ORNL-4823 (1972).

Qa78 S. M. Qaim and R. Woelfle (20840), Nucl. Phys. A295, 150 (1978).

Re60 T. Retz-Schmidt, T. W. Bonner, G. V. Din, and J. L. Weil, Bull. Am. Phys. Soc. $\underline{5}, 110(1960)$.

Ri57 J. R. Risser, J. E. Price, and C. M. Class, Phys. Rev. 105, 1288 (1957).

Ri68 E. M. Rimmer and P. S. Fisher (21163), Nucl. Phys. A108, 567 (1968).

Sa71 W. Salathe, E. Baumgartner, and P. Huber (20517), Helv. Phys. Acta. 44, 815 (1971).

Sa81 SA Jun, Ian G. Hong-Qing, Zhang Ying, Liand Done-Qi, Shen Wei-Qi, Wang Xiao-Zhong, Dong Min-Li, Ye Chung-Ying, Gu, Yi-fan. Chinese J. Nucl. Phys. $\underline{3}$, 400-302 (1981), in Chinese.

Sc67 R. B. Schwartz, H. T. Heaton, R. A. Schrack, Bull. Am. Phys. Soc. 15, 567 (1967); see also, H. T. Heaton, J. L. Menke, R. A. Schrack, and

R. B. Schwartz, Nucl. Sci. Eng. 56, 27 (1975).

St76 A. P. Stevens (30409). INIS Microfiches. Thesis Univ. Capetown. IAEA Vienna.

Su83 T. S. Subrumanian, J. L. Romero, F. P. Brady, J. W. Watson, D. H. Fitzgerald, R. Garret, G. A. Needham, J. L. Ullman, C. I. Zanelli, D. J. Brenner, and R. A. Prael (12838), Phys. Rev. C28, 521 (1983).

Va58 S. S. Vasilev, V. V. Komarov, and A. M. Povova, Sov. Phys. JETP, 6,1016 (1958).

Va70 L. Van der Zwan and K. W. Geiger, Nucl. Phys. A152, 481 (1970). 
Ve68 V. V. Verbinsky, F. G. Perey, J. K. Dickens, and W. R. Burrus, Phys. Rev. $\underline{170}, 916$ (1968).

Ve73 D. E. Velkley, Phys. Rev. C7, 1736 (1973).

We79 A. H. Wells, Rad. Res. $\underline{80}, 1$ (1979).

We81 P. Welch, J. Johnson, G. Randers-Pehrson, and J. Rapaport (12912), Bull. Am. Phys. Soc. 26, 708 (1981).

Wi86 J. S. Winfield, S. M. Austin, R. P. De Vito, U.E.P. Berg, Z. Chen, and W. Sterrenburg, Phys. Rev. C32, 1 (1986). 
The linear model is ${ }^{1}$

$$
\mathrm{y}=\mathrm{Ab}+\epsilon,
$$

where $y$ is a specified n-element observation vector,

$A$ is a specified $n$ by $p$ design matrix containing the differentials of each measurement with respect to the parameters to be fitted,

$\mathrm{b}$ is a $\mathrm{p}$ element regression vector to be determined, (the solution),

$\epsilon$ is an unknown n-element noise vector with zero mean and covariance $Z$,

$\mathrm{n}$ is the total number of measurements, and $\mathrm{P}$ is the number of unknown parameters to be determined, leading to $n-p$ degrees of freedom.

The solution satisfies the normal equations

$$
A^{T} Z^{-1} A b=A^{T} Z^{-1} y,
$$

where $\mathrm{Z}$ is the covariance matrix of the input data. In the construction of the covariance matrix it is assumed that all uncertainties in the measurements are estimated at the one standard deviation (68\% confidence) level.

The solution, which can be obtained by matrix inversion of the covariance matrix, $Z$, is

$$
b=\left(\begin{array}{lllll}
A^{T} & Z^{-1} & A
\end{array}\right)^{-1} A^{T} Z^{-1} y,
$$

with residual vector

$$
\mathrm{r}=\mathrm{y}-\mathrm{Ab},
$$

and covariance matrix

$$
V=\left(\begin{array}{lll}
A^{T} & Z^{-1} & A
\end{array}\right)^{-1}
$$

The statistical parameter $\chi^{2}$ is given by

$$
\chi^{2}=\mathrm{r}^{\mathrm{T}} \mathrm{z}^{-1} \mathrm{r}
$$

Although in theory $Z$ will be positive semi-definite, it will not necessarily be positive-definite. Occasions can occur when the solution cannot be obtained by straightforward matrix inversion of $\mathrm{Z}$, because wrong results can be obtained if the matrix is near-singular. It is always safer to use the method of Cholesky factorization to solve the equations. The procedure is to derive a weight matrix $W$ such that $W^{T} W=Z^{-1}$. Then if $A^{\prime}=W A$ and $y^{\prime}=$ Wy the solution is identical to that of the model $\mathrm{y}^{\prime}=\mathrm{A}^{\prime} \mathrm{b}+\mathrm{f}$, where $\mathrm{f}$ has zero mean and only diagonal variance.

\footnotetext{
${ }^{1}$ E. J. Axton, A. G. Bardell, S. J. Felgate, E.M.R. Long, Metrologia 21, 181 (1985).
} 
The solution is then given by

$$
b=\left(A^{\prime}\right)^{-1} y^{\prime} \text {, where }\left(A^{\prime}\right)^{-1} \text { is the pseudo-inverse of } A^{\prime}
$$

with (weighted) residual vector

$$
r^{\prime}=y^{\prime}-A^{\prime} b,
$$

and covariance matrix

$$
V=\left[\left(A^{\prime}\right)^{T} A^{\prime}\right]^{-1}
$$

The statistical parameter $\chi$ is given by

$$
\chi^{2}=\left(r^{\prime}\right)^{T} r^{\prime} .
$$

The residual vector $r$ can be obtained from

$$
r=W^{-1} r^{\prime},
$$

but it is better to save time by using the expression for $r$ given above.

The Cholesky method is safer, and therefore less vulnerable to criticism, and it also uses considerably less computer time and space when large matrices are involved. FORTRAN ${ }^{2}$ and $\mathrm{APL}^{3}$ algorithms are available for this operation.

The uncertainties in the fitted parameters are derived from the diagonal elements of $\mathrm{V}$. These are normally referred to as internal uncertainties which are derived from the statistical uncertainties of the measurements. To obtain what are normally referred to as external uncertainties, which also take into account the goodness of fit, it is necessary to multiply $V$ by $\chi^{2} /(n-p)$, where $n$ is the number of observations, and $p$ is the number of unknown parameters to be fitted.

In order to linearize the problem it is necessary to guess starter values GP for the $\mathrm{p}$ unknown parameters to be determined. Each measurement $\mathrm{Y}$ is expressed as a function $f(G P)$, and the observation vector $y$ consists of the differences $Y-f(G P)$. The solution $b$ is a vector of small corrections to the $G P$, with covariance $V$. The calculation is then iterated by restarting with the corrected GP until b becomes zero or negligible.

${ }^{2}$ S. L. Hammarling, E.M.R. Long, D. W. Martin, NPL Report DITC 33183 (1983).

${ }^{3}$ C. Bastian, "An APL Workspace of Interactive Multi-parametric Evaluation," CBNM Report GE/R/LI/142/84 (1984). 
Appendix 2. Input Data and Fitted Values

\begin{tabular}{|c|c|c|c|c|c|c|}
\hline Author & $\begin{array}{l}\text { Measured } \\
\text { Quantity }\end{array}$ & $\begin{array}{l}\text { Measured } \\
\text { Value }\end{array}$ & Uncertainty & $\begin{array}{l}\text { Fitted } \\
\text { Value }\end{array}$ & Residual & $\begin{array}{l}\text { Weighted } \\
\text { Residual }\end{array}$ \\
\hline ENDF/B-V & $\operatorname{gp}[1]$ & 1.000 & .040 & .941 & .059 & 1.485 \\
\hline ENDF/B-V & gP [2] & 1.000 & .080 & .945 & .056 & .694 \\
\hline ENDF/B-V & gp [3] & 1.000 & .150 & 1.079 & -.079 & -.524 \\
\hline ENDF/B-V & gP [4] & 1.000 & .250 & .890 & .110 & .438 \\
\hline ENDF/B-V & $\operatorname{gp}[5]$ & 1.000 & .050 & 1.000 & -.000 & -.002 \\
\hline ENDF/B-V & $\operatorname{gp}[6]$ & 1.000 & .150 & .947 & .054 & .357 \\
\hline ENDF/B -V & $g p[7]$ & 1.000 & .150 & 1.162 & -.162 & -1.078 \\
\hline ENDF/B-V & $\operatorname{gp}[8]$ & 1.000 & .250 & 1.045 & -.045 & -.180 \\
\hline ENDF/B-V & $\operatorname{gp}[9]$ & 1.000 & .250 & 1.005 & -.005 & -.018 \\
\hline ENDF/B-V & $\operatorname{gp}[10]$ & 1.000 & .250 & 1.060 & -.060 & -.239 \\
\hline De84 & $\mathrm{fk} 14.1 *$ & 1.780 & .110 & 1.832 & -.052 & -.474 \\
\hline Mc 87 & fk 14.6 & 1.800 & .160 & 2.018 & -.218 & -1.361 \\
\hline De 85 & fk 15 & 2.100 & .160 & 2.209 & -.109 & -.679 \\
\hline Bu85 & fk 15 & 2.350 & .210 & 2.209 & .141 & .673 \\
\hline Bu 85 & fle 17 & 2.460 & .240 & 2.734 & -.274 & -1.142 \\
\hline De 86 & fk 17.8 & 2.920 & .220 & 2.927 & -.007 & -.031 \\
\hline De85 & fk 17.9 & 2.970 & .300 & 2.965 & .005 & .016 \\
\hline De86 & fk 19.8 & 3.550 & .280 & 3.131 & .419 & 1.496 \\
\hline $\mathrm{Ha} 84$ & $\operatorname{csa} 14.1 *$ & 72.0 & 9.0 & 72.3 & -.30 & -.038 \\
\hline Br 84 & $\operatorname{cs} 3 a 16$ & 350.0 & 34.0 & 352.9 & -2.9 & -.085 \\
\hline Br 84 & $\operatorname{cs} 3 a 17$ & 292.0 & 22.2 & 322.7 & -30.7 & -1.384 \\
\hline Br 84 & $\operatorname{cs} 3 a 18$ & 315.0 & 23.3 & 316.9 & -01.9 & -.082 \\
\hline Br 84 & $\operatorname{cs} 3 a 19$ & 319.0 & 22.3 & 285.2 & 33.8 & 1.515 \\
\hline Br84 & $\operatorname{cs} 3 a 20$ & 283.0 & 16.7 & 269.9 & 13.1 & .783 \\
\hline Va58 & $\operatorname{cs} 3 a 14$ & 176.0 & 82.0 & 196.0 & -20.0 & -.244 \\
\hline An 83 & $\operatorname{cs} 3 a 14$ & 301.0 & 89.0 & 196.0 & 105.0 & 1.179 \\
\hline $\mathrm{Fa} 71$ & $\operatorname{cs} 3 a 14$ & 190.0 & 20.0 & 196.0 & -06.0 & -.302 \\
\hline Fr55 & $\operatorname{cs} 3 a 14.1$ & 230.0 & 50.0 & 200.3 & 29.7 & .595 \\
\hline Gr69 & $\operatorname{cs} 3 a 14.1$ & 190.0 & 20.0 & 200.3 & -10.3 & -.514 \\
\hline Co76 & $\operatorname{cs} 3 a 14.2$ & 202.0 & 30.0 & 204.5 & -02.5 & -.085 \\
\hline An86 & $\operatorname{cs} 3 a 11.915$ & 176.8 & 24.6 & 148.8 & 28.0 & 1.138 \\
\hline An86 & $\operatorname{cs} 3 a 12.895$ & 167.1 & 15.9 & 143.9 & 23.2 & 1.459 \\
\hline An86 & $\operatorname{cs} 3 a 14$ & 201.5 & 16.0 & 196.0 & 05.5 & .341 \\
\hline An86 & $\operatorname{cs} 3 a 14.8$ & 227.6 & 13.3 & 238.2 & -10.6 & -.795 \\
\hline An86 & $\operatorname{cs} 3 a 17$ & 272.0 & 17.0 & 322.7 & -50.7 & -2.983 \\
\hline An 86 & $\operatorname{cs} 3 a 19$ & 300.0 & 14.2 & 285.2 & 14.8 & 1.045 \\
\hline Ho 76 & csta 14.4 & 654.0 & 92.0 & 730.3 & -76.3 & -.829 \\
\hline $\mathrm{Fa} 78$ & csta 14.8 & 900.0 & 70.0 & 786.0 & 114.1 & 1.629 \\
\hline $\mathrm{Kn} 86$ & csta 14.8 & 894.0 & 60.0 & 786.0 & 108.1 & 1.801 \\
\hline Ho 76 & csta 14.9 & 744.0 & 60.0 & 799.7 & -55.7 & -.927 \\
\hline $\mathrm{Ha} 84$ & fka $14.1 *$ & .490 & .060 & .488 & .002 & .028 \\
\hline $\mathrm{Ha} 84$ & $\mathrm{fk} 3 \mathrm{a} 14.1$ & .560 & .080 & .749 & -.189 & -2.361 \\
\hline An 84 & feb3a 10.91 & 3.010 & 1.260 & 2.237 & .773 & .614 \\
\hline An84 & feb $3 a 12.93$ & 4.020 & 1.110 & 3.718 & .303 & .273 \\
\hline An84 & feb3a 14.95 & 5.630 & 1.130 & 5.277 & .354 & .313 \\
\hline An84 & feb3a 16.87 & 5.940 & 1.210 & 6.491 & -.551 & -.456 \\
\hline An 84 & feb $3 a 18.94$ & 7.690 & 1.190 & 8.150 & -.460 & -.386 \\
\hline
\end{tabular}

$*$ Kerma values are in $\mathrm{fGy} \cdot \mathrm{m}$. Cross section values are in $\mathrm{mb} . \overline{\mathrm{E}}$ values are in $\mathrm{MeV}$. 


\section{Appendix 3. Description of Functions Used in the Tables}

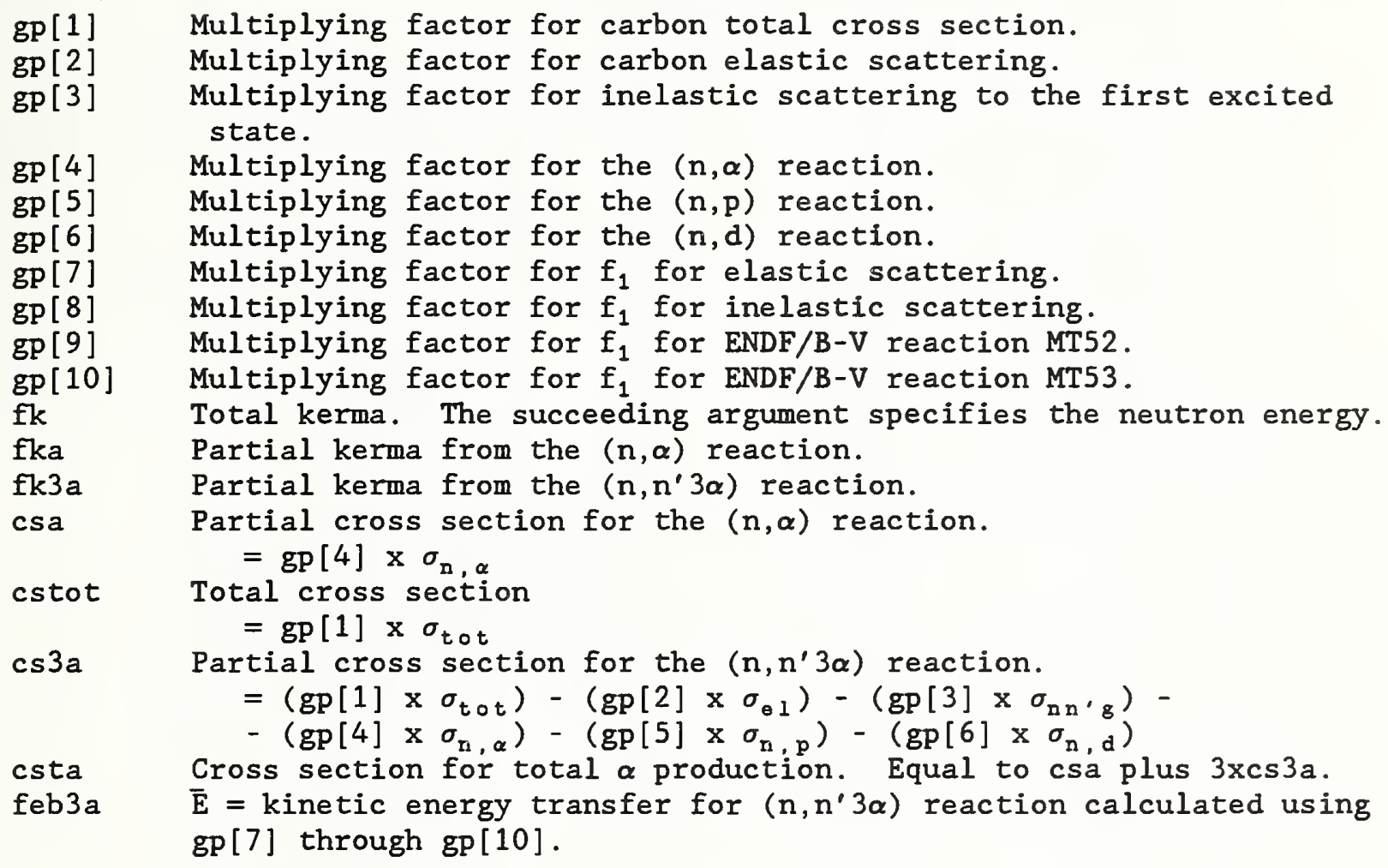

Several tens of such functions are used in the definition of total kerma. Only those listed in the input table are defined here. As an example of their use, the first element of the observation vector $y$ is 1-gp[1]. The eleventh element is 1.78 -( $\mathrm{fk} \mathrm{14.1).}$ 


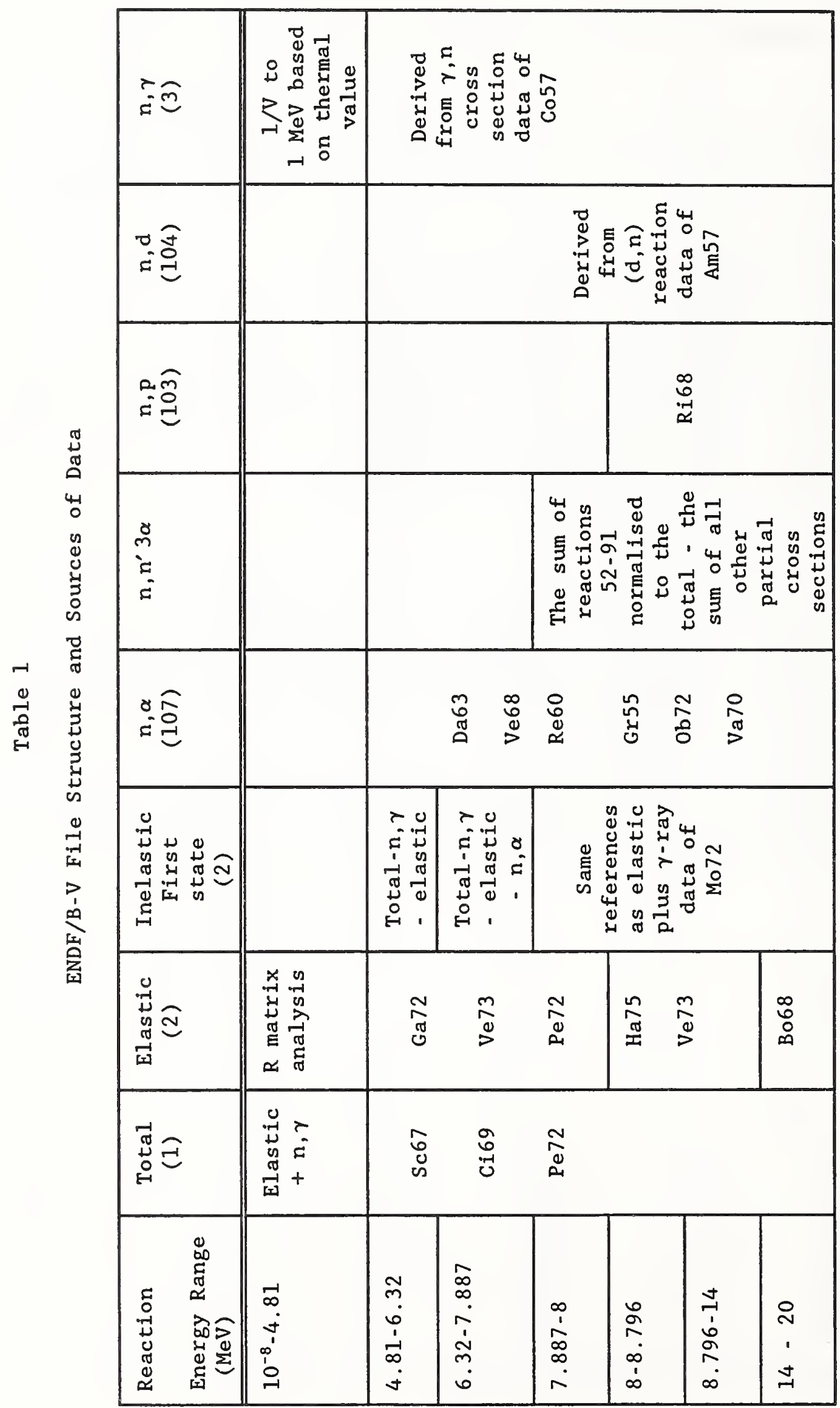


Table 2

Reactions with Thresholds Below $32 \mathrm{MeV}$

\begin{tabular}{|c|c|c|c|}
\hline Reaction & \multicolumn{2}{|c|}{ Threshold } & $\mathrm{Q} \mathrm{MeV}$ \\
\hline${ }^{12} C(n, \alpha)$ & ${ }^{9} \mathrm{Be}$ & 6.181 & 5.702 \\
\hline${ }^{12} C(n, n \alpha)$ & ${ }^{8} \mathrm{Be}$ & 7.986 & 7.367 \\
\hline${ }^{12} \mathrm{C}\left(\mathrm{n},{ }^{5} \mathrm{He}\right)$ & ${ }^{8} \mathrm{Be}$ & 8.954 & 8.260 \\
\hline${ }^{12} \mathrm{C}(\mathrm{n}, \mathrm{p})$ & $12 \mathrm{~B}$ & 13.646 & 12.588 \\
\hline${ }^{12} C(n, d)$ & ${ }^{11} \mathrm{~B}$ & 14.887 & 13.733 \\
\hline${ }^{12} C(n, n p)$ & ${ }^{11} \mathrm{~B}$ & 17.298 & 15.957 \\
\hline${ }^{12} C(n, 2 n)$ & ${ }^{11} \mathrm{C}$ & 20.296 & 18.722 \\
\hline${ }^{12} c(n, t)$ & ${ }^{10} \mathrm{~B}$ & 20.522 & 18.931 \\
\hline${ }^{12} \mathrm{C}\left(\mathrm{n},{ }^{3} \mathrm{He}\right)$ & ${ }^{10} \mathrm{Be}$ & 21.105 & 19.468 \\
\hline${ }^{12} \mathrm{C}\left(\mathrm{n},{ }^{6} \mathrm{Li}\right)$ & ${ }^{7} \mathrm{Li}$ & 22.683 & 20.924 \\
\hline${ }^{12} \mathrm{C}(\mathrm{n}, \alpha \mathrm{d})$ & ${ }^{7} \mathrm{Li}$ & 24.281 & 22.398 \\
\hline${ }^{12} C(n, \alpha p)$ & ${ }^{8} \mathrm{Li}$ & 24.489 & 22.590 \\
\hline${ }^{12} C(n, \alpha t)$ & ${ }^{6} \mathrm{Li}$ & 25.357 & 23.391 \\
\hline${ }^{12} \mathrm{C}(\mathrm{n}, \mathrm{dt}) 2 \alpha$ & & 26.955 & 24.865 \\
\hline${ }^{12} C(n, d t)$ & ${ }^{8} \mathrm{Be}$ & 27.055 & 24.957 \\
\hline${ }^{12} \mathrm{C}(\mathrm{n}, \mathrm{pd})$ & ${ }^{10} \mathrm{Be}$ & 27.060 & 24.962 \\
\hline${ }^{12} \mathrm{C}(\mathrm{n}, \mathrm{nd})$ & ${ }^{10} \mathrm{~B}$ & 27.306 & 25.189 \\
\hline${ }^{12} \mathrm{C}\left(\mathrm{n},{ }^{6} \mathrm{He}\right)$ & ${ }^{7} \mathrm{Be}$ & 27.422 & 25.296 \\
\hline${ }^{12} \mathrm{C}(\mathrm{n}, \mathrm{pt})$ & ${ }^{9} \mathrm{Be}$ & 27.661 & 25.516 \\
\hline${ }^{12} C(n, 2 n) \alpha$ & ${ }^{7} \mathrm{Be}$ & 28.475 & 26.267 \\
\hline${ }^{12} \mathrm{C}(\mathrm{n}, 2 \mathrm{p})$ & ${ }^{11} \mathrm{Be}$ & 28.927 & 26.684 \\
\hline${ }^{12} \mathrm{C}\left(\mathrm{n},{ }^{3} \mathrm{He}\right) \alpha$ & ${ }^{6} \mathrm{He}$ & 29.142 & 26.882 \\
\hline${ }^{12} \mathrm{C}(\mathrm{n}, \mathrm{np} t) 2 \alpha$ & & 29.366 & 27.089 \\
\hline${ }^{12} \mathrm{C}(\mathrm{n}, \mathrm{np} t)$ & ${ }^{8} \mathrm{Be}$ & 29.466 & 27.181 \\
\hline${ }^{12} \mathrm{C}(\mathrm{n}, \mathrm{n} 2 \mathrm{p})$ & ${ }^{10} \mathrm{Be}$ & 29.472 & 27.187 \\
\hline${ }^{12} \mathrm{C}(\mathrm{n}, \mathrm{nt})$ & ${ }^{9} \mathrm{~B}$ & 29.666 & 27.366 \\
\hline${ }^{12} C(n, 2 n p)$ & ${ }^{10} \mathrm{~B}$ & 29.717 & 27.413 \\
\hline${ }^{12} \mathrm{C}\left(\mathrm{n},{ }^{3} \mathrm{He}\right) 2 \alpha 2 \mathrm{n}$ & & 30.195 & 27.853 \\
\hline${ }^{12} \mathrm{C}(\mathrm{n}, \alpha \mathrm{pt})$ & ${ }^{5} \mathrm{He}$ & 30.335 & 27.983 \\
\hline
\end{tabular}


Table 3.

Total Cross Section Ratios of Various Data Sets to Ci78

$\begin{array}{ccccc}\text { Ref. } & \begin{array}{c}\text { Energy } \\ \text { Range } \\ (\mathrm{MeV})\end{array} & \begin{array}{c}\text { Unweighted } \\ \text { mean } \\ \text { ratio }\end{array} & \begin{array}{c}\text { Standard } \\ \text { deviation }\end{array} & \begin{array}{c}\text { Standard } \\ \text { error } \\ \text { of mean }\end{array} \\ \text { Au79 } & 5-8 & 0.9848 & 0.0630 & 0.0056 \\ \text { Au79 } & 8-9.92 & 0.9817 & 0.0205 & 0.0022 \\ \text { Au79 } & 10-13.82 & 0.9871 & 0.0134 & 0.0015 \\ \text { La75 } & 5-8 & 1.0017 & 0.0494 & 0.0044 \\ \text { La75 } & 8-10 & 1.0016 & 0.0158 & 0.0017 \\ \text { Sc67 } & 5-8 & 1.0023 & 0.0633 & 0.0056 \\ \text { Sc67 } & 8-9.92 & 1.0071 & 0.0273 & 0.0029 \\ \text { Sc67 } & 10-14.812 & 1.0143 & 0.0285 & 0.0030 \\ \text { ENDF/B-V } & 5-8 & 1.0063 & 0.0411 & 0.0036 \\ \text { ENDF/B-V } & 8-10 & 0.9987 & 0.0155 & 0.0010 \\ \text { ENDF/B-V } & 10-14.812 & 0.9844 & 0.0138 & 0.0014 \\ \text { ENDF/B-V } & 15-20 & 1.0023 & 0.0218 & 0.0026\end{array}$


Table 4

Total Cross Sections Reduced to ENDF/B-V Energy Grid

\begin{tabular}{|c|c|c|c|c|c|}
\hline$E_{n} \mathrm{MeV}$ & $\mathrm{mb}$ & $\Delta \mathrm{mb}$ & $\mathrm{E}_{\mathrm{n}} \mathrm{MeV}$ & $\mathrm{mb}$ & $\Delta \mathrm{mb}$ \\
\hline 5.000 & 1178.400 & 20.496 & 6.240 & 1416.300 & 24.470 \\
\hline 5.001 & 1193.000 & 17.895 & 6.250 & 1482.200 & 23.914 \\
\hline 5.030 & 1174.400 & 18.774 & 6.285 & 2410.800 & 37.807 \\
\hline 5.053 & 1170.300 & 18.440 & 6.295 & 2736.200 & 46.010 \\
\hline 5.100 & 1148.200 & 18.166 & 6.303 & 2623.700 & 44.941 \\
\hline 5.120 & 1138.800 & 18.360 & 6.310 & 2394.900 & 40.465 \\
\hline 5.150 & 1132.300 & 18.045 & 6.320 & 1941.500 & 32.660 \\
\hline 5.180 & 1121.100 & 18.083 & 6.330 & 1701.300 & 28.798 \\
\hline 5.200 & 1103.600 & 17.833 & 6.340 & 1511.200 & 25.862 \\
\hline 5.230 & 1094.800 & 17.239 & 6.350 & 1479.700 & 25.404 \\
\hline 5.280 & 1061.600 & 16.876 & 6.360 & 1640.400 & 27.712 \\
\hline 5.300 & 1056.000 & 17.163 & 6.370 & 1420.700 & 23.486 \\
\hline 5.330 & 1041.600 & 17.493 & 6.390 & 1174.100 & 19.922 \\
\hline 5.335 & 1077.400 & 21.326 & 6.400 & 1157.200 & 20.603 \\
\hline 5.340 & 1013.400 & 17.957 & 6.410 & 1122.700 & 20.193 \\
\hline 5.360 & 1572.800 & 26.160 & 6.420 & 1093.600 & 19.923 \\
\hline 5.362 & 1853.100 & 33.647 & 6.430 & 1107.900 & 19.965 \\
\hline 5.370 & 2023.200 & 35.829 & 6.440 & 1079.800 & 19.559 \\
\hline 5.371 & 1996.800 & 37.007 & 6.450 & 1079.000 & 18.531 \\
\hline 5.378 & 1771.800 & 32.569 & 6.470 & 1056.100 & 17.660 \\
\hline 5.380 & 1685.100 & 29.735 & 6.490 & 1056.300 & 17.645 \\
\hline 5.390 & 1460.500 & 24.863 & 6.510 & 1043.400 & 17.125 \\
\hline 5.400 & 1322.300 & 22.803 & 6.540 & 991.800 & 16.631 \\
\hline 5.410 & 1258.200 & 21.933 & 6.553 & 913.320 & 17.376 \\
\hline 5.420 & 1226.200 & 21.408 & 6.560 & 863.340 & 17.197 \\
\hline 5.430 & 1197.600 & 21.027 & 6.570 & 772.930 & 15.443 \\
\hline 5.440 & 1192.700 & 19.965 & 6.580 & 732.310 & 14.779 \\
\hline 5.460 & 1145.800 & 18.282 & 6.590 & 746.190 & 15.059 \\
\hline 5.500 & 1118.900 & 17.535 & 6.600 & 735.500 & 13.852 \\
\hline 5.550 & 1100.100 & 17.760 & 6.620 & 775.900 & 13.710 \\
\hline 5.553 & 1111.100 & 18.003 & 6.640 & 749.720 & 13.531 \\
\hline 5.600 & 1087.800 & 17.037 & 6.658 & 939.870 & 16.904 \\
\hline 5.650 & 1078.400 & 16.883 & 6.665 & 855.590 & 17.982 \\
\hline 5.700 & 1067.400 & 16.490 & 6.670 & 842.130 & 17.205 \\
\hline 5.800 & 1079.800 & 16.556 & 6.680 & 840.890 & 15.226 \\
\hline 5.900 & 1078.300 & 16.540 & 6.700 & 838.770 & 13.761 \\
\hline 6.000 & 1095.900 & 16.924 & 6.750 & 817.920 & 13.042 \\
\hline 6.050 & 1102.000 & 17.842 & 6.810 & 800.940 & 12.529 \\
\hline 6.053 & 1106.300 & 17.548 & 6.920 & 771.600 & 12.046 \\
\hline 6.125 & 1132.400 & 17.663 & 7.000 & 745.790 & 11.868 \\
\hline 6.160 & 1162.600 & 18.879 & 7.053 & 749.840 & 12.142 \\
\hline 6.174 & 1190.500 & 21.109 & 7.100 & 749.050 & 12.257 \\
\hline 6.180 & 1196.100 & 20.435 & 7.140 & 768.240 & 12.627 \\
\hline 6.200 & 1222.500 & 20.596 & 7.180 & 794.810 & 13.336 \\
\hline 6.210 & 1271.000 & 22.265 & 7.200 & 843.690 & 14.650 \\
\hline 6.220 & 1285.500 & 22.551 & 7.220 & 874.250 & 16.141 \\
\hline 6.230 & 1334.200 & 23.168 & 7.225 & 884.730 & 15.864 \\
\hline
\end{tabular}


Table 4 (Continued)

\begin{tabular}{|c|c|c|c|c|c|}
\hline$E_{n} \mathrm{MeV}$ & $\mathrm{mb}$ & $\Delta \mathrm{mb}$ & $\mathrm{E}_{\mathrm{n}} \mathrm{MeV}$ & $\mathrm{mb}$ & $\Delta \mathrm{mb}$ \\
\hline 7.250 & 972.010 & 16.303 & 8.166 & 1666.000 & 26.571 \\
\hline 7.270 & 1061.500 & 18.289 & 8.200 & 1507.700 & 24.147 \\
\hline 7.280 & 1130.900 & 18.071 & 8.210 & 1453.600 & 25.103 \\
\hline 7.340 & 1639.700 & 25.538 & 8.218 & 1435.900 & 23.595 \\
\hline 7.350 & 1758.500 & 29.804 & 8.240 & 1382.400 & 21.791 \\
\hline 7.360 & 1753.900 & 29.666 & 8.280 & 1286.400 & 20.523 \\
\hline 7.370 & 1811.000 & 28.946 & 8.296 & 1252.600 & 23.131 \\
\hline 7.400 & 1778.100 & 28.105 & 8.296 & 1250.900 & 18.765 \\
\hline 7.420 & 1766.800 & 27.528 & 8.320 & 1228.800 & 20.309 \\
\hline 7.470 & 1750.200 & 26.919 & 8.330 & 1206.600 & 19.054 \\
\hline 7.529 & 1749.700 & 27.231 & 8.391 & 1140.900 & 18.113 \\
\hline 7.542 & 1727.700 & 28.642 & 8.400 & 1131.700 & 18.861 \\
\hline 7.553 & 1718.200 & 27.121 & 8.426 & 1133.500 & 18.417 \\
\hline 7.594 & 1696.300 & 26.501 & 8.448 & 1116.200 & 19.188 \\
\hline 7.620 & 1693.400 & 26.631 & 8.450 & 1096.600 & 18.476 \\
\hline 7.650 & 1713.500 & 27.170 & 8.480 & 1109.600 & 18.026 \\
\hline 7.667 & 1774.100 & 28.872 & 8.500 & 1085.800 & 19.673 \\
\hline 7.680 & 1799.900 & 29.247 & 8.500 & 1075.200 & 16.130 \\
\hline 7.698 & 1926.000 & 31.955 & 8.520 & 1082.800 & 17.545 \\
\hline 7.700 & 1930.500 & 31.584 & 8.553 & 1064.300 & 16.848 \\
\hline 7.725 & 2238.900 & 35.323 & 8.600 & 1077.900 & 17.366 \\
\hline 7.745 & 2441.200 & 39.845 & 8.611 & 1078.200 & 17.248 \\
\hline 7.750 & 2398.900 & 39.181 & 8.664 & 1061.800 & 16.713 \\
\hline 7.770 & 2280.500 & 36.257 & 8.700 & 1066.100 & 17.494 \\
\hline 7.789 & 2141.600 & 34.071 & 8.708 & 1059.800 & 17.242 \\
\hline 7.810 & 2051.800 & 33.131 & 8.750 & 1057.000 & 16.995 \\
\hline 7.819 & 2061.300 & 32.420 & 8.768 & 1063.200 & 17.316 \\
\hline 7.860 & 2007.000 & 31.209 & 8.800 & 1067.000 & 17.052 \\
\hline 7.887 & 1975.100 & 32.153 & 8.833 & 1068.700 & 17.387 \\
\hline 7.888 & 1950.400 & 29.324 & 8.850 & 1067.700 & 17.328 \\
\hline 7.897 & 1949.300 & 30.967 & 8.885 & 1089.200 & 17.293 \\
\hline 7.930 & 1916.700 & 30.542 & 8.920 & 1074.800 & 17.360 \\
\hline 7.936 & 1891.700 & 29.399 & 8.940 & 1094.800 & 17.530 \\
\hline 8.000 & 1843.300 & 28.682 & 8.980 & 1117.300 & 17.860 \\
\hline 8.005 & 1857.600 & 32.804 & 9.000 & 1122.100 & 19.234 \\
\hline 8.010 & 1813.200 & 33.742 & 9.005 & 1143.700 & 20.063 \\
\hline 8.014 & 1858.400 & 29.883 & 9.020 & 1142.800 & 19.557 \\
\hline 8.044 & 1850.500 & 29.570 & 9.030 & 1155.900 & 19.781 \\
\hline 8.053 & 1898.300 & 30.441 & 9.045 & 1160.500 & 19.996 \\
\hline 8.079 & 1907.700 & 31.241 & 9.053 & 1186.300 & 20.468 \\
\hline 8.080 & 1892.800 & 28.395 & 9.067 & 1183.400 & 19.973 \\
\hline 8.100 & 1901.400 & 31.756 & 9.080 & 1215.100 & 19.025 \\
\hline 8.101 & 1919.400 & 29.568 & 9.149 & 1286.800 & 20.075 \\
\hline 8.105 & 1905.100 & 35.143 & 9.163 & 1308.200 & 21.493 \\
\hline 8.109 & 1876.700 & 32.208 & 9.180 & 1301.600 & 20.658 \\
\hline 8.120 & 1860.900 & 30.957 & 9.219 & 1329.000 & 20.850 \\
\hline 8.131 & 1824.600 & 31.032 & 9.250 & 1324.100 & 21.411 \\
\hline 8.138 & 1809.200 & 29.519 & 9.254 & 1340.600 & 21.318 \\
\hline 8.160 & 1717.700 & 28.033 & 9.300 & 1319.900 & 20.923 \\
\hline
\end{tabular}


Table 4 (Continued)

\begin{tabular}{|c|c|c|c|c|c|}
\hline$E_{n} \mathrm{MeV}$ & $\mathrm{mb}$ & $\Delta \mathrm{mb}$ & $\mathrm{E}_{\mathrm{D}} \mathrm{MeV}$ & $\mathrm{mb}$ & $\Delta \mathrm{mb}$ \\
\hline 9.310 & 1321.100 & 20.856 & 10.940 & 1417.200 & 21.842 \\
\hline 9.360 & 1293.100 & 20.100 & 11.000 & 1424.500 & 22.201 \\
\hline 9.400 & 1267.600 & 19.723 & 11.004 & 1415.400 & 22.285 \\
\hline 9.450 & 1252.300 & 19.426 & 11.053 & 1429.200 & 22.071 \\
\hline 9.500 & 1237.400 & 19.447 & 11.096 & 1416.600 & 22.387 \\
\hline 9.522 & 1238.900 & 19.738 & 11.100 & 1422.700 & 22.097 \\
\hline 9.553 & 1224.300 & 19.946 & 11.166 & 1417.800 & 22.029 \\
\hline 9.560 & 1231.700 & 20.060 & 11.170 & 1418.300 & 21.957 \\
\hline 9.590 & 1224.700 & 19.873 & 11.250 & 1408.200 & 21.569 \\
\hline 9.600 & 1222.300 & 19.888 & 11.300 & 1405.400 & 21.466 \\
\hline 9.630 & 1229.500 & 19.920 & 11.400 & 1396.500 & 21.237 \\
\hline 9.640 & 1241.100 & 19.843 & 11.500 & 1361.100 & 20.796 \\
\hline 9.678 & 1237.100 & 19.971 & 11.553 & 1349.800 & 20.538 \\
\hline 9.680 & 1237.400 & 22.597 & 11.700 & 1330.900 & 20.261 \\
\hline 9.692 & 1237.800 & 21.123 & 11.750 & 1350.200 & 21.380 \\
\hline 9.700 & 1248.800 & 20.473 & 11.751 & 1342.800 & 21.099 \\
\hline 9.726 & 1237.100 & 20.066 & 11.800 & 1346.300 & 20.951 \\
\hline 9.740 & 1256.600 & 21.344 & 11.828 & 1359.700 & 20.971 \\
\hline 9.750 & 1232.600 & 19.509 & 11.900 & 1399.500 & 21.674 \\
\hline 9.800 & 1242.900 & 19.502 & 11.909 & 1391.600 & 23.334 \\
\hline 9.821 & 1231.700 & 20.495 & 11.917 & 1408.000 & 21.726 \\
\hline 9.830 & 1233.000 & 19.771 & 12.000 & 1446.100 & 22.122 \\
\hline 9.868 & 1208.000 & 19.003 & 12.050 & 1482.500 & 23.393 \\
\hline 9.900 & 1188.700 & 19.112 & 12.053 & 1492.500 & 23.658 \\
\hline 9.917 & 1190.800 & 20.287 & 12.088 & 1498.000 & 23.611 \\
\hline 9.921 & 1177.500 & 18.410 & 12.100 & 1503.500 & 23.078 \\
\hline 10.000 & 1173.400 & 18.294 & 12.196 & 1434.800 & 21.987 \\
\hline 10.003 & 1163.800 & 18.592 & 12.224 & 1414.500 & 22.254 \\
\hline 10.050 & 1161.800 & 18.582 & 12.250 & 1400.800 & 21.744 \\
\hline 10.053 & 1150.900 & 17.777 & 12.300 & 1364.100 & 20.845 \\
\hline 10.170 & 1137.200 & 17.383 & 12.400 & 1348.100 & 20.511 \\
\hline 10.250 & 1125.800 & 17.373 & 12.500 & 1336.700 & 20.430 \\
\hline 10.300 & 1117.400 & 17.282 & 12.553 & 1347.300 & 20.786 \\
\hline 10.372 & 1136.200 & 17.665 & 12.599 & 1350.100 & 20.643 \\
\hline 10.400 & 1144.100 & 17.964 & 12.700 & 1363.500 & 20.861 \\
\hline 10.448 & 1163.900 & 18.234 & 12.738 & 1356.700 & 20.935 \\
\hline 10.478 & 1181.500 & 18.851 & 12.800 & 1379.500 & 21.050 \\
\hline 10.500 & 1198.600 & 19.884 & 12.900 & 1397.800 & 21.269 \\
\hline 10.506 & 1198.900 & 19.516 & 12.990 & 1408.500 & 21.688 \\
\hline 10.536 & 1218.900 & 19.573 & 13.000 & 1409.700 & 21.998 \\
\hline 10.550 & 1216.300 & 20.688 & 13.053 & 1406.000 & 21.651 \\
\hline 10.553 & 1232.900 & 19.346 & 13.100 & 1406.200 & 21.937 \\
\hline 10.620 & 1274.100 & 19.550 & 13.120 & 1405.900 & 21.468 \\
\hline 10.690 & 1311.800 & 20.385 & 13.250 & 1387.800 & 21.177 \\
\hline 10.700 & 1312.100 & 20.647 & 13.280 & 1367.600 & 21.641 \\
\hline 10.750 & 1352.000 & 20.860 & 13.300 & 1375.600 & 20.900 \\
\hline 10.800 & 1378.800 & 21.392 & 13.500 & 1387.600 & 21.057 \\
\hline 10.830 & 1392.200 & 21.464 & 13.540 & 1397.200 & 21.957 \\
\hline 10.900 & 1415.000 & 21.757 & 13.553 & 1395.800 & 22.097 \\
\hline
\end{tabular}


Table 4 (Continued)

\begin{tabular}{|c|c|c|c|c|c|}
\hline $\mathrm{E}_{\mathrm{n}} \mathrm{MeV}$ & $\mathrm{mb}$ & $\Delta \mathrm{mb}$ & $\mathrm{E}_{\mathrm{n}} \mathrm{MeV}$ & $\mathrm{mb}$ & $\Delta \mathrm{mb}$ \\
\hline 13.587 & 1396.000 & 21.551 & 16.256 & 1472.500 & 22.268 \\
\hline 13.646 & 1367.700 & 21.025 & 16.440 & 1446.400 & 22.067 \\
\hline 13.700 & 1360.600 & 20.971 & 16.443 & 1441.600 & 22.226 \\
\hline 13.748 & 1344.300 & 20.642 & 16.532 & 1431.800 & 22.055 \\
\hline 13.822 & 1303.000 & 20.247 & 16.553 & 1429.100 & 21.855 \\
\hline 13.830 & 1307.200 & 20.009 & 16.695 & 1408.600 & 21.389 \\
\hline 13.965 & 1297.200 & 19.805 & 16.820 & 1404.500 & 21.600 \\
\hline 14.000 & 1302.700 & 20.210 & 16.824 & 1400.800 & 21.428 \\
\hline 14.053 & 1307.500 & 19.938 & 16.974 & 1391.100 & 21.177 \\
\hline 14.182 & 1310.500 & 19.963 & 17.053 & 1398.400 & 21.666 \\
\hline 14.250 & 1316.700 & 20.080 & 17.074 & 1403.800 & 21.890 \\
\hline 14.364 & 1299.000 & 19.838 & 17.138 & 1386.100 & 21.115 \\
\hline 14.419 & 1294.000 & 19.847 & 17.300 & 1406.400 & 21.554 \\
\hline 14.500 & 1315.100 & 20.166 & 17.301 & 1405.100 & 21.475 \\
\hline 14.553 & 1342.500 & 20.943 & 17.467 & 1399.100 & 21.287 \\
\hline 14.566 & 1341.500 & 20.696 & 17.553 & 1407.400 & 21.615 \\
\hline 14.653 & 1374.700 & 21.084 & 17.616 & 1413.800 & 21.756 \\
\hline 14.694 & 1387.100 & 21.414 & 17.687 & 1413.700 & 22.292 \\
\hline 14.750 & 1395.400 & 21.685 & 17.900 & 1427.000 & 22.305 \\
\hline 14.767 & 1393.400 & 21.865 & 17.901 & 1430.600 & 22.098 \\
\hline 14.807 & 1407.000 & 22.145 & 18.000 & 1439.300 & 22.094 \\
\hline 14.812 & 1411.200 & 22.982 & 18.053 & 1452.500 & 22.642 \\
\hline 14.837 & 1406.700 & 22.153 & 18.087 & 1443.900 & 22.389 \\
\hline 14.863 & 1402.700 & 22.130 & 18.158 & 1468.300 & 22.451 \\
\hline 14.888 & 1397.700 & 22.969 & 18.273 & 1465.100 & 22.248 \\
\hline 14.892 & 1407.300 & 22.568 & 18.460 & 1454.400 & 22.118 \\
\hline 14.906 & 1408.600 & 24.443 & 18.553 & 1468.100 & 22.501 \\
\hline 14.909 & 1406.800 & 22.473 & 18.632 & 1481.600 & 22.794 \\
\hline 14.927 & 1397.900 & 22.188 & 18.700 & 1485.900 & 22.719 \\
\hline 14.954 & 1401.400 & 22.574 & 18.833 & 1482.200 & 22.506 \\
\hline 14.962 & 1401.800 & 22.264 & 19.030 & 1482.200 & 22.699 \\
\hline 14.996 & 1421.500 & 22.985 & 19.034 & 1497.200 & 24.076 \\
\hline 15.000 & 1406.600 & 23.551 & 19.053 & 1497.100 & 23.065 \\
\hline 15.006 & 1409.400 & 22.365 & 19.185 & 1506.700 & 22.925 \\
\hline 15.045 & 1417.900 & 22.454 & 19.346 & 1526.500 & 23.193 \\
\hline 15.053 & 1423.100 & 22.573 & 19.511 & 1548.700 & 23.691 \\
\hline 15.093 & 1427.400 & 21.728 & 19.553 & 1554.500 & 23.958 \\
\hline 15.248 & 1440.200 & 22.000 & 19.660 & 1557.300 & 24.303 \\
\hline 15.250 & 1439.700 & 21.888 & 19.661 & 1563.200 & 24.074 \\
\hline 15.448 & 1457.200 & 22.133 & 19.794 & 1539.000 & 23.519 \\
\hline 15.477 & 1458.600 & 22.481 & 19.892 & 1533.700 & 23.508 \\
\hline 15.553 & 1466.900 & 22.256 & 20.000 & 1531.400 & 23.758 \\
\hline 15.731 & 1490.500 & 22.514 & 20.100 & 1517.800 & 23.290 \\
\hline 15.966 & 1509.300 & 22.903 & 20.200 & 1519.600 & 23.320 \\
\hline 15.970 & 1521.200 & 25.125 & 20.300 & 1500.100 & 23.049 \\
\hline 15.990 & 1511.300 & 24.320 & 20.400 & 1486.200 & 22.858 \\
\hline 16.000 & 1519.400 & 23.712 & 20.500 & 1483.600 & 22.822 \\
\hline 16.053 & 1504.800 & 23.485 & 20.600 & 1466.400 & 22.575 \\
\hline 16.068 & 1506.000 & 22.912 & 20.700 & 1454.100 & 22.411 \\
\hline
\end{tabular}


Table 4 (Continued)

\begin{tabular}{|c|c|c|c|c|c|}
\hline $\mathrm{E}_{\mathrm{n}} \mathrm{MeV}$ & $\mathrm{mb}$ & $\Delta \mathrm{mb}$ & $\mathrm{E}_{\mathrm{n}} \mathrm{MeV}$ & $\mathrm{mb}$ & $\Delta \mathrm{mb}$ \\
\hline 20.800 & 1445.900 & 22.301 & 25.700 & 1423.100 & 23.512 \\
\hline 20.900 & 1456.900 & 22.457 & 25.800 & 1402.500 & 23.242 \\
\hline 21.000 & 1460.900 & 22.547 & 25.900 & 1400.400 & 23.300 \\
\hline 21.100 & 1458.000 & 22.510 & 26.000 & 1420.100 & 23.655 \\
\hline 21.200 & 1450.800 & 22.406 & 26.100 & 1389.600 & 23.246 \\
\hline 21.300 & 1463.500 & 22.620 & 26.200 & 1391.100 & 23.363 \\
\hline 21.400 & 1455.200 & 22.516 & 26.300 & 1411.100 & 23.710 \\
\hline 21.500 & 1448.200 & 22.426 & 26.400 & 1413.100 & 23.820 \\
\hline 21.600 & 1453.200 & 22.522 & 26.500 & 1397.200 & 23.715 \\
\hline 21.700 & 1450.100 & 22.478 & 26.600 & 1402.200 & 23.777 \\
\hline 21.800 & 1435.000 & 22.273 & 26.700 & 1401.600 & 23.894 \\
\hline 21.900 & 1428.500 & 22.200 & 26.800 & 1398.000 & 23.965 \\
\hline 22.000 & 1422.700 & 22.124 & 26.900 & 1390.500 & 23.898 \\
\hline 22.100 & 1413.300 & 22.001 & 27.000 & 1395.300 & 23.932 \\
\hline 22.200 & 1434.800 & 22.330 & 27.100 & 1392.600 & 24.003 \\
\hline 22.300 & 1415.300 & 22.084 & 27.200 & 1415.700 & 24.396 \\
\hline 22.400 & 1425.800 & 22.243 & 27.300 & 1402.800 & 24.317 \\
\hline 22.500 & 1425.000 & 22.263 & 27.400 & 1384.400 & 24.175 \\
\hline 22.600 & 1422.700 & 22.260 & 27.500 & 1411.800 & 24.752 \\
\hline 22.700 & 1432.600 & 22.436 & 27.600 & 1384.400 & 24.465 \\
\hline 22.800 & 1432.900 & 22.452 & 27.700 & 1374.200 & 24.256 \\
\hline 22.900 & 1432.500 & 22.478 & 27.800 & 1390.500 & 24.657 \\
\hline 23.000 & 1437.100 & 22.555 & 27.900 & 1368.100 & 26.563 \\
\hline 23.100 & 1436.100 & 22.582 & 28.000 & 1390.500 & 25.272 \\
\hline 23.200 & 1447.100 & 22.781 & 28.100 & 1358.400 & 24.455 \\
\hline 23.300 & 1442.100 & 22.730 & 28.200 & 1384.500 & 24.893 \\
\hline 23.400 & 1457.500 & 23.005 & 28.300 & 1375.300 & 24.861 \\
\hline 23.500 & 1441.400 & 22.776 & 28.400 & 1359.100 & 24.917 \\
\hline 23.600 & 1455.400 & 23.005 & 28.500 & 1375.900 & 25.082 \\
\hline 23.700 & 1446.400 & 22.917 & 28.600 & 1368.900 & 25.103 \\
\hline 23.800 & 1445.900 & 22.935 & 28.700 & 1372.900 & 25.176 \\
\hline 23.900 & 1442.100 & 22.906 & 28.800 & 1377.200 & 25.428 \\
\hline 24.000 & 1450.300 & 23.052 & 28.900 & 1332.500 & 25.015 \\
\hline 24.100 & 1430.200 & 22.796 & 29.000 & 1355.500 & 25.335 \\
\hline 24.200 & 1417.400 & 22.687 & 29.100 & 1342.900 & 25.240 \\
\hline 24.300 & 1444.200 & 23.123 & 29.200 & 1367.300 & 25.621 \\
\hline 24.400 & 1422.900 & 22.809 & 29.300 & 1336.600 & 25.364 \\
\hline 24.500 & 1438.400 & 23.092 & 29.400 & 1355.800 & 25.704 \\
\hline 24.600 & 1423.800 & 22.949 & 29.500 & 1332.400 & 25.609 \\
\hline 24.700 & 1427.000 & 23.068 & 29.600 & 1350.300 & 25.881 \\
\hline 24.800 & 1414.200 & 22.901 & 29.700 & 1331.900 & 25.764 \\
\hline 24.900 & 1430.500 & 23.154 & 29.800 & 1299.700 & 25.266 \\
\hline 25.000 & 1423.300 & 23.134 & 29.900 & 1351.200 & 26.186 \\
\hline 25.100 & 1407.900 & 22.989 & 30.000 & 1342.600 & 26.370 \\
\hline 25.200 & 1403.500 & 22.940 & 30.100 & 1338.500 & 26.301 \\
\hline 25.300 & 1424.400 & 23.271 & 30.200 & 1316.700 & 25.932 \\
\hline 25.400 & 1394.400 & 22.902 & 30.300 & 1318.100 & 26.129 \\
\hline 25.500 & 1412.000 & 23.204 & 30.400 & 1327.300 & 26.289 \\
\hline 25.600 & 1405.200 & 23.158 & 30.500 & 1297.500 & 26.083 \\
\hline
\end{tabular}


Table 4 (Continued)

$\mathrm{E}_{\mathrm{n}} \mathrm{MeV} \quad \mathrm{mb} \quad \Delta \mathrm{mb}$

$\begin{array}{lll}30.600 & 1328.500 & 26.554\end{array}$

$\begin{array}{lll}30.700 & 1338.800 & 26.983\end{array}$

$\begin{array}{lll}30.800 & 1323.400 & 26.669\end{array}$

$\begin{array}{lll}30.900 & 1358.100 & 27.253\end{array}$

$\begin{array}{lll}31.000 & 1319.200 & 26.789\end{array}$

$\begin{array}{lll}31.100 & 1311.500 & 26.960\end{array}$

$\begin{array}{lll}31.200 & 1325.600 & 27.017\end{array}$

$\begin{array}{lll}31.300 & 1309.800 & 26.961\end{array}$

$\begin{array}{lll}31.400 & 1281.400 & 27.030\end{array}$

$\begin{array}{lll}31.500 & 1281.000 & 27.069\end{array}$

$\begin{array}{lll}31.600 & 1346.800 & 27.887\end{array}$

$\begin{array}{lll}31.700 & 1317.500 & 27.637\end{array}$

$\begin{array}{lll}31.800 & 1326.300 & 27.885\end{array}$

$\begin{array}{lll}31.900 & 1290.800 & 27.813\end{array}$

$\begin{array}{lll}32.000 & 1316.600 & 34.922\end{array}$ 
Table 5a

Input Data for Evaluation of Cross Section for Elastic Scattering

\begin{tabular}{|c|c|c|c|c|c|c|c|c|c|}
\hline $\operatorname{Ref}$ & & $\mathrm{E}_{\mathrm{n}} \mathrm{MeV}$ & $\sigma_{e} \mathrm{mb}$ & $\Delta \sigma_{\theta}$ & $\operatorname{Ref}$ & & $\mathrm{E}_{\mathrm{n}} \mathrm{MeV}$ & $\sigma_{e} \mathrm{mb}$ & $\Delta \sigma_{e}$ \\
\hline $\mathrm{Ha} 75$ & & 8.0000 & 1433.30 & 46.13 & $\mathrm{Ha} 75$ & & 14.0000 & 788.77 & 25.66 \\
\hline $\mathrm{Pe} 71$ & I & 8.0000 & 1371.20 & 99.95 & G176 & I & 14.0000 & 911.91 & 51.78 \\
\hline $\mathrm{Pe} 72$ & & 8.0400 & 1202.80 & 91.41 & Bo68 & $I$ & 14.0000 & 835.82 & 86.93 \\
\hline Pe71 & I & 8.0400 & 1336.80 & 97.32 & Ba85 & & 14.2000 & 872.10 & 65.90 \\
\hline Ve73 & & 8.2000 & 1000.00 & 53.81 & G176 & I & 14.2000 & 900.60 & 46.22 \\
\hline Pe71 & I & 8.2000 & 1114.00 & 81.01 & Bo68 & I & 14.2000 & 838.31 & 87.17 \\
\hline $\mathrm{Pe} 72$ & & 8.5000 & 838.57 & 60.38 & G176 & & 14.4300 & 887.60 & 41.10 \\
\hline $\mathrm{Ha} 75$ & & 8.5000 & 723.26 & 24.55 & Bo68 & I & 14.4300 & 841.17 & 87.44 \\
\hline Pe71 & I & 8.5000 & 791.70 & 58.26 & $\mathrm{Ha} 75$ & & 14.5000 & 716.06 & 42.51 \\
\hline Pe69 & & 8.5600 & 802.63 & 56.99 & Ar 71 & & 14.5000 & 714.95 & 79.20 \\
\hline $\mathrm{Pe} 71$ & I & 8.5600 & 788.00 & 58.39 & GI76 & I & 14.5000 & 895.30 & 42.76 \\
\hline $\mathrm{Ha} 75$ & & 9.0000 & 700.00 & 23.07 & Bo68 & I & 14.5000 & 842.94 & 87.61 \\
\hline Ve73 & & 9.0000 & 710.00 & 39.41 & Gu81 & & 14.7000 & 830.00 & 84.34 \\
\hline Gl76 & I & 9.0000 & 670.56 & 18.11 & G176 & I & 14.7000 & 917.30 & 47.88 \\
\hline $\mathrm{Ha} 75$ & & 9.5000 & 657.85 & 21.29 & Bo68 & I & 14.7000 & 854.19 & 88.69 \\
\hline G176 & I & 9.5000 & 665.77 & 17.31 & G176 & & 14.9300 & 942.60 & 54.30 \\
\hline $\mathrm{Ha} 75$ & & 10.0000 & 674.06 & 22.36 & Bo68 & I & 14.9300 & 867.14 & 89.94 \\
\hline G176 & I & 10.0000 & 635.56 & 16.88 & $\mathrm{De} 70$ & & 17.2700 & 884.00 & 36.45 \\
\hline $\mathrm{Ha} 75$ & & 10.5000 & 708.44 & 23.64 & Bo68 & I & 17.2700 & 778.93 & 80.95 \\
\hline G176 & I & 10.5000 & 647.46 & 16.44 & $\mathrm{Ba} 85$ & & 18.2000 & 897.20 & 75.80 \\
\hline $\mathrm{Ha} 75$ & & 11.0000 & 775.57 & 25.22 & Bo68 & I & 18.2000 & 808.43 & 82.98 \\
\hline G176 & I & 11.0000 & 846.88 & 26.31 & De70 & & 18.2500 & 899.00 & 37.07 \\
\hline $\mathrm{Ha} 75$ & & 11.5000 & 841.82 & 27.42 & Bo68 & I & 18.2500 & 812.42 & 83.37 \\
\hline G176 & I & 11.5000 & 810.78 & 21.75 & $\mathrm{De} 70$ & & 19.8800 & 1044.00 & 43.05 \\
\hline Sa81 & & 11.6500 & 853.01 & 70.83 & Bo68 & I & 19.8800 & 927.06 & 94.57 \\
\hline G176 & I & 11.6500 & 819.73 & 21.78 & Me84 & & 20.8000 & 902.45 & 54.15 \\
\hline $\mathrm{Ha} 75$ & & 12.0000 & 820.87 & 26.80 & Bo68 & I & 20.8000 & 868.74 & 88.86 \\
\hline G176 & I & 12.0000 & 908.44 & 27.71 & Me84 & & 22.0000 & 867.41 & 52.04 \\
\hline $\mathrm{Ha} 75$ & & 12.5000 & 823.62 & 26.86 & Bo68 & I & 22.0000 & 803.94 & 82.54 \\
\hline G176 & I & 12.5000 & 825.32 & 25.61 & Me84 & & 24.0000 & 919.03 & 55.14 \\
\hline $\mathrm{Ha} 75$ & & 13.0000 & 946.84 & 30.93 & Bo68 & I & 24.0000 & 740.52 & 76.38 \\
\hline G176 & I & 13.0000 & 971.70 & 35.94 & $\mathrm{Me} 84$ & & 26.0000 & 887.46 & 53.25 \\
\hline $\mathrm{Ha} 75$ & & 13.5000 & 891.13 & 28.88 & Wi 86 & & 40.0000 & 703.00 & 29.28 \\
\hline
\end{tabular}


Table 5b

Evaluated Data for Cross Section for Elastic Scattering

\begin{tabular}{|c|c|c|c|c|c|c|c|}
\hline $\operatorname{Ref}$ & $\mathrm{E}_{\mathrm{n}} \mathrm{MeV}$ & $\sigma_{\mathrm{e}} \mathrm{mb}$ & $\Delta \sigma_{e}$ & $\operatorname{Ref}$ & $\mathrm{E}_{\mathrm{n}} \mathrm{MeV}$ & $\sigma_{\mathrm{e}} \mathrm{mb}$ & $\Delta \sigma_{e}$ \\
\hline ENDF/B - V & 5.0000 & 1158.30 & 57.92 & ENDF/B-V & 6.2850 & 2141.40 & 107.07 \\
\hline ENDF/B-V & 5.0007 & 1157.90 & 57.90 & ENDF/B-V & 6.2950 & 2232.50 & 111.63 \\
\hline ENDF/B-V & 5.0300 & 1144.80 & 57.24 & ENDF/B-V & 6.3030 & 2125.10 & 106.26 \\
\hline ENDF/B-V & 5.0530 & 1136.70 & 56.84 & ENDF/B-V & 6.3100 & 1834.00 & 91.70 \\
\hline ENDF/B-V & 5.1000 & 1120.10 & 56.01 & ENDF/B-V & 6.3200 & 1559.90 & 78.00 \\
\hline ENDF/B-V & 5.1200 & 1112.50 & 55.63 & ENDF/B-V & 6.3300 & 1379.00 & 68.95 \\
\hline ENDF/B-V & 5.1500 & 1094.10 & 54.71 & ENDF/B-V & 6.3400 & 1248.00 & 62.40 \\
\hline ENDF/B-V & 5.1800 & 1074.60 & 53.73 & ENDF/B-V & 6.3500 & 1158.20 & 57.91 \\
\hline ENDF/B-V & 5.2000 & 1058.00 & 52.90 & ENDF/B-V & 6.3600 & 1075.60 & 53.78 \\
\hline ENDF/B-V & 5.2300 & 1035.00 & 51.75 & ENDF/B-V & 6.3700 & 1001.30 & 50.07 \\
\hline ENDF/B-V & 5.2800 & 993.97 & 49.70 & ENDF/B-V & 6.3900 & 912.64 & 45.63 \\
\hline ENDF/B-V & 5.3000 & 973.97 & 48.70 & ENDF/B-V & 6.4000 & 862.44 & 43.12 \\
\hline ENDF/B-V & 5.3300 & 962.97 & 48.15 & ENDF/B-V & 6.4100 & 826.94 & 41.35 \\
\hline ENDF/B-V & 5.3350 & 974.47 & 48.72 & ENDF/B-V & 6.4200 & 810.94 & 40.55 \\
\hline ENDF/B-V & 5.3400 & 1036.00 & 51.80 & ENDF/B-V & 6.4300 & 820.64 & 41.03 \\
\hline ENDF/B-V & 5.3600 & 1503.80 & 75.19 & ENDF/B-V & 6.4400 & 826.93 & 41.35 \\
\hline ENDF/B-V & 5.3620 & 1551.60 & 77.58 & ENDF/B-V & 6.4500 & 837.94 & 41.90 \\
\hline ENDF/B-V & 5.3700 & 1692.10 & 84.61 & ENDF/B-V & 6.4700 & 852.50 & 42.63 \\
\hline ENDF/B-V & 5.3710 & 1710.10 & 85.51 & ENDF/B-V & 6.4900 & 838.05 & 41.90 \\
\hline ENDF/B-V & 5.3780 & 1550.80 & 77.54 & ENDF/B-V & 6.5100 & 773.61 & 38.68 \\
\hline ENDF/B-V & 5.3800 & 1517.70 & 75.89 & ENDF/B-V & 6.5400 & 634.44 & 31.72 \\
\hline ENDF/B - V & 5.3900 & 1354.20 & 67.71 & ENDF/B-V & 6.5530 & 582.22 & 29.11 \\
\hline ENDF/B-V & 5.4000 & 1242.40 & 62.12 & ENDF/B-V & 6.5600 & 554.10 & 27.71 \\
\hline ENDF/B-V & 5.4100 & 1150.60 & 57.53 & ENDF/B-V & 6.5700 & 520.59 & 26.03 \\
\hline ENDF/B-V & 5.4200 & 1108.80 & 55.44 & ENDF/B-V & 6.5800 & 501.27 & 25.06 \\
\hline ENDF/B-V & 5.4300 & 1079.50 & 53.98 & ENDF/B-V & 6.5900 & 496.94 & 24.85 \\
\hline ENDF/B-V & 5.4400 & 1048.30 & 52.42 & ENDF/B-V & 6.6000 & 522.61 & 26.13 \\
\hline ENDF/B-V & 5.4600 & 1015.80 & 50.79 & ENDF/B-V & 6.6200 & 606.44 & 30.32 \\
\hline ENDF/B-V & 5.5000 & 990.97 & 49.55 & ENDF/B-V & 6.6400 & 681.94 & 34.10 \\
\hline ENDF/B-V & 5.5500 & 980.96 & 49.05 & ENDF/B-V & 6.6575 & 718.94 & 35.95 \\
\hline ENDF/B-V & 5.5530 & 980.12 & 49.01 & ENDF/B-V & 6.6650 & 711.94 & 35.60 \\
\hline ENDF/B-V & 5.6000 & 966.96 & 48.35 & $\mathrm{ENDF} / \mathrm{B}-\mathrm{V}$ & 6.6700 & 698.94 & 34.95 \\
\hline ENDF/B-V & 5.6500 & 947.96 & 47.40 & ENDF/B-V & 6.6800 & 670.56 & 33.53 \\
\hline ENDF/B-V & 5.7000 & 925.96 & 46.30 & ENDF/B-V & 6.7000 & 643.80 & 32.19 \\
\hline ENDF/B-V & 5.8000 & 901.96 & 45.10 & ENDF/B-V & 6.7500 & 637.76 & 31.89 \\
\hline $\mathrm{ENDF} / \mathrm{B}-\mathrm{V}$ & 5.9000 & 895.46 & 44.77 & ENDF/B-V & 6.8100 & 626.76 & 31.34 \\
\hline ENDF/B-V & 6.0000 & 886.95 & 44.35 & ENDF/B-V & 6.9200 & 595.60 & 29.78 \\
\hline ENDF/B-V & 6.0500 & 885.95 & 44.30 & ENDF/B-V & 7.0000 & 568.92 & 28.45 \\
\hline ENDF / B - V & 6.0530 & 886.35 & 44.32 & ENDF/B-V & 7.0530 & 568.39 & 28.42 \\
\hline ENDF/B-V & 6.1250 & 895.95 & 44.80 & ENDF/B-V & 7.1000 & 567.92 & 28.40 \\
\hline ENDF/B-V & 6.1600 & 912.22 & 45.61 & ENDF/B-V & 7.1400 & 581.92 & 29.10 \\
\hline ENDF/B-V & 6.1800 & 945.08 & 47.25 & ENDF/B-V & 7.1800 & 617.92 & 30.90 \\
\hline ENDF/B-V & 6.2000 & 1012.90 & 50.65 & ENDF/B-V & 7.2000 & 644.42 & 32.22 \\
\hline ENDF/B-V & 6.2100 & 1043.00 & 52.15 & ENDF/B-V & 7.2200 & 682.91 & 34.15 \\
\hline ENDF/B-V & 6.2200 & 1083.00 & 54.15 & ENDF/B-V & 7.2250 & 691.33 & 34.57 \\
\hline ENDF/B-V & 6.2300 & 1152.90 & 57.65 & ENDF/B-V & 7.2500 & 773.41 & 38.67 \\
\hline ENDF/B-V & 6.2400 & 1243.00 & 62.15 & ENDF/B-V & 7.2700 & 864.59 & 43.23 \\
\hline ENDF/B-V & 6.2500 & 1423.00 & 71.15 & ENDF/B-V & 7.2800 & 936.58 & 46.83 \\
\hline
\end{tabular}


Table 5b (Continued)

\begin{tabular}{|c|c|c|c|c|c|c|c|c|}
\hline $\operatorname{Ref}$ & $\mathrm{E}_{\mathrm{n}} \mathrm{MeV}$ & $\sigma_{\mathrm{e}} \mathrm{mb}$ & $\Delta \sigma_{\theta}$ & $\operatorname{Ref}$ & & $\mathrm{E}_{\mathrm{n}} \mathrm{MeV}$ & $\sigma_{\theta} \mathrm{mb}$ & $\Delta \sigma_{\theta}$ \\
\hline ENDF/B -V & 7.3400 & 1366.70 & 68.34 & G176 & B & 9.9700 & 649.65 & 40.88 \\
\hline ENDF / B - V & 7.3500 & 1416.60 & 70.83 & Fit2 & & 10.0000 & 654.71 & 43.26 \\
\hline ENDF/B-V & 7.3600 & 1431.60 & 71.58 & G176 & B & 10.2200 & 611.28 & 38.35 \\
\hline ENDF/B-V & 7.3700 & 1448.60 & 72.43 & Fit2 & & 10.5000 & 676.29 & 45.13 \\
\hline ENDF/B - V & 7.4000 & 1435.30 & 71.77 & G176 & B & 10.6900 & 688.21 & 43.53 \\
\hline ENDF / B - V & 7.4200 & 1424.70 & 71.24 & G176 & B & 10.9600 & 872.83 & 56.50 \\
\hline ENDF /B -V & 7.4700 & 1408.20 & 70.41 & Fit2 & & 11.0000 & 776.56 & 51.47 \\
\hline ENDF / B - V & 7.5287 & 1406.90 & 70.35 & G176 & B & 11.1700 & 802.90 & 51.34 \\
\hline ENDF/B-V & 7.5417 & 1405.30 & 70.27 & Fit2 & & 11.5000 & 831.92 & 54.96 \\
\hline ENDF/B-V & 7.5530 & 1402.40 & 70.12 & Fit2 & & 11.6500 & 832.38 & 61.88 \\
\hline $\mathrm{ENDF} / \mathrm{B}-\mathrm{V}$ & 7.5937 & 1392.00 & 69.60 & G176 & B & 11.7400 & 837.41 & 53.19 \\
\hline ENDF/B-V & 7.6200 & 1377.50 & 68.88 & G176 & B & 11.9600 & 929.16 & 59.83 \\
\hline ENDF/B-V & 7.6500 & 1396.60 & 69.83 & Fit3 & & 12.0000 & 853.63 & 33.71 \\
\hline ENDF/B-V & 7.6674 & 1442.70 & 72.14 & G176 & B & 12.4900 & 808.16 & 32.54 \\
\hline ENDF/B-V & 7.6800 & 1469.20 & 73.46 & Fit3 & & 12.5000 & 843.22 & 33.05 \\
\hline ENDF/B - V & 7.6977 & 1533.10 & 76.66 & G176 & B & 12.9500 & 958.29 & 39.44 \\
\hline ENDF / B - V & 7.7000 & 1541.30 & 77.07 & Fit3 & & 13.0000 & 974.61 & 38.55 \\
\hline ENDF/B-V & 7.7250 & 1718.40 & 85.92 & Fit3 & & 13.5000 & 920.40 & 36.18 \\
\hline ENDF/B-V & 7.7450 & 1900.30 & 95.02 & G176 & B & 13.9400 & 899.89 & 42.72 \\
\hline ENDF/B-V & 7.7500 & 1917.00 & 95.85 & Fit3 & & 14.0000 & 817.99 & 32.33 \\
\hline ENDF/B-V & 7.7700 & 1790.60 & 89.53 & Fit3 & & 14.2000 & 863.56 & 48.25 \\
\hline ENDF/B-V & 7.7887 & 1692.50 & 84.63 & Fit3 & & 14.4300 & 858.34 & 52.33 \\
\hline ENDF/B-V & 7.8100 & 1590.90 & 79.55 & Bo68 & B & 14.4796 & 854.03 & 44.01 \\
\hline ENDF/B - V & 7.8191 & 1568.70 & 78.44 & Fit4 & & 14.5000 & 836.84 & 36.01 \\
\hline ENDF/B-V & 7.8600 & 1491.70 & 74.59 & Fit4 & & 14.7000 & 872.70 & 40.29 \\
\hline ENDF/B-V & 7.8870 & 1465.40 & 73.27 & Fit4 & & 14.9300 & 891.92 & 42.03 \\
\hline ENDF/B-V & 7.8884 & 1464.10 & 73.21 & Bo68 & B & 15.1223 & 917.63 & 46.32 \\
\hline ENDF/B-V & 7.8971 & 1451.60 & 72.58 & Bo68 & B & 15.3909 & 970.63 & 48.28 \\
\hline ENDF/B-V & 7.9300 & 1411.50 & 70.58 & Bo68 & B & 15.5827 & 981.22 & 48.68 \\
\hline ENDF/B-V & 7.9361 & 1408.30 & 70.42 & Bo68 & B & 15.7746 & 979.71 & 48.62 \\
\hline Fit1 & 8.0000 & 1438.57 & 86.99 & Bo68 & B & 16.0048 & 1009.29 & 51.89 \\
\hline $\mathrm{Pe} 71 \mathrm{~B}$ & 8.0100 & 1323.23 & 86.95 & Bo68 & B & 16.1966 & 967.85 & 50.33 \\
\hline Fit1 & 8.0400 & 1233.36 & 90.77 & Bo68 & B & 16.3981 & 946.31 & 49.52 \\
\hline $\mathrm{Pe} 71 \mathrm{~B}$ & 8.1100 & 1241.62 & 81.29 & Bo68 & B & 16.5420 & 921.45 & 48.60 \\
\hline Fit1 & 8.2000 & 1067.87 & 77.68 & Bo68 & B & 16.7338 & 901.56 & 47.86 \\
\hline $\mathrm{Pe} 71 \mathrm{~B}$ & 8.2000 & 1082.29 & 70.95 & Bo68 & B & 16.8777 & 898.25 & 47.74 \\
\hline $\mathrm{Pe} 71 \mathrm{~B}$ & 8.3100 & 893.81 & 58.39 & Bo6 68 & B & 17.0887 & 888.31 & 47.38 \\
\hline $\mathrm{Pe} 71 \mathrm{~B}$ & 8.4100 & 827.75 & 54.80 & Bo68 & B & 17.2326 & 888.31 & 47.38 \\
\hline Fit1 & 8.5000 & 747.24 & 46.60 & Fit5 & & 17.2700 & 874.91 & 87.49 \\
\hline $\mathrm{Pe} 71 \mathrm{~B}$ & 8.5100 & 762.66 & 50.75 & Bo68 & B & 17.3381 & 822.26 & 82.23 \\
\hline Fit1 & 8.5600 & 753.93 & 52.03 & Bo68 & B & 17.8177 & 863.79 & 86.38 \\
\hline $\mathrm{Pe} 71 \mathrm{~B}$ & 8.6100 & 768.49 & 51.97 & Fit5 & & 18.2000 & 897.63 & 89.76 \\
\hline $\mathrm{Pe} 71 \mathrm{~B}$ & 8.6900 & 768.49 & 53.73 & Fit5 & & 18.2500 & 892.78 & 89.28 \\
\hline G176 B & 8.9700 & 670.96 & 42.45 & Bo68 & B & 18.3645 & 912.24 & 91.22 \\
\hline Fit2 & 9.0000 & 688.70 & 45.29 & Bo68 & B & 18.7962 & 941.66 & 94.17 \\
\hline G176 B & 9.2000 & 744.54 & 46.83 & Bo 68 & B & 19.1607 & 988.38 & 98.84 \\
\hline Fit2 & 9.5000 & 659.41 & 42.60 & Bo68 & B & 19.3909 & 1022.99 & 102.30 \\
\hline G176 B & 9.5600 & 661.93 & 41.55 & Bo68 & B & 19.5156 & 1028.18 & 102.82 \\
\hline
\end{tabular}


Table 5b (Continued)

\begin{tabular}{llrrl} 
Ref & $\mathrm{E}_{\mathrm{n}} \mathrm{MeV}$ & \multicolumn{1}{c}{$\sigma_{\theta} \mathrm{mb}$} & \multicolumn{1}{c}{$\Delta \sigma_{\theta}$} \\
& & & & \\
Bo68 & B & 19.6211 & 1026.45 & 102.65 \\
Bo68 & B & 19.8225 & 1031.64 & 103.16 \\
Fit5 & & 19.8800 & 1033.71 & 103.37 \\
Bo68 & B & 20.0432 & 1022.99 & 153.45 \\
Bo68 & B & 20.5036 & 978.00 & 146.70 \\
Fit5 & & 20.8000 & 911.70 & 136.76 \\
Bo68 & B & 20.8106 & 964.16 & 144.62 \\
Bo68 & B & 21.5300 & 912.24 & 136.84 \\
Fit5 & & 22.0000 & 868.18 & 130.23 \\
Bo68 & B & 22.0288 & 891.48 & 133.72 \\
Bo68 & B & 22.3933 & 872.44 & 130.87 \\
Bo68 & B & 22.8345 & 855.14 & 128.27 \\
Bo68 & B & 23.1319 & 856.87 & 128.53 \\
Bo68 & B & 23.5252 & 837.83 & 125.67 \\
Fit5 & & 24.0000 & 900.63 & 135.09 \\
Bo68 & B & 24.0000 & 822.26 & 123.34 \\
Me84 & B & 26.0000 & 885.51 & 132.83 \\
Wi86 & B & 40.0000 & 717.37 & 107.61
\end{tabular}


Table 6a

Input Data for Evaluation of Cross Section for Inelastic Scattering

\begin{tabular}{|c|c|c|c|c|c|c|c|c|c|}
\hline $\operatorname{Ref}$ & & $\mathrm{E}_{\mathrm{n}} \mathrm{MeV}$ & $\sigma_{\text {in }} \mathrm{mb}$ & $\Delta \sigma_{1 \mathrm{n}}$ & $\operatorname{Ref}$ & & $\mathrm{E}_{\mathrm{n}} \mathrm{MeV}$ & $\sigma_{\text {in }} \mathrm{mb}$ & $\Delta \sigma_{i n}$ \\
\hline $\operatorname{Pe} 71$. & & 5.3200 & 116.00 & 20.88 & $\mathrm{Pe} 71$ & & 7.7000 & 321.00 & 25.68 \\
\hline $\operatorname{Pe} 71$ & & 5.4200 & 130.00 & 16.90 & Mo72 & I & 7.7000 & 283.41 & 29.75 \\
\hline $\operatorname{Pe} 71$ & & 5.5200 & 128.00 & 14.08 & $\mathrm{Pe} 71$ & & 7.8100 & 383.00 & 30.64 \\
\hline $\mathrm{Pe} 71$ & & 5.6200 & 131.00 & 13.10 & Mo72 & I & 7.8100 & 323.03 & 34.06 \\
\hline $\mathrm{Pe} 71$ & & 5.7200 & 153.00 & 15.30 & $\mathrm{Pe} 71$ & & 7.9100 & 354.00 & 28.32 \\
\hline $\mathrm{Pe} 71$ & & 5.8000 & 168.00 & 15.12 & Mo72 & I & 7.9100 & 313.25 & 32.81 \\
\hline $\mathrm{Pe} 71$ & & 5.9300 & 204.00 & 18.36 & $\mathrm{Ha} 75$ & & 8.0000 & 378.31 & 13.02 \\
\hline $\mathrm{Pe} 71$ & & 6.0200 & 230.00 & 20.70 & Mo72 & I & 8.0000 & 347.73 & 36.50 \\
\hline Pe71 & & 6.1200 & 243.00 & 21.87 & $\mathrm{Pe} 71$ & & 8.0100 & 406.00 & 32.48 \\
\hline $\mathrm{Pe} 71$ & & 6.2100 & 254.00 & 22.86 & Mo72 & I & 8.0100 & 354.22 & 37.19 \\
\hline Pe71 & & 6.2600 & 290.00 & 23.20 & Pe69 & & 8.0400 & 409.02 & 29.45 \\
\hline Pe71 & & 6.3100 & 333.00 & 26.64 & Mo72 & I & 8.0400 & 369.53 & 38.55 \\
\hline $\mathrm{Pe} 71$ & & 6.3600 & 338.00 & 27.04 & Pe71 & & 8.1100 & 476.00 & 38.08 \\
\hline Pe71 & & 6.4100 & 264.00 & 21.12 & Mo 72 & I & 8.1100 & 412.98 & 43.11 \\
\hline $\mathrm{Pe} 71$ & & 6.4600 & 251.00 & 20.08 & $\mathrm{Pe} 71$ & & 8.2000 & 428.00 & 34.24 \\
\hline Pe71 & & 6.5200 & 261.00 & 20.88 & Ve68 & & 8.2000 & 497.80 & 21.66 \\
\hline Mo72 & I & 6.5200 & 217.21 & 22.82 & Mo72 & I & 8.2000 & 446.65 & 46.53 \\
\hline Pe 71 & & 6.5700 & 254.00 & 20.32 & Pe71 & & 8.3100 & 304.00 & 24.32 \\
\hline Mo72 & I & 6.5700 & 224.05 & 23.44 & Mo72 & I & 8.3100 & 307.63 & 32.73 \\
\hline $\operatorname{Pe} 71$ & & 6.6200 & 200.00 & 16.00 & Pe71 & & 8.4100 & 236.00 & 18.88 \\
\hline Mo72 & I & 6.6200 & 214.85 & 22.44 & Mo72 & $I$ & 8.4100 & 281.34 & 30.27 \\
\hline $\mathrm{Pe} 71$ & & 6.7200 & 167.00 & 13.36 & $\mathrm{Ha} 75$ & & 8.5000 & 242.93 & 9.14 \\
\hline Mo72 & I & 6.7200 & 165.57 & 17.66 & Pe69 & & 8.5000 & 248.01 & 18.60 \\
\hline $\mathrm{Pe} 71$ & & 6.8200 & 157.00 & 12.56 & Mo72 & I & 8.5000 & 263.73 & 28.08 \\
\hline Mo72 & I & 6.8200 & 144.06 & 15.53 & $\mathrm{Pe} 71$ & & 8.5100 & 230.00 & 18.40 \\
\hline Pe71 & & 6.9200 & 153.00 & 12.24 & Mo72 & I & 8.5100 & 261.58 & 27.82 \\
\hline Mo72 & I & 6.9200 & 156.27 & 16.85 & Pe69 & & 8.5600 & 245.08 & 17.40 \\
\hline $\operatorname{Pe} 71$ & & 7.0300 & 161.00 & 12.88 & Mo72 & I & 8.5600 & 293.34 & 31.34 \\
\hline Pe69 & & 7.0300 & 166.60 & 12.16 & Pe71 & & 8.6100 & 230.00 & 18.40 \\
\hline Mo72 & I & 7.0300 & 166.42 & 17.73 & Mo72 & I & 8.6100 & 275.48 & 29.66 \\
\hline $\mathrm{Pe} 71$ & & 7.1300 & 166.00 & 13.28 & Pe71 & & 8.6900 & 226.00 & 18.08 \\
\hline Mo72 & I & 7.1300 & 182.33 & 19.46 & Mo72 & I & 8.6900 & 255.38 & 27.74 \\
\hline $\operatorname{Pe} 71$ & & 7.2300 & 200.00 & 16.00 & Gl76 & & 8.9700 & 334.00 & 9.10 \\
\hline Mo72 & I & 7.2300 & 210.75 & 22.47 & Mo 72 & I & 8.9700 & 254.90 & 27.72 \\
\hline Pe71 & & 7.3300 & 286.00 & 22.88 & $\mathrm{Ha} 75$ & & 9.0000 & 273.90 & 9.51 \\
\hline Mo72 & I & 7.3300 & 288.62 & 30.13 & Ve 73 & & 9.0000 & 277.77 & 10.55 \\
\hline Pe71 & & 7.4000 & 317.00 & 25.36 & G176 & $I$ & 9.0000 & 330.48 & 8.95 \\
\hline Mo72 & I & 7.4000 & 346.42 & 36.06 & Mo72 & I & 9.0000 & 259.18 & 28.15 \\
\hline Mc72 & & 7.4800 & 327.83 & 33.07 & G176 & & 9.2000 & 307.00 & 8.00 \\
\hline Mo72 & I & 7.4800 & 344.70 & 35.74 & Mo 72 & I & 9.2000 & 258.79 & 28.71 \\
\hline $\mathrm{Pe} 71$ & & 7.5000 & 312.00 & 24.96 & $\mathrm{Ha} 75$ & & 9.5000 & 279.83 & 10.21 \\
\hline Mo 72 & I & 7.5000 & 341.16 & 35.47 & G176 & $I$ & 9.5000 & 342.33 & 9.24 \\
\hline Pe69 & & 7.5400 & 302.40 & 21.77 & Mo72 & I & 9.5000 & 264.45 & 29.50 \\
\hline Mo72 & I & 7.5400 & 334.31 & 34.83 & G176 & & 9.5600 & 349.40 & 9.50 \\
\hline Pe71 & & 7.6000 & 274.00 & 21.92 & Mo 72 & I & 9.5600 & 289.34 & 31.52 \\
\hline Pe69 & & 7.6000 & 273.47 & 22.70 & Ad80 & & 9.8000 & 354.72 & 23.04 \\
\hline Mo72 & I & 7.6000 & 321.58 & 33.56 & G176 & I & 9.8000 & 325.81 & 9.08 \\
\hline
\end{tabular}


Table 6a (Continued)

\begin{tabular}{|c|c|c|c|c|c|c|c|c|c|}
\hline $\operatorname{Ref}$ & & $E_{n} \mathrm{MeV}$ & $\sigma_{\text {in }} \mathrm{mb}$ & $\Delta \sigma_{\text {in }}$ & $\operatorname{Ref}$ & & $\mathrm{E}_{\mathrm{n}} \mathrm{MeV}$ & $\sigma_{\text {in }} \mathrm{mb}$ & $\Delta \sigma_{1 \mathrm{n}}$ \\
\hline Mo72 & I & 9.8000 & 327.12 & 36.27 & G176 & $I$ & 12.5000 & 215.52 & 5.85 \\
\hline G176 & & 9.9700 & 309.10 & 8.80 & Mo72 & I & 12.5000 & 216.91 & 22.61 \\
\hline Mo72 & I & 9.9700 & 316.52 & 34.98 & G176 & & 12.9500 & 252.30 & 9.70 \\
\hline $\mathrm{Ha} 75$ & & 10.0000 & 345.01 & 11.96 & Mo72 & I & 12.9500 & 213.17 & 22.42 \\
\hline G176 & I & 10.0000 & 307.66 & 8.64 & $\mathrm{Ha} 75$ & & 13.0000 & 218.76 & 8.78 \\
\hline Mo72 & I & 10.0000 & 295.34 & 32.51 & G176 & I & 13.0000 & 252.33 & 7.88 \\
\hline G176 & & 10.2200 & 297.10 & 7.50 & Mo72 & I & 13.0000 & 212.90 & 22.41 \\
\hline Mo72 & I & 10.2200 & 293.22 & 29.71 & $\mathrm{Ha} 75$ & & 13.5000 & 207.75 & 8.50 \\
\hline $\mathrm{Ha} 75$ & & 10.5000 & 331.19 & 11.04 & G176 & $I$ & 13.5000 & 252.63 & 8.37 \\
\hline G176 & I & 10.5000 & 339.93 & 8.67 & Mo72 & $I$ & 13.5000 & 190.98 & 20.43 \\
\hline Mo72 & I & 10.5000 & 282.32 & 28.65 & G176 & & 13.9400 & 252.90 & 15.20 \\
\hline G176 & & 10.6900 & 369.00 & 9.10 & Mo72 & I & 13.9400 & 182.59 & 19.72 \\
\hline Mo72 & I & 10.6900 & 285.35 & 28.99 & $\mathrm{Ha} 75$ & & 14.0000 & 184.63 & 7.37 \\
\hline G176 & & 10.9600 & 365.20 & 10.50 & G176 & I & 14.0000 & 247.77 & 8.76 \\
\hline Mo72 & I & 10.9600 & 300.67 & 30.58 & Mo72 & I & 14.0000 & 181.92 & 19.67 \\
\hline $\mathrm{Ha} 75$ & & 11.0000 & 342.31 & 11.17 & $\mathrm{Ba} 85$ & & 14.2000 & 214.40 & 19.09 \\
\hline G176 & I & 11.0000 & 356.53 & 10.24 & G176 & $I$ & 14.2000 & 230.67 & 8.49 \\
\hline Mo72 & I & 11.0000 & 302.95 & 30.81 & Mo72 & I & 14.2000 & 178.49 & 19.39 \\
\hline G176 & & 11.1700 & 319.70 & 8.40 & G176 & & 14.4300 & 211.00 & 9.50 \\
\hline Mo72 & $I$ & 11.1700 & 301.89 & 30.74 & Mo72 & $I$ & 14.4300 & 173.50 & 18.98 \\
\hline $\mathrm{Ha} 75$ & & 11.5000 & 259.84 & 8.87 & $\mathrm{Ha} 75$ & & 14.5000 & 146.39 & 7.93 \\
\hline G176 & $I$ & 11.5000 & 293.18 & 7.86 & G176 & I & 14.5000 & 205.34 & 7.76 \\
\hline Mo72 & $I$ & 11.5000 & 281.36 & 28.77 & Mo72 & I & 14.5000 & 171.98 & 18.85 \\
\hline Sa 81 & & 11.6500 & 275.58 & 35.49 & Gu81 & & 14.7000 & 199.21 & 41.87 \\
\hline G176 & I & 11.6500 & 281.13 & 7.60 & G176 & $I$ & 14.7000 & 189.18 & 6.51 \\
\hline Mo72 & $I$ & 11.6500 & 269.24 & 27.59 & Mo72 & I & 14.7000 & 165.74 & 18.29 \\
\hline G176 & & 11.7400 & 273.90 & 7.40 & G176 & & 14.9300 & 170.60 & 9.80 \\
\hline Mo72 & $I$ & 11.7400 & 260.15 & 26.70 & Mo72 & I & 14.9300 & 156.73 & 17.46 \\
\hline G176 & & 11.9600 & 264.80 & 8.30 & $\mathrm{Ba} 85$ & & 18.2000 & 121.80 & 11.62 \\
\hline Mo72 & $I$ & 11.9600 & 237.93 & 24.54 & Mo72 & I & 18.2000 & 93.06 & 12.61 \\
\hline $\mathrm{Ha} 75$ & & 12.0000 & 238.39 & 9.46 & Me84 & & 20.8000 & 96.33 & 9.63 \\
\hline G176 & $I$ & 12.0000 & 261.02 & 7.64 & Me 84 & & 22.0000 & 81.15 & 8.12 \\
\hline Mo72 & $I$ & 12.0000 & 233.89 & 24.15 & Me84 & & 24.0000 & 78.51 & 7.85 \\
\hline G176 & & 12.4900 & 214.70 & 6.60 & $\mathrm{Me} 84$ & & 26.0000 & 62.48 & 6.25 \\
\hline Mo72 & $I$ & 12.4900 & 217.13 & 22.63 & Me 84 & 0 & 30.0000 & 53.30 & 8.00 \\
\hline Ha75 & & 12.5000 & 218.74 & 8.27 & Me 84 & 0 & 35.0000 & 41.70 & 6.30 \\
\hline
\end{tabular}


Table $6 \mathrm{~b}$

Evaluated Cross Section for Inelastic Scattering

\begin{tabular}{|c|c|c|c|c|c|c|c|}
\hline $\operatorname{Ref}$ & $\mathrm{E}_{\mathrm{n}} \mathrm{MeV}$ & $\sigma_{\text {in }} \mathrm{mb}$ & $\Delta \sigma_{i n}$ & $\operatorname{Ref}$ & $\mathrm{E}_{\mathrm{n}} \mathrm{MeV}$ & $\sigma_{\text {in }} \mathrm{mb}$ & $\Delta \sigma_{i n}$ \\
\hline Mo72 & 4.8574 & 13.29 & 2.11 & Fit6 & 8.0100 & 384.48 & 29.92 \\
\hline Mo72 & 4.9084 & 31.50 & 3.97 & Fit6 & 8.0400 & 414.41 & 27.21 \\
\hline Mo72 & 4.9576 & 67.17 & 7.55 & Fit6 & 8.1100 & 446.85 & 34.12 \\
\hline Mo72 & 5.0075 & 62.69 & 7.01 & Fit6 & 8.2000 & 464.72 & 28.47 \\
\hline Mo72 & 5.0583 & 56.61 & 6.50 & Fit6 & 8.3100 & 317.60 & 25.64 \\
\hline Mo72 & 5.1070 & 60.14 & 6.88 & Fit6 & 8.4100 & 265.01 & 22.02 \\
\hline Mo72 & 5.1565 & 75.29 & 8.37 & Fit6 & 8.5000 & 253.50 & 15.38 \\
\hline Mo72 & 5.2067 & 90.20 & 9.89 & Fit6 & 8.5100 & 254.73 & 20.59 \\
\hline Mo72 & 5.2576 & 99.56 & 10.80 & Fit6 & 8.5600 & 260.03 & 16.78 \\
\hline Mo72 & 5.3064 & 102.06 & 11.16 & Fit6 & 8.6100 & 258.65 & 21.52 \\
\hline $\mathrm{Pe} 71$ & 5.3200 & 116.00 & 20.88 & Fit 6 & 8.6900 & 247.70 & 20.91 \\
\hline Pe71 & 5.4200 & 130.00 & 16.90 & Fit7 & 8.9700 & 324.61 & 21.28 \\
\hline $\mathrm{Pe} 71$ & 5.5200 & 128.00 & 14.08 & Fit 7 & 9.0000 & 306.31 & 17.40 \\
\hline Pe71 & 5.6200 & 131.00 & 13.10 & Fit7 & 9.2000 & 300.97 & 18.02 \\
\hline $\mathrm{Pe} 71$ & 5.7200 & 153.00 & 15.30 & Fit7 & 9.5000 & 321.36 & 19.02 \\
\hline $\operatorname{Pe} 71$ & 5.8000 & 168.00 & 15.12 & Fit7 & 9.5600 & 341.67 & 22.34 \\
\hline Pe71 & 5.9300 & 204.00 & 18.36 & Fit7 & 9.8000 & 320.58 & 20.57 \\
\hline Pe71 & 6.0200 & 230.00 & 20.70 & Fit7 & 9.9700 & 306.05 & 21.87 \\
\hline Pe71 & 6.1200 & 243.00 & 21.87 & Fit7 & 10.0000 & 323.23 & 19.49 \\
\hline Pe71 & 6.2100 & 254.00 & 22.86 & Fit7 & 10.2200 & 295.13 & 17.17 \\
\hline $\mathrm{Pe} 71$ & 6.2600 & 290.00 & 23.20 & Fit7 & 10.5000 & 332.60 & 17.50 \\
\hline Pe71 & 6.3100 & 333.00 & 26.64 & Fit7 & 10.6900 & 360.71 & 20.14 \\
\hline $\operatorname{Pe} 71$ & 6.3600 & 338.00 & 27.04 & Fit7 & 10.9600 & 348.78 & 23.56 \\
\hline $\operatorname{Pe} 71$ & 6.4100 & 264.00 & 21.12 & Fit7 & 11.0000 & 355.26 & 19.62 \\
\hline Mo72 & 6.5079 & 220.44 & 23.18 & Fit7 & 11.1700 & 316.60 & 19.05 \\
\hline Mo72 & 6.5553 & 229.80 & 24.09 & Fit7 & 11.5000 & 283.45 & 16.01 \\
\hline Mo72 & 6.6073 & 229.96 & 23.94 & Fit7 & 11.6500 & 277.55 & 16.65 \\
\hline Mo72 & 6.6598 & 190.50 & 20.14 & Fit7 & 11.7400 & 271.89 & 17.35 \\
\hline Mo 72 & 6.7089 & 173.00 & 18.43 & Fit7 & 11.9600 & 261.39 & 18.60 \\
\hline Mo72 & 6.7586 & 158.91 & 17.05 & Fit7 & 12.0000 & 254.62 & 16.50 \\
\hline Mo72 & 6.8088 & 146.09 & 15.76 & Fit7 & 12.4900 & 213.18 & 13.69 \\
\hline Mo72 & 6.8595 & 153.77 & 16.53 & Fit7 & 12.5000 & 215.35 & 12.85 \\
\hline Mo72 & 6.9065 & 162.37 & 17.54 & Fit 7 & 12.9500 & 245.21 & 19.18 \\
\hline Fit6 & 6.9200 & 160.68 & 13.35 & Fit7 & 13.0000 & 239.12 & 16.71 \\
\hline Fit6 & 7.0300 & 172.94 & 11.55 & Fit7 & 13.5000 & 229.26 & 17.04 \\
\hline Fit6 & 7.1300 & 180.70 & 14.71 & Fit7 & 13.9400 & 233.06 & 21.49 \\
\hline Fit6 & 7.2300 & 213.41 & 17.32 & Fit7 & 14.0000 & 210.24 & 16.11 \\
\hline Fit6 & 7.3300 & 297.89 & 22.74 & Fit 7 & 14.2000 & 215.34 & 19.84 \\
\hline Fit6 & 7.4000 & 346.94 & 26.22 & Fit 7 & 14.4300 & 202.60 & 20.95 \\
\hline Fit 6 & 7.4800 & 352.04 & 27.88 & Fit 7 & 14.5000 & 183.17 & 16.69 \\
\hline Fit6 & 7.5000 & 341.76 & 25.70 & Fit7 & 14.7000 & 184.61 & 16.66 \\
\hline Fit 6 & 7.5400 & 322.89 & 21.36 & Fit7 & 14.9300 & 168.15 & 13.32 \\
\hline Fit 6 & 7.6000 & 305.52 & 21.94 & Mo72 B & 15.0950 & 167.97 & 18.84 \\
\hline Fit 6 & 7.7000 & 306.53 & 23.85 & Mo72 B & 15.5960 & 150.17 & 17.50 \\
\hline Fit6 & 7.8100 & 355.45 & 28.05 & Mo72 B & 16.0920 & 136.55 & 16.39 \\
\hline Fit6 & 7.9100 & 338.00 & 26.10 & Mo72 B & 16.5800 & 114.39 & 14.45 \\
\hline Fit 6 & 8.0000 & 379.26 & 22.41 & Mo72 B & 17.0740 & 116.68 & 14.93 \\
\hline
\end{tabular}


Table 6b (Continued)

\begin{tabular}{lrrrr} 
Ref & $E_{n} \mathrm{MeV}$ & \multicolumn{1}{c}{$\sigma_{\text {in }} \mathrm{mb}$} & \multicolumn{1}{c}{$\Delta \sigma_{\text {in }}$} \\
& & & & \\
Mo72 & B & 17.5730 & 122.06 & 15.52 \\
Mo72 & B & 18.0760 & 100.25 & 13.60 \\
Fit7 & & 18.2000 & 113.36 & 24.27 \\
Mo72 & B & 18.5820 & 115.62 & 15.60 \\
Mo72 & B & 19.0900 & 83.39 & 13.07 \\
Me84 & 20.8000 & 96.33 & 9.63 \\
Me84 & 22.0000 & 81.15 & 8.12 \\
Me84 & 24.0000 & 78.51 & 7.85 \\
Me84 & 26.0000 & 62.48 & 6.25 \\
Me72 & 0 & 30.0000 & 53.30 & 8.00 \\
Me72 0 & 35.0000 & 41.70 & 6.30
\end{tabular}


Table 7a

Input Data for Evaluation of the ${ }^{12} \mathrm{C}\left(n, \alpha_{0}\right)^{9} \mathrm{Be}$ Cross Section

\begin{tabular}{|c|c|c|c|c|c|c|c|c|c|}
\hline $\operatorname{Ref}$ & & $\mathrm{E}_{\mathrm{n}} \mathrm{MeV}$ & $\sigma_{\mathrm{n}, \alpha_{0}}^{\mathrm{mb}}$ & $\Delta \sigma_{\mathrm{n}, \alpha_{0}}$ & $\operatorname{Ref}$ & & $\mathrm{E}_{\mathrm{n}} \mathrm{MeV}$ & $\sigma_{\mathrm{n}, \alpha_{0}} \mathrm{mb}$ & $\Delta \sigma_{\mathrm{n}, \alpha_{0}}$ \\
\hline $\operatorname{Re} 60$ & & 7.5900 & 48.36 & 4.87 & Di 87 & I & 9.7400 & 200.90 & 12.77 \\
\hline Di87 & I & 7.5900 & 76.40 & 4.36 & $\mathrm{Ob} 72$ & & 9.8300 & 176.12 & 18.14 \\
\hline $\operatorname{Re} 60$ & & 7.6600 & 75.82 & 7.63 & Ge76 & & 9.8300 & 164.00 & 16.40 \\
\hline Di 87 & I & 7.6600 & 97.20 & 5.52 & Di87 & I & 9.8300 & 166.40 & 10.44 \\
\hline $\operatorname{Re} 60$ & & 7.8700 & 167.16 & 16.82 & $\operatorname{Re} 60$ & & 9.8800 & 198.81 & 20.00 \\
\hline Di 87 & I & 7.8700 & 123.14 & 6.88 & Di87 & I & 9.8800 & 156.73 & 9.32 \\
\hline $\mathrm{Ge} 76$ & & 8.0000 & 156.00 & 15.60 & ob 72 & & 9.9300 & 187.46 & 19.31 \\
\hline Di87 & I & 8.0000 & 122.53 & 8.17 & Di87 & I & 9.9300 & 149.43 & 15.49 \\
\hline $\operatorname{Re} 60$ & & 8.1100 & 161.19 & 16.22 & $\operatorname{Re} 60$ & & 10.0000 & 187.46 & 18.86 \\
\hline Di 87 & I & 8.1100 & 98.38 & 6.39 & Di87 & I & 10.0000 & 156.14 & 7.43 \\
\hline $\operatorname{Re} 60$ & & 8.2700 & 101.49 & 10.21 & Ob 72 & & 10.0300 & 182.69 & 18.82 \\
\hline Di 87 & I & 8.2700 & 75.02 & 4.45 & Di 87 & I & 10.0300 & 149.20 & 8.41 \\
\hline $\operatorname{Re} 60$ & & 8.4800 & 85.97 & 8.65 & $\operatorname{Re} 60$ & & 10.1400 & 164.78 & 16.58 \\
\hline Di87 & $I$ & 8.4800 & 65.24 & 3.70 & Ob72 & & 10.1500 & 145.67 & 15.00 \\
\hline $\operatorname{Re} 60$ & & 8.6400 & 90.15 & 9.07 & Ob72 & & 10.2500 & 145.07 & 14.94 \\
\hline Ge 76 & & 8.6400 & 50.40 & 5.04 & $\operatorname{Re} 60$ & & 10.2800 & 141.49 & 14.23 \\
\hline Di87 & I & 8.6400 & 57.62 & 3.88 & $\mathrm{Ob} 72$ & & 10.3200 & 131.34 & 13.53 \\
\hline $\operatorname{Re} 60$ & & 8.8100 & 107.46 & 10.81 & $\operatorname{Re} 60$ & & 10.3800 & 140.90 & 14.17 \\
\hline Di87 & I & 8.8100 & 78.57 & 5.81 & ob72 & & 10.4300 & 126.57 & 13.04 \\
\hline $\operatorname{Re} 60$ & & 8.9400 & 139.70 & 14.05 & $\mathrm{Ob} 72$ & & 10.5500 & 109.25 & 11.25 \\
\hline Di87 & I & 8.9400 & 170.74 & 9.54 & Ob72 & & 10.6100 & 105.07 & 10.82 \\
\hline $\mathrm{Ge} 76$ & & 8.9900 & 202.00 & 20.20 & Ob72 & & 10.6900 & 102.69 & 10.58 \\
\hline Di87 & I & 8.9900 & 197.62 & 10.42 & Ob72 & & 10.8700 & 96.72 & 9.96 \\
\hline $\operatorname{Re} 60$ & & 9.1200 & 223.88 & 22.52 & ob 72 & & 11.0400 & 82.39 & 8.49 \\
\hline Di87 & I & 9.1200 & 265.71 & 15.81 & Ve68 & & 11.3000 & 81.00 & 12.15 \\
\hline $\operatorname{Re} 60$ & & 9.1800 & 264.48 & 26.61 & Ve 68 & & 12.1000 & 103.00 & 15.45 \\
\hline $\mathrm{Ob} 72$ & & 9.1800 & 278.81 & 28.72 & Ve68 & & 12.8000 & 93.00 & 13.95 \\
\hline Di87 & I & 9.1800 & 253.48 & 17.17 & Ve 68 & & 13.6000 & 72.00 & 10.80 \\
\hline $\mathrm{Ge} 76$ & & 9.2200 & 305.00 & 30.50 & Br68 & & 13.9000 & 79.00 & 20.00 \\
\hline Di87 & I & 9.2200 & 277.67 & 14.10 & Al63 & & 14.0000 & 62.00 & 15.00 \\
\hline $\operatorname{Re} 60$ & & 9.3100 & 296.72 & 29.85 & Ki69 & & 14.1000 & 76.00 & 11.00 \\
\hline Di 87 & I & 9.3100 & 267.90 & 13.65 & Gr55 & & 14.1000 & 80.00 & 20.00 \\
\hline Ob72 & & 9.3500 & 318.81 & 32.84 & $\mathrm{Ha} 84$ & & 14.1000 & 72.00 & 9.00 \\
\hline Di87 & I & 9.3500 & 255.46 & 13.65 & Ch64 & & 14.5000 & 69.00 & 14.72 \\
\hline Ge76 & & 9.4100 & 265.00 & 26.50 & $\operatorname{Br} 68$ & & 15.6000 & 77.00 & 20.00 \\
\hline Di 87 & I & 9.4100 & 253.23 & 15.03 & $\mathrm{Sa} 71$ & I & 15.6000 & 38.53 & 3.89 \\
\hline $\operatorname{Re} 60$ & & 9.4200 & 282.39 & 28.41 & Hu66 & & 16.0000 & 46.10 & 16.00 \\
\hline Di87 & I & 9.4200 & 252.86 & 16.57 & $\mathrm{Sa} 71$ & I & 16.0000 & 28.62 & 2.97 \\
\hline Ob72 & & 9.4800 & 272.84 & 28.10 & Hu66 & & 17.0000 & 50.80 & 18.00 \\
\hline Di 87 & I & 9.4800 & 220.53 & 13.84 & Sa71 & I & 17.0000 & 35.38 & 3.06 \\
\hline $\operatorname{Re} 60$ & & 9.5700 & 232.84 & 23.42 & st76 & & 18.6500 & 14.50 & 3.60 \\
\hline Di 87 & I & 9.5700 & 176.73 & 10.98 & $\mathrm{Sa} 71$ & I & 18.6500 & 16.90 & 1.74 \\
\hline $\mathrm{Ob} 72$ & & 9.6800 & 208.36 & 21.46 & $s+76$ & & 18.9200 & 19.20 & 4.00 \\
\hline Di 87 & I & 9.6800 & 146.29 & 15.42 & $s t 76$ & & 19.1200 & 18.20 & 3.60 \\
\hline $\operatorname{Re} 60$ & & 9.7200 & 186.87 & 18.80 & St76 & & 19.2000 & 19.60 & 4.90 \\
\hline Di87 & I & 9.7200 & 208.57 & 15.16 & $s t 76$ & & 19.4600 & 22.00 & 5.70 \\
\hline $\operatorname{Re} 60$ & & 9.7400 & 192.24 & 19.34 & st7 6 & & 19.7200 & 30.70 & 9.50 \\
\hline
\end{tabular}


Table 7a (Continued)

\begin{tabular}{lcrc} 
Ref & $E_{\mathrm{n}} \mathrm{MeV}$ & $\sigma_{\mathrm{n}, \alpha_{0}} \mathrm{mb}$ & \multicolumn{1}{c}{$\Delta \sigma_{\mathrm{n}, \alpha_{0}}$} \\
& & 25.00 & 10.80 \\
St76 & 19.9000 & 35.20 & 8.40 \\
St76 & 19.9800 & 40.90 & 7.40 \\
St76 & 20.1400 & 29.80 & 9.20 \\
St76 & 20.2300 & 24.60 & 9.10 \\
St76 & 20.4800 & 18.90 & 6.60 \\
St76 & 20.7300 & 21.20 & 6.10 \\
St76 & 20.9800 & 23.30 & 7.00 \\
St76 & 21.2200 & 31.00 & 10.90 \\
St76 & 21.4600 & &
\end{tabular}


Table 7b

Evaluated Cross Section for the Reaction ${ }^{12} \mathrm{C}\left(\mathrm{n}, \alpha_{0}\right)^{9} \mathrm{Be}$

\begin{tabular}{|c|c|c|c|c|c|c|c|}
\hline $\operatorname{Ref}$ & $\mathrm{E}_{\mathrm{n}} \mathrm{MeV}$ & $\sigma_{\mathrm{n}, \alpha_{0}}^{\mathrm{mb}}$ & $\Delta \sigma_{\mathrm{n}, \alpha_{0}}$ & $\operatorname{Ref}$ & $\mathrm{E}_{\mathrm{n}} \mathrm{MeV}$ & $\sigma_{\mathrm{n}, \alpha_{0}}^{\mathrm{mb}}$ & $\Delta \sigma_{\mathrm{n}, \alpha_{0}}$ \\
\hline ENDF/B-V & .0000 & .00 & .00 & Ve69 & 11.3000 & 81.00 & 12.15 \\
\hline ENDF/B - V & 6.1737 & .00 & .00 & Ve 69 & 12.1000 & 103.00 & 15.45 \\
\hline ENDF/B-V & 6.3400 & 1.00 & .20 & Ve69 & 12.8000 & 93.00 & 13.95 \\
\hline ENDF/B-V & 7.1800 & 1.00 & .20 & Ve 69 & 13.6000 & 72.00 & 10.80 \\
\hline ENDF/B-V & 7.2800 & 6.00 & 1.20 & Br68 & 13.9000 & 79.00 & 20.00 \\
\hline ENDF/B-V & 7.3400 & 11.00 & 2.20 & A163 & 14.0000 & 62.00 & 15.00 \\
\hline Fit8 & 7.5900 & 62.86 & 7.77 & Fit9 & 14.1000 & 75.25 & 11.52 \\
\hline Fit8 & 7.6600 & 89.20 & 10.82 & Ch64 & 14.5000 & 69.00 & 14.72 \\
\hline Fit8 & 7.8700 & 130.91 & 15.62 & $\mathrm{Sa} 81 \mathrm{~B}$ & 14.8000 & 51.77 & 7.26 \\
\hline Fit8 & 8.0000 & 131.60 & 16.93 & $\mathrm{Sa} 81 \mathrm{~B}$ & 15.1600 & 49.66 & 6.06 \\
\hline Fit8 & 8.1100 & 108.26 & 13.82 & $\mathrm{Sa} 81 \mathrm{~B}$ & 15.3800 & 50.09 & 6.97 \\
\hline Fit8 & 8.2700 & 80.07 & 9.80 & $\mathrm{Sa} 81 \mathrm{~B}$ & 15.5700 & 46.73 & 5.37 \\
\hline Fit8 & 8.4800 & 69.15 & 8.30 & Fit10 & 15.6000 & 46.78 & 8.81 \\
\hline Fit8 & 8.6400 & 58.96 & 7.19 & $\mathrm{Sa} 81 \mathrm{~B}$ & 15.7600 & 37.86 & 4.28 \\
\hline Fit8 & 8.8100 & 85.65 & 11.50 & $\mathrm{Sa} 81 \mathrm{~B}$ & 15.8800 & 39.64 & 5.21 \\
\hline Fit8 & 8.9400 & 160.18 & 19.25 & Fit10 & 16.0000 & 34.15 & 6.58 \\
\hline Fit8 & 8.9900 & 201.25 & 23.50 & $\mathrm{Sa} 81 \mathrm{~B}$ & 16.0100 & 33.18 & 3.77 \\
\hline Fit8 & 9.1200 & 250.55 & 30.88 & Sa81 B & 16.0700 & 35.96 & 5.21 \\
\hline Fit8 & 9.1800 & 252.18 & 30.34 & $\mathrm{Sa} 81 \mathrm{~B}$ & 16.1300 & 41.34 & 6.32 \\
\hline Fit8 & 9.2200 & 286.61 & 32.92 & $\mathrm{Sa} 81 \mathrm{~B}$ & 16.1900 & 30.39 & 4.89 \\
\hline Fit8 & 9.3100 & 274.98 & 31.58 & $\mathrm{Sa} 81 \mathrm{~B}$ & 16.2500 & 34.21 & 4.85 \\
\hline Fit8 & 9.3500 & 262.72 & 30.78 & $\mathrm{Sa} 81 \mathrm{~B}$ & 16.3100 & 28.33 & 2.99 \\
\hline Fit8 & 9.4100 & 259.44 & 31.84 & $\mathrm{Sa} 81 \mathrm{~B}$ & 16.3700 & 32.27 & 4.17 \\
\hline Fit8 & 9.4200 & 261.11 & 33.27 & Sa81 B & 16.4300 & 41.73 & 5.21 \\
\hline Fit8 & 9.4800 & 226.96 & 28.49 & $\mathrm{Sa} 81 \mathrm{~B}$ & 16.4800 & 35.49 & 3.70 \\
\hline Fit8 & 9.5700 & 188.52 & 23.50 & $\mathrm{Sa} 81 \mathrm{~B}$ & 16.5300 & 35.70 & 4.02 \\
\hline Fit8 & 9.6800 & 161.49 & 25.21 & $\mathrm{Sa} 81 \mathrm{~B}$ & 16.6000 & 38.85 & 4.29 \\
\hline Fit8 & 9.7200 & 198.29 & 26.55 & $S a 81 B$ & 16.7200 & 40.87 & 4.98 \\
\hline Fit8 & 9.7400 & 197.86 & 24.96 & $\mathrm{Sa} 81 \mathrm{~B}$ & 16.8300 & 39.60 & 4.06 \\
\hline Fit8 & 9.8300 & 163.59 & 19.32 & $\mathrm{Sa} 81 \mathrm{~B}$ & 16.9500 & 42.08 & 4.19 \\
\hline Fit8 & 9.8800 & 165.67 & 20.27 & Fit10 & 17.0000 & 41.86 & 7.78 \\
\hline Fit8 & 9.9300 & 156.28 & 24.32 & Sa $81 B$ & 17.0100 & 41.53 & 4.23 \\
\hline Fit8 & 10.0000 & 162.05 & 18.12 & Sa $81 B$ & 17.1000 & 44.14 & 4.26 \\
\hline Fit8 & 10.0300 & 152.97 & 18.34 & Sa81 B & 17.2100 & 45.82 & 5.66 \\
\hline $\operatorname{Re} 60 \mathrm{~B}$ & 10.1400 & 157.95 & 15.89 & Sa81 B & 17.4100 & 39.44 & 5.55 \\
\hline $\mathrm{Ob} 72 \mathrm{~B}$ & 10.1500 & 124.99 & 12.87 & $\mathrm{Sa} 81 \mathrm{~B}$ & 17.6000 & 32.32 & 4.55 \\
\hline $\mathrm{Ob} 72 \mathrm{~B}$ & 10.2500 & 124.48 & 12.82 & $\mathrm{Sa} 81 \mathrm{~B}$ & 17.8000 & 29.52 & 5.34 \\
\hline $\operatorname{Re} 60 \mathrm{~B}$ & 10.2800 & 135.63 & 13.65 & Sa81 B & 18.0000 & 28.66 & 4.18 \\
\hline Ob72 B & 10.3200 & 112.70 & 11.61 & $\mathrm{Sa} 81 \mathrm{~B}$ & 18.3600 & 19.12 & 2.53 \\
\hline $\operatorname{Re} 60 \mathrm{~B}$ & 10.3800 & 135.06 & 13.59 & $\mathrm{Sa} 81 \mathrm{~B}$ & 18.6000 & 19.32 & 2.52 \\
\hline Ob72 B & 10.4300 & 108.60 & 11.19 & Fit 10 & 18.6500 & 19.31 & 3.60 \\
\hline $\mathrm{Ob} 72 \mathrm{~B}$ & 10.5500 & 93.74 & 9.66 & $\mathrm{Sa} 81 \mathrm{~B}$ & 18.8000 & 21.55 & 3.15 \\
\hline $\mathrm{Ob} 72 \mathrm{~B}$ & 10.6100 & 90.16 & 9.29 & St76 B & 18.9200 & 22.39 & 4.66 \\
\hline $\mathrm{Ob} 72 \mathrm{~B}$ & 10.6900 & 88.11 & 9.07 & St76 B & 19.1200 & 21.22 & 4.20 \\
\hline $\mathrm{Ob} 72 \mathrm{~B}$ & 10.8700 & 82.98 & 8.55 & St76 B & 19.2000 & 22.86 & 5.71 \\
\hline $\mathrm{Ob} 72 \mathrm{~B}$ & 11.0400 & 70.69 & 7.28 & St 76 B & 19.4600 & 25.66 & 6.65 \\
\hline
\end{tabular}


Table 7b (Continued)

\begin{tabular}{llrrr} 
Ref & & $E_{n} \mathrm{MeV}$ & \multicolumn{1}{c}{$\sigma_{\mathrm{n}, \alpha_{0}} \mathrm{mb}$} & \multicolumn{1}{c}{$\Delta \sigma_{\mathrm{n}, \alpha_{0}}$} \\
& & & 35.80 & 11.08 \\
St76 & B & 19.7200 & 35.15 & 12.59 \\
St76 & B & 19.9000 & 29.15 & 9.80 \\
St76 & B & 19.9800 & 41.05 & 8.63 \\
St76 & B & 20.1400 & 47.70 & 10.73 \\
St76 & B & 20.2300 & 34.75 & 10.61 \\
St76 & B & 20.4800 & 28.69 & 7.70 \\
St76 & B & 20.7300 & 22.04 & 7.11 \\
St76 & B & 20.9800 & 24.72 & 8.16 \\
St76 & B & 21.2200 & 27.17 & 12.71 \\
St76 & B & 21.4600 & 36.15 & 4.27 \\
Exp & & 22.0000 & 17.08 & 3.02 \\
Exp & & 24.0000 & 12.07 & 2.13 \\
Exp & 26.0000 & 8.53 & 1.51 \\
Exp & 28.0000 & 6.03 & 1.07 \\
Exp & 30.0000 & 4.27 & .75 \\
Exp & 32.0000 & 3.02 &
\end{tabular}


Table 8a

Input Data for the Evaluation of the ${ }^{12} C\left(n, n^{\prime} 3 \alpha\right)$ Reaction

$\begin{array}{lrrr}\text { Ref } & E_{n} \text { MeV } & \sigma \text { mb } & \Delta \sigma \\ & & & \\ \text { ENDF/B-V } & 8.2960 & .58 & .12 \\ \text { ENDF/B-V } & 9.5000 & 21.29 & 4.26 \\ \text { ENDF/B-V } & 10.0000 & 30.00 & 6.00 \\ \text { ENDF/B-V } & 10.5000 & 57.00 & 11.40 \\ \text { An86 } & 11.9150 & 177.00 & 25.00 \\ \text { An86 } & 12.8950 & 167.00 & 16.00 \\ \text { Fr55 } & 12.9000 & 190.00 & 50.00 \\ \text { Fa71 } & 14.0000 & 190.00 & 20.00 \\ \text { Va58 } & 14.0000 & 173.80 & 85.00 \\ \text { An86 } & 14.0000 & 202.00 & 16.00 \\ \text { Fr55 } & 14.1000 & 230.00 & 50.00 \\ \text { Co76 } & 14.2000 & 202.20 & 30.00 \\ \text { Gr69 } & 14.2000 & 190.00 & 20.00 \\ \text { An86 } & 14.8000 & 228.00 & 13.00 \\ \text { Va58 } & 15.0000 & 198.70 & 85.00 \\ \text { Fr55 } & 15.5000 & 316.00 & 73.00 \\ \text { Br84 } & 16.0000 & 350.00 & 97.00 \\ \text { Va58 } & 16.0000 & 324.20 & 85.00 \\ \text { Br84 } & 17.0000 & 292.00 & 76.00 \\ \text { Va58 } & 17.0000 & 344.10 & 130.60 \\ \text { An86 } & 17.0000 & 272.00 & 17.00 \\ \text { Br84 } & 18.0000 & 315.00 & 74.00 \\ \text { Va58 } & 18.0000 & 349.70 & 120.00 \\ \text { Fr55 } & 18.8000 & 283.00 & 59.00 \\ \text { Br84 } & 19.0000 & 319.00 & 70.00 \\ \text { Va58 } & 19.0000 & 274.50 & 105.00 \\ \text { An86 } & 19.0000 & 300.00 & 14.00 \\ \text { Br84 } & 20.0000 & 289.00 & 59.00 \\ \text { Br84 } & 21.0000 & 290.00 & 59.00 \\ \text { Br84 } & 22.0000 & 322.00 & 62.00 \\ \text { Br84 } & 23.0000 & 292.00 & 57.00 \\ \text { Br84 } & 24.0000 & 299.00 & 56.00 \\ \text { Br84 } & 25.0000 & 252.00 & 50.00 \\ \text { Br84 } & 26.0000 & 294.00 & 57.00 \\ \text { Br84 } & 27.0000 & 248.00 & 57.00 \\ \text { Br84 } & 28.0000 & 233.00 & 60.00 \\ \text { Br84 } & 29.0000 & 223.00 & 63.00 \\ \text { Br84 } & 30.0000 & 179.00 & 60.00 \\ \text { Br84 } & 31.0000 & 255.00 & 56.00 \\ \text { Br84 } & 32.0000 & 218.00 & 66.00 \\ \text { Br84 } & 33.0000 & 225.00 & 71.00 \\ \text { Br84 } & 34.0000 & 242.00 & 73.00 \\ \text { Br84 } & 35.0000 & 186.00 & 62.00\end{array}$


Table $8 \mathrm{~b}$

Evaluated Cross Section for the ${ }^{12} \mathrm{C}\left(\mathrm{n}, \mathrm{n}^{\prime} 3 \alpha\right)$ Reaction

\begin{tabular}{lrrr} 
Ref & \multicolumn{1}{c}{$E_{\mathrm{n}} \mathrm{MeV}$} & \multicolumn{1}{c}{$\boldsymbol{\sigma} \mathrm{mb}$} & \multicolumn{1}{c}{$\Delta \sigma$} \\
ENDF/B-V & & & \\
ENDF/B-V & 7.0000 & .00 & .00 \\
ENDF/B-V & 8.2960 & .00 & .00 \\
ENDF/B-V & 9.5000 & 21.29 & .12 \\
ENDF/B-V & 10.0000 & 30.00 & 6.00 \\
ENDF/B-V & 10.5000 & 57.00 & 11.40 \\
Fit11 & 11.0000 & 91.25 & 18.25 \\
Fit11 & 11.5000 & 114.28 & 22.86 \\
Fit11 & 12.0000 & 135.97 & 20.40 \\
Fit11 & 12.5000 & 156.33 & 23.45 \\
Fit11 & 13.0000 & 175.35 & 26.30 \\
Fit11 & 13.5000 & 193.03 & 28.95 \\
Fit11 & 14.0000 & 209.37 & 31.41 \\
Fit11 & 14.5000 & 224.38 & 33.66 \\
Fit11 & 15.0000 & 238.05 & 35.71 \\
Fit11 & 15.5000 & 250.38 & 37.56 \\
Fit11 & 16.0000 & 261.38 & 39.21 \\
Fit11 & 16.5000 & 271.04 & 40.66 \\
Fit11 & 17.0000 & 279.36 & 41.90 \\
Fit11 & 17.5000 & 286.34 & 42.95 \\
Fit11 & 18.0000 & 291.99 & 43.80 \\
Fit11 & 18.5000 & 296.30 & 44.45 \\
Fit11 & 19.0000 & 299.28 & 44.89 \\
Fit11 & 19.5000 & 300.91 & 45.14 \\
Fit11 & 20.0000 & 301.21 & 45.18 \\
Fit12 & 21.0000 & 300.99 & 60.20 \\
Fit12 & 22.0000 & 292.71 & 58.54 \\
Fit12 & 23.0000 & 284.60 & 56.92 \\
Fit12 & 24.0000 & 276.68 & 55.34 \\
Fit12 & 25.0000 & 268.93 & 53.79 \\
Fit12 & 26.0000 & 261.36 & 52.27 \\
Fit12 & 27.0000 & 253.97 & 50.79 \\
Fit12 & 28.0000 & 246.77 & 49.35 \\
Fit12 & 29.0000 & 239.74 & 47.95 \\
Fit12 & 30.0000 & 232.89 & 46.58 \\
Fit12 & 31.0000 & 226.22 & 45.24 \\
Fit12 & 32.0000 & 219.73 & 43.95
\end{tabular}


Table 9

Evaluated Data for the ${ }^{12} \mathrm{C}(\mathrm{n}, \mathrm{p})^{12} \mathrm{~B}$ Reaction $\operatorname{Ref} \quad \mathrm{E}_{\mathrm{n}} \mathrm{MeV} \quad \sigma \mathrm{mb} \quad \Delta \sigma$

$\begin{array}{lrrr}\text { ENDF/B-V } & 14.5000 & .00 & .00 \\ \text { ENDF/B-V } & 15.0000 & 1.00 & .20 \\ \text { ENDF/B-V } & 15.4770 & 4.00 & .80 \\ \text { ENDF/B-V } & 15.9660 & 8.00 & 1.60 \\ \text { ENDF/B-V } & 16.4430 & 11.00 & 2.20 \\ \text { ENDF/B-V } & 16.9740 & 13.00 & 2.60 \\ \text { ENDF/B-V } & 17.4670 & 16.00 & 3.20 \\ \text { ENDF/B-V } & 17.9010 & 19.00 & 3.80 \\ \text { ENDF/B-V } & 18.4600 & 19.00 & 3.80 \\ \text { ENDF/B-V } & 19.0340 & 18.00 & 3.60 \\ \text { ENDF/B-V } & 19.5110 & 15.00 & 3.00 \\ \text { ENDF/B-V } & 20.0000 & 13.00 & 2.60 \\ \text { EXP } & 22.0000 & 6.63 & 1.33 \\ \text { ExP } & 24.0000 & 3.40 & .68 \\ \text { ExP } & 26.0000 & 1.75 & .35 \\ \text { ExP } & 28.0000 & .90 & .18 \\ \text { ExP } & 30.0000 & .46 & .09 \\ \text { ExP } & 32.0000 & .24 & .05\end{array}$


Table 10

Evaluated Data for the ${ }^{12} \mathrm{C}(\mathrm{n}, \mathrm{d})^{11} \mathrm{~B}$ Reaction

\begin{tabular}{|c|c|c|c|}
\hline $\operatorname{Ref}$ & $\mathrm{E}_{\mathrm{n}} \mathrm{MeV}$ & $\sigma \mathrm{mb}$ & $\Delta \sigma$ \\
\hline ENDF/B-V & 15.2500 & .00 & .00 \\
\hline ENDF/B-V & 15.4770 & 2.00 & .40 \\
\hline ENDF/B-V & 15.9660 & 20.00 & 4.00 \\
\hline ENDF/B-V & 16.4430 & 30.00 & 6.00 \\
\hline ENDF/B-V & 16.9740 & 40.00 & 8.00 \\
\hline ENDF / B - V & 17.4670 & 50.00 & 10.00 \\
\hline ENDF/B-V & 17.9010 & 60.00 & 12.00 \\
\hline ENDF /B-V & 18.4600 & 70.00 & 14.00 \\
\hline ENDF / B - V & 19.0340 & 68.00 & 13.60 \\
\hline ENDF/B-V & 19.5110 & 60.00 & 12.00 \\
\hline $\operatorname{Exp}$ & 20.0000 & 53.00 & 10.60 \\
\hline Exp & 22.0000 & 31.64 & 6.33 \\
\hline Exp & 24.0000 & 18.90 & 3.78 \\
\hline $\operatorname{Exp}$ & 26.0000 & 11.29 & 2.26 \\
\hline Exp & 28.0000 & 6.74 & 1.35 \\
\hline $\operatorname{Exp}$ & 30.0000 & 4.03 & .81 \\
\hline Exp & 32.0000 & 2.40 & .48 \\
\hline
\end{tabular}


Table 11

Evaluated Data for the ${ }^{12} C(n, 2 n)^{11} C$ Reaction

$\begin{array}{lrrr}\text { Ref } & \mathrm{E}_{\mathrm{n}} \mathrm{MeV} & \sigma \mathrm{mb} & \Delta \sigma \\ \text { An81 } & 22.8 & 3.0 & 0.3 \\ \text { An81 } & 23.9 & 6.3 & 0.6 \\ \text { An81 } & 25.0 & 11.4 & 1.0 \\ \text { An81 } & 26.0 & 13.9 & 1.3 \\ \text { An81 } & 26.7 & 16.3 & 1.5 \\ \text { An81 } & 28.0 & 20.7 & 1.9 \\ \text { An81 } & 29.7 & 22.9 & 2.3 \\ \text { An81 } & 30.4 & 25.8 & 2.3 \\ \text { An81 } & 31.3 & 27.0 & 2.4 \\ \text { An81 } & 32.6 & 24.2 & 2.4 \\ \text { An81 } & 33.6 & 27.0 & 2.7\end{array}$


Table 12

Integrals of Double Differential Charged Particle Production Data (Su83)

\begin{tabular}{|c|r|r|r|r|r|c|}
\hline \multirow{2}{*}{$E_{n}$ MeV } & \multicolumn{7}{|c|}{ Cross Sections mb } \\
\cline { 2 - 7 } & \multicolumn{1}{|c|}{$\mathrm{p}$} & $\mathrm{d}$ & \multicolumn{1}{c|}{$\mathrm{t}$} & \multicolumn{1}{c|}{${ }^{3} \mathrm{He}$} & \multicolumn{1}{c|}{$\alpha$} & sum \\
\hline 27.4 & 51.93 & 34.73 & 6.46 & - & 430.72 & 523.84 \\
39.7 & 91.79 & 65.97 & 21.63 & 5.91 & 322.75 & 512.14 \\
60.7 & 121.97 & 75.48 & 26.33 & 10.10 & 266.15 & 500.03 \\
\hline
\end{tabular}

\begin{tabular}{|c|c|r|r|r|r|r|}
\hline \multirow{2}{*}{$\mathrm{E}_{\mathrm{n}} \mathrm{MeV}$} & \multicolumn{7}{|c|}{ Kerma fGy・m $\mathrm{m}^{2}$} \\
\cline { 2 - 7 } & $\mathrm{p}$ & $\mathrm{d}$ & $\mathrm{t}$ & ${ }^{3} \mathrm{He}$ & \multicolumn{1}{c|}{$\boldsymbol{\alpha}$} & sum \\
\hline 27.4 & 0.233 & 0.224 & 0.022 & - & 1.943 & 2.422 \\
39.7 & 0.633 & 0.633 & 0.107 & 0.050 & 1.603 & 3.026 \\
60.7 & 1.727 & 1.233 & 0.261 & 0.109 & 1.349 & 4.679 \\
\hline
\end{tabular}




\section{Table 13}

Evaluated Cross Sections for the Reactions Discussed in Section 3.12

$$
{ }^{12} \mathrm{C}(\mathrm{n}, \mathrm{np})^{11} \mathrm{~B}
$$

$\begin{array}{cc}E_{n} \mathrm{MeV} & \mathrm{mb} \\ & \\ 17.301 & 0 \\ 17.888 & 1.0 \\ 18.377 & 10.0 \\ 18.854 & 15.0 \\ 19.385 & 20.0 \\ 19.878 & 25.0 \\ 20.311 & 30.0 \\ 20.871 & 35.0 \\ 21.445 & 34.0 \\ 21.922 & 30.0 \\ 22.411 & 26.5 \\ 24.411 & 15.82 \\ 26.411 & 9.45 \\ 28.411 & 5.65 \\ 30.411 & 3.37 \\ 32.411 & 2.01\end{array}$

Uncertainties $30 \%$

$$
{ }^{12} \mathrm{C}(\mathrm{n}, \mathrm{t}){ }^{10} \mathrm{~B}
$$

$\mathrm{E}_{\mathrm{n}} \mathrm{MeV} \quad \mathrm{mb}$

$$
20.522
$$

21.0

22.5

23.0

23.8

24.0

26.0

27.0

28.0

29.0

30.0

31.0

32.0

0

0.2

8.6

11.0

12.2

12.0

8.0

6.5

5.3

5.4

3.4

2.8

2.4

Uncertainties $30 \%$

$$
{ }^{12} \mathrm{C}(\mathrm{n}, \mathrm{d} \alpha)^{7} \mathrm{Li}
$$

$\mathrm{E}_{\mathrm{n}} \mathrm{MeV}$

$\mathrm{mb}$

24.28

0

24.70

0.9

25.0

1.5

26.0

27.0

27.2

27.3

27.4

28.0

29.0

30.0

32.0

16.0

25.7

27.54

27.93

27.80

27.0

22.0

18.0

12.0

Uncertainties $30 \%$

$$
{ }^{12} \mathrm{C}(\mathrm{n}, \mathrm{p} \alpha)^{8} \mathrm{Li}
$$

$\mathrm{E}_{\mathrm{n}} \mathrm{MeV}$

$$
\begin{aligned}
& 24.5 \\
& 25.1
\end{aligned}
$$

25.2

27.0

27.5

28.0

29.0

30.0

31.0

32.0

Uncertainties $30 \%$

$$
{ }^{12} \mathrm{C}\left(\mathrm{n},{ }^{6} \mathrm{Li}\right){ }^{7} \mathrm{Li}
$$

$\mathrm{E}_{\mathrm{n}} \mathrm{MeV} \quad \mathrm{mb}$

$\begin{array}{rr}23.3 & 0 \\ 23.7 & 6.8 \\ 24.0 & 14 \\ 26.0 & 100 \\ 26.5 & 100 \\ 30.0 & 62 \\ 31.0 & 54 \\ 32.0 & 48\end{array}$

Uncertainties $25 \%$ 


\section{Table 14}

Blanket Cross Sections for the Remaining 17 Reactions in Table 2 ( $\sigma_{\text {spare }}$ )

$\mathrm{E}_{\mathrm{n}} \mathrm{MeV}$

26.3

26.4

26.6

27.0

27.1

27.2

27.7

28.0

29.0

32.0 mb

0

1

2

7

8.5

10.5

18.0

24.0

45.0

117.0 
Table $15 a$

Unified Cross Sections and Uncertainties (mb)

\begin{tabular}{|c|c|c|c|c|c|c|c|c|}
\hline $\mathrm{E}_{\mathrm{n}} \mathrm{MeV}$ & $\sigma_{\mathrm{t}}$ & $\Delta \sigma_{\mathrm{t}}$ & $\sigma_{c}$ & $\Delta \sigma_{c}$ & $\sigma_{\theta}$ & $\Delta \sigma_{\theta}$ & $\sigma_{\text {in }}$ & $\Delta \sigma_{\text {in }}$ \\
\hline 5.000 & 1183.158 & 19.337 & .029 & .004 & 1120.308 & 20.259 & 62.821 & 6.853 \\
\hline 5.001 & 1195.430 & 17.107 & .029 & .004 & 1132.466 & 18.207 & 62.935 & 6.860 \\
\hline 5.030 & 1177.322 & 17.850 & .029 & .004 & 1117.640 & 18.744 & 59.652 & 6.372 \\
\hline 5.053 & 1172.529 & 17.550 & .029 & .004 & 1115.529 & 18.463 & 56.970 & 6.372 \\
\hline 5.100 & 1151.167 & 17.291 & .030 & .004 & 1091.899 & 18.279 & 59.238 & 6.590 \\
\hline 5.120 & 1142.467 & 17.448 & .030 & .004 & 1078.841 & 18.508 & 63.596 & 6.889 \\
\hline 5.150 & 1135.682 & 17.154 & .031 & .004 & 1063.017 & 18.567 & 72.634 & 7.923 \\
\hline 5.180 & 1124.659 & 17.160 & .031 & .004 & 1043.176 & 18.786 & 81.452 & 8.565 \\
\hline 5.200 & 1107.829 & 16.925 & .031 & .004 & 1020.789 & 18.879 & 87.008 & 9.376 \\
\hline 5.230 & 1098.157 & 16.384 & .032 & .004 & 1004.746 & 18.553 & 93.380 & 9.730 \\
\hline 5.280 & 1064.891 & 16.015 & .032 & .005 & 965.431 & 18.466 & 99.428 & 10.321 \\
\hline 5.300 & 1058.087 & 16.230 & .033 & .005 & 957.165 & 18.768 & 100.890 & 10.677 \\
\hline 5.330 & 1045.566 & 16.575 & .033 & .005 & 932.920 & 22.868 & 112.613 & 17.993 \\
\hline 5.335 & 1079.582 & 19.737 & .033 & .005 & 963.081 & 24.405 & 116.468 & 17.428 \\
\hline 5.340 & 1027.137 & 17.062 & .033 & .005 & 921.685 & 22.682 & 105.419 & 16.863 \\
\hline 5.360 & 1578.277 & 24.761 & .033 & .005 & 1458.550 & 28.161 & 119.694 & 15.149 \\
\hline 5.362 & 1825.566 & 30.960 & .033 & .005 & 1697.984 & 33.358 & 127.548 & 15.023 \\
\hline 5.370 & 1992.353 & 33.067 & .033 & .005 & 1864.097 & 35.226 & 128.222 & 14.556 \\
\hline 5.371 & 1971.627 & 34.040 & .033 & .005 & 1844.485 & 36.096 & 127.108 & 14.514 \\
\hline 5.378 & 1757.693 & 30.103 & .033 & .005 & 1630.761 & 32.378 & 126.899 & 14.247 \\
\hline 5.380 & 1679.555 & 27.750 & .033 & .005 & 1553.816 & 30.300 & 125.705 & 14.203 \\
\hline 5.390 & 1462.731 & 23.401 & .034 & .005 & 1337.656 & 26.488 & 125.041 & 14.215 \\
\hline 5.400 & 1327.647 & 21.477 & .034 & .005 & 1202.716 & 24.973 & 124.898 & 14.594 \\
\hline 5.410 & 1260.705 & 20.586 & .034 & .005 & 1133.367 & 24.456 & 127.304 & 15.286 \\
\hline 5.420 & 1227.717 & 20.082 & .034 & .005 & 1098.628 & 24.474 & 129.055 & 16.256 \\
\hline 5.430 & 1199.040 & 19.695 & .034 & .005 & 1070.013 & 23.621 & 128.992 & 15.197 \\
\hline 5.440 & 1190.950 & 18.745 & .034 & .005 & 1060.363 & 22.423 & 130.552 & 14.242 \\
\hline 5.460 & 1145.717 & 17.264 & .034 & .005 & 1016.440 & 20.600 & 129.243 & 12.803 \\
\hline 5.500 & 1118.953 & 16.589 & .035 & .005 & 990.546 & 19.895 & 128.372 & 12.456 \\
\hline 5.550 & 1101.177 & 16.755 & .036 & .005 & 972.744 & 19.696 & 128.398 & 11.813 \\
\hline 5.553 & 1110.879 & 16.956 & .036 & .005 & 981.756 & 19.793 & 129.088 & 11.696 \\
\hline 5.600 & 1088.805 & 16.120 & .036 & .005 & 958.867 & 19.138 & 129.901 & 11.686 \\
\hline 5.650 & 1079.166 & 15.960 & .037 & .005 & 941.923 & 19.025 & 137.207 & 11.764 \\
\hline 5.700 & 1068.152 & 15.605 & .037 & .005 & 920.034 & 19.461 & 148.080 & 13.211 \\
\hline 5.800 & 1078.741 & 15.636 & .039 & .005 & 909.819 & 20.077 & 168.883 & 14.423 \\
\hline 5.900 & 1079.683 & 15.628 & .040 & .006 & 885.323 & 20.698 & 194.321 & 15.569 \\
\hline 6.000 & 1097.581 & 15.968 & .041 & .006 & 875.404 & 21.997 & 222.136 & 17.519 \\
\hline 6.050 & 1104.150 & 16.735 & .042 & .006 & 872.694 & 22.550 & 231.414 & 17.801 \\
\hline 6.053 & 1107.979 & 16.492 & .042 & .006 & 875.640 & 22.394 & 232.297 & 17.745 \\
\hline 6.125 & 1133.209 & 16.642 & .045 & .006 & 890.746 & 23.612 & 242.418 & 19.592 \\
\hline 6.160 & 1162.293 & 17.654 & .046 & .007 & 914.013 & 23.555 & 248.234 & 18.540 \\
\hline 6.174 & 1189.434 & 19.196 & .047 & .007 & 938.844 & 23.896 & 250.543 & 18.555 \\
\hline
\end{tabular}


Table $15 b$

Average Correlation Matrix for Total and Partial Cross Sections from 5 to $6.174 \mathrm{MeV}$

$\begin{array}{llll}\sigma_{\mathrm{t}} & 1.000 & & \\ \sigma_{\mathrm{e}} & .796 & 1.000 & \\ \sigma_{\text {in }} & .088 & -.509 & 1.000\end{array}$


Table 16a

Unified Cross Sections and Uncertainties (mb)

$\mathrm{E}_{\mathrm{n}} \mathrm{MeV}$

$\begin{array}{llll}6.1800 & 1196.018 & 18.995\end{array}$

$\begin{array}{llll}6.2000 & 1227.807 & 19.295\end{array}$

$\begin{array}{llll}6.2100 & 1274.483 & 20.736\end{array}$

$\begin{array}{llll}6.2200 & 1293.173 & 21.035\end{array}$

$\begin{array}{llll}6.2300 & 1345.103 \quad 21.677\end{array}$

$\begin{array}{llll}6.2400 & 1428.825 & 22.930\end{array}$

$\begin{array}{llll}6.2500 & 1503.159 & 22.769\end{array}$

$\begin{array}{llll}6.2850 & 2415.353 & 35.741\end{array}$

$6.2950 \quad 2710.692 \quad 42.679$

$\begin{array}{llll}6.3030 & 2598.989 & 41.563\end{array}$

$\begin{array}{lll}6.3100 & 2360.339 & 37.258\end{array}$

$\begin{array}{lll}6.3200 & 1935.126 & 30.348\end{array}$

6.3300

6.3400

6.3500

6.3600

6.3700

6.3900

6.4000

6.4100

6.4200

6.4300

6.4400

6.4500

6.4700

6.4900

6.5100

6.5400

6.5530

6.5600

6.5700

6.5800

6.5900

6.6000

6.6200

6.6400

6.6580

6.6650

6.6700

6.6800

6.7000

6.7500

6.8100

6.9200

7.0000

7.0530
$1703.125 \quad 26.810$

1520.69224 .143

$1481.987 \quad 23.584$

$1600.922 \quad 25.173$

1406.45421 .656

$1178.541 \quad 18.541$

$1154.890 \quad 18.939$

$1117.816 \quad 18.517$

1090.07218 .260

1102.98018 .318

$1079.625 \quad 18.020$

$1079.838 \quad 17.234$

1060.28516 .563

$1057.663 \quad 16.539$

1037.36016 .008

$972.187 \quad 15.320$

895.67515 .780

$849.167 \quad 15.564$

$769.464 \quad 14.140$

$732.294 \quad 13.577$

$743.225 \quad 13.784$

$737.918 \quad 12.895$

$781.930 \quad 12.891$

$935.894 \quad 15.641$

863.10816 .449

$849.118 \quad 15.804$

$842.789 \quad 14.158$

836.62412 .901

$815.874 \quad 12.266$

797.90111 .799

$769.893 \quad 11.301$

$744.972 \quad 11.057$

$749.068 \quad 11.282$
$763.901 \quad 12.821$ $\sigma_{\mathrm{c}} \quad \Delta \sigma_{\mathrm{c}}$

$.047 \quad .007$

$.048 \quad .007$

$.048 \quad .007$

.049 .007

.049 .007

.049 .007

.050 .007

.051 .007

.051 .007

.052 .007

.052 .007

.052 .007

.053 .007

.053 .008

.053 .008

.054 .008

.054 .008

.055 .008

.055 .008

.056 .008

.056 .008

.056 .008

.057 .008

.057 .008

.058 .008

.059 .008

.059 .008

.060 .009

.061 .009

.061 .009

.062 .009

.062 .009

.062 .009

.063 .009

.063 .009

.064 .009

.065 .009

.065 .009

.065 .009

.066 .009

.066 .009

.068 .010

.070 .010

.074 .010

.077 .011

.079 .011 $\sigma_{e} \quad \Delta \sigma_{e}$

$945.518 \quad 24.678$

$980.810 \quad 25.840$

$1023.889 \quad 27.219$

1038.76027 .102

1085.40527 .556

$1162.203 \quad 28.727$

$1237.474 \quad 29.522$

2104.88141 .072

$2382.642 \quad 47.192$

$2263.234 \quad 46.462$

$2011.488 \quad 42.836$

$1596.250 \quad 36.673$

$1368.536 \quad 33.479$

$1192.743 \quad 31.312$

$1146.317 \quad 30.762$

1224.28031 .423

$1066.038 \quad 28.303$

$889.340 \quad 24.914$

872.56024 .432

$847.417 \quad 23.863$

825.55423 .549

841.42323 .635

827.71423 .549

833.65723 .301

828.12123 .297

830.36523 .513

804.42523 .089

705.79321 .258

$631.747 \quad 20.751$

590.88420 .181

$530.436 \quad 19.138$

$501.316 \quad 18.607$

505.01218 .569

$514.008 \quad 18.932$

$576.943 \quad 19.951$

591.89720 .190

736.91921 .252

682.47721 .367

670.10720 .837

$661.352 \quad 19.664$

$655.544 \quad 18.704$

$649.995 \quad 17.765$

$645.774 \quad 16.924$

606.03515 .395

$573.618 \quad 13.981$

$572.617 \quad 14.248$ $\sigma_{\text {in }} \quad \Delta \sigma_{\text {in }}$

$250.416 \quad 19.037$

246.79120 .310

$250.328 \quad 21.202$

254.08620 .363

259.31120 .025

266.17420 .231

265.17721 .049

$309.752 \quad 22.939$

$327.269 \quad 23.908$

$334.925 \quad 24.883$

$347.980 \quad 25.746$

$337.943 \quad 24.580$

$333.597 \quad 23.915$

$326.896 \quad 23.715$

$334.616 \quad 23.998$

$375.586 \quad 24.687$

339.36122 .791

$288.146 \quad 20.183$

$281.274 \quad 19.472$

$269.343 \quad 19.195$

$263.461 \quad 19.024$

260.50019 .010

$250.854 \quad 19.034$

$245.124 \quad 19.119$

$231.106 \quad 19.484$

$226.239 \quad 19.993$

$231.8 \% 5 \quad 20.293$

$265.332 \quad 19.541$

$262.866 \quad 19.560$

$257.221 \quad 19.284$

$237.967 \quad 18.630$

$229.916 \quad 18.288$

$237.151 \quad 18.291$

$222.848 \quad 18.504$

$203.925 \quad 18.735$

$170.941 \quad 18.282$

$197.910 \quad 18.014$

$179.567 \quad 17.704$

$177.947 \quad 17.389$

$180.371 \quad 16.821$

$180.013 \quad 16.291$

$164.811 \quad 15.214$

151.05614 .255

$162.783 \quad 12.331$

$170.277 \quad 10.201$

$175.372 \quad 10.466$ $\sigma_{\mathrm{n}, \alpha} \quad \Delta \sigma_{\mathrm{n}, \alpha}$

$.038 \quad .008$

$.158 \quad .032$

$.218 \quad .044$

$.278 \quad .056$

$.338 \quad .068$

$.399 \quad .080$

$.459 \quad .092$

$.669 \quad .134$

.730 .146

$.778 \quad .156$

$.820 \quad .164$

$.880 \quad .176$

$.940 \quad .188$

.999 .200

$1.000 \quad .198$

1.002 .195

1.001 .193

$1.000 \quad .189$

1.000 .186

$1.000 \quad .184$

$1.000 \quad .182$

$1.000 \quad .180$

$1.000 \quad .178$

$1.000 \quad .176$

$1.000 \quad .172$

$1.000 \quad .168$

$1.001 \quad .165$

1.002 .160

$1.001 \quad .158$

$1.001 \quad .157$

$1.000 \quad .155$

$1.000 \quad .154$

1.000 .153

$1.000 \quad .151$

$.999 \quad .149$

$.998 \quad .147$

$1.000 \quad .146$

$1.000 \quad .145$

1.000 .145

$1.000 \quad .144$

$1.000 \quad .143$

1.000 .142

$1.000 \quad .143$

$1.000 \quad .151$

$1.000 \quad .163$

$1.000 \quad .173$ 
Table 16a (Continued)

\begin{tabular}{|c|c|c|c|c|c|c|c|c|c|c|}
\hline $\mathrm{E}_{\mathrm{n}} \mathrm{MeV}$ & $\sigma_{\mathrm{t}}$ & $\Delta \sigma_{\mathrm{t}}$ & $\sigma_{\mathrm{c}}$ & $\Delta \sigma_{\mathrm{c}}$ & $\sigma_{\theta}$ & $\Delta \sigma_{\mathrm{e}}$ & $\sigma_{\text {in }}$ & $\Delta \sigma_{\text {in }}$ & $\sigma_{\mathrm{n}, \alpha}$ & $\Delta \sigma_{\mathrm{n}, \alpha}$ \\
\hline 7.1000 & 748.824 & 11.400 & .081 & .011 & 569.136 & 14.922 & 178.607 & 11.624 & 1.000 & .182 \\
\hline .1400 & 768.072 & 11.762 & .083 & .012 & 582.812 & 15.870 & 184.177 & 12.891 & 1.000 & .191 \\
\hline 7.1800 & 797.674 & 12.404 & .085 & .012 & 602.546 & 16.244 & 194.044 & 12.663 & .999 & .200 \\
\hline .2000 & 844.627 & 13.536 & .086 & .012 & 639.885 & 17.432 & 202.656 & 13.544 & 2.000 & .289 \\
\hline 7.2200 & 877.618 & 14.847 & .087 & .012 & 667.835 & 19.047 & 206.700 & 14.971 & 2.997 & .495 \\
\hline 7.2250 & 887.890 & 14.664 & .087 & .012 & 676.327 & 19.213 & 208.230 & 15.367 & 3.246 & .551 \\
\hline 7.2500 & 976.749 & 15.201 & .088 & .012 & 746.745 & 19.918 & 225.429 & 15.3 & & .842 \\
\hline 7.2700 & 1069.018 & 17.014 & .089 & .013 & 822.589 & 21.546 & 240.865 & 15.8 & 5.474 & 1.080 \\
\hline .2800 & 1138.707 & 16.992 & .090 & .013 & 884.156 & 22.086 & 248.4 & 16. & 66 & 1.200 \\
\hline .3400 & 1644.538 & 24.059 & .092 & .013 & 1332.063 & 30.127 & 301 & & & 2.199 \\
\hline .3500 & 1756.149 & 27.643 & .093 & .013 & 1429. & 32.510 & 313. & 20. & & 2.144 \\
\hline 7.3600 & 1755.517 & 27.570 & .093 & .013 & 1422.189 & 32.506 & 318.0 & 20. & 15. & 2.136 \\
\hline 7.3700 & 1808.552 & 27.034 & .094 & .013 & 1463.925 & 32.411 & 327.297 & 20. & 17.237 & 2.175 \\
\hline 7.4000 & 1781.396 & 26.379 & .095 & .013 & 1413.809 & 33.939 & 344.074 & 24.8 & 23. & 2.544 \\
\hline 7.4200 & 1770.795 & 25.850 & .096 & .014 & 1397.950 & 32.5 & 345.200 & 22. & & 2.941 \\
\hline 7.4700 & 1755.586 & 25.345 & .098 & .014 & 1371.349 & 33.297 & 346.306 & 24.741 & 37.8 & 4.204 \\
\hline 7.5290 & 1754.002 & 25.535 & .101 & .014 & 1378.189 & 31.054 & 774 & 19. & & 5.891 \\
\hline .5420 & 1734.654 & 26.695 & .101 & .014 & 1363.449 & 32.150 & 03 & & & 6.277 \\
\hline 7.5530 & 1725.268 & 25.433 & .102 & .014 & 1355.155 & 30.873 & .253 & 19.3 & 54. & 6.615 \\
\hline 7.5940 & 1704.122 & 24.915 & .102 & .014 & 1338.046 & 31.078 & 302.372 & 20.3 & & 7.587 \\
\hline 7.6200 & 1701.060 & 24.989 & .103 & .015 & 1326.267 & 30.830 & 301.179 & 19.7 & 73 & 7.642 \\
\hline 7.6500 & 1722.517 & 25.477 & .104 & .015 & 1337.039 & 31.4 & 301.108 & 19.3 & 84. & 9.729 \\
\hline 7.6670 & 1782.403 & 26.982 & .104 & .015 & 1390.871 & 33.033 & 301.893 & 20.1 & 89.5 & 10.605 \\
\hline 7.6800 & 1808.523 & 27.356 & .104 & .015 & 1414.798 & 33.709 & 301.564 & & 92 & 10.455 \\
\hline 7.6980 & 1927.406 & 29.719 & .105 & .015 & 1525.012 & 36.194 & .747 & & 96 & 10.363 \\
\hline 200 & 1932.411 & 29.443 & .105 & .015 & 1529.921 & 36.147 & 445 & 22.9 & 96 & 10.360 \\
\hline 7.7250 & 2225.306 & 32.850 & .105 & .015 & 1798.830 & 38.494 & 323.042 & 21.63 & 103.329 & 10.495 \\
\hline 7.7450 & 2425.897 & 36.918 & .106 & .015 & 1987.321 & 42.007 & 331.247 & 21.603 & 107.223 & 10.800 \\
\hline 7.7500 & 2392.678 & 36.432 & .106 & .015 & 1954.238 & 41.730 & 330.768 & 21.725 & 107.566 & 10.899 \\
\hline 7.7700 & 2275.103 & 33.792 & .106 & .015 & 1823.509 & 39.932 & 339.897 & 22.695 & 111.590 & 11.379 \\
\hline 7.7890 & 2143.098 & 31.824 & .107 & .015 & 1683.256 & 39.0 & 345.157 & 24 & 114.579 & 11.948 \\
\hline 7.8100 & 2053.589 & 30.884 & .107 & .015 & 1580.589 & 39.345 & 354.165 & 26.7 & 118.727 & 12.715 \\
\hline 7.8190 & 2058.984 & 30.242 & .107 & .015 & 1582.253 & 38.412 & 355.435 & 25.535 & 121.188 & 13.075 \\
\hline 7.8600 & 2001.733 & 29.056 & .108 & .015 & 1521.782 & 36.480 & 349.681 & 22.491 & 130.162 & 14.879 \\
\hline .8870 & 1969.841 & 29.752 & .109 & .015 & 1492.710 & 36.877 & 344.928 & 22.960 & 132.094 & 14.431 \\
\hline 7.8880 & 1948.754 & 27.466 & .109 & .015 & 1474.355 & 35.516 & 342.874 & 23.013 & 131.416 & 14.361 \\
\hline
\end{tabular}


Table $16 \mathrm{~b}$

Average Correlation Matrix for Total and Partial Cross Sections from 6.18 to $7.888 \mathrm{MeV}$

$\begin{array}{lllll}\sigma_{\mathrm{t}} & 1.000 & & & \\ \sigma_{\mathrm{e}} & .650 & 1.000 & & \\ \sigma_{\text {in }} & .159 & -.619 & 1.000 & \\ \sigma_{\mathrm{n}, \alpha_{0}} & .014 & -.067 & -.010 & 1.000\end{array}$


్ำ

ตㅋำ

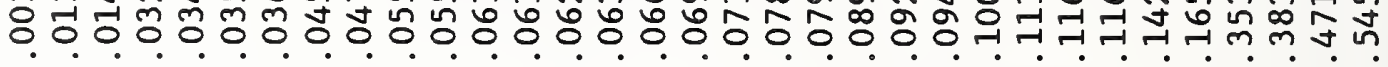

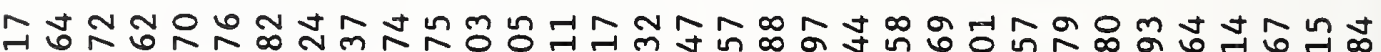

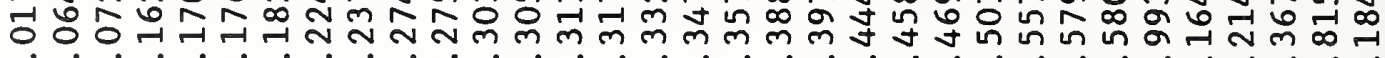
- $\dot{v} \sim \dot{m}$

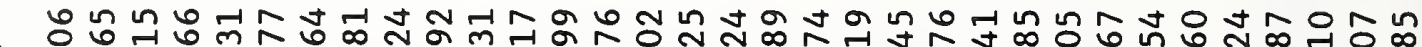
익

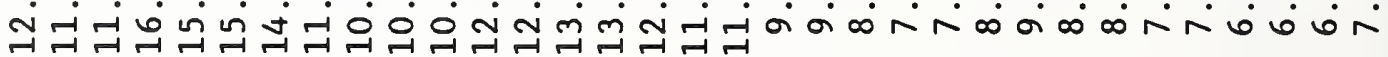

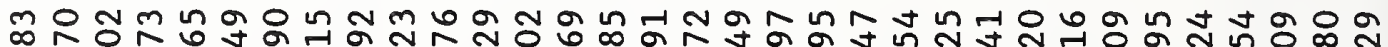

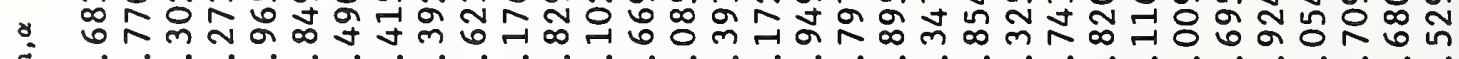

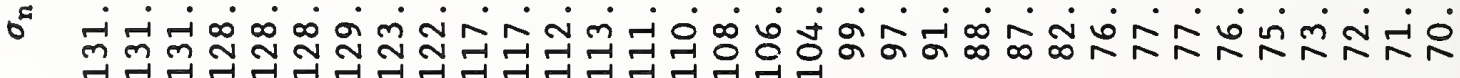

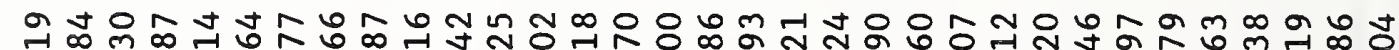

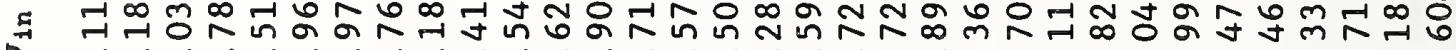

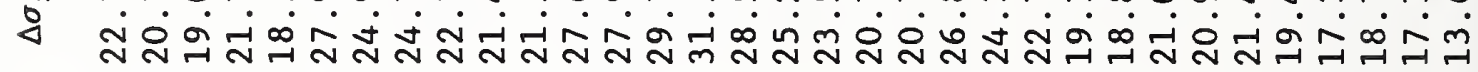

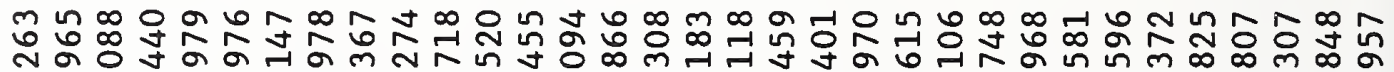

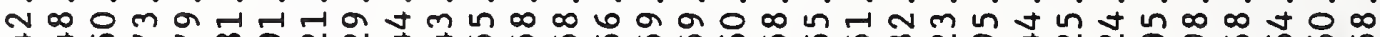
गे

- 6 ง 守

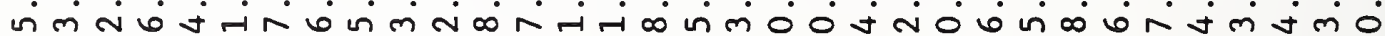

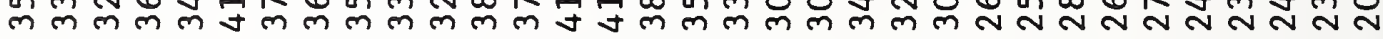

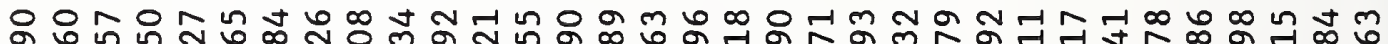
ㄱำ

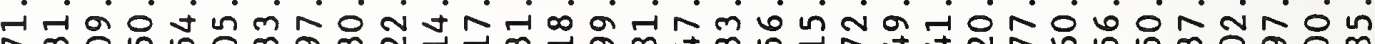
․ㅔㅇㅔ

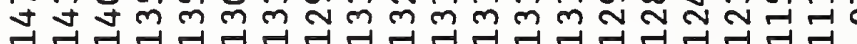

ஓ a $00-1-1-1 N N$ N 0

Na ㄴำ ำ

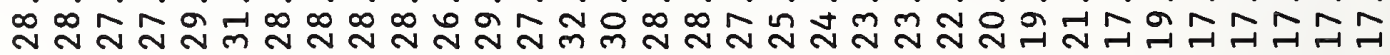

-1 $\infty 6 m \infty$ n రु ก

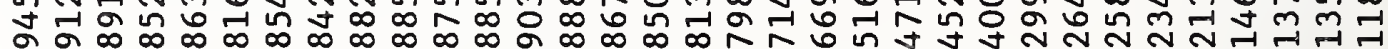

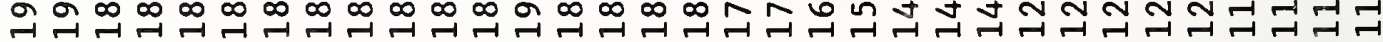

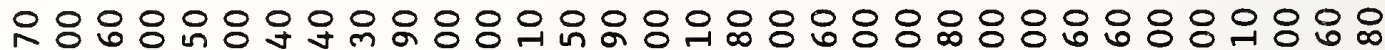
क

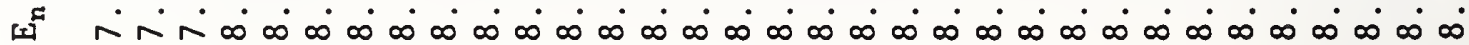


मे

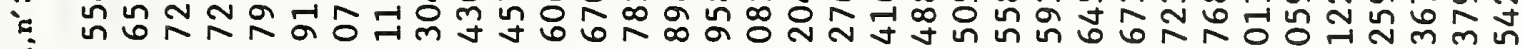

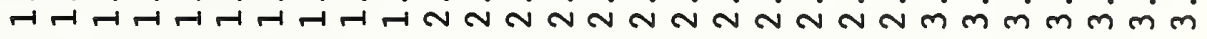

"ే

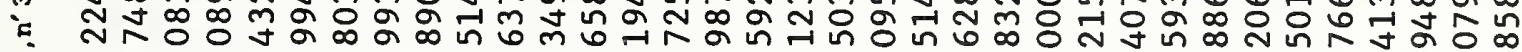

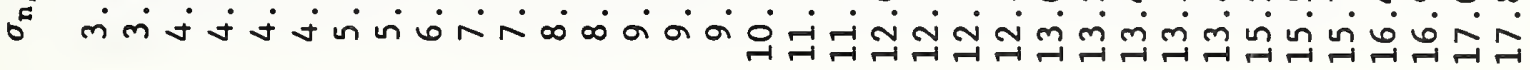

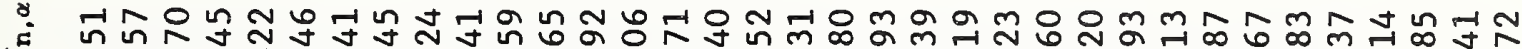

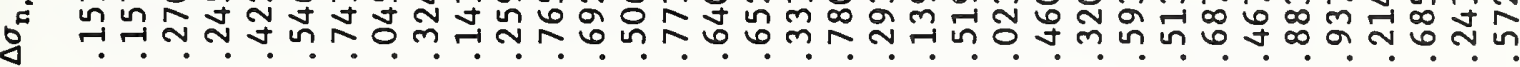

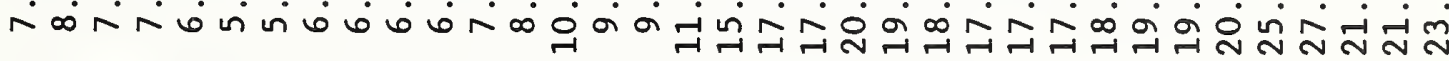

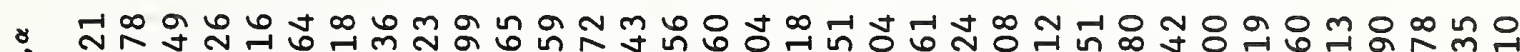

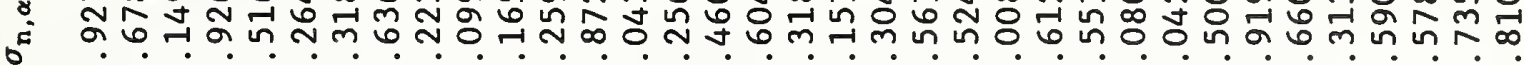

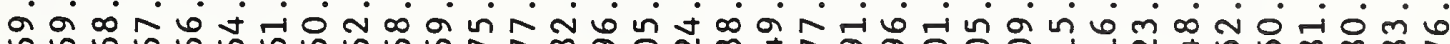

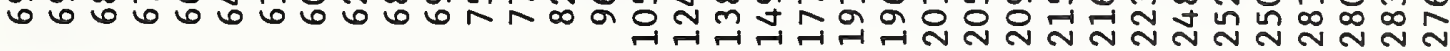

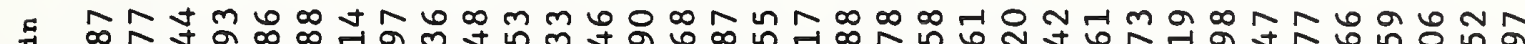
ব

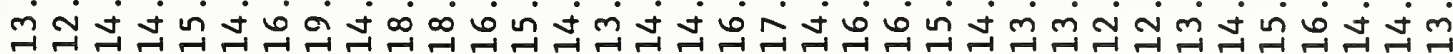

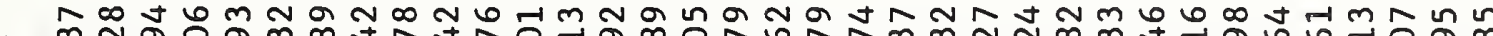
Е

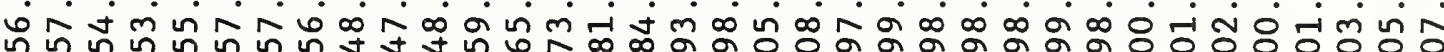

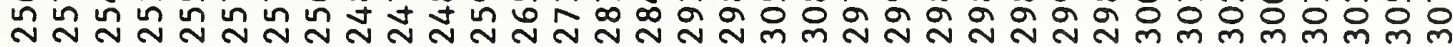

○ $\quad$ m

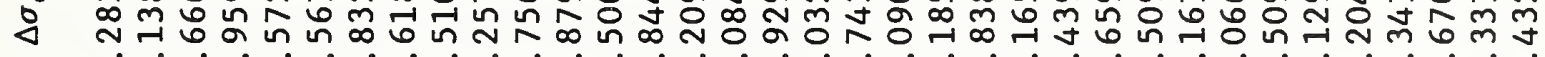

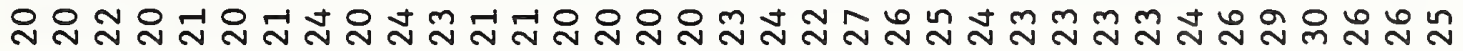

$\forall \infty \forall 6$ オ ฟึ๊

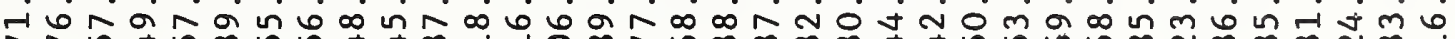

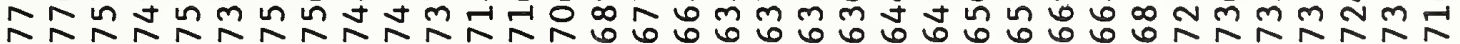

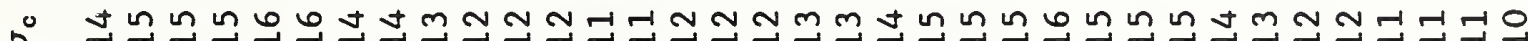

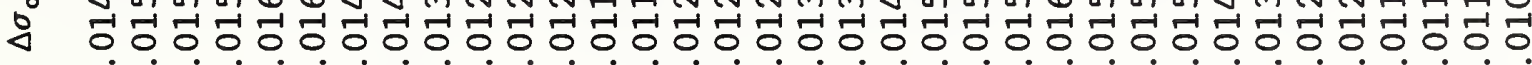

0

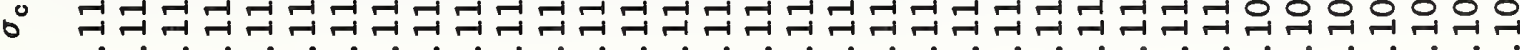

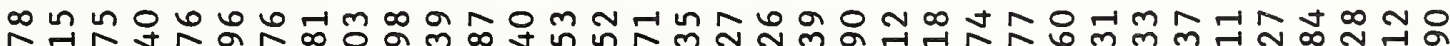
N ம

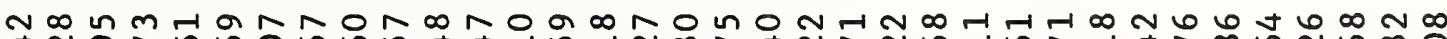

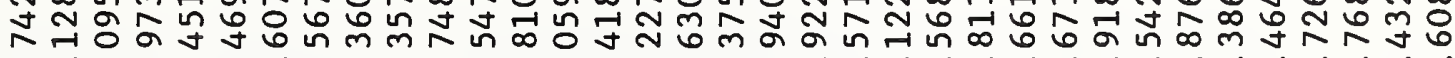

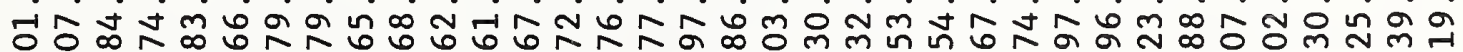

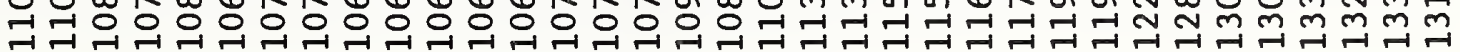

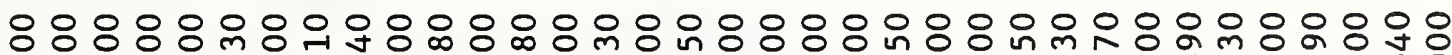
ษ

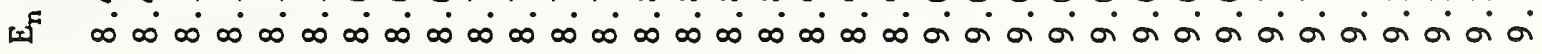




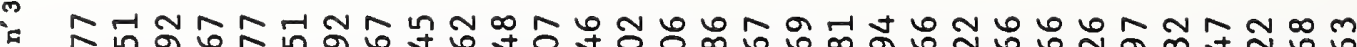

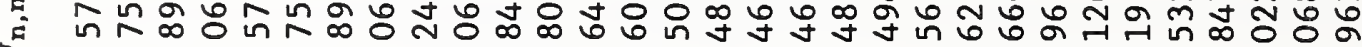

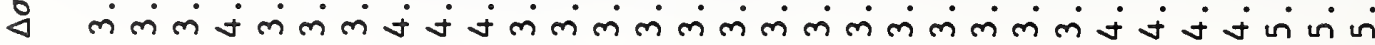

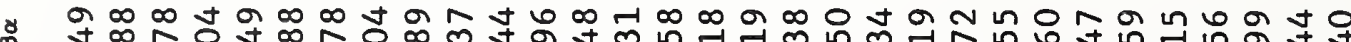
రి

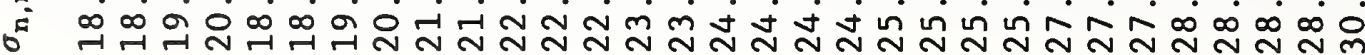

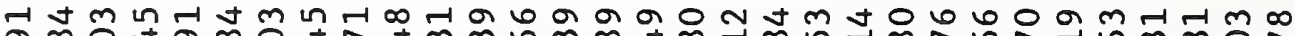
" न \

ดิ

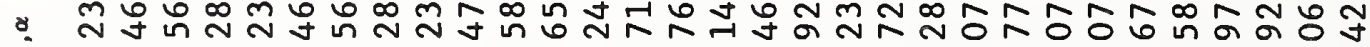

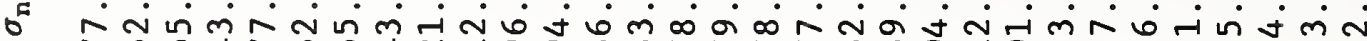

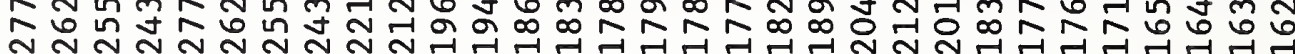

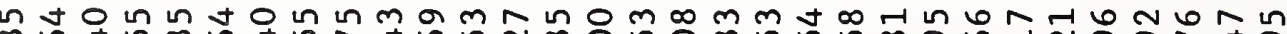

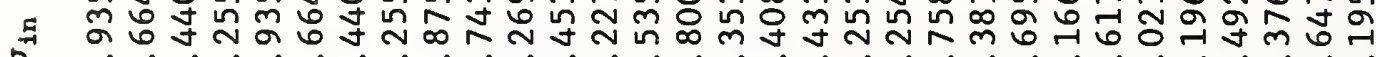

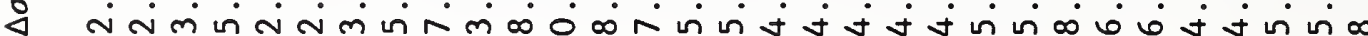

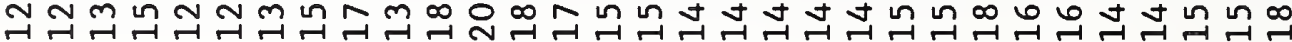

$\infty$ t $N \infty y \infty N$ in ๓

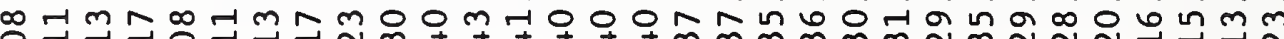

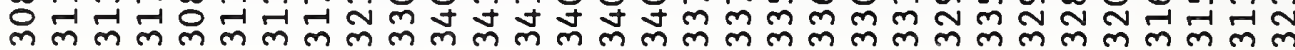

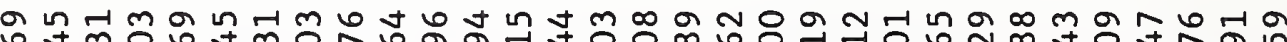

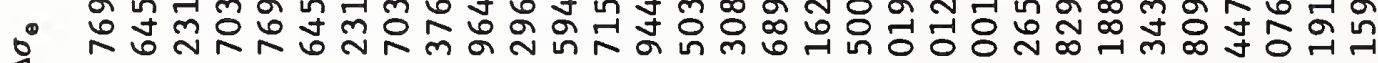

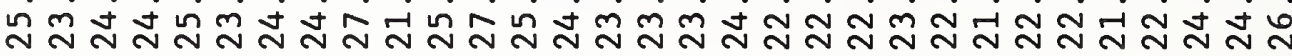

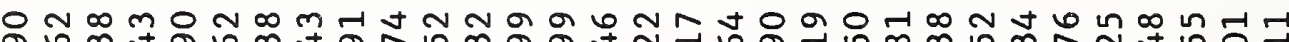
๙ n त

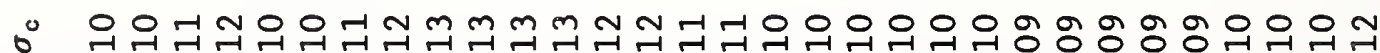

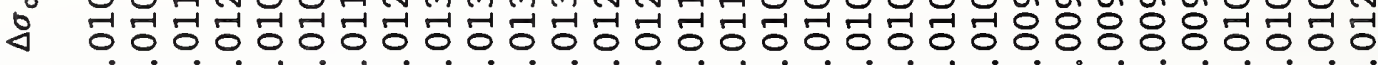

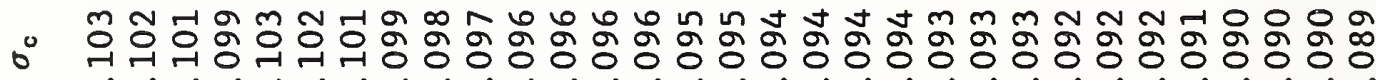

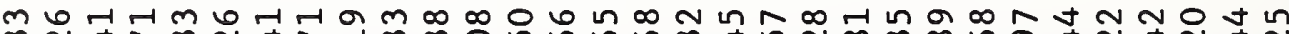

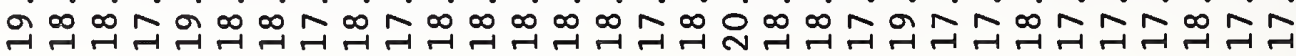

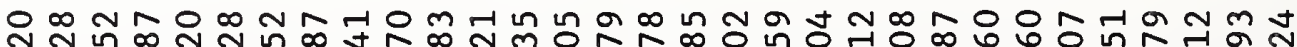
극 승 ㄱำ

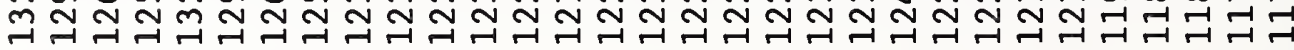

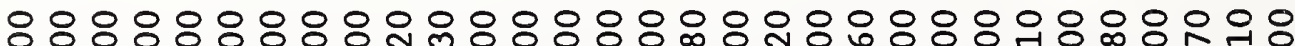

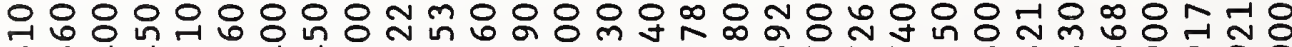
m

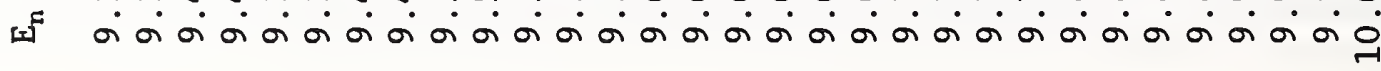


Table 17b

Average Correlation Matrix for Total and Partial Cross Sections from 7.89 to $10 \mathrm{MeV}$

$\begin{array}{lrrrrrr}\sigma_{\mathrm{t}} & 1.00 & & & & \\ \sigma_{\mathrm{e}} & .56 & 1.00 & & & \\ \sigma_{\mathrm{in}} & .15 & -.48 & 1.00 & & \\ \sigma_{\mathrm{n}, \alpha_{0}} & .13 & -.37 & -.11 & 1.00 & \\ \sigma_{\mathrm{n}, \mathrm{n}^{\prime} 3 \alpha} & .02 & -.04 & -.01 & -.02 & 1.00\end{array}$


해

¿ $m m$ ต

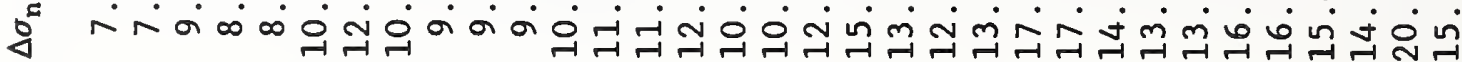

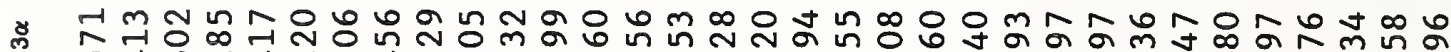

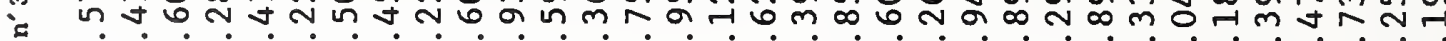

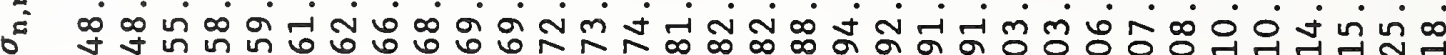

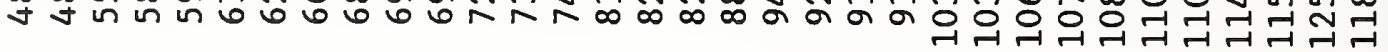

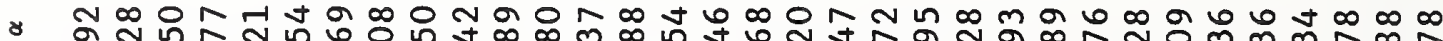

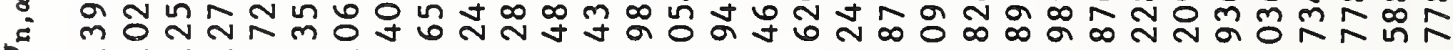

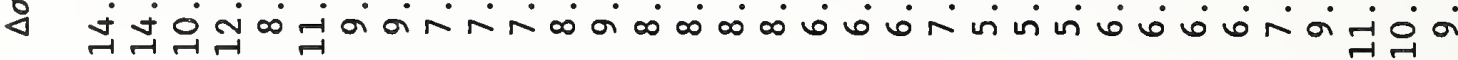

ㅊㅇㅇㅇㅇㅇ in

*

b m N

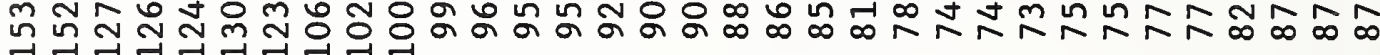

พำ

¿

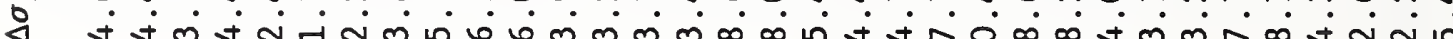
可

n นึ้

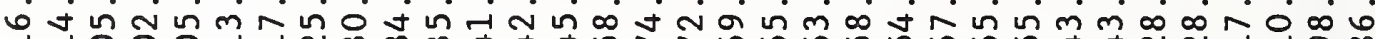
m

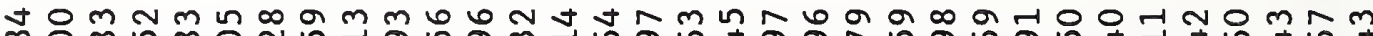

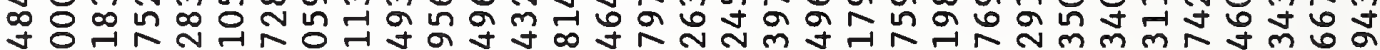

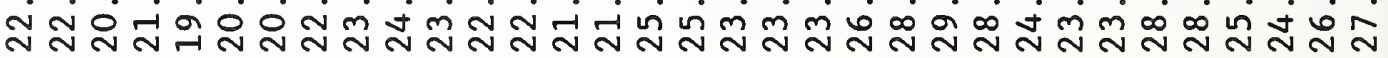

同

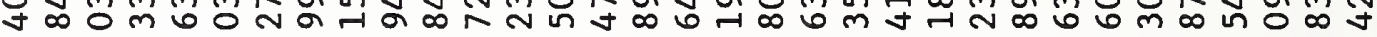

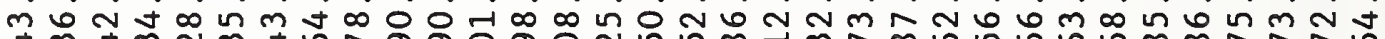
ปै

。

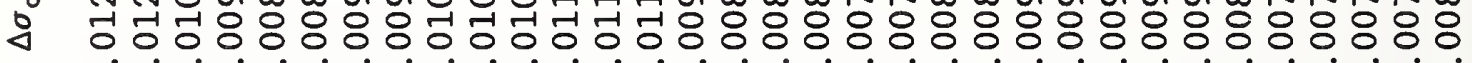

$\infty \infty$ in

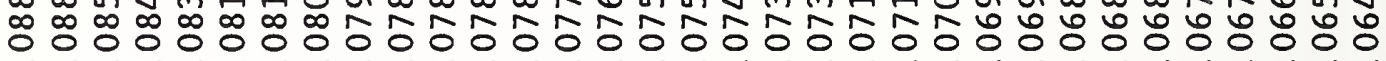

ํํำ

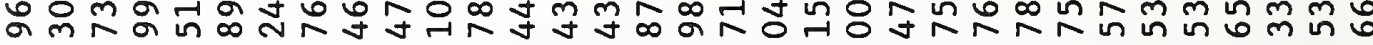
0

ง

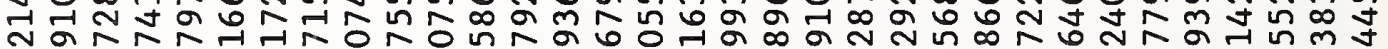
N

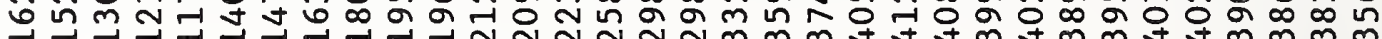

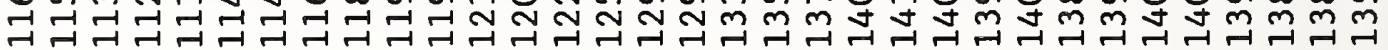

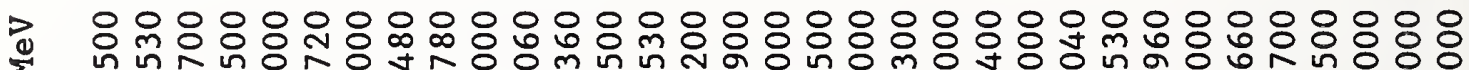
¿ a्य

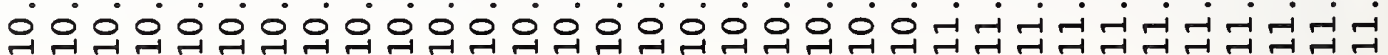


워ำ

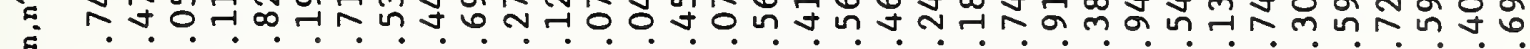

g 담

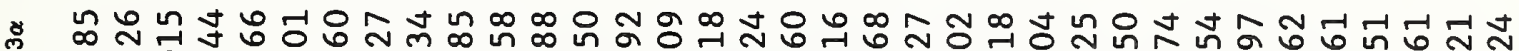

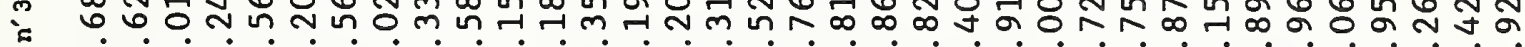
¿

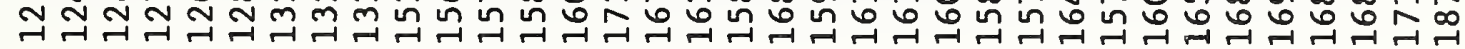

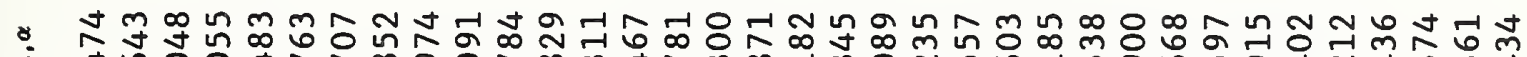

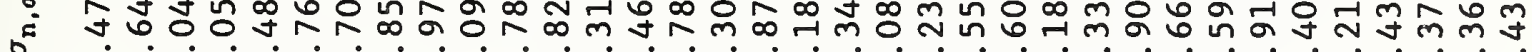

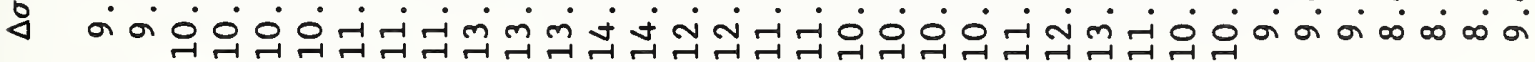

음

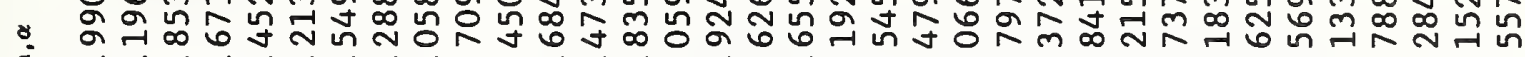

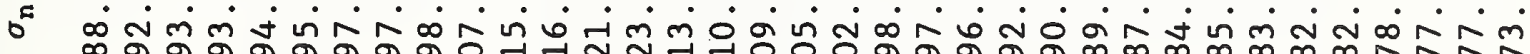

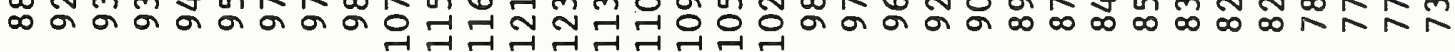

囱 귱 穴

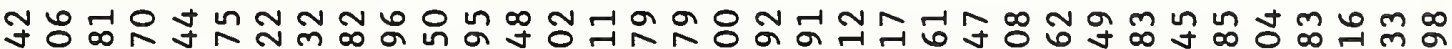

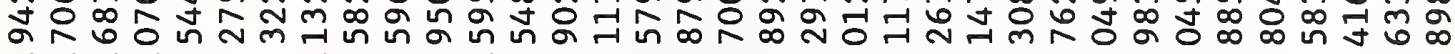

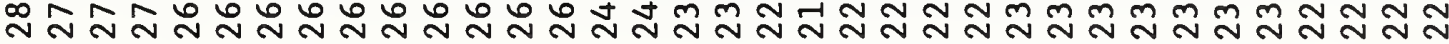

ปึ 8 $m$ o

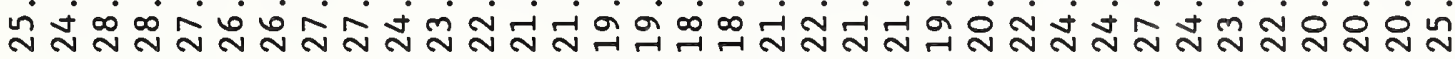
부워

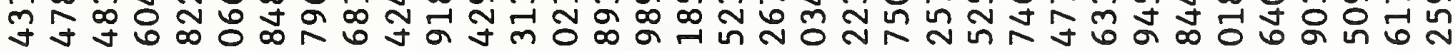

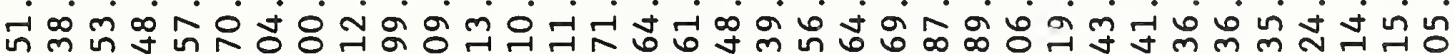

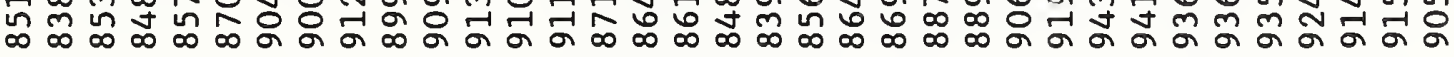

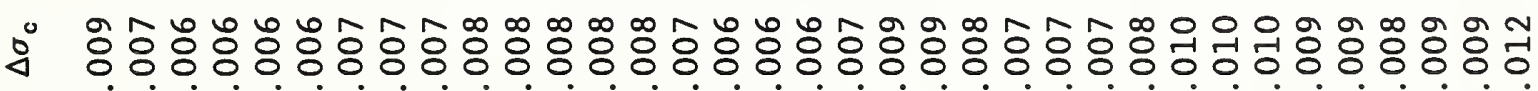

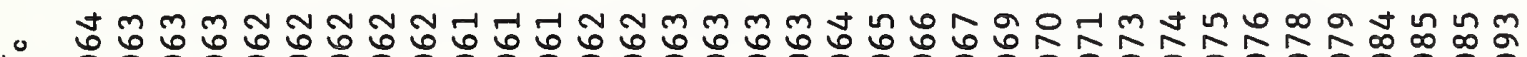
○

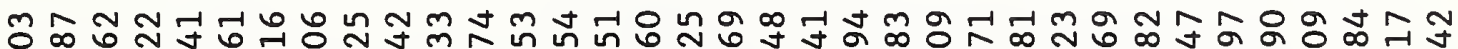
光

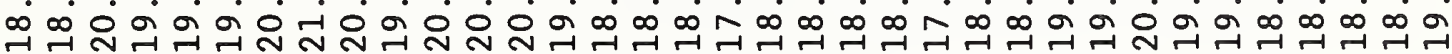

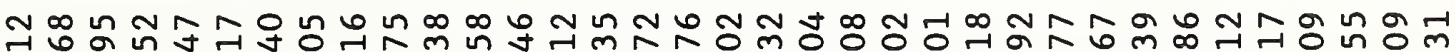
궁의

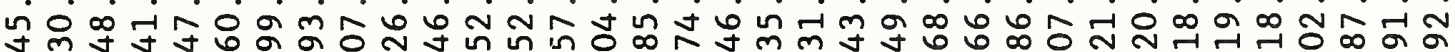

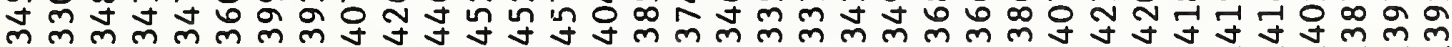
m 证윳ำ 


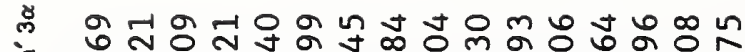

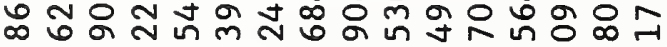

จ

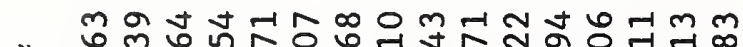

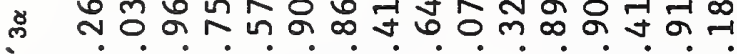
:

¿ ผ

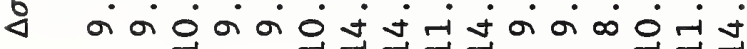

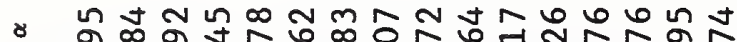
Nํํㅠำ

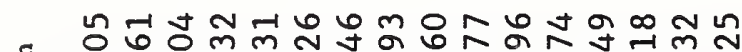

거

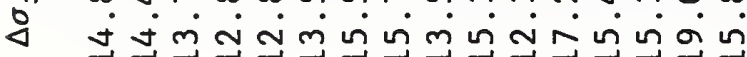

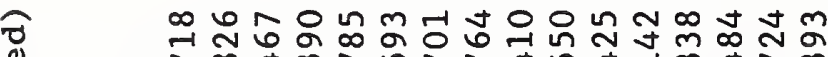

ร

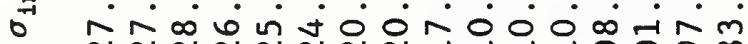

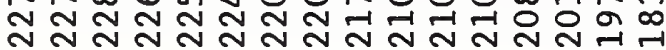

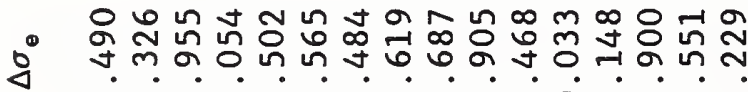

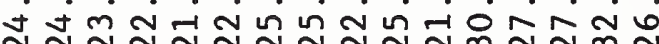
约ง

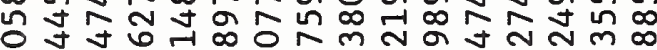

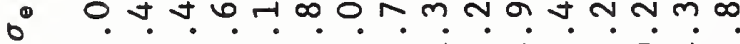
o $\sigma^{\circ}$ in 0 O न人ㅇํㅇㅇㅛ

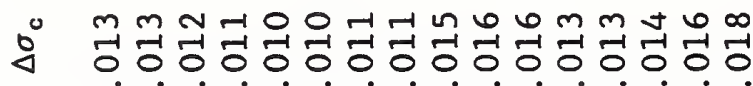

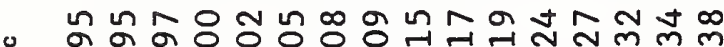

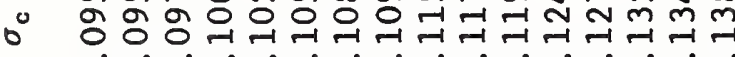

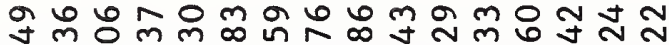

\&

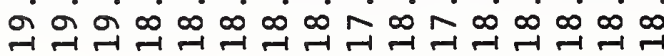

絃 สำ

Oे 寸

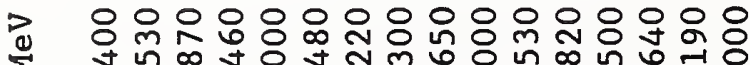

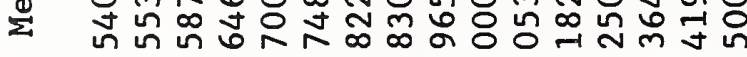

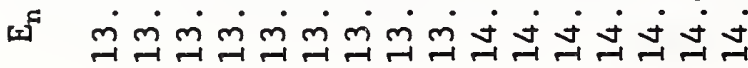




\section{Table $18 \mathrm{~b}$}

Average Correlation Matrix for Total and Partial Cross Sections from 10.05 to $14.5 \mathrm{MeV}$

$\begin{array}{llllll}\sigma_{\mathrm{t}} & 1.00 & & & & \\ \sigma_{\theta} & .502 & 1.000 & & & \\ \sigma_{\mathrm{in}} & .149 & -.342 & 1.000 & & \\ \sigma_{\mathrm{n}, \alpha_{0}} & .108 & -.229 & -.070 & 1.000 & \\ \sigma_{\mathrm{n}, \mathrm{n} \cdot 3 \alpha} & .197 & -.412 & -.126 & -.093 & 1.000\end{array}$




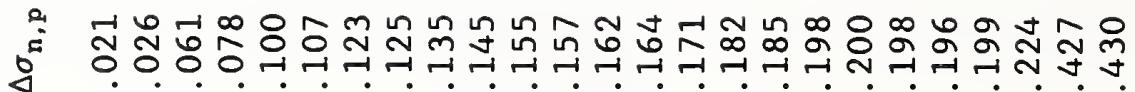

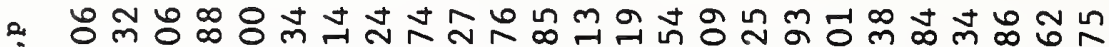
॰ ㄱำ

- $-A-H A N$

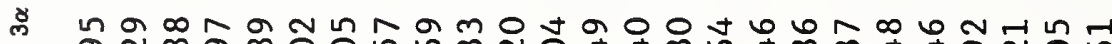

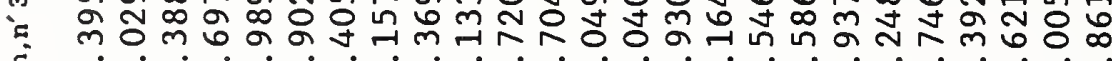

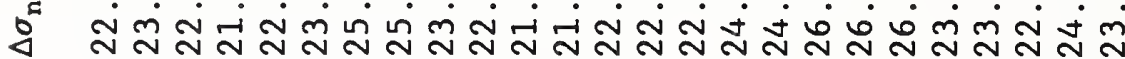

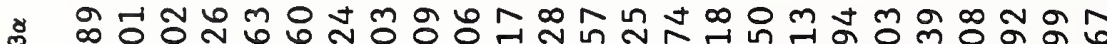
\% 엉ㅇㅇㅇㅝ

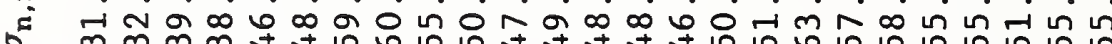
กิ సิ Nิ

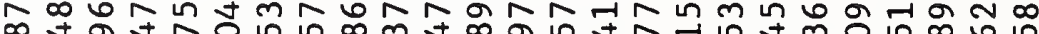

-

每. F F

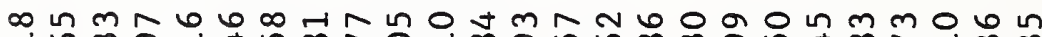

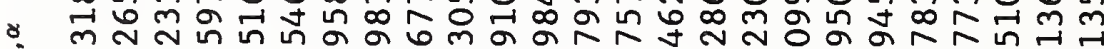

o ธิ

舟 ㄴำ \& ก

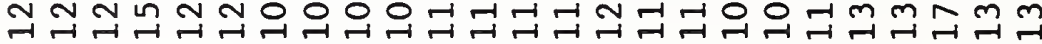
an $n \infty N \omega 0$ N

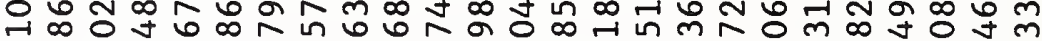

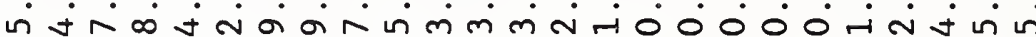

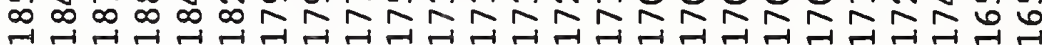

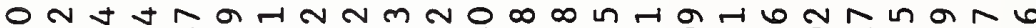

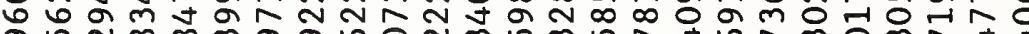
. . . . . . . . . . . . . ส้ สี un nm $m+\infty$ t $N N-t N \infty a m+m b$ t $m N N+N \infty$ न m०रू⿻

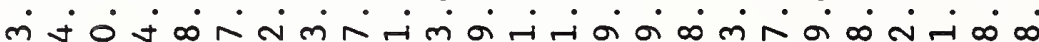

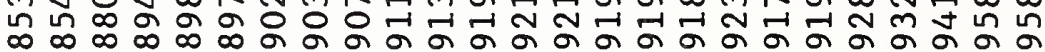

- $\quad \infty 6$ n $n$ n

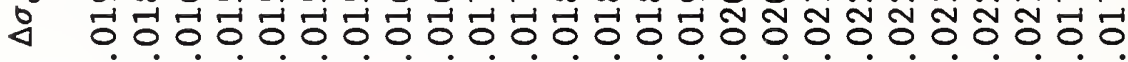

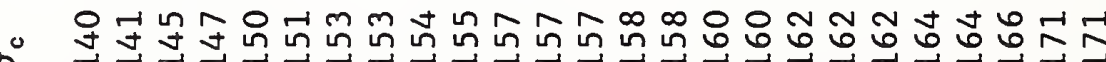

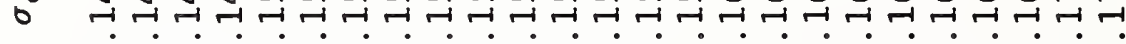

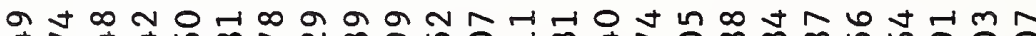
Џ

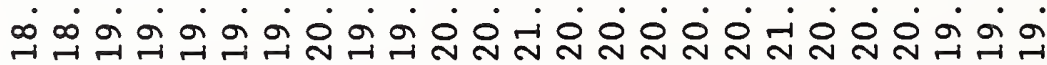

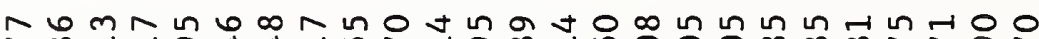
ษ

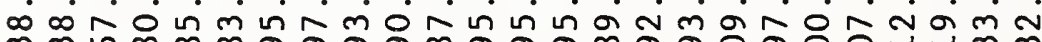

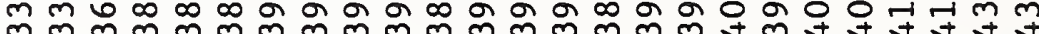

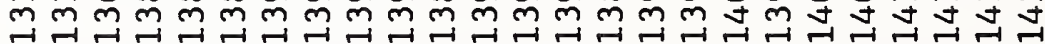

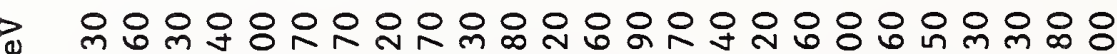

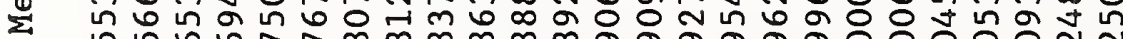
n un u

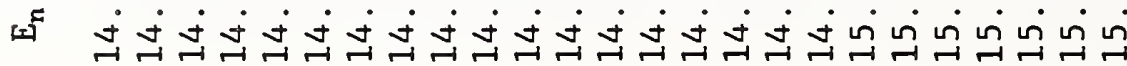


Average Correlation Matrix for Total and Partial Cross Sections from 14.553 to $15.25 \mathrm{MeV}$

$\begin{array}{lllllll}\sigma_{\mathrm{t}} & 1.000 & & & & \\ \sigma_{\theta} & .414 & 1.000 & & & & \\ \sigma_{\mathrm{in}} & .120 & -.220 & 1.000 & & & \\ \sigma_{\mathrm{n}, \alpha_{0}} & .058 & -.103 & -.031 & 1.000 & & \\ \sigma_{\mathrm{n}, \mathrm{n} \cdot 3 \alpha} & .323 & -.571 & -.168 & -.083 & 1.000 & \\ \sigma_{\mathrm{n}, \mathrm{p}} & .002 & -.003 & -.001 & .000 & -.002 & 1.000\end{array}$




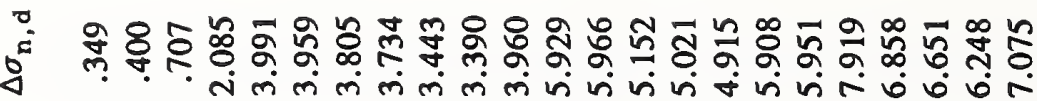

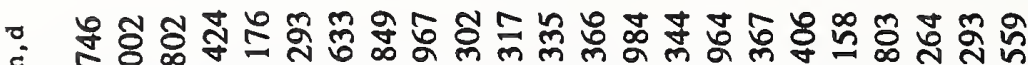
๑ ذ

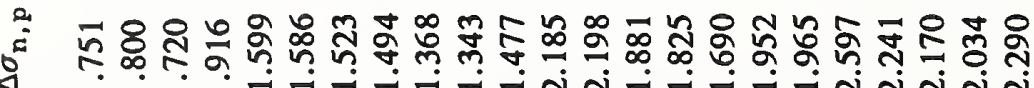

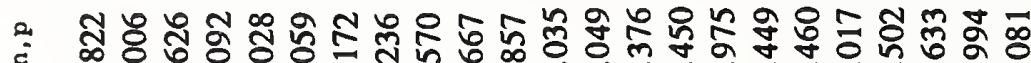

ல

8

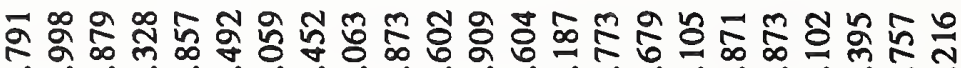

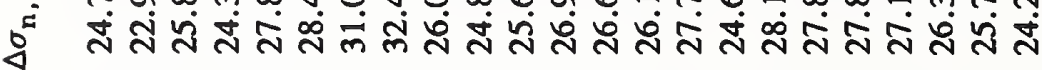

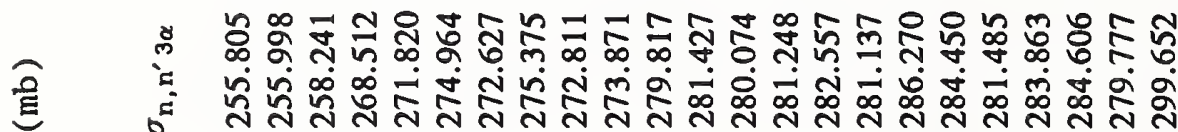

ซ ४

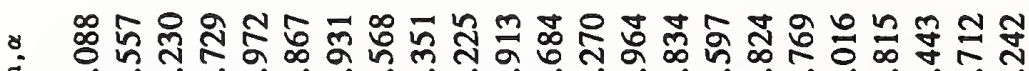

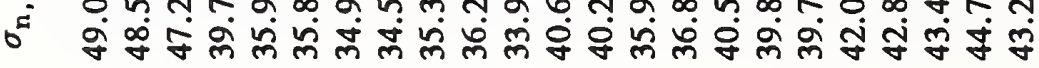

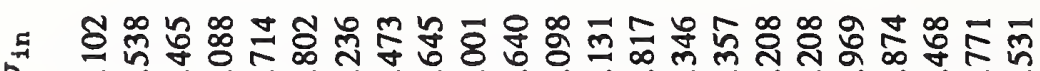

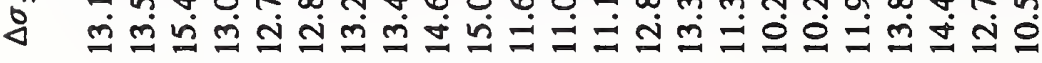

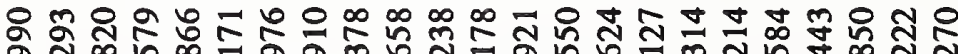
댕ำ

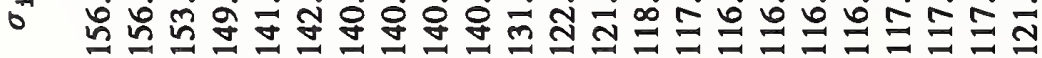

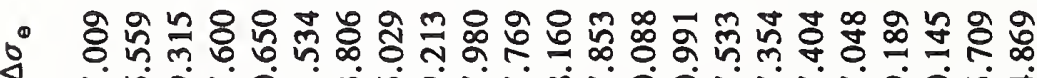

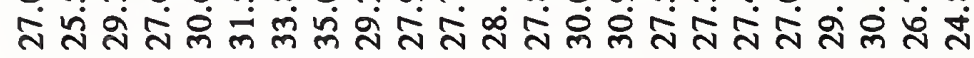

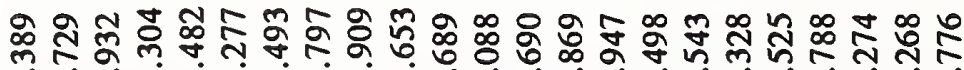

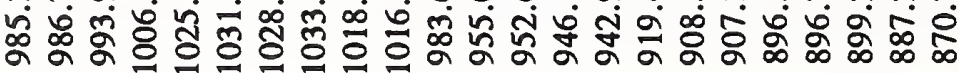

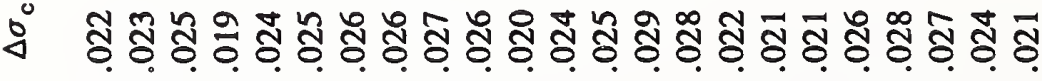

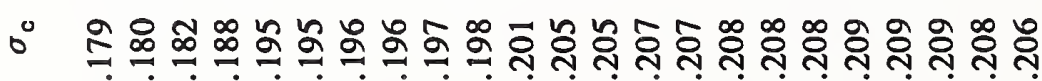

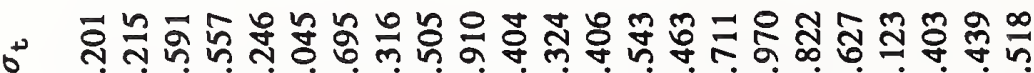

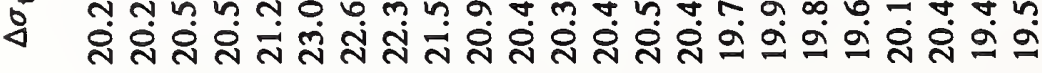

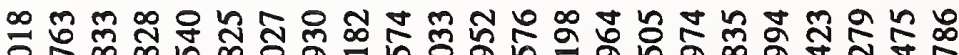

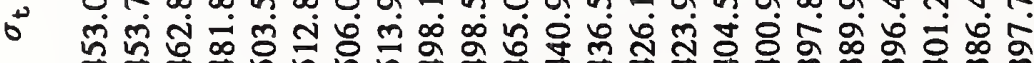

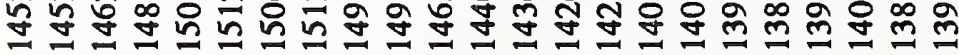

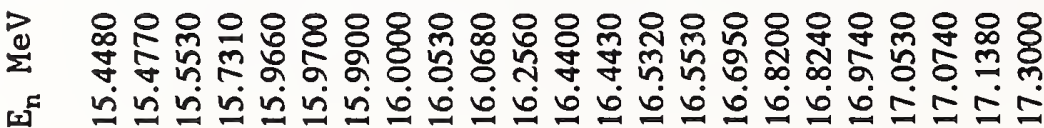


Table 20b

Average Correlation Matrix for Total and Partial Cross Sections from 15.448 to $17.3 \mathrm{MeV}$

$\begin{array}{lllllllll}\sigma_{\mathrm{t}} & 1.000 & & & & & & \\ \sigma_{\mathrm{c}} & .000 & 1.000 & & & & & & \\ \sigma_{\mathrm{e}} & .397 & .000 & 1.000 & & & & \\ \sigma_{\mathrm{in}} & .098 & .000 & -.221 & 1.000 & & & & \\ \sigma_{\mathrm{n}, \alpha_{0}} & .031 & .000 & -.070 & -.017 & 1.000 & & \\ \sigma_{\mathrm{n}, \mathrm{n} \cdot 3 \alpha} & .283 & .000 & -.634 & -.155 & -.050 & 1.000 & \\ \sigma_{\mathrm{n}, \mathrm{p}} & .012 & .000 & -.027 & -.007 & -.002 & -.020 & 1.000 \\ \sigma_{\mathrm{n}, \mathrm{d}} & .033 & .000 & -.073 & -.018 & -.006 & -.055 & -.003 & 1.000\end{array}$


Table 21a

Unified Cross Sections (mb)

\begin{tabular}{|c|c|c|c|c|c|c|c|c|c|}
\hline $\mathrm{E} \mathrm{MeV}$ & $\sigma_{\mathrm{t}}$ & $\sigma_{c}$ & $\sigma_{\theta}$ & $\sigma_{\text {in }}$ & $\sigma_{\mathrm{n}, \alpha}$ & $\sigma_{n, n}, 3 \alpha$ & $\sigma_{n, p}$ & $\sigma_{\mathrm{n}, \mathrm{d}}$ & $\sigma_{\mathrm{n}, \mathrm{n}}$ \\
\hline & 402.917 & 206 & & & 43.064 & 292.126 & 15.032 & & \\
\hline .4670 & 1396.497 & .205 & & 122.280 & 37.458 & 296.446 & 16.059 & 50.574 & .16 \\
\hline .5530 & 1404.788 & .204 & 880.400 & 123.190 & 34.206 & 297.302 & 16.656 & 52.586 & \\
\hline & 1411.090 & .203 & 887.324 & 121.548 & & & & & \\
\hline .6870 & 1411.154 & .202 & 889.699 & & & & & & \\
\hline & 1424.712 & .199 & & 108. & & & & & 1.22 \\
\hline & 1428.1 & .199 & 908 & 46 & & & & & 1.24 \\
\hline & 1436.929 & 197 & 917 & 104. & & & & & 3.07 \\
\hline & 1449.562 & .197 & 929.470 & 102. & & & & & 4.05 \\
\hline & 1441.627 & .196 & 923.358 & 102.375 & & & & & 4.67 \\
\hline 18.1580 & 1465.661 & .196 & 935.750 & & & & & & 5.99 \\
\hline 18.2730 & 1463.116 & .196 & 928 & 115. & & & & & 8.11 \\
\hline 8.4600 & 1454 & .195 & 922 & & & & & & 10.88 \\
\hline & 146 & .195 & & & & & & & \\
\hline & 148 & .19 & & & & & & & 12.70 \\
\hline & 1484 & .196 & 952 & & & & & & 13.42 \\
\hline & 1481.603 & .196 & 956 & & & & & & 14.80 \\
\hline & 1482.226 & 197 & 971. & & & & & & 16.66 \\
\hline 19.0340 & 1496.544 & .197 & 982.8 & & & & & & 16.72 \\
\hline 19.0530 & 1496.541 & .19 & 984. & & & & & & 16.90 \\
\hline 50 & 1506 & .200 & 997 & & & & & & 18.13 \\
\hline & 152 & .203 & & & & & & & 19.64 \\
\hline & 154 & .206 & & & & & & & 21.31 \\
\hline & 155 & .207 & 103 & & & & & & 21.75 \\
\hline 19.6600 & 1556.761 & .208 & 1037.082 & & & & & & 22.83 \\
\hline 19.6610 & 1562.423 & .208 & 1041.642 & 87.9 & & .744 & 14 & & 22.86 \\
\hline 19.7940 & 1539.361 & .209 & 1023.968 & & & & & & 24.11 \\
\hline 19.8 & 1534 & .210 & 1022.950 & & & & & & 25.11 \\
\hline & 153 & 21 & 1008. & & & & & & 26.35 \\
\hline & 1518 & 211 & & & & & & & 27.48 \\
\hline 20.2000 & & .211 & & & & & & & 28.68 \\
\hline 20.3000 & 1500.749 & .211 & 983.887 & 92.478 & 32.983 & 299.603 & 12.041 & 49.734 & 29.81 \\
\hline 60.4000 & & .21 & & & & & 11.722 & 48.661 & 30.73 \\
\hline 20.5000 & 1483.957 & .211 & 970.789 & 94.026 & 28.119 & 300.128 & 11.406 & 47.628 & 31.65 \\
\hline
\end{tabular}


Table 21a (Continued)

Unified Uncertainties (mb)

\begin{tabular}{|c|c|c|c|c|c|c|c|c|c|}
\hline $\mathrm{E} \mathrm{MeV}$ & $\Delta \sigma_{\mathrm{t}}$ & $\Delta \sigma_{c}$ & $\Delta \sigma_{e}$ & $\Delta \sigma_{\text {in }}$ & $\Delta \sigma_{n, \alpha}$ & $\Delta \sigma_{n, n} \cdot 3 \alpha$ & $\Delta \sigma_{\mathrm{n}, \mathrm{p}}$ & $\Delta \sigma_{\mathrm{n}, \mathrm{d}}$ & $\Delta \sigma_{n, n p}$ \\
\hline 17.3010 & 20.97 & .04 & 43.92 & 15.02 & 5.60 & 38.44 & 3.00 & 9.29 & .00 \\
\hline 17.4670 & 20.78 & .04 & 43.90 & 15.20 & 5.24 & 38.56 & 3.20 & 9.95 & .05 \\
\hline 17.5530 & 21.09 & .04 & 44.22 & 15.30 & 4.79 & 38.75 & 3.32 & 10.34 & .07 \\
\hline 17.6160 & 21.23 & .04 & 44.39 & 15.17 & 4.61 & 38.87 & 3.40 & 10.63 & .09 \\
\hline 17.6870 & 21.73 & .04 & 44.69 & 14.91 & 4.89 & 39.02 & 3.50 & 10.95 & .13 \\
\hline 17.9000 & 21.76 & .04 & 45.14 & 14.13 & 4.76 & 39.42 & 3.80 & 11.91 & .37 \\
\hline 17.9010 & 21.57 & .04 & 45.09 & 14.13 & 4.75 & 39.42 & 3.80 & 11.92 & .37 \\
\hline 18.0000 & 21.58 & .04 & 45.26 & 13.77 & 4.18 & 39.61 & 3.80 & 12.26 & .92 \\
\hline 18.0530 & 22.09 & .04 & 45.49 & 13.57 & 3.94 & 39.70 & 3.80 & 12.45 & 1.21 \\
\hline 18.0870 & 21.86 & .04 & 45.64 & 14.41 & 3.78 & 39.76 & 3.80 & 12.57 & 1.40 \\
\hline 18.1580 & 21.93 & .04 & 47.06 & 20.26 & 3.46 & 39.96 & 3.80 & 12.82 & 1.79 \\
\hline 18.2730 & 21.75 & .04 & 47.64 & 22.09 & 2.93 & 40.13 & 3.80 & 13.23 & 2.43 \\
\hline 18.4600 & 21.64 & .04 & 47.19 & 18.10 & 2.53 & 40.40 & 3.80 & 13.88 & 3.26 \\
\hline 18.5530 & 22.00 & .04 & 47.00 & 16.07 & 2.52 & 40.50 & 3.77 & 13.82 & 3.55 \\
\hline 18.6320 & 22.28 & .04 & 47.04 & 15.20 & 3.21 & 40.58 & 3.74 & 13.77 & 3.80 \\
\hline 18.7000 & 22.21 & .04 & 47.06 & 14.87 & 3.45 & 40.65 & 3.71 & 13.72 & 4.01 \\
\hline 18.8330 & 22.02 & .04 & 47.10 & 14.23 & 3.56 & 40.81 & 3.67 & 13.63 & 4.43 \\
\hline 19.0300 & 22.22 & .04 & 47.43 & 13.28 & 4.41 & 41.09 & 3.60 & 13.50 & 4.99 \\
\hline 19.0340 & 23.51 & .04 & 47.82 & 13.26 & 4.40 & 41.12 & 3.60 & 13.50 & 5.00 \\
\hline 19.0530 & 22.57 & .04 & 47.54 & 13.16 & 4.35 & 41.12 & 3.57 & 13.44 & 5.06 \\
\hline 19.1850 & 22.45 & .04 & 47.69 & 12.80 & 5.42 & 41.27 & 3.41 & 13.01 & 5.43 \\
\hline 19.3460 & 22.72 & .04 & 48.01 & 12.48 & 6.23 & 41.48 & 3.21 & 12.48 & 5.88 \\
\hline 19.5110 & 23.20 & .04 & 48.33 & 12.16 & 7.50 & 41.61 & 3.00 & 11.94 & 6.37 \\
\hline 19.5530 & 23.45 & .04 & 48.46 & 12.08 & 8.21 & 41.62 & 2.97 & 11.82 & 6.50 \\
\hline 19.6600 & 23.77 & .04 & 48.72 & 11.86 & 10.02 & 41.64 & 2.88 & 11.52 & 6.83 \\
\hline 19.6610 & 23.56 & .04 & 48.65 & 11.86 & 10.04 & 41.63 & 2.88 & 11.51 & 6.83 \\
\hline 19.7940 & 23.04 & .04 & 48.69 & 11.60 & 11.64 & 41.66 & 2.77 & 11.14 & 7.23 \\
\hline 19.8920 & 23.06 & .04 & 49.17 & 11.41 & 12.46 & 41.88 & 2.69 & 10.86 & 7.53 \\
\hline 20.0000 & 23.46 & .04 & 51.07 & 11.21 & 9.63 & 43.10 & 2.60 & 10.57 & 7.91 \\
\hline 20.1000 & 31.92 & .04 & 56.00 & 11.02 & 8.91 & 44.75 & 2.54 & 10.37 & 8.26 \\
\hline 20.2000 & 31.95 & .04 & 57.00 & 10.82 & 10.01 & 46.04 & 2.47 & 10.15 & 8.60 \\
\hline 20.3000 & 31.57 & .04 & 57.76 & 10.62 & 10.67 & 47.30 & 2.41 & 9.94 & 8.95 \\
\hline 20.4000 & 31.30 & .04 & 58.46 & 10.42 & 10.63 & 48.54 & 2.35 & 9.73 & 9.22 \\
\hline 20.5000 & 31.24 & .04 & 59.23 & 10.22 & 10.36 & 49.77 & 2.28 & 9.52 & 9.49 \\
\hline
\end{tabular}


Table 21b

Average Correlation Matrix of Total and Partial Cross Sections from 17.301 to $20.5 \mathrm{MeV}$

\begin{tabular}{|c|c|c|c|c|c|c|c|c|}
\hline$\sigma_{t}$ & 1.00 & & & & & & & \\
\hline$\sigma_{\mathrm{c}}$ & .00 & 1.00 & & & & & & \\
\hline$\sigma_{\theta}$ & .39 & .00 & 1.00 & & & & & \\
\hline$\sigma_{i n}$ & .03 & .00 & -.22 & 1.00 & & & & \\
\hline$\sigma_{\mathrm{n}, \alpha}$ & .01 & .00 & -.10 & -.01 & 1.00 & & & \\
\hline$\sigma_{n, n}, 3 \alpha$ & .09 & .00 & -.78 & -.06 & -.02 & 1.00 & & \\
\hline$\sigma_{\mathrm{n}, \mathrm{p}}$ & .01 & .00 & -.05 & .00 & .00 & -.01 & 1.00 & \\
\hline$\sigma_{\mathrm{n}, \mathrm{d}}$ & .02 & .00 & -.19 & -.01 & -.01 & -.05 & .00 & 1.00 \\
\hline$\sigma_{n, n p}$ & .01 & .00 & -.07 & .00 & .00 & -.01 & .00 & .00 \\
\hline
\end{tabular}




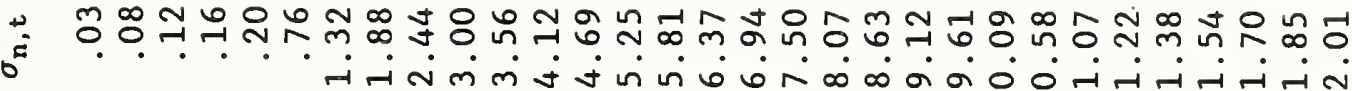
게

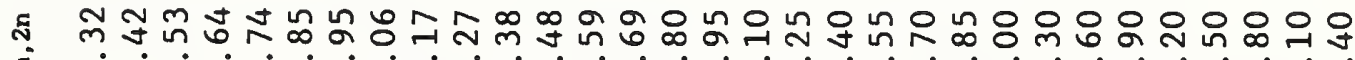
$0^{5}$

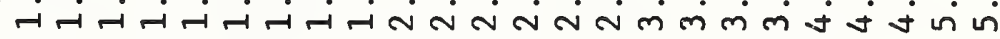

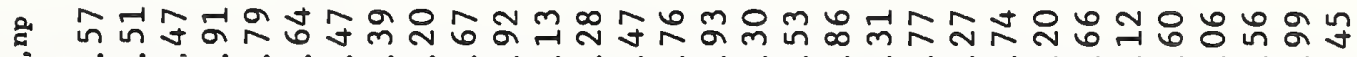

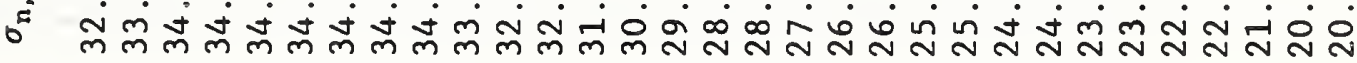

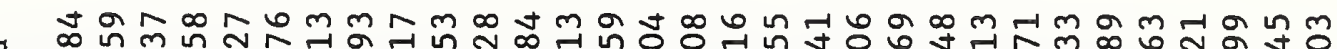

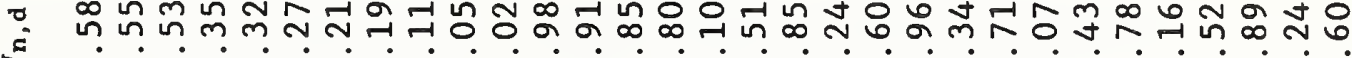

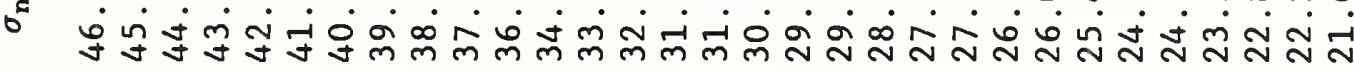

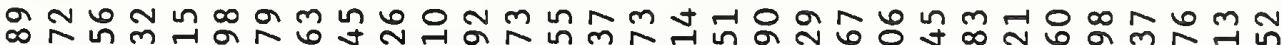

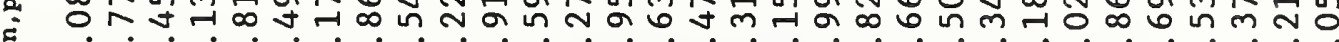

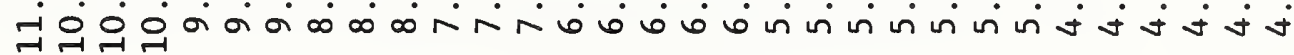

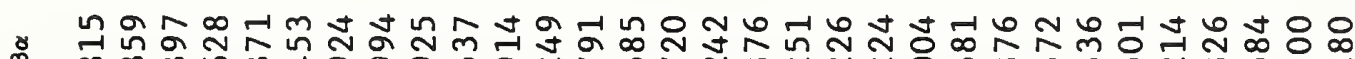
m ○

이의 - I

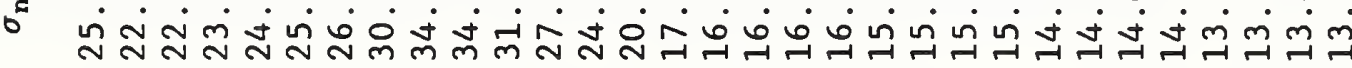

억ㄱำ

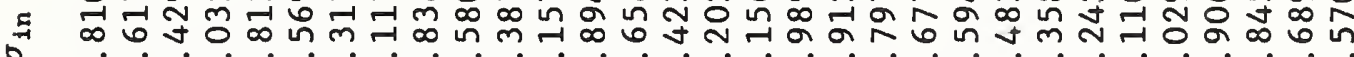
बें

ㄴำ $\sim$ 의 in 오의

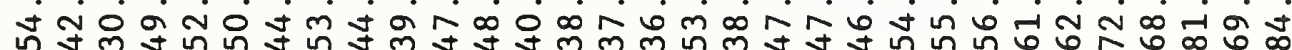

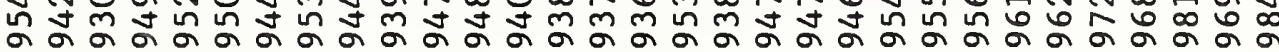

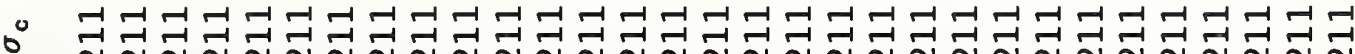

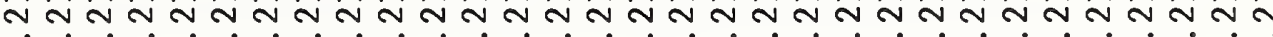

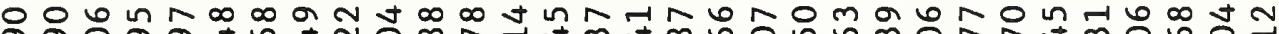
긍ㅇำ

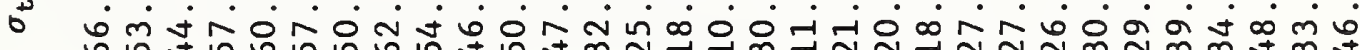
in

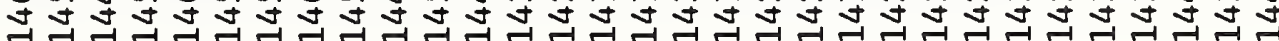

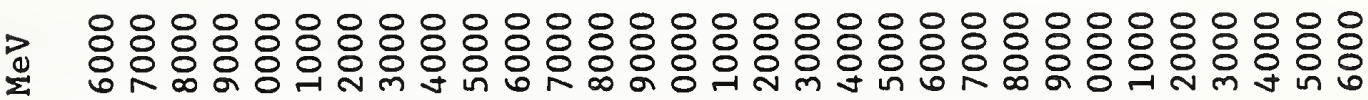

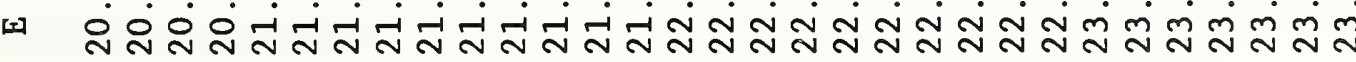




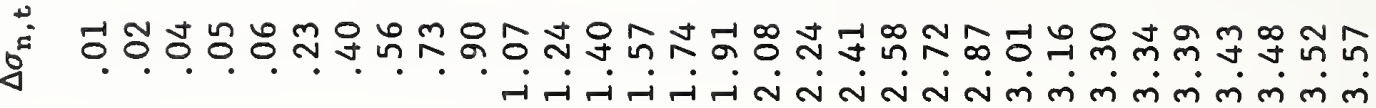

$\stackrel{\substack{5 \\ \hdashline}}{\square}$

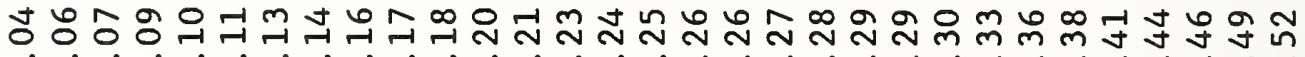

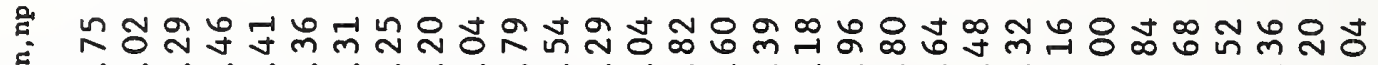

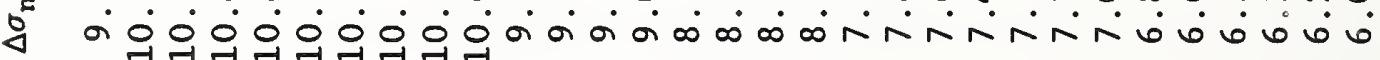

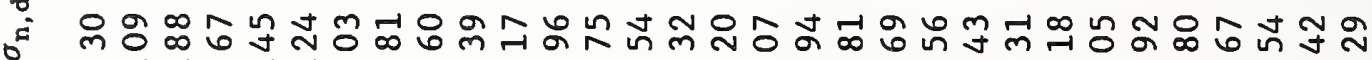

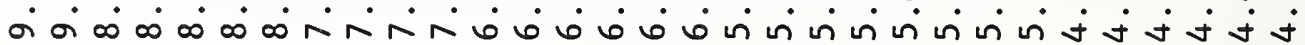

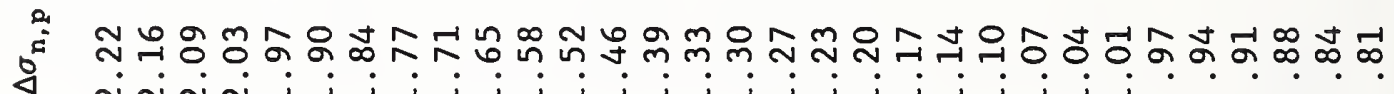

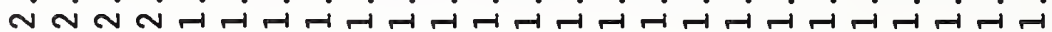

a $m$ m

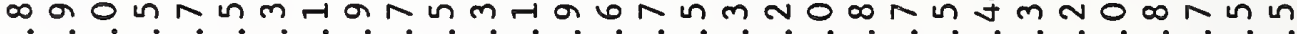

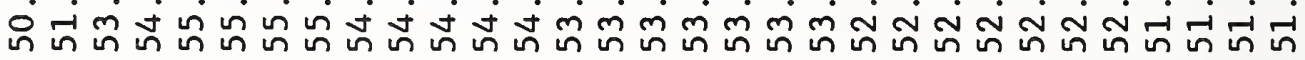

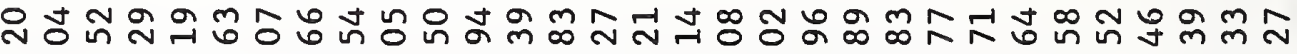

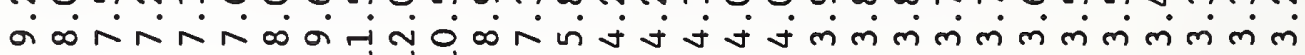

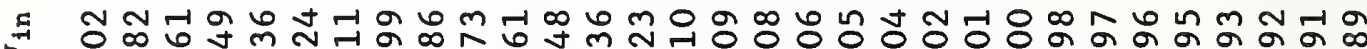

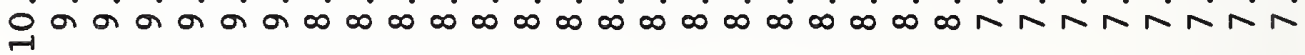

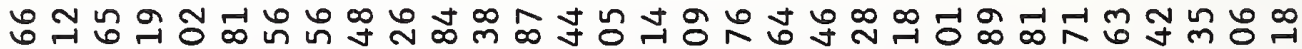

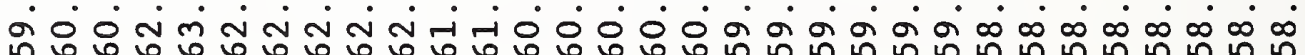

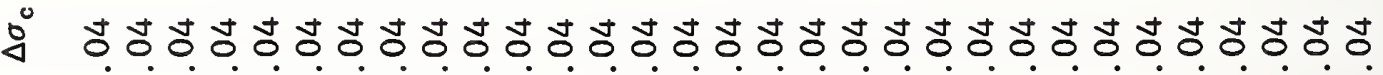

कm $\infty$. ง

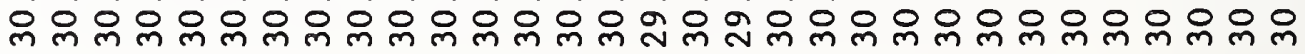


Average Correlation Matrix of Total and Partial Cross Sections from 20.6 to $23.6 \mathrm{MeV}$

\begin{tabular}{|c|c|c|c|c|c|c|c|c|c|c|}
\hline$\sigma_{t}$ & 1.00 & & & & & & & & & \\
\hline$\sigma_{c}$ & .00 & 1.00 & & & & & & & & \\
\hline$\sigma_{\mathrm{e}}$ & .42 & .00 & 1.00 & & & & & & & \\
\hline$\sigma_{\text {in }}$ & .01 & .00 & -.11 & 1.00 & & & & & & \\
\hline$\sigma_{n, \alpha}$ & .01 & .00 & -.08 & .00 & 1.00 & & & & & \\
\hline$\sigma_{\mathrm{n}, \mathrm{n}} \cdot 3 \alpha$ & .09 & .00 & -.83 & -.02 & -.02 & 1.00 & & & & \\
\hline$\sigma_{\mathrm{n}, \mathrm{p}}$ & .00 & .00 & -.02 & .00 & .00 & .00 & 1.00 & & & \\
\hline$\sigma_{\mathrm{n}, \mathrm{d}}$ & .01 & .00 & -.09 & .00 & .00 & -.02 & .00 & 1.00 & & \\
\hline$\sigma_{\mathrm{n}, \mathrm{np}}$ & .01 & .00 & -.11 & .00 & .00 & -.02 & .00 & .00 & 1.00 & \\
\hline$\sigma_{n, n 2 n}$ & .00 & .00 & .00 & .00 & .00 & .00 & .00 & .00 & .00 & 1.00 \\
\hline$\sigma_{\mathrm{n}, \mathrm{t}}$ & .00 & .00 & -.02 & .00 & .00 & -.01 & .00 & .00 & .00 & .00 \\
\hline
\end{tabular}




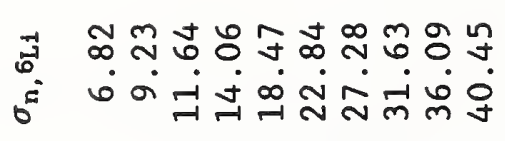

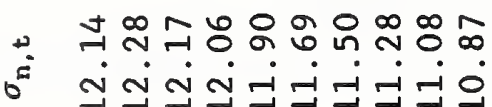

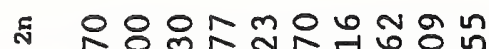

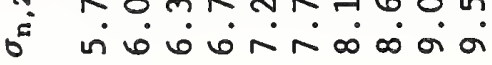

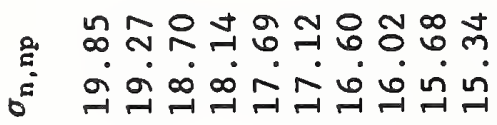

nงtato n

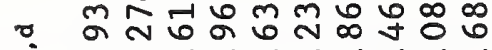
o $\dot{0} \dot{0} \dot{0} \infty \dot{\infty} \dot{0} \dot{0}$

\section{.}

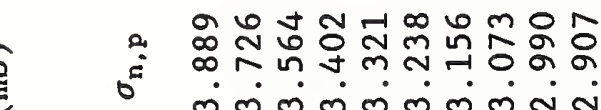

ด

$\underset{\sim}{\infty}$

D.

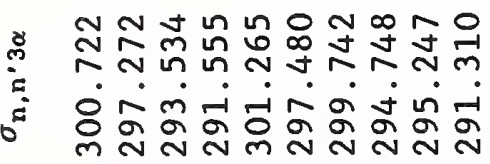

N"⿻

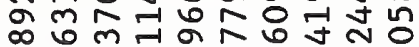

ช क om

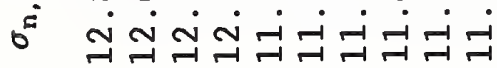

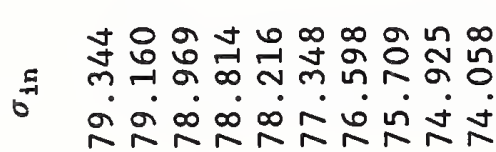

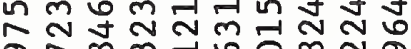
नू $\infty$ ल

- ம்ín்

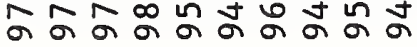

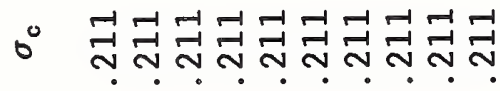

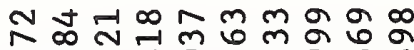

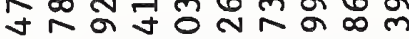

○

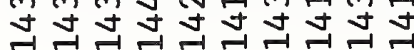

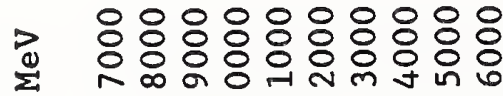

a

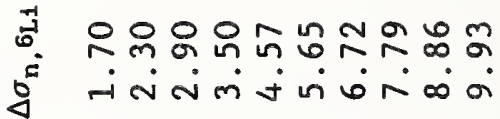

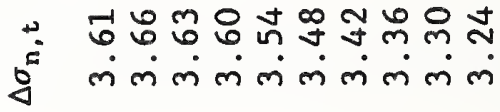

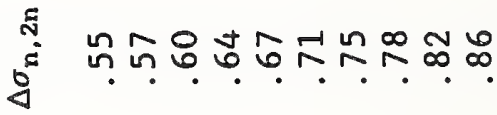

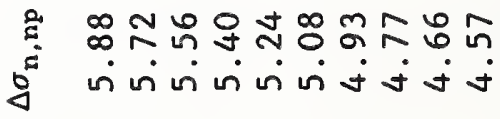

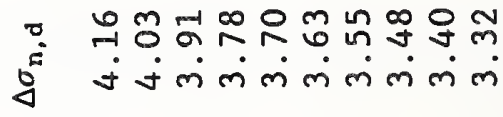

है

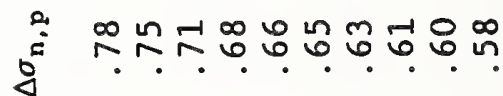

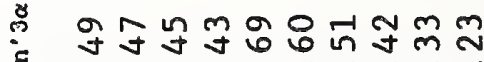

$=$ - $\dot{1} \dot{-1} \dot{0} \dot{0} \dot{0}$

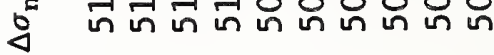

ㅇำㅇำ

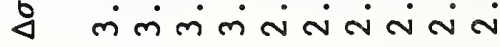
d

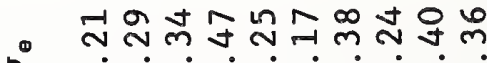

马 $\square_{0}^{\infty} \infty \infty^{\infty} \infty$ in

$b_{0}$

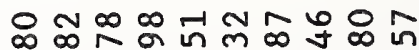

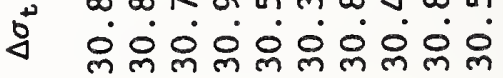

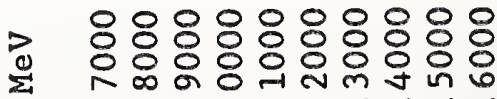

س 
Average Correlation Matrix of Total and Partial Cross Sections from 23.7 to $24.6 \mathrm{MeV}$

\begin{tabular}{|c|c|c|c|c|c|c|c|c|c|c|c|}
\hline$\sigma_{t}$ & 1.00 & & & & & & & & & & \\
\hline$\sigma_{c}$ & .00 & 1.00 & & & & & & & & & \\
\hline$\sigma_{e}$ & .44 & .00 & 1.00 & & & & & & & & \\
\hline$\sigma_{\text {in }}$ & .01 & .00 & -.11 & 1.00 & & & & & & & \\
\hline$\sigma_{n, \alpha}$ & .00 & .00 & -.04 & .00 & 1.00 & & & & & & \\
\hline$\sigma_{n, n} \cdot 3 \alpha$ & .09 & .00 & -.82 & -.02 & -.01 & 1.00 & & & & & \\
\hline$\sigma_{\mathrm{n}, \mathrm{p}}$ & .00 & .00 & -.01 & .00 & .00 & .00 & 1.00 & & & & \\
\hline$\sigma_{\mathrm{n}, \mathrm{d}}$ & .01 & .00 & -.05 & .00 & .00 & -.01 & .00 & 1.00 & & & \\
\hline$\sigma_{n, n p}$ & .01 & .00 & -.07 & .00 & .00 & -.02 & .00 & .00 & 1.00 & & \\
\hline$\sigma_{n, 2 n}$ & .00 & .00 & -.01 & .00 & .00 & .00 & .00 & .00 & .00 & 1.00 & \\
\hline$\sigma_{\mathrm{n}, \mathrm{d} \alpha}$ & .01 & .00 & -.05 & .00 & .00 & -.01 & .00 & .00 & .00 & .00 & 1.00 \\
\hline$\sigma_{\mathrm{n}, \mathrm{p} \alpha}$ & .01 & .00 & -.07 & .00 & .00 & -.02 & .00 & .00 & .00 & .00 & .00 \\
\hline
\end{tabular}




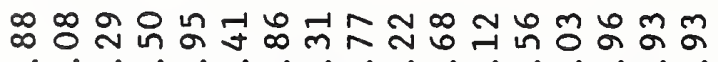

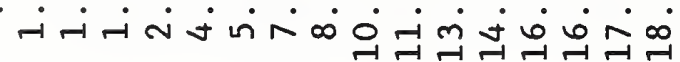

굽

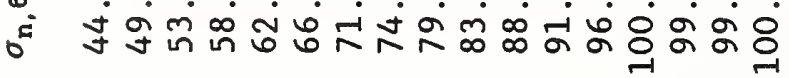

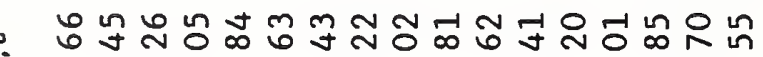

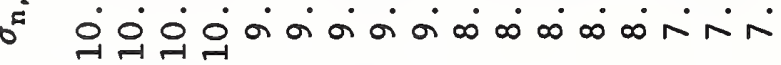

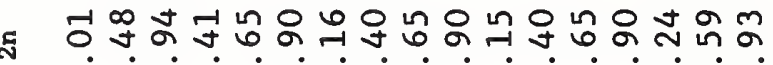
b

궁ำ o

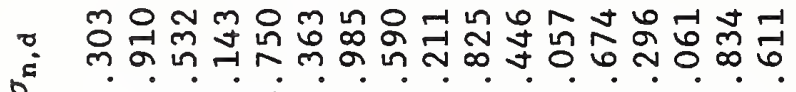
붐

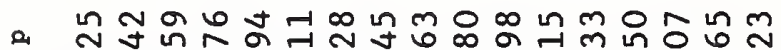

=

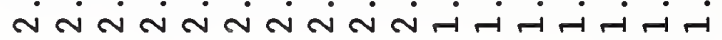

o anñกn กิ สิด ดั

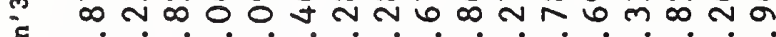

$\infty \infty \infty \infty \infty N+N)$

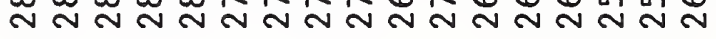

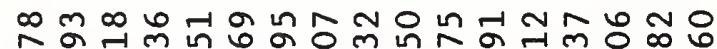

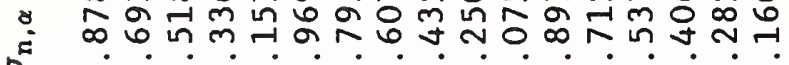
0응 0 i

ติ-

సิ

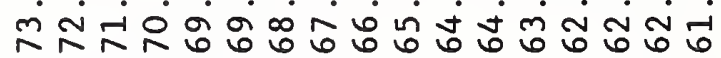

o

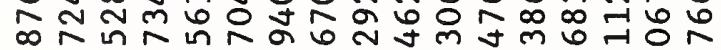
In jo in í

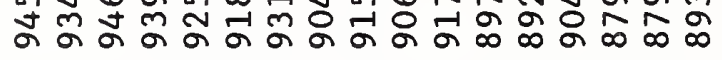

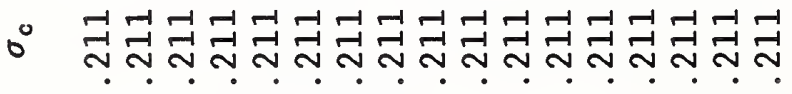

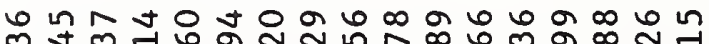
กัง ติ

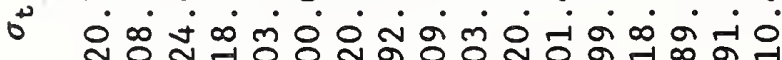

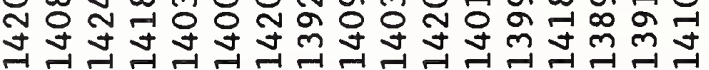

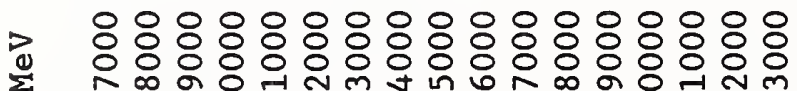

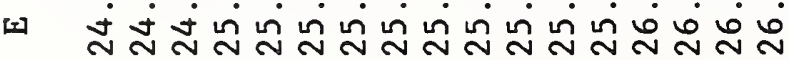




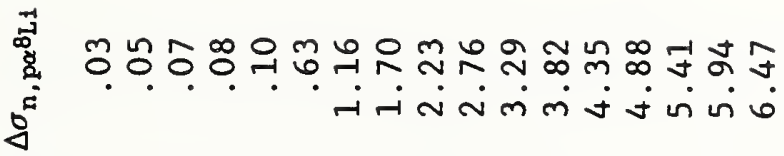

竎 ำ 8

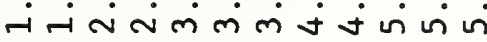

공 g

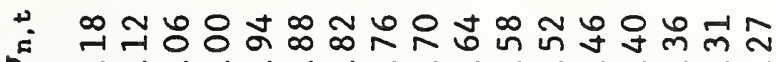

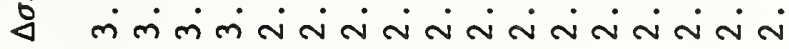

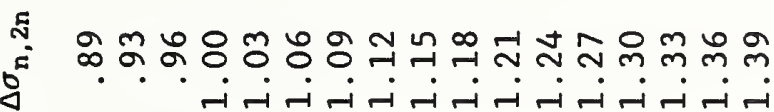

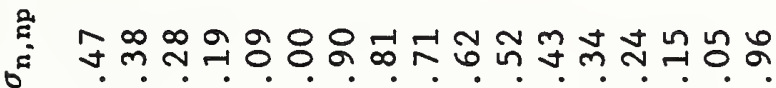
ப $\dot{j} \dot{j} \dot{j} \dot{j} \dot{j} \dot{m} \dot{m} \dot{m} \dot{m} \dot{m} \dot{\sim}$

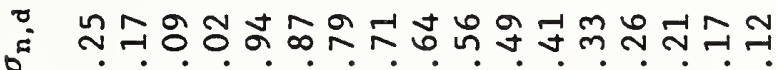

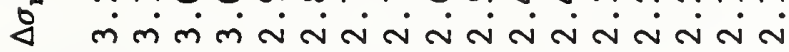

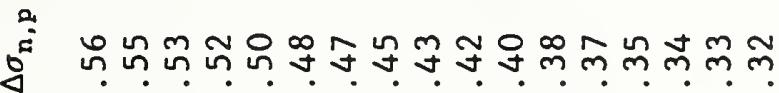

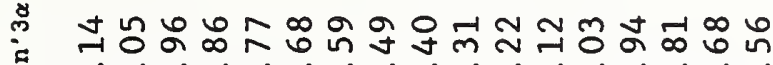

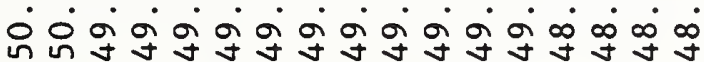

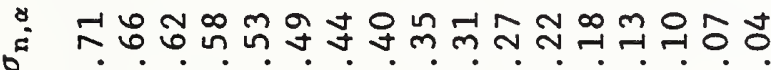

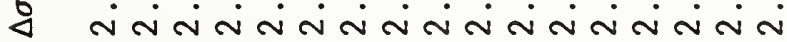

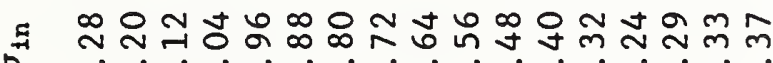
-

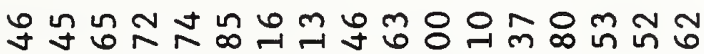

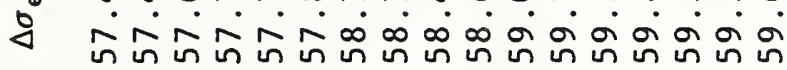

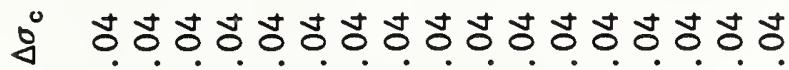

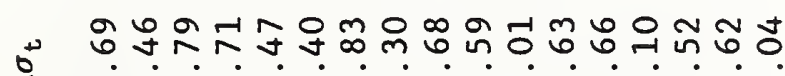

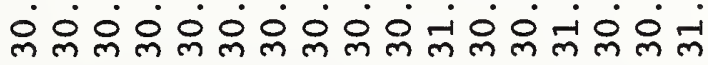

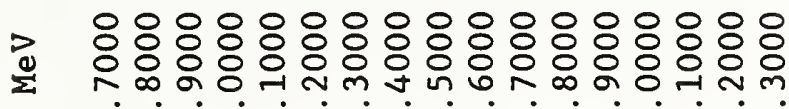

m 

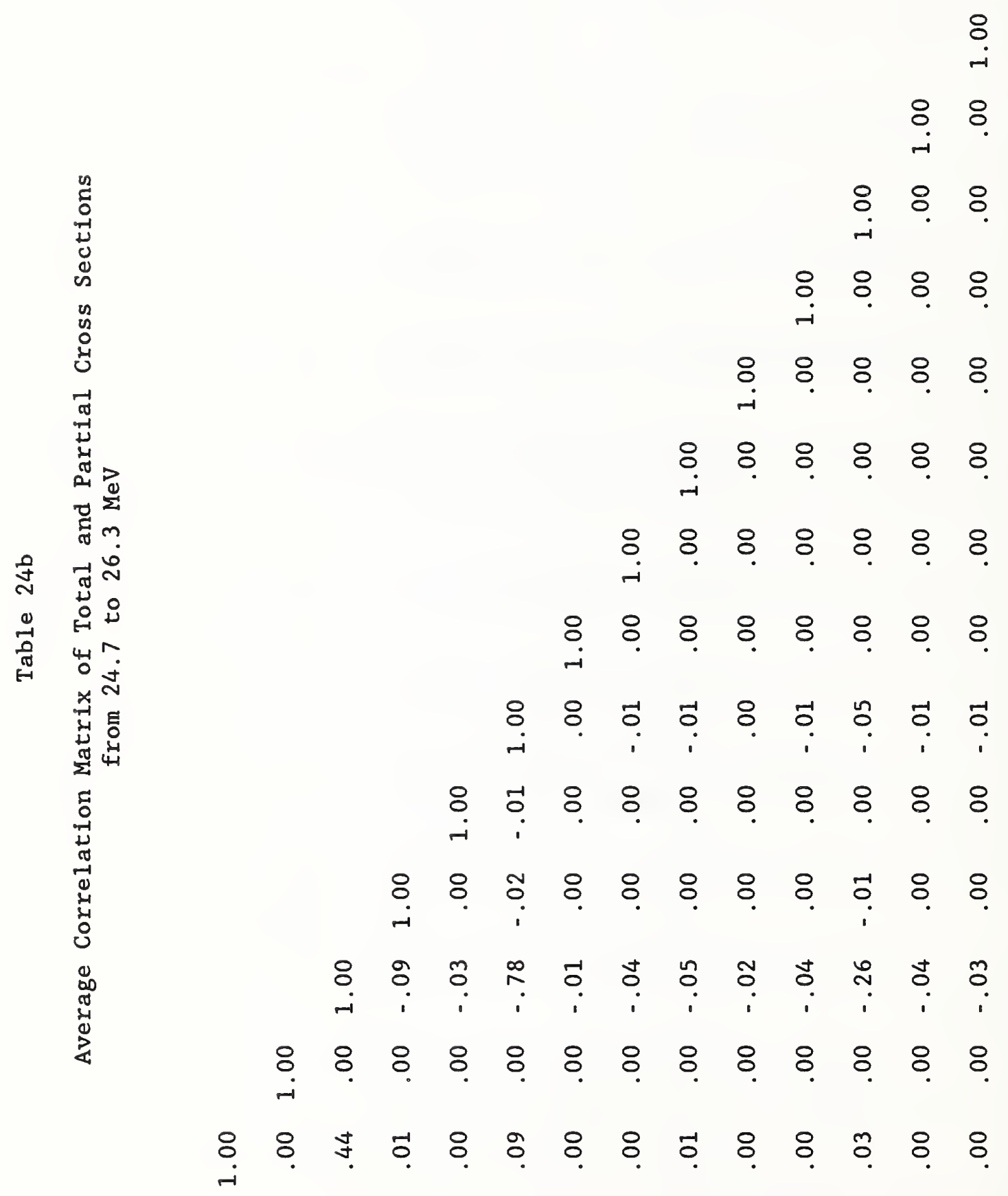

$\therefore$ 
ঋ ه

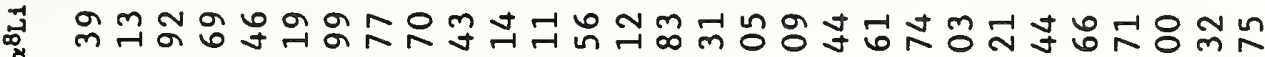
के $\dot{0} \dot{0} \dot{0} \dot{0} \dot{0} \dot{0} \dot{0} \dot{0}$ ธ

공ำ - ó

ำ -

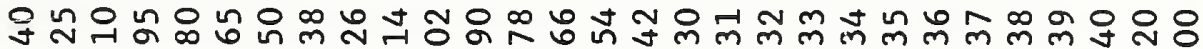
o r r م

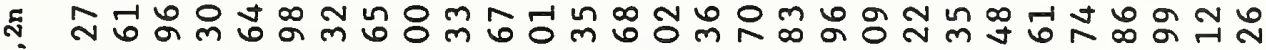

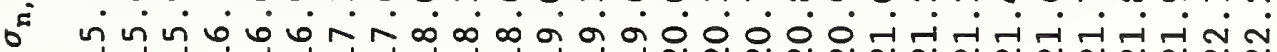

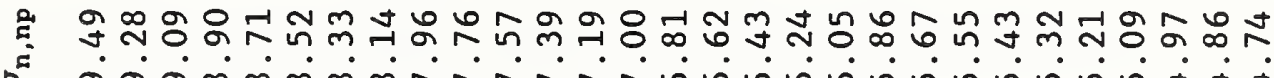

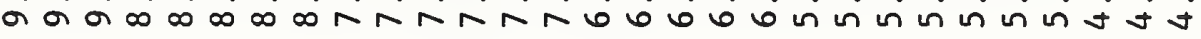
․

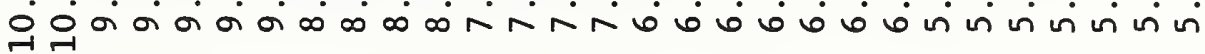

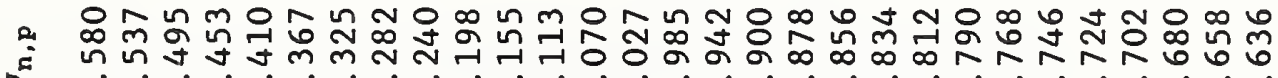

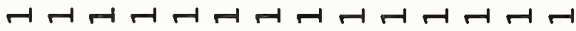

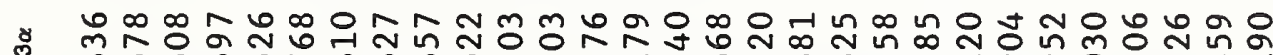
m n Un - Ñ்

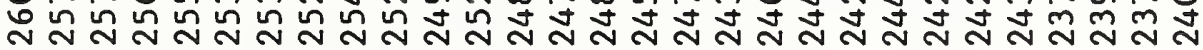

ช రొ

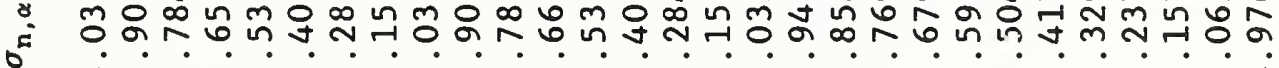

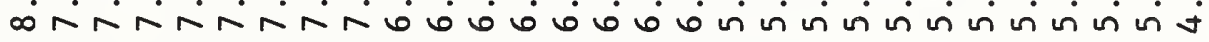

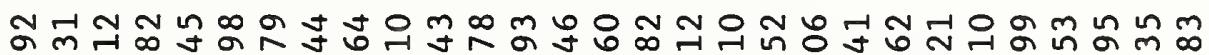
in $m$ r எஎ -

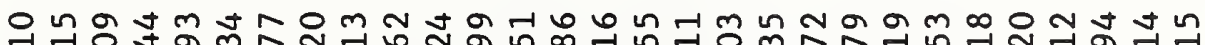

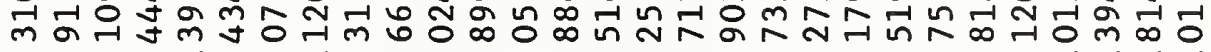
ח న

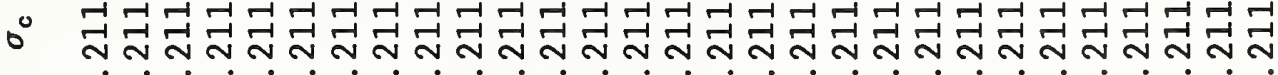

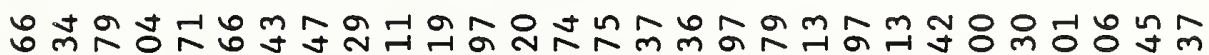

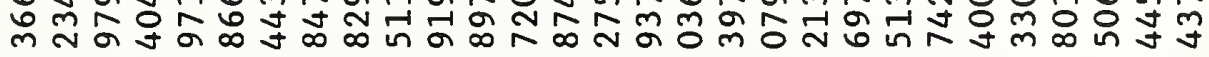

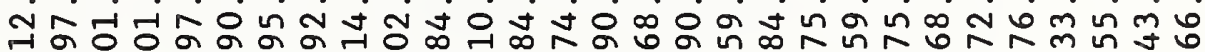
声华青 u n

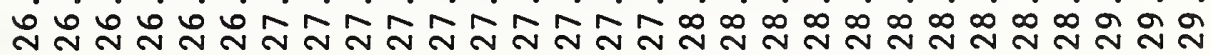




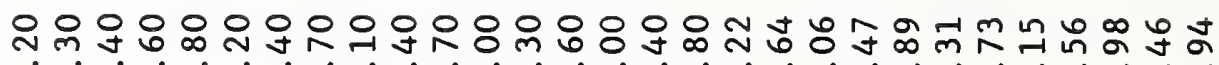
话

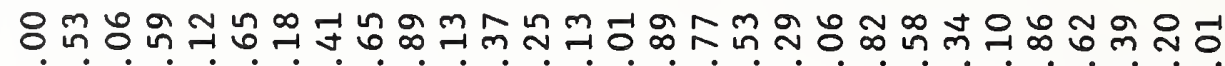

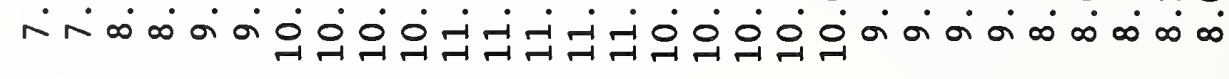

ตำง ن

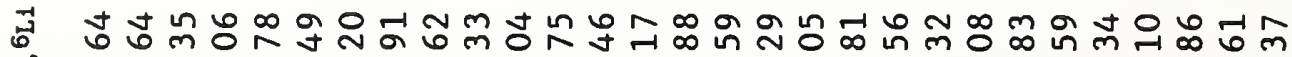

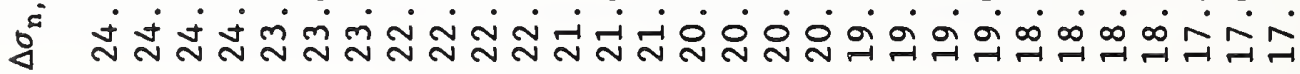

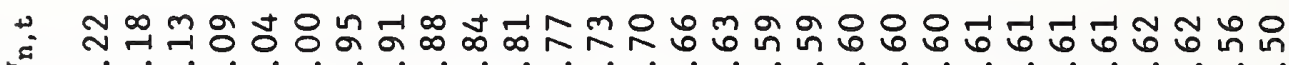

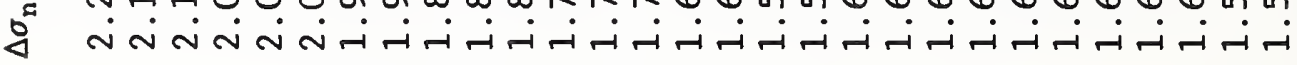

งี ㄱำำ

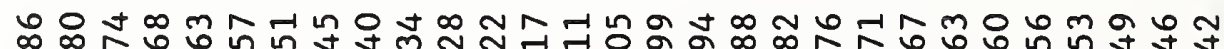

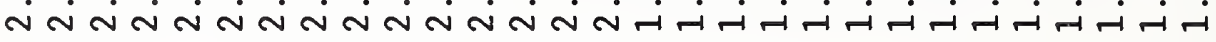

$\infty m$ ต

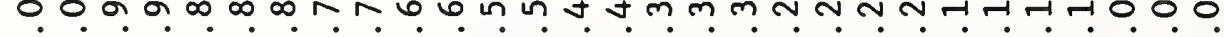
N ำ

मे mont-

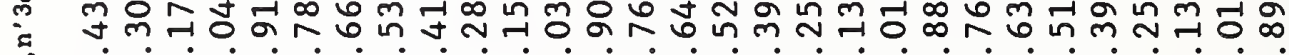
¿

- 개의

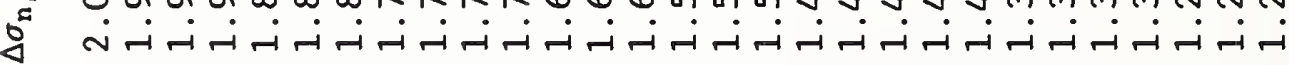

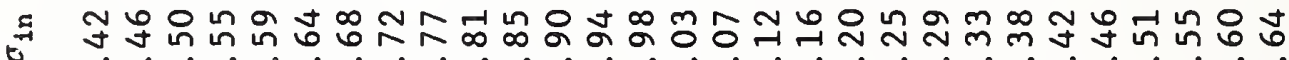
\&

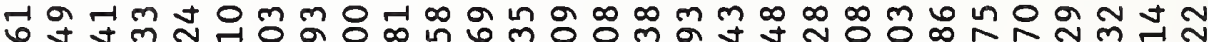

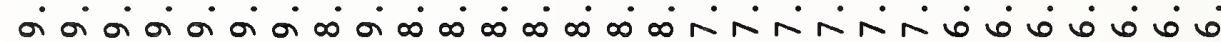

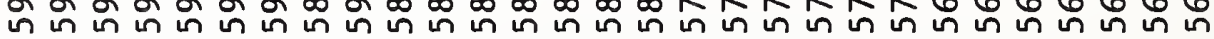

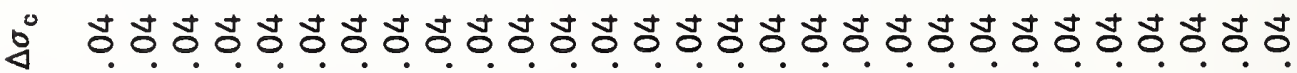

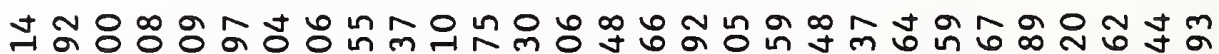

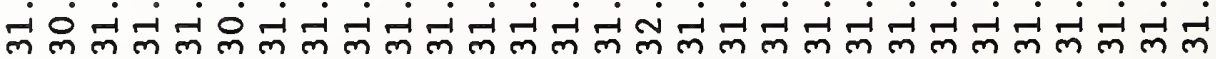




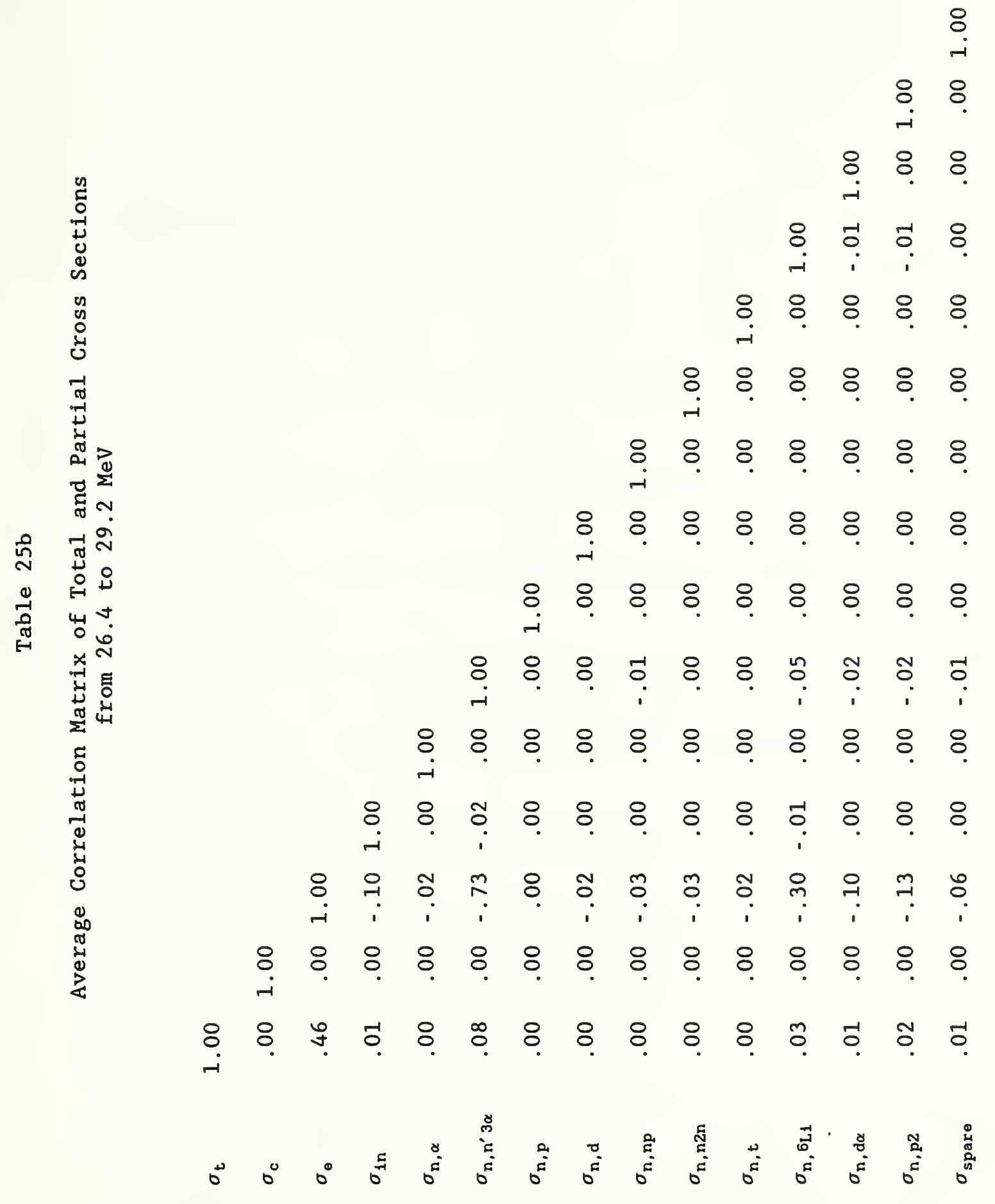


แ

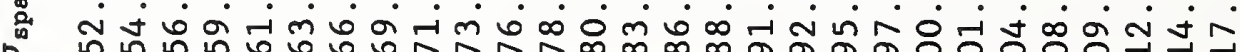

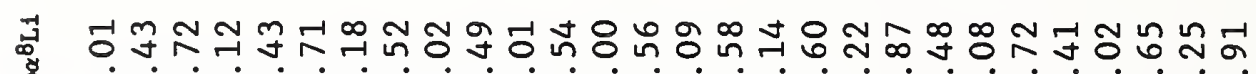

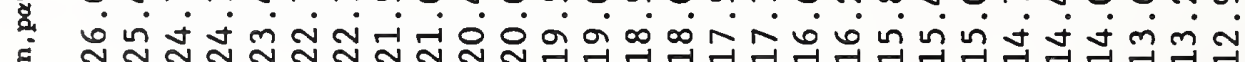

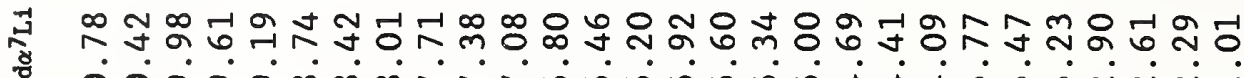

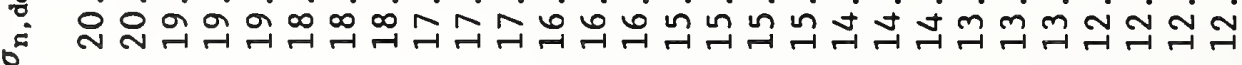

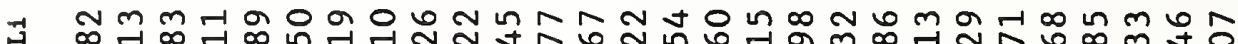

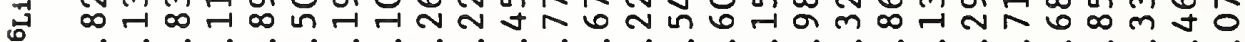

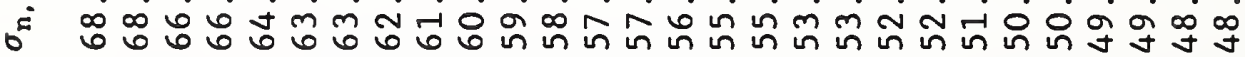
$\because \quad \infty$ 워

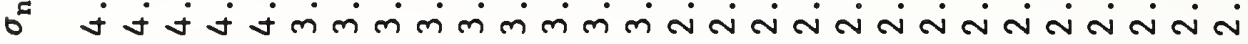

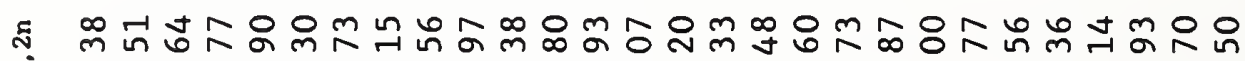

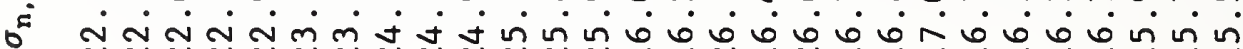

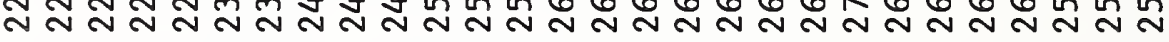

:

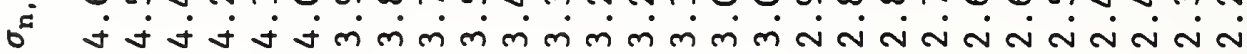

- $\quad$ m b $\dot{j} \dot{j} \dot{j} \dot{j} \dot{j} \dot{j} \dot{j} \dot{m} \dot{m} \dot{m} \dot{m} \dot{m} \dot{m} \dot{m} \dot{\sim} \sim \dot{N} \dot{N} \dot{N} \dot{N}$

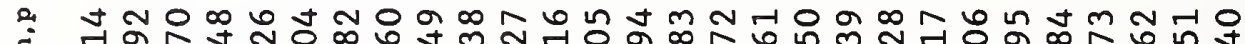
o

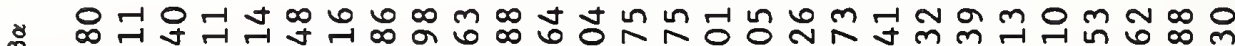

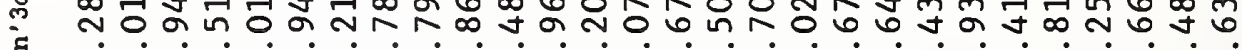
o.

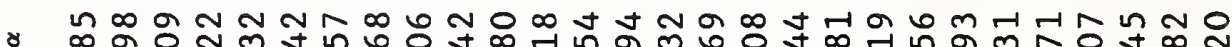

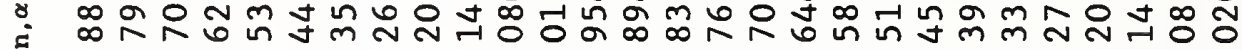
$\dot{j} \dot{j} \dot{j} \dot{j} \dot{j} \dot{j} \dot{j} \dot{j} \dot{j} \dot{j} \dot{n} \dot{m} \dot{m} \dot{m} \dot{m} \dot{n} \dot{n} \dot{n} \dot{m} \dot{n} \dot{n}$ ㄴำก

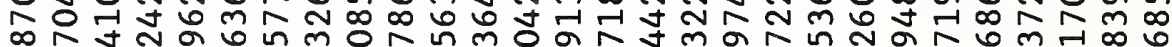
जी N

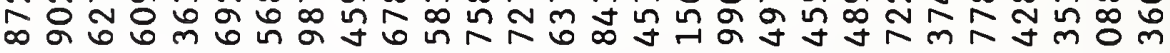

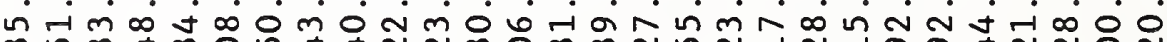

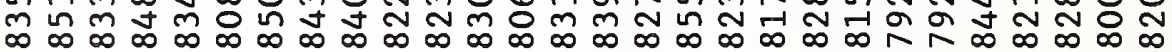

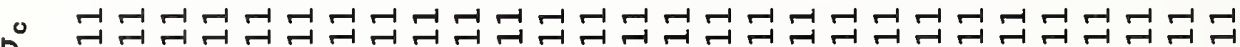

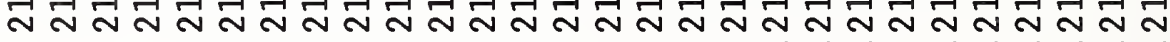

욱 ๙

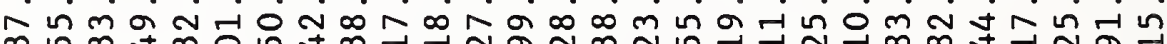

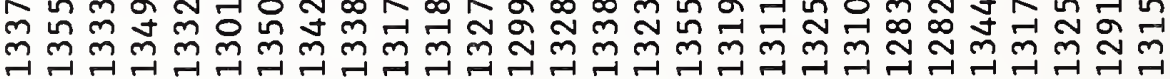




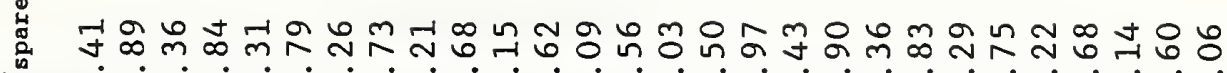
\&

章

๙

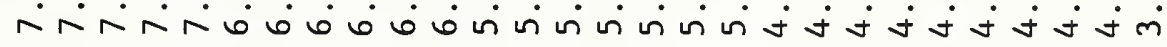

$\frac{8}{8}$

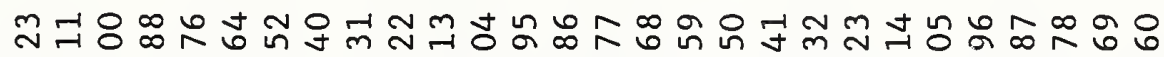

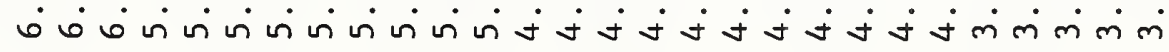

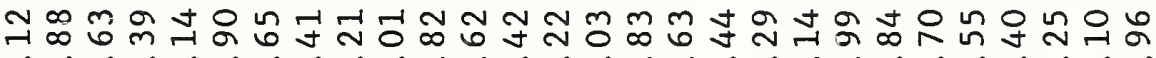
घ

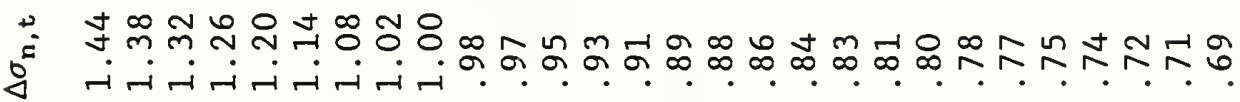

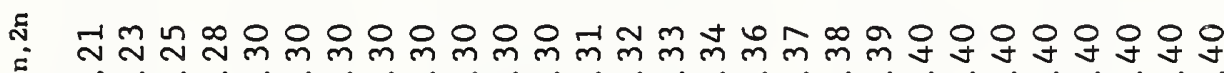

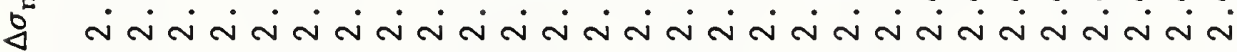

일

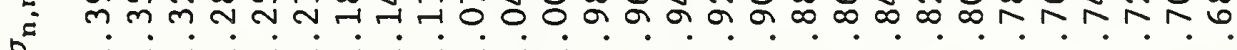
-i

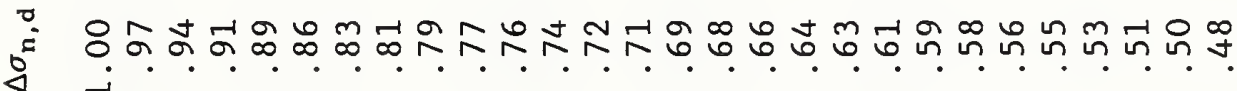

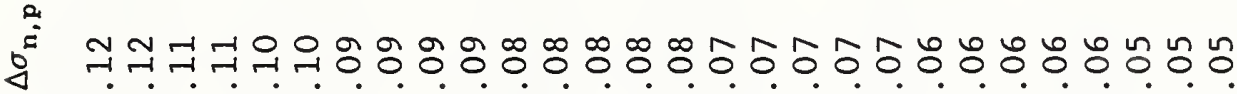

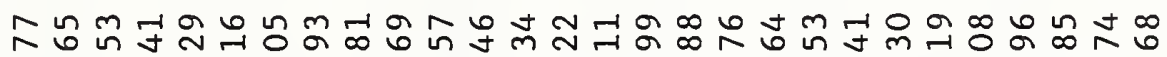

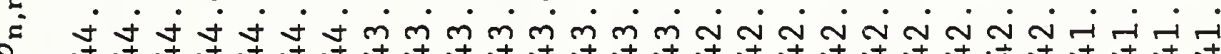

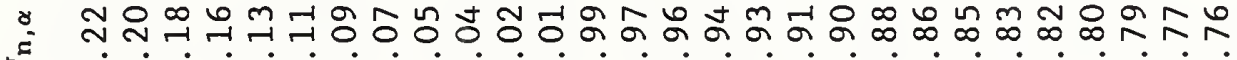

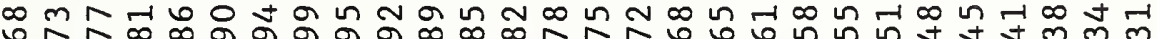

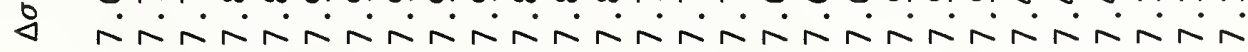

ต

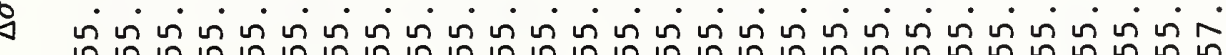

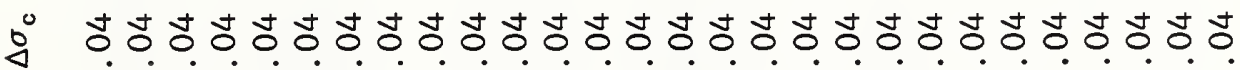

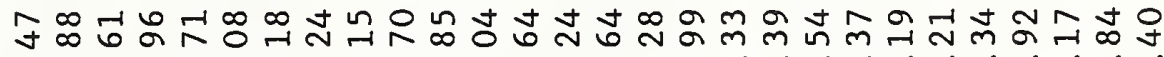
४ ลิ 
Average Correlation Matrix of Total and Partial Cross Sections from 29.3 to $32 \mathrm{MeV}$

\begin{tabular}{|c|c|c|c|c|c|c|c|c|c|c|c|c|c|c|}
\hline$\sigma_{\mathrm{t}}$ & 1.00 & & & & & & & & & & & & & \\
\hline$\sigma_{c}$ & .00 & 1.00 & & & & & & & & & & & & \\
\hline$\sigma_{\theta}$ & .50 & .00 & 1.00 & & & & & & & & & & & \\
\hline$\sigma_{\text {in }}$ & .01 & .00 & -.11 & 1.00 & & & & & & & & & & \\
\hline$\sigma_{n, \alpha}$ & .00 & .00 & -.01 & .00 & 1.00 & & & & & & & & & \\
\hline$\sigma_{n, n} \cdot 3 \alpha$ & .09 & .00 & -.70 & -.02 & .00 & 1.00 & & & & & & & & \\
\hline$\sigma_{n, p}$ & .00 & .00 & .00 & .00 & .00 & .00 & 1.00 & & & & & & & \\
\hline$\sigma_{\mathrm{n}, \mathrm{d}}$ & .00 & .00 & -.01 & .00 & .00 & .00 & .00 & 1.00 & & & & & & \\
\hline$\sigma_{n, n p}$ & .00 & .00 & -.01 & .00 & .00 & .00 & .00 & .00 & 1.00 & & & & & \\
\hline$\sigma_{n, n 2 n}$ & .00 & .00 & -.03 & .00 & .00 & -.01 & .00 & .00 & .00 & 1.00 & & & & \\
\hline$\sigma_{n, t}$ & .00 & .00 & -.01 & .00 & .00 & .00 & .00 & .00 & .00 & .00 & 1.00 & & & \\
\hline$\sigma_{\mathrm{n},{ }^{6} \mathrm{Li}}$ & .03 & .00 & -.21 & -.01 & .00 & -.04 & .00 & .00 & .00 & .00 & .00 & 1.00 & & \\
\hline$\sigma_{\mathrm{n}, \mathrm{d} \alpha}$ & .01 & .00 & -.07 & .00 & .00 & -.01 & .00 & .00 & .00 & .00 & .00 & .00 & 1.00 & \\
\hline$\sigma_{n, p \alpha}$ & .01 & .00 & -.08 & .00 & .00 & -.01 & .00 & .00 & .00 & .00 & .00 & .00 & .00 & 1.00 \\
\hline$\sigma_{\text {spare }}$ & .03 & .00 & -.25 & -.01 & .00 & -.04 & .00 & .00 & .00 & .00 & .00 & -.01 & .00 & .00 \\
\hline
\end{tabular}


Table 27

Normalized Components of the ${ }^{12} C\left(n, n^{\prime} 3 \alpha\right)$ Reaction

\begin{tabular}{|c|c|c|c|c|c|c|c|}
\hline$E_{n}$ & $\sigma(\mathrm{mb})$ & $E_{n}$ & $\sigma(\mathrm{mb})$ & $E_{n}$ & $\sigma(\mathrm{mb})$ & $E_{n}$ & $\sigma(\mathrm{mb})$ \\
\hline & M91 & MT52 & $7.653 \mathrm{MeV}$ & MT53 & $9.638 \mathrm{MeV}$ & MT54 & $10.8 \mathrm{Me}$ \\
\hline 7.89 & .00 & 8.30 & .00 & 10.45 & .00 & 11.71 & .00 \\
\hline 8.00 & .16 & 8.50 & 3.20 & 10.50 & 1.00 & 12.00 & 3.46 \\
\hline 8.50 & .88 & 9.00 & 7.00 & 11.00 & 10.00 & 12.50 & 8.71 \\
\hline 9.00 & 5.51 & 9.50 & 11.40 & 11.50 & 20.00 & 13.00 & 13.34 \\
\hline 9.50 & 9.99 & 10.00 & 15.50 & 12.00 & 30.00 & 13.50 & 16.92 \\
\hline 10.00 & 14.54 & 10.50 & 19.00 & 12.50 & 39.00 & 14.00 & 19.48 \\
\hline 10.50 & 49.61 & 11.00 & 23.60 & 13.00 & 47.50 & 14.50 & 22.22 \\
\hline 11.00 & 70.29 & 11.50 & 28.00 & 13.50 & 60.00 & 15.00 & 23.73 \\
\hline 11.50 & 70.20 & 12.00 & 28.80 & 14.00 & 65.00 & 15.50 & 24.05 \\
\hline 12.00 & 91.33 & 12.50 & 28.40 & 14.50 & 73.00 & 16.00 & 24.01 \\
\hline 12.50 & 83.76 & 13.00 & 26.60 & 15.00 & 77.00 & 16.50 & 22.49 \\
\hline 13.00 & 70.45 & 13.50 & 23.40 & 15.50 & 76.00 & 17.00 & 20.37 \\
\hline 13.50 & 80.58 & 14.00 & 20.00 & 16.00 & 75.00 & 17.50 & 18.21 \\
\hline 14.00 & 89.55 & 14.50 & 16.50 & 16.50 & 72.00 & 18.00 & 16.03 \\
\hline 14.50 & 83.87 & 15.00 & 14.00 & 17.00 & 69.00 & 18.50 & 13.84 \\
\hline 15.00 & 100.68 & 15.50 & 12.20 & 17.50 & 63.50 & 19.00 & 11.74 \\
\hline 15.50 & 89.08 & 16.00 & 10.80 & 18.00 & 59.00 & 19.50 & 9.94 \\
\hline 16.00 & 98.99 & 16.50 & 9.76 & 18.50 & 54.00 & 20.00 & 8.32 \\
\hline 16.50 & 97.45 & 17.00 & 9.16 & 19.00 & 49.00 & 20.50 & 6.97 \\
\hline 17.00 & 86.94 & 17.50 & 8.59 & 19.50 & 45.00 & 21.00 & 5.92 \\
\hline 17.50 & 94.29 & 18.00 & 8.06 & 20.00 & 42.00 & 21.50 & 5.00 \\
\hline 18.00 & 86.34 & 18.50 & 7.57 & 20.50 & 38.02 & 22.00 & 4.25 \\
\hline 18.50 & 76.15 & 19.00 & 7.10 & 21.00 & 36.03 & 22.50 & 3.69 \\
\hline 19.00 & 66.22 & 19.50 & 6.66 & 21.50 & 34.14 & 23.00 & 3.21 \\
\hline 19.50 & 62.16 & 20.00 & 6.25 & 22.00 & 32.35 & 23.50 & 2.80 \\
\hline 20.00 & 48.77 & 20.50 & 5.87 & 22.50 & 30.65 & 24.00 & 2.43 \\
\hline 20.50 & 45.03 & 21.00 & 5.51 & 23.00 & 29.05 & 24.50 & 2.12 \\
\hline 21.00 & 38.53 & 21.50 & 5.17 & 23.50 & 27.53 & 25.00 & 1.84 \\
\hline 21.50 & 33.86 & 22.00 & 4.85 & 24.00 & 26.08 & 25.50 & 1.60 \\
\hline 22.00 & 35.73 & 22.50 & 4.55 & 24.50 & 24.71 & 26.00 & 1.39 \\
\hline 22.50 & 32.13 & 23.00 & 4.27 & 25.00 & 23.42 & 26.50 & 1.21 \\
\hline 23.00 & 34.78 & 23.50 & 4.01 & 25.50 & 22.19 & 27.00 & 1.05 \\
\hline 23.50 & 37.62 & 24.00 & 3.76 & 26.00 & 21.03 & 27.50 & .92 \\
\hline 24.00 & 27.68 & 24.50 & 3.53 & 26.50 & 19.93 & 28.00 & .80 \\
\hline 24.50 & 34.43 & 25.00 & 3.31 & 27.00 & 18.88 & 28.50 & .69 \\
\hline 25.00 & 29.99 & 25.50 & 3.11 & 27.50 & 17.89 & 29.00 & .60 \\
\hline 25.50 & 21.63 & 26.00 & 2.92 & 28.00 & 16.95 & 29.50 & .52 \\
\hline 26.00 & 19.61 & 26.50 & 2.74 & 28.50 & 16.06 & 30.00 & .46 \\
\hline 26.50 & 16.35 & 27.00 & 2.57 & 29.00 & 15.22 & 30.50 & .40 \\
\hline 27.00 & 17.66 & 27.50 & 2.41 & 29.50 & 14.42 & 31.00 & .35 \\
\hline 27.50 & 19.98 & 28.00 & 2.26 & 30.00 & 13.67 & 31.50 & .30 \\
\hline 28.00 & 19.18 & 28.50 & 2.13 & 30.50 & 12.95 & 32.00 & .26 \\
\hline 28.50 & 18.74 & 29.00 & 1.99 & 31.00 & 12.27 & & \\
\hline 29.00 & 16.86 & 29.50 & 1.87 & 31.50 & 11.63 & & \\
\hline 29.50 & 15.24 & 30.00 & 1.76 & 32.00 & 11.02 & & \\
\hline 30.00 & 15.35 & 30.50 & 1.65 & & & & \\
\hline 30.50 & 11.13 & 31.00 & 1.55 & & & & \\
\hline 31.00 & 11.18 & 31.50 & 1.45 & & & & \\
\hline 31.50 & 7.90 & 32.00 & 1.36 & & & & \\
\hline 32.00 & 8.52 & & & & & & \\
\hline
\end{tabular}


Table 27 (Continued)

\begin{tabular}{|c|c|c|c|c|c|c|c|}
\hline$E_{n}$ & $\sigma(\mathrm{mb})$ & $E_{n}$ & $\sigma(\mathrm{mb})$ & $E_{n}$ & $\sigma(\mathrm{mb})$ & $E_{n}$ & $\sigma(\mathrm{mb})$ \\
\hline MT55 & $11.8 \mathrm{MeV}$ & MT56 & $12.7 \mathrm{MeV}$ & MT57 & $13.35 \mathrm{MeV}$ & MT58 & $14.08 \mathrm{MeV}$ \\
\hline 12.79 & .00 & 13.77 & .00 & 14.47 & .00 & 15.26 & .00 \\
\hline 13.00 & 2.26 & 14.00 & 4.73 & 14.50 & .00 & 15.50 & 1.69 \\
\hline 13.50 & 7.02 & 14.50 & 13.66 & 15.00 & 3.69 & 16.00 & 4.82 \\
\hline 14.00 & 11.31 & 15.00 & 21.67 & 15.50 & 6.91 & 16.50 & 7.63 \\
\hline 14.50 & 14.70 & 15.50 & 27.96 & 16.00 & 9.58 & 17.00 & 9.83 \\
\hline 15.00 & 17.12 & 16.00 & 32.45 & 16.50 & 11.49 & 17.50 & 11.40 \\
\hline 15.50 & 19.40 & 16.50 & 36.84 & 17.00 & 12.88 & 18.00 & 12.95 \\
\hline 16.00 & 21.29 & 17.00 & 40.11 & 17.50 & 14.91 & 18.50 & 14.08 \\
\hline 16.50 & 21.44 & 17.50 & 40.46 & 18.00 & 14.92 & 19.00 & 14.21 \\
\hline 17.00 & 21.63 & 18.00 & 40.70 & 18.50 & 15.36 & 19.50 & 14.28 \\
\hline 17.50 & 20.49 & 18.50 & 38.43 & 19.00 & 14.91 & 20.00 & 13.48 \\
\hline 18.00 & 18.57 & 19.00 & 34.82 & 19.50 & 13.55 & 20.50 & 12.21 \\
\hline 18.50 & 16.67 & 19.50 & 31.22 & 20.00 & 12.28 & 21.00 & 10.95 \\
\hline 19.00 & 14.69 & 20.00 & 27.50 & 20.50 & 10.83 & 21.50 & 9.64 \\
\hline 19.50 & 12.76 & 20.50 & 23.84 & 21.00 & 9.53 & 22.00 & 8.36 \\
\hline 20.00 & 10.81 & 21.00 & 20.21 & 21.50 & 8.07 & 22.50 & 7.09 \\
\hline 20.50 & 9.18 & 21.50 & 17.15 & 22.00 & 6.88 & 23.00 & 6.01 \\
\hline 21.00 & 7.69 & 22.00 & 14.36 & 22.50 & 5.78 & 23.50 & 5.04 \\
\hline 21.50 & 6.43 & 22.50 & 12.02 & 23.00 & 4.82 & 24.00 & 4.21 \\
\hline 22.00 & 5.45 & 23.00 & 10.19 & 23.50 & 4.06 & 24.50 & 3.57 \\
\hline 22.50 & 4.62 & 23.50 & 8.64 & 24.00 & 3.48 & 25.00 & 3.03 \\
\hline 23.00 & 3.90 & 24.00 & 7.29 & 24.50 & 2.89 & 25.50 & 2.56 \\
\hline 23.50 & 3.39 & 24.50 & 6.35 & 25.00 & 2.51 & 26.00 & 2.22 \\
\hline 24.00 & 2.95 & 25.00 & 5.52 & 25.50 & 2.18 & 26.50 & 1.94 \\
\hline 24.50 & 2.57 & 25.50 & 4.80 & 26.00 & 1.90 & 27.00 & 1.68 \\
\hline 25.00 & 2.23 & 26.00 & 4.18 & 26.50 & 1.65 & 27.50 & 1.46 \\
\hline 25.50 & 1.94 & 26.50 & 3.63 & 27.00 & 1.44 & 28.00 & 1.27 \\
\hline 26.00 & 1.69 & 27.00 & 3.16 & 27.50 & 1.25 & 28.50 & 1.11 \\
\hline 26.50 & 1.47 & 27.50 & 2.75 & 28.00 & 1.09 & 29.00 & .96 \\
\hline 27.00 & 1.28 & 28.00 & 2.39 & 28.50 & .95 & 29.50 & .84 \\
\hline 27.50 & 1.11 & 28.50 & 2.08 & 29.00 & .82 & 30.00 & .73 \\
\hline 28.00 & .97 & 29.00 & 1.81 & 29.50 & .72 & 30.50 & .63 \\
\hline 28.50 & .84 & 29.50 & 1.57 & 30.00 & .62 & 31.00 & .55 \\
\hline 29.00 & .73 & 30.00 & 1.37 & 30.50 & .54 & 31.50 & .48 \\
\hline 29.50 & .64 & 30.50 & 1.19 & 31.00 & .47 & 32.00 & .42 \\
\hline 30.00 & .55 & 31.00 & 1.04 & 31.50 & .41 & & \\
\hline 30.50 & .48 & 31.50 & .90 & 32.00 & .36 & & \\
\hline 31.00 & .42 & 32.00 & .78 & & & & \\
\hline 31.50 & .36 & & & & & & \\
\hline 32.00 & .32 & & & & & & \\
\hline
\end{tabular}


Table 27 (Continued)

$\begin{array}{cccccccc}\mathrm{E}_{\mathrm{n}} & \sigma(\mathrm{mb}) & \mathrm{E}_{\mathrm{n}} & \sigma(\mathrm{mb}) & \mathrm{E}_{\mathrm{n}} & \sigma(\mathrm{mb}) & \mathrm{E}_{\mathrm{n}} & \sigma(\mathrm{mb}) \\ \text { MT59 } & 15.08 \mathrm{MeV} & \text { MT60 } & 16.08 \mathrm{MeV} & \text { MT61 } & 17.08 \mathrm{MeV} & \text { MT62 } & 18.08 \mathrm{MeV}\end{array}$

\begin{tabular}{|c|c|c|c|c|c|c|c|}
\hline 16.35 & .00 & 17.43 & .00 & 18.52 & .00 & 19.60 & .00 \\
\hline 16.50 & 4.52 & 17.50 & 1.73 & 19.00 & 10.51 & 20.00 & 8.59 \\
\hline 17.00 & 17.36 & 18.00 & 12.55 & 19.50 & 20.43 & 20.50 & 18.27 \\
\hline 17.50 & 29.10 & 18.50 & 22.65 & 20.00 & 28.77 & 21.00 & 26.59 \\
\hline 18.00 & 38.55 & 19.00 & 30.97 & 20.50 & 34.81 & 21.50 & 32.78 \\
\hline 18.50 & 45.26 & 19.50 & 36.86 & 21.00 & 39.19 & 22.00 & 37.25 \\
\hline 19.00 & 50.00 & 20.00 & 41.13 & 21.50 & 41.89 & 22.50 & 40.11 \\
\hline 19.50 & 52.71 & 20.50 & 43.66 & 22.00 & 43.18 & 23.00 & 41.56 \\
\hline 20.00 & 53.61 & 21.00 & 44.74 & 22.50 & 42.74 & 23.50 & 41.40 \\
\hline 20.50 & 52.51 & 21.50 & 44.04 & 23.00 & 41.15 & 24.00 & 40.03 \\
\hline 21.00 & 50.26 & 22.00 & 42.24 & 23.50 & 39.05 & 24.50 & 38.06 \\
\hline 21.50 & 47.40 & 22.50 & 39.99 & 24.00 & 36.34 & 25.00 & 35.54 \\
\hline 22.00 & 43.75 & 23.00 & 37.08 & 24.50 & 32.92 & 25.50 & 32.34 \\
\hline 22.50 & 39.30 & 23.50 & 33.45 & 25.00 & 29.12 & 26.00 & 28.72 \\
\hline 23.00 & 34.45 & 24.00 & 29.46 & 25.50 & 25.06 & 26.50 & 24.83 \\
\hline 23.50 & 29.51 & 24.50 & 25.25 & 26.00 & 21.39 & 27.00 & 21.21 \\
\hline 24.00 & 25.09 & 25.00 & 21.53 & 26.50 & 18.01 & 27.50 & 17.90 \\
\hline 24.50 & 21.05 & 25.50 & 18.08 & 27.00 & 15.02 & 28.00 & 14.95 \\
\hline 25.00 & 17.57 & 26.00 & 15.07 & 27.50 & 12.64 & 28.50 & 12.56 \\
\hline 25.50 & 14.86 & 26.50 & 12.71 & 28.00 & 10.81 & 29.00 & 10.71 \\
\hline 26.00 & 12.66 & 27.00 & 10.88 & 28.50 & 9.02 & 29.50 & 8.98 \\
\hline 26.50 & 10.62 & 27.50 & 9.06 & 29.00 & 7.80 & 30.00 & 7.71 \\
\hline 27.00 & 9.23 & 28.00 & 7.88 & 29.50 & 6.78 & 30.50 & 6.70 \\
\hline 27.50 & 8.03 & 28.50 & 6.85 & 30.00 & 5.90 & 31.00 & 5.83 \\
\hline 28.00 & 6.99 & 29.00 & 5.96 & 30.50 & 5.13 & 31.50 & 5.07 \\
\hline 28.50 & 6.08 & 29.50 & 5.19 & 31.00 & 4.46 & 32.00 & 4.41 \\
\hline 29.00 & 5.29 & 30.00 & 4.51 & 31.50 & 3.88 & & \\
\hline 29.50 & 4.60 & 30.50 & 3.92 & 32.00 & 3.38 & & \\
\hline 30.00 & 4.00 & 31.00 & 3.41 & & & & \\
\hline 30.50 & 3.48 & 31.50 & 2.97 & & & & \\
\hline 31.00 & 3.03 & 32.00 & 2.58 & & & & \\
\hline 31.50 & 2.63 & & & & & & \\
\hline 32.00 & 2.29 & & & & & & \\
\hline
\end{tabular}


Table 27 (Continued)

$\begin{array}{lrl}E_{\mathrm{n}} & \sigma(\mathrm{mb}) & E_{\mathrm{n}} \\ \text { MT63 } & 19.08 \mathrm{MeV} & \mathrm{MT} 64 \\ & & \\ 20.68 & .00 & 21.77 \\ 21.00 & 6.70 & 22.00 \\ 21.50 & 16.13 & 22.50 \\ 22.00 & 24.42 & 23.00 \\ 22.50 & 30.75 & 23.50 \\ 23.00 & 35.30 & 24.00 \\ 23.50 & 38.32 & 24.50 \\ 24.00 & 39.92 & 25.00 \\ 24.50 & 40.04 & 25.50 \\ 25.00 & 38.87 & 26.00 \\ 25.50 & 37.04 & 26.50 \\ 26.00 & 34.70 & 27.00 \\ 26.50 & 31.73 & 27.50 \\ 27.00 & 28.28 & 28.00 \\ 27.50 & 24.57 & 28.50 \\ 28.00 & 21.01 & 29.00 \\ 28.50 & 17.78 & 29.50 \\ 29.00 & 14.87 & 30.00 \\ 29.50 & 12.46 & 30.50 \\ 30.00 & 10.60 & 31.00 \\ 30.50 & 8.94 & 31.50 \\ 31.00 & 7.61 & 32.00 \\ 31.50 & 6.62 & \\ 32.00 & 5.76 & \end{array}$

$\begin{array}{rrrrr}\sigma(m b) & E_{n} & \sigma(m b) & E_{n} & \sigma(m b) \\ 20.08 \mathrm{MeV} & \text { MT65 } & 21.08 \mathrm{MeV} & \text { MT66 } & 22.08 \mathrm{Me} \\ & & & & \\ .00 & 22.85 & .00 & 23.94 & .00 \\ 3.73 & 23.00 & 2.44 & 24.00 & 1.08 \\ 10.80 & 23.50 & 9.58 & 24.50 & 8.30 \\ 17.13 & 24.00 & 16.11 & 25.00 & 15.04 \\ 22.10 & 24.50 & 21.38 & 25.50 & 20.61 \\ 25.65 & 25.00 & 25.12 & 26.00 & 24.54 \\ 28.08 & 25.50 & 27.76 & 26.50 & 27.40 \\ 29.43 & 26.00 & 29.28 & 27.00 & 29.09 \\ 29.73 & 26.50 & 29.79 & 27.50 & 29.83 \\ 28.99 & 27.00 & 29.18 & 28.00 & 29.37 \\ 27.69 & 27.50 & 27.93 & 28.50 & 28.17 \\ 26.03 & 28.00 & 26.35 & 29.00 & 26.67 \\ 23.91 & 28.50 & 24.32 & 29.50 & 24.74 \\ 21.40 & 29.00 & 21.86 & 30.00 & 22.32 \\ 18.68 & 29.50 & 19.17 & 30.50 & 19.67 \\ 15.98 & 30.00 & 16.41 & 31.00 & 16.86 \\ 13.56 & 30.50 & 13.96 & 31.50 & 14.38 \\ 11.36 & 31.00 & 11.71 & 32.00 & 12.08 \\ 9.50 & 31.50 & 9.78 & & \\ 8.06 & 32.00 & 8.27 & & \\ 6.83 & & & & \\ 5.77 & & & & \\ & & & & \end{array}$

MT67

$23.08 \mathrm{MeV}$ MT68

$24.08 \mathrm{MeV}$ MT69

$25.08 \mathrm{MeV}$

MT70 $26.08 \mathrm{MeV}$

25.02

$.00 \quad 26.10$

.00

27.19

.00

28.27

.00

25.50

7.19

26.50

6.08

4.90

28.50

3.67

12.99

27.50

11.89

29.00

10.73

26.50

19.80

27.50

28.50

18.04

29.50

17.08

23.38

23.98

28.00

29.00

22.75

30.00

22.07

27.50

27.01

28.50

26.58

28.64

29.50

26.12

30.50

25.62

28.00

28.88

29.00

29.68

30.00

28.37

31.00

28.07

29.77

29.50

29.58

30.50

29.56

31.50

29.43

29.00

29.48

30.00

28.60

31.00

29.66

32.00

29.73

30.00

26.94

31.00

30.50

25.08

27.20

28.81

31.50
32.00

27.45

31.00

31.50

22.73

31.50

25.40

20.10

32.00

17.30

\section{MT71}

$27.08 \mathrm{MeV}$

MT72

29.36

.00

30.44

2.37

30.50

30.00

9.51

31.00

16.06

31.50

23.12

21.34

32.00

$28.08 \mathrm{MeV}$

MT73

$29.08 \mathrm{MeV}$

31.00

25.09

32.00

27.74

$$
31.52
$$$$
32.00
$$$$
.00
$$$$
7.14
$$ 
Table 28

Cross Sections Unfolded from the Cross Section $\sigma_{\text {spare }}$ in Tables 25a and 26a

$$
{ }^{12} \mathrm{C}(\mathrm{n}, \mathrm{t} \alpha)^{6} \mathrm{Li}
$$

$\mathrm{E}_{\mathrm{n}} \mathrm{MeV} \quad \mathrm{mb}$

26.300

.000

26.500

1.500

27.000

7.000

27.500

15.008

28.000

15.529

28.500

13.896

29.000

11.742

29.500

10.976

30.000

9.885

30.500

7.877

31.000

7.348

31.500

6.795

32.000

6.262

$$
{ }^{12} \mathrm{C}(\mathrm{n}, \mathrm{pd}){ }^{10} \mathrm{Be}
$$

$\mathrm{E}_{\mathrm{n}} \mathrm{MeV} \quad \mathrm{mb}$

27.660

.000

28.000

3.577

28.500

5.155

29.000

6.439

29.500

8.293

30.000

9.240

30.500

9.180

31.000

8.143

31.500

7.170

32.000

6.222
${ }^{12} \mathrm{C}(\mathrm{n}, \mathrm{pt}){ }^{9} \mathrm{Be}$

$\mathrm{E}_{\mathrm{n}} \mathrm{MeV} \quad \mathrm{mb}$

$28.280 \quad .000$

$29.000 \quad 3.509$

$29.500 \quad 4.599$

$30.000 \quad 7.091$

$30.500 \quad 7.934$

$31.000 \quad 9.597$

$31.500 \quad 8.592$

$32.000 \quad 7.667$

$$
{ }^{12} \mathrm{C}(\mathrm{n}, \mathrm{dt}) 2 \alpha
$$

$\mathrm{E}_{\mathrm{n}} \mathrm{MeV} \quad \mathrm{mb}$

27.600

.000

28.000

2.452

28.500

5.828

29.000

6.768

29.500

8.903

30.000

9.344

30.500

8.878

31.000

8.259

31.500

7.565

32.000

6.924

$$
{ }^{12} \mathrm{C}(\mathrm{n}, \mathrm{dt})^{8} \mathrm{Be}
$$

$\mathrm{E}_{\mathrm{n}} \mathrm{MeV} \quad \mathrm{mb}$

27.650

.000

28.000

2.452

28.500

5.828

29.000

6.768

29.500

8.903

30.000

9.344

30.500

9.124

31.000

31.500

8.337

32.000

$$
\left.{ }^{12} \mathrm{C}(\mathrm{n}, \mathrm{nd})\right)^{10} \mathrm{~B}
$$

$\mathrm{E}_{\mathrm{n}} \mathrm{MeV} \quad \mathrm{mb}$

27.810

.000

3.810

29.000

5.514

29.500

7.562

30.000

8.488

30.500

9.067

31.000

8.744

31.500

7.841

32.000

7.005

$$
{ }^{12} \mathrm{C}\left(\mathrm{n},{ }^{6} \mathrm{He}\right)^{7} \mathrm{Be}
$$

$\mathrm{E}_{\mathrm{n}} \mathrm{MeV} \quad \mathrm{mb}$

28.220

.000

29.000

4.261

29.500

6.464

30.000

7.843

30.500

8.689

31.000

9.093

31.500

8.335

32.000
${ }^{12} \mathrm{C}(\mathrm{n}, 2 \mathrm{n} \alpha)^{7} \mathrm{Be}$

$\mathrm{E}_{\mathrm{n}} \mathrm{MeV} \quad \mathrm{mb}$

$29.280 \quad .000$

$29.500 \quad 1.220$

$30.000 \quad 3.223$

$30.500 \quad 4.722$

$31.000 \quad 6.689$

$31.500 \quad 8.691$

$32.000 \quad 9.835$

$$
{ }^{12} \mathrm{C}(\mathrm{n}, 2 \mathrm{p})^{11} \mathrm{Be}
$$

$\mathrm{E}_{\mathrm{n}} \mathrm{MeV} \quad \mathrm{mb}$

$29.280 \quad .000$

$30.000 \quad 2.041$

$30.500 \quad 3.495$

$31.000 \quad 5.429$

$31.500 \quad 7.308$

$32.000 \quad 9.233$ 
Table 28 (Continued)

$$
{ }^{12} \mathrm{C}(\mathrm{n}, \mathrm{He}){ }^{6} \mathrm{He}
$$

$\mathrm{E}_{\mathrm{n}} \mathrm{MeV} \quad \mathrm{mb}$

29.530

.000

30.000

.430

30.500

2. 267

31.000

4.265

31.500

6.321

32.000

8.430

${ }^{12} \mathrm{C}(\mathrm{n}, \mathrm{npt}) 2 \alpha$

$\mathrm{E}_{\mathrm{n}} \mathrm{MeV}$

$\mathrm{mb}$

29.940

.000

30.500

1.795

31.000

3.684

31.500

5.530

32.000

7.627

$$
{ }^{12} \mathrm{C}(\mathrm{n}, \mathrm{npt})^{8} \mathrm{Be}
$$

$\mathrm{E}_{\mathrm{n}} \mathrm{MeV}$

mb

29.700

.000

30.000

.860

30.500

2. 361

31.000

3.684

31.500

5.728

32.000

7.627

$$
{ }^{12} \mathrm{C}(\mathrm{n}, \mathrm{n} 2 \mathrm{p})^{10} \mathrm{Be}
$$

$\mathrm{E}_{\mathrm{n}} \mathrm{MeV}$

$\mathrm{mb}$

29.800

30.000

.000

30.500

.860

31.000

2. 361

3.684

31.500

5.728

32.000

7.627

$$
{ }^{12} \mathrm{C}(\mathrm{n}, \mathrm{nt})^{9} \mathrm{~B}
$$

$\mathrm{E}_{\mathrm{n}} \mathrm{MeV} \quad \mathrm{mb}$

$29.800 \quad .000$

$30.000 \quad .430$

$30.500 \quad 1.889$

$31.000 \quad 3.490$

$31.500 \quad 5.135$

$32.000 \quad 6.924$

$$
{ }^{12} \mathrm{C}(\mathrm{n}, 2 \mathrm{np}){ }^{10} \mathrm{~B}
$$

$\mathrm{E}_{\mathrm{n}} \mathrm{MeV} \quad \mathrm{mb}$

$\begin{array}{lr}29.870 & .000 \\ 30.500 & .944 \\ 31.000 & 2.327 \\ 31.500 & 3.753 \\ 32.000 & 5.419\end{array}$

$$
{ }^{12} \mathrm{C}\left(\mathrm{n}, 2 \mathrm{n}{ }^{3} \mathrm{He}\right) 2 \alpha
$$

$\mathrm{E}_{\mathrm{n}} \mathrm{MeV} \quad \mathrm{mb}$

$$
\begin{array}{lr}
31.220 & .000 \\
32.000 & 1.806
\end{array}
$$

$$
{ }^{12} \mathrm{C}(\mathrm{n}, \mathrm{pt} \alpha){ }^{5} \mathrm{He}
$$

$\mathrm{E}_{\mathrm{n}} \mathrm{MeV} \quad \mathrm{mb}$

$30.900 \quad .000$

$31.000 \quad .194$

$31.500 \quad 2.173$

$32.000 \quad 4.215$ 
Table 29. Extension to $32 \mathrm{MeV}$ of ENDF/B-V Files for $\mathrm{fl}$

\begin{tabular}{|c|c|c|c|c|}
\hline \multirow[t]{2}{*}{$E_{n} \mathrm{MeV}$} & \multirow[t]{2}{*}{ Elastic Scatter } & \multicolumn{3}{|c|}{ Inelastic Scatter } \\
\hline & & $\begin{array}{c}\text { MT51 } \\
4.439 \mathrm{MeV}\end{array}$ & $\begin{array}{c}\text { MT52 } \\
7.653 \mathrm{MeV}\end{array}$ & $\begin{array}{c}\text { MT53 } \\
9.638 \mathrm{MeV}\end{array}$ \\
\hline 20 & $0.730 \pm 0.037$ & $0.490 \pm 0.060$ & $0.233 \pm 0.060$ & $0.231 \pm 0.046$ \\
\hline 20.8 & $0.789 \pm 0.016$ & & & \\
\hline 22 & $0.804 \pm 0.016$ & & & \\
\hline 24 & $0.814 \pm 0.016$ & & & \\
\hline 26 & $0.833 \pm 0.017$ & & & \\
\hline 32 & $0.867 \pm 0.017$ & $0.541 \pm 0.060$ & $0.233 \pm 0.060$ & $0.231 \pm 0.046$ \\
\hline
\end{tabular}


Table 30

Kerma Factors and Uncertainties $\left(f G y \cdot m^{2}\right.$ )

$\begin{array}{lcccc}\mathrm{E}_{\mathrm{n}} \mathrm{MeV} & \mathrm{K}_{\mathrm{e}} & \mathrm{K}_{\text {in }} & \mathrm{K}_{\mathrm{t}} & \Delta \mathrm{K}_{\mathrm{t}} \\ 5.0000 & .486 & .019 & .504 & .012 \\ 5.0010 & .491 & .019 & .510 & .011 \\ 5.0300 & .489 & .018 & .507 & .011 \\ 5.0530 & .491 & .017 & .508 & .011 \\ 5.1000 & .486 & .018 & .505 & .011 \\ 5.1200 & .483 & .020 & .503 & .011 \\ 5.1500 & .480 & .023 & .503 & .011 \\ 5.1800 & .475 & .026 & .501 & .011 \\ 5.2000 & .467 & .028 & .495 & .011 \\ 5.2300 & .463 & .030 & .493 & .010 \\ 5.2800 & .446 & .033 & .479 & .010 \\ 5.3000 & .442 & .033 & .475 & .010 \\ 5.3300 & .390 & .037 & .427 & .011 \\ 5.3350 & .395 & .039 & .434 & .013 \\ 5.3400 & .371 & .035 & .406 & .012 \\ 5.3600 & .557 & .040 & .597 & .020 \\ 5.3620 & .648 & .043 & .691 & .023 \\ 5.3700 & .714 & .043 & .757 & .025 \\ 5.3710 & .707 & .042 & .749 & .025 \\ 5.3780 & .626 & .042 & .669 & .022 \\ 5.3800 & .597 & .042 & .639 & .021 \\ 5.3900 & .540 & .042 & .581 & .017 \\ 5.4000 & .508 & .042 & .550 & .015 \\ 5.4100 & .501 & .043 & .543 & .014 \\ 5.4200 & .507 & .043 & .550 & .013 \\ 5.4300 & .499 & .043 & .542 & .013 \\ 5.4400 & .500 & .044 & .544 & .012 \\ 5.4600 & .490 & .043 & .533 & .011 \\ 5.5000 & .490 & .043 & .533 & .011 \\ 5.5500 & .492 & .043 & .535 & .011 \\ 5.5530 & .497 & .043 & .540 & .011 \\ 5.6000 & .492 & .043 & .535 & .011 \\ 5.6500 & .490 & .046 & .536 & .010 \\ 5.7000 & .486 & .051 & .536 & .010 \\ 5.8000 & .495 & .060 & .555 & .010 \\ 5.9000 & .495 & .073 & .568 & .010 \\ 6.0000 & .503 & .086 & .589 & .011 \\ 6.0500 & .508 & .091 & .600 & .011 \\ 6.0530 & .511 & .092 & .602 & .011 \\ 6.1250 & .536 & .096 & .632 & .011 \\ 6.1600 & .561 & .097 & .659 & .012 \\ 6.1740 & .581 & .098 & .679 & .013\end{array}$


Table 31

Kerma Factors and Uncertainties $\left(\mathrm{fGy} \cdot \mathrm{m}^{2}\right)$

\begin{tabular}{|c|c|c|c|c|c|}
\hline$E_{n} \mathrm{MeV}$ & $\mathrm{K}_{\mathrm{e}}$ & $\mathrm{K}_{\text {in }}$ & $K_{n, \alpha}$ & $\mathrm{K}_{\mathrm{t}}$ & $\Delta K_{t}$ \\
\hline 6.1800 & .587 & .098 & .000 & .685 & .013 \\
\hline 6.2000 & .616 & .096 & .000 & .713 & .013 \\
\hline 6.2100 & .647 & .097 & .000 & .745 & .014 \\
\hline 6.2200 & .660 & .099 & .000 & .759 & .014 \\
\hline 6.2300 & .694 & .101 & .000 & .795 & .015 \\
\hline 6.2400 & .745 & .104 & .000 & .849 & .016 \\
\hline 6.2500 & .795 & .108 & .000 & .903 & .016 \\
\hline 6.2850 & 1.257 & .143 & .000 & 1.400 & .025 \\
\hline 6.2950 & 1.382 & .154 & .000 & 1.536 & .030 \\
\hline 6.3030 & 1.282 & .158 & .000 & 1.440 & .030 \\
\hline 6.3100 & 1.115 & .164 & .000 & 1.280 & .027 \\
\hline 6.3200 & .858 & .160 & .000 & 1.018 & .022 \\
\hline 6.3300 & .712 & .158 & .000 & .870 & .020 \\
\hline 6.3400 & .600 & .154 & .001 & .755 & .018 \\
\hline 6.3500 & .557 & .158 & .001 & .715 & .018 \\
\hline 6.3600 & .573 & .176 & .001 & .750 & .020 \\
\hline 6.3700 & .499 & .159 & .001 & .659 & .018 \\
\hline 6.3900 & .417 & .134 & .001 & .551 & .015 \\
\hline 6.4000 & .409 & .131 & .001 & .540 & .015 \\
\hline 6.4100 & .397 & .125 & .001 & .522 & .015 \\
\hline 6.4200 & .387 & .121 & .001 & .509 & .014 \\
\hline 6.4300 & .394 & .119 & .001 & .515 & .015 \\
\hline 6.4400 & .388 & .115 & .001 & .504 & .014 \\
\hline 6.4500 & .391 & .112 & .001 & .503 & .014 \\
\hline 6.4700 & .377 & .106 & .001 & .482 & .014 \\
\hline 6.4900 & .354 & .103 & .001 & .456 & .015 \\
\hline 6.5100 & .331 & .101 & .001 & .436 & .015 \\
\hline 6.5400 & .291 & .108 & .001 & .410 & .014 \\
\hline 6.5530 & .266 & .110 & .001 & .385 & .013 \\
\hline 6.5600 & .259 & .109 & .001 & .375 & .012 \\
\hline 6.5700 & .245 & .105 & .001 & .352 & .011 \\
\hline 6.5800 & .243 & .104 & .001 & .348 & .010 \\
\hline 6.5900 & .256 & .107 & .001 & .366 & .010 \\
\hline 6.6000 & .273 & .105 & .001 & .377 & .009 \\
\hline 6.6200 & .324 & .101 & .001 & .421 & .009 \\
\hline 6.6400 & .340 & .092 & .001 & .423 & .009 \\
\hline 6.6580 & .432 & .095 & .001 & .529 & .011 \\
\hline 6.6650 & .403 & .091 & .001 & .492 & .011 \\
\hline 6.6700 & .398 & .090 & .001 & .487 & .011 \\
\hline 6.6800 & .397 & .091 & .001 & .488 & .010 \\
\hline 6.7000 & .397 & .089 & .001 & .488 & .010 \\
\hline 6.7500 & .401 & .082 & .001 & .485 & .009 \\
\hline 6.8100 & .405 & .076 & .001 & .483 & .009 \\
\hline 6.9200 & .388 & .085 & .001 & .473 & .009 \\
\hline 7.0000 & .366 & .090 & .001 & .458 & .009 \\
\hline 7.0530 & .360 & .094 & .001 & .455 & .009 \\
\hline 7.1000 & .345 & .095 & .001 & .441 & .009 \\
\hline 7.1400 & .334 & .097 & .001 & .432 & .010 \\
\hline
\end{tabular}


Table 31 (Continued)

$\begin{array}{lrrrrr}\mathrm{E}_{\mathrm{n}} \mathrm{MeV} & \mathrm{K}_{\mathrm{e}} & \mathrm{K}_{\text {in }} & \mathrm{K}_{\mathrm{n}, \alpha} & \mathrm{K}_{\mathrm{t}} & \Delta \mathrm{K}_{\mathrm{t}} \\ 7.1800 & .316 & .103 & .001 & .420 & .012 \\ 7.2000 & .313 & .108 & .002 & .423 & .013 \\ 7.2200 & .302 & .111 & .004 & .417 & .015 \\ 7.2250 & .300 & .112 & .004 & .417 & .015 \\ 7.2500 & .297 & .125 & .006 & .428 & .018 \\ 7.2700 & .297 & .135 & .007 & .440 & .021 \\ 7.2800 & .303 & .141 & .008 & .452 & .023 \\ 7.3400 & .405 & .177 & .014 & .597 & .038 \\ 7.3500 & .439 & .186 & .017 & .641 & .040 \\ 7.3600 & .474 & .188 & .020 & .682 & .038 \\ 7.3700 & .527 & .194 & .023 & .744 & .038 \\ 7.4000 & .621 & .204 & .032 & .858 & .032 \\ 7.4200 & .689 & .206 & .038 & .934 & .029 \\ 7.4700 & .779 & .212 & .054 & 1.046 & .026 \\ 7.5290 & .828 & .210 & .073 & 1.112 & .025 \\ 7.5420 & .827 & .206 & .078 & 1.113 & .025 \\ 7.5530 & .828 & .206 & .082 & 1.117 & .025 \\ 7.5940 & .840 & .201 & .097 & 1.141 & .024 \\ 7.6200 & .843 & .202 & .113 & 1.160 & .024 \\ 7.6500 & .858 & .203 & .132 & 1.195 & .025 \\ 7.6670 & .897 & .204 & .141 & 1.244 & .027 \\ 7.6800 & .914 & .203 & .146 & 1.266 & .027 \\ 7.6980 & .986 & .207 & .155 & 1.349 & .029 \\ 7.7000 & .989 & .206 & .156 & 1.353 & .029 \\ 7.7250 & 1.162 & .215 & .168 & 1.544 & .033 \\ 7.7450 & 1.278 & .216 & .176 & 1.670 & .037 \\ 7.7500 & 1.252 & .214 & .177 & 1.644 & .036 \\ 7.7700 & 1.151 & .216 & .186 & 1.552 & .035 \\ 7.7890 & 1.027 & .219 & .192 & 1.438 & .034 \\ 7.8100 & .905 & .226 & .201 & 1.333 & .035 \\ 7.8190 & .880 & .229 & .206 & 1.316 & .036 \\ 7.8600 & .757 & .234 & .226 & 1.216 & .040 \\ 7.8870 & .732 & .237 & .232 & 1.200 & .040 \\ 7.8880 & .722 & .235 & .231 & 1.188 & .039\end{array}$


Table 32

Kerma Factors and Uncertainties $\left(\mathrm{fGy} \cdot \mathrm{m}^{2}\right.$ )

\begin{tabular}{|c|c|c|c|c|c|c|}
\hline $\mathrm{E}_{\mathrm{n}} \mathrm{MeV}$ & $\mathrm{K}_{e}$ & $\mathrm{~K}_{\text {in }}$ & $K_{n, \alpha}$ & $K_{n, n^{\prime} 3 \alpha}$ & $k_{t}$ & $\Delta K_{t}$ \\
\hline 7.8970 & .718 & .237 & .232 & .000 & 1.186 & .039 \\
\hline 7.9300 & .686 & .246 & .236 & .000 & 1.167 & .038 \\
\hline 7.9360 & .673 & .246 & .236 & .000 & 1.155 & .038 \\
\hline 8.0000 & .621 & .271 & .237 & .000 & 1.129 & .042 \\
\hline 8.0050 & .618 & .276 & .239 & .000 & 1.133 & .042 \\
\hline 8.0100 & .591 & .278 & .239 & .000 & 1.108 & .042 \\
\hline 8.0140 & .599 & .285 & .241 & .000 & 1.125 & .041 \\
\hline 8.0440 & .553 & .302 & .232 & .000 & 1.088 & .040 \\
\hline 8.0530 & .558 & .307 & .231 & .000 & 1.096 & .041 \\
\hline 8.0790 & .528 & .313 & .225 & .000 & 1.065 & .042 \\
\hline 8.0800 & .524 & .312 & .224 & .000 & 1.060 & .042 \\
\hline 8.1000 & .504 & .319 & .218 & .000 & 1.038 & .045 \\
\hline 8.1010 & .509 & .322 & .218 & .000 & 1.045 & .045 \\
\hline 8.1050 & .499 & .321 & .216 & .000 & 1.032 & .046 \\
\hline 8.1090 & .488 & .319 & .213 & .000 & 1.017 & .046 \\
\hline 8.1200 & .471 & .318 & .211 & .000 & .997 & .045 \\
\hline 8.1310 & .447 & .315 & .207 & .000 & .968 & .044 \\
\hline 8.1380 & .435 & .314 & .206 & .000 & .953 & .043 \\
\hline 8.1600 & .393 & .308 & .197 & .000 & .897 & .041 \\
\hline 8.1660 & .377 & .304 & .194 & .000 & .875 & .040 \\
\hline 8.2000 & .317 & .298 & .183 & .000 & .798 & .036 \\
\hline 8.2100 & .310 & .278 & .179 & .000 & .774 & .035 \\
\hline 8.2180 & .309 & .272 & .177 & .000 & .763 & .035 \\
\hline 8.2400 & .304 & .255 & .169 & .000 & .732 & .034 \\
\hline 8.2800 & .312 & .222 & .159 & .000 & .696 & .033 \\
\hline 8.2960 & .318 & .209 & .161 & .000 & .690 & .032 \\
\hline 8.2960 & .318 & .209 & .161 & .000 & .690 & .031 \\
\hline 8.3200 & .332 & .196 & .161 & .000 & .691 & .030 \\
\hline 8.3300 & .334 & .192 & .160 & .001 & .688 & .029 \\
\hline 8.3910 & .355 & .172 & .158 & .001 & .688 & .026 \\
\hline 8.4000 & .358 & .169 & .158 & .002 & .687 & .026 \\
\hline 8.4260 & .373 & .167 & .157 & .002 & .700 & .025 \\
\hline 8.4480 & .378 & .166 & .156 & .002 & .702 & .025 \\
\hline 8.4500 & .372 & .165 & .155 & .002 & .694 & .025 \\
\hline 8.4800 & .396 & .165 & .156 & .003 & .719 & .025 \\
\hline 8.5000 & .400 & .163 & .153 & .003 & .719 & .024 \\
\hline 8.5000 & .400 & .163 & .153 & .003 & .719 & .023 \\
\hline 8.5200 & .407 & .163 & .151 & .003 & .724 & .023 \\
\hline 8.5530 & .409 & .165 & .147 & .004 & .725 & .021 \\
\hline 8.6000 & .435 & .165 & .143 & .004 & .747 & .022 \\
\hline 8.6110 & .439 & .165 & .142 & .004 & .750 & .022 \\
\hline 8.6640 & .454 & .161 & .148 & .005 & .768 & .022 \\
\hline 8.7000 & .465 & .161 & .164 & .006 & .796 & .021 \\
\hline 8.7080 & .463 & .162 & .167 & .006 & .799 & .021 \\
\hline 8.7500 & .463 & .173 & .184 & .007 & .827 & .023 \\
\hline 8.7680 & .466 & .180 & .192 & .007 & .845 & .024 \\
\hline 8.8000 & .469 & .191 & .204 & .007 & .872 & .027 \\
\hline 8.8330 & .467 & .199 & .242 & .008 & .918 & .026 \\
\hline
\end{tabular}


Table 32 (Continued)

\begin{tabular}{|c|c|c|c|c|c|c|}
\hline $\mathrm{E}_{\mathrm{n}} \mathrm{MeV}$ & $K_{\theta}$ & $\mathrm{K}_{\mathrm{in}}$ & $K_{n, \alpha}$ & $K_{n, n^{\prime} 3 \alpha}$ & $\mathrm{K}_{\mathrm{t}}$ & $\Delta \mathrm{K}_{\mathrm{t}}$ \\
\hline 8.8500 & .463 & .204 & .267 & .008 & .945 & .025 \\
\hline 8.8850 & .467 & .213 & .319 & .008 & 1.010 & .028 \\
\hline 8.9200 & .455 & .216 & .358 & .009 & 1.044 & .035 \\
\hline 8.9400 & .460 & .222 & .388 & .009 & 1.086 & .039 \\
\hline 8.9800 & .467 & .231 & .467 & .010 & 1.178 & .039 \\
\hline 9.0000 & .470 & .226 & .508 & .010 & 1.216 & .044 \\
\hline 9.0050 & .479 & .228 & .522 & .010 & 1.241 & .043 \\
\hline 9.0200 & .475 & .226 & .536 & .010 & 1.250 & .041 \\
\hline 9.0300 & .479 & .227 & .550 & .011 & 1.268 & .040 \\
\hline 9.0450 & .479 & .226 & .563 & .011 & 1.281 & .041 \\
\hline 9.0530 & .488 & .227 & .580 & .011 & 1.308 & .041 \\
\hline 9.0670 & .485 & .225 & .585 & .011 & 1.309 & .043 \\
\hline 9.0800 & .495 & .226 & .607 & .011 & 1.343 & .046 \\
\hline 9.1490 & .507 & .227 & .690 & .013 & 1.439 & .047 \\
\hline 9.1630 & .513 & .229 & .703 & .013 & 1.460 & .051 \\
\hline 9.1800 & .509 & .227 & .700 & .013 & 1.451 & .061 \\
\hline 9.2190 & .497 & .226 & .796 & .014 & 1.536 & .065 \\
\hline 9.2500 & .486 & .227 & .800 & .014 & 1.531 & .054 \\
\hline 9.2540 & .491 & .229 & .810 & .015 & 1.547 & .053 \\
\hline 9.3000 & .469 & .231 & .801 & .015 & 1.518 & .060 \\
\hline 9.3100 & .466 & .232 & .804 & .017 & 1.521 & .064 \\
\hline 9.3600 & .445 & .234 & .772 & .018 & 1.470 & .057 \\
\hline 9.4000 & .424 & .234 & .760 & .019 & 1.439 & .059 \\
\hline 9.4500 & .407 & .237 & .733 & .020 & 1.399 & .053 \\
\hline 9.5000 & .395 & .240 & .676 & .022 & 1.334 & .057 \\
\hline 9.5220 & .393 & .243 & .653 & .022 & 1.313 & .049 \\
\hline 9.5530 & .387 & .247 & .609 & .023 & 1.268 & .052 \\
\hline 9.5600 & .389 & .250 & .604 & .023 & 1.267 & .055 \\
\hline 9.5900 & .388 & .244 & .582 & .024 & 1.240 & .053 \\
\hline 9.6000 & .387 & .240 & .576 & .024 & 1.231 & .050 \\
\hline 9.6300 & .389 & .238 & .565 & .025 & 1.220 & .049 \\
\hline 9.6400 & .392 & .239 & .567 & .026 & 1.225 & .051 \\
\hline 9.6780 & .388 & .235 & .571 & .027 & 1.219 & .063 \\
\hline 9.6800 & .387 & .235 & .569 & .027 & 1.216 & .064 \\
\hline 9.6920 & .385 & .231 & .585 & .027 & 1.228 & .054 \\
\hline 9.7000 & .385 & .230 & .610 & .027 & 1.253 & .052 \\
\hline 9.7260 & .374 & .222 & .661 & .028 & 1.287 & .055 \\
\hline 9.7400 & .376 & .223 & .689 & .029 & 1.317 & .064 \\
\hline 9.7500 & .372 & .219 & .657 & .029 & 1.278 & .059 \\
\hline 9.8000 & .375 & .216 & .603 & .031 & 1.228 & .047 \\
\hline 9.8210 & .372 & .211 & .586 & .031 & 1.203 & .052 \\
\hline 9.8300 & .373 & .210 & .586 & .032 & 1.202 & .056 \\
\hline 9.8680 & .365 & 201 & .575 & .033 & 1.174 & .050 \\
\hline 9.9000 & .358 & .195 & .560 & .034 & 1.147 & .049 \\
\hline 9.9170 & .358 & .193 & .559 & .034 & 1.144 & .056 \\
\hline 9.9210 & .354 & .191 & .553 & .034 & 1.133 & .059 \\
\hline 10.0000 & .340 & .187 & .561 & .037 & 1.127 & .057 \\
\hline
\end{tabular}


Table 33

Kerma Factors and Uncertainties $\left(\mathrm{fGy} \cdot \mathrm{m}^{2}\right.$ )

\begin{tabular}{|c|c|c|c|c|c|c|}
\hline $\mathrm{E}_{\mathrm{n}} \mathrm{MeV}$ & $\mathrm{K}_{\Theta}$ & $\mathrm{K}_{\text {in }}$ & $K_{n, \alpha}$ & $K_{n, n^{\prime} 3 \alpha}$ & $k_{t}$ & $\Delta \mathrm{K}_{\mathrm{t}}$ \\
\hline 10.0500 & .336 & .193 & .537 & .062 & 1.128 & .050 \\
\hline 10.0530 & .333 & .192 & .534 & .062 & 1.121 & .049 \\
\hline 10.1700 & .343 & .203 & .457 & .077 & 1.083 & .040 \\
\hline 10.2500 & .344 & .213 & .463 & .085 & 1.108 & .046 \\
\hline 10.3000 & .344 & .223 & .459 & .089 & 1.118 & .037 \\
\hline 10.3720 & .352 & .242 & .489 & .096 & 1.182 & .045 \\
\hline 10.4000 & .359 & .250 & .467 & .099 & 1.178 & .040 \\
\hline 10.4480 & .374 & .264 & .406 & .108 & 1.156 & .041 \\
\hline 10.4780 & .383 & .273 & .395 & .113 & 1.169 & .038 \\
\hline 10.5000 & .392 & .280 & .387 & .117 & 1.181 & .038 \\
\hline 10.5060 & .392 & .281 & .385 & .118 & 1.180 & .038 \\
\hline 10.5360 & .395 & .285 & .376 & .124 & 1.185 & .041 \\
\hline 10.5500 & .392 & .286 & .371 & .126 & 1.180 & .044 \\
\hline 10.5530 & .398 & .288 & .373 & .129 & 1.192 & .043 \\
\hline 10.6200 & .402 & .297 & .366 & .146 & 1.216 & .043 \\
\hline 10.6900 & .409 & .308 & .364 & .151 & 1.237 & .046 \\
\hline 10.7000 & .409 & .306 & .363 & .152 & 1.235 & .045 \\
\hline 10.7500 & .423 & .303 & .359 & .166 & 1.255 & .043 \\
\hline 10.8000 & .432 & .298 & .355 & .181 & 1.271 & .045 \\
\hline 10.8300 & .440 & .295 & .354 & .179 & 1.273 & .046 \\
\hline 10.9000 & .453 & .287 & .342 & .181 & 1.270 & .048 \\
\hline 10.9400 & .456 & .282 & .330 & .185 & 1.259 & .047 \\
\hline 11.0000 & .436 & .292 & .318 & .213 & 1.264 & .051 \\
\hline 11.0040 & .434 & .290 & .317 & .212 & 1.258 & .051 \\
\hline 11.0530 & .446 & .282 & .318 & .222 & 1.272 & .050 \\
\hline 11.0960 & .449 & .274 & .325 & .225 & 1.277 & .048 \\
\hline 11.1000 & .452 & .274 & .327 & .227 & 1.283 & .048 \\
\hline 11.1660 & .470 & .263 & .340 & .235 & 1.310 & .053 \\
\hline 11.1700 & .471 & .263 & .340 & .236 & 1.313 & .053 \\
\hline 11.2500 & .476 & .253 & .370 & .249 & 1.350 & .058 \\
\hline 11.3000 & .481 & .248 & .392 & .255 & 1.378 & .063 \\
\hline 11.4000 & .494 & .238 & .399 & .281 & 1.415 & .065 \\
\hline 11.5000 & .503 & .228 & .408 & .271 & 1.412 & .060 \\
\hline 11.5530 & .500 & .225 & .419 & .283 & 1.429 & .061 \\
\hline 11.7000 & .506 & .218 & .445 & .302 & 1.472 & .061 \\
\hline 11.7500 & .519 & .216 & .456 & .315 & 1.508 & .065 \\
\hline 11.7510 & .516 & .215 & .456 & .313 & 1.502 & .065 \\
\hline 11.8000 & .526 & .212 & .463 & .316 & 1.520 & .071 \\
\hline 11.8280 & .536 & .212 & .469 & .323 & 1.541 & .069 \\
\hline 11.9000 & .565 & .209 & .486 & .340 & 1.602 & .070 \\
\hline 11.9090 & .563 & .208 & .486 & .340 & 1.598 & .071 \\
\hline 11.9170 & .571 & .208 & .490 & .344 & 1.615 & .071 \\
\hline 12.0000 & .571 & .208 & .545 & .405 & 1.732 & .077 \\
\hline 12.0500 & .584 & .212 & .589 & .415 & 1.803 & .078 \\
\hline 12.0530 & .587 & .212 & .596 & .418 & 1.816 & .078 \\
\hline 12.0880 & .589 & .213 & .624 & .424 & 1.853 & .080 \\
\hline 12.1000 & .591 & .214 & .637 & .430 & 1.874 & .080 \\
\hline 12.1960 & .577 & .211 & .590 & .473 & 1.851 & .077 \\
\hline
\end{tabular}


Table 33 (Continued)

$\begin{array}{lcccccc}E_{n} \mathrm{MeV} & \mathrm{K}_{\boldsymbol{\theta}} & \mathrm{K}_{\mathrm{in}} & \mathrm{K}_{\mathrm{n}, \boldsymbol{\alpha}} & \mathrm{K}_{\mathrm{n}, \mathrm{n}^{\prime} 3 \alpha} & \mathrm{K}_{\mathrm{t}} & \Delta \mathrm{K}_{\mathrm{t}} \\ 12.2240 & .576 & .210 & .582 & .459 & 1.826 & .074 \\ 12.2500 & .576 & .210 & .577 & .451 & 1.814 & .072 \\ 12.3000 & .574 & .208 & .561 & .441 & 1.784 & .069 \\ 12.4000 & .579 & .208 & .550 & .476 & 1.814 & .072 \\ 12.5000 & .603 & .207 & .539 & .458 & 1.808 & .068 \\ 12.5530 & .602 & .212 & .537 & .467 & 1.819 & .071 \\ 12.5990 & .600 & .216 & .533 & .468 & 1.818 & .075 \\ 12.7000 & .599 & .224 & .522 & .473 & 1.819 & .077 \\ 12.7380 & .595 & .226 & .511 & .466 & 1.800 & .080 \\ 12.8000 & .598 & .232 & .513 & .469 & 1.814 & .088 \\ 12.9000 & .592 & .239 & .505 & .496 & 1.835 & .083 \\ 12.9900 & .594 & .244 & .497 & .481 & 1.816 & .086 \\ 13.0000 & .592 & .243 & .500 & .489 & 1.822 & .088 \\ 13.0530 & .592 & .244 & .494 & .511 & 1.841 & .081 \\ 13.1000 & .595 & .245 & .491 & .526 & 1.857 & .078 \\ 13.1200 & .596 & .246 & .490 & .528 & 1.859 & .078 \\ 13.2500 & .599 & .248 & .478 & .540 & 1.865 & .078 \\ 13.2800 & .595 & .247 & .471 & .541 & 1.852 & .077 \\ 13.3000 & .597 & .248 & .471 & .553 & 1.868 & .077 \\ 13.5000 & .604 & .252 & .461 & .627 & 1.944 & .084 \\ 13.5400 & .606 & .253 & .459 & .639 & 1.958 & .087 \\ 13.5530 & .605 & .253 & .457 & .639 & 1.956 & .089 \\ 13.5870 & .604 & .254 & .453 & .643 & 1.955 & .093 \\ 13.6460 & .592 & .253 & .453 & .631 & 1.930 & .087 \\ 13.7000 & .586 & .253 & .460 & .643 & 1.942 & .086 \\ 13.7480 & .578 & .251 & .460 & .632 & 1.922 & .093 \\ 13.8220 & .562 & .246 & .441 & .606 & 1.856 & .109 \\ 13.8300 & .561 & .246 & .441 & .619 & 1.869 & .110 \\ 13.9650 & .543 & .243 & .422 & .676 & 1.887 & .099 \\ 14.0000 & .528 & .236 & .415 & .766 & 1.946 & .114 \\ 14.0530 & .535 & .236 & .459 & .758 & 1.988 & .091 \\ 14.1820 & .547 & .236 & .495 & .754 & 2.031 & .105 \\ 14.2500 & .556 & .233 & .492 & .775 & 2.055 & .097 \\ 14.3640 & .559 & .225 & .481 & .783 & 2.047 & .105 \\ 14.4190 & .558 & .220 & .479 & .801 & 2.057 & .117 \\ 14.5000 & .573 & .203 & .489 & .867 & 2.132 & .115\end{array}$


Table 34

Kerma Factors and Uncertainties $\left(f G y \cdot m^{2}\right.$ )

$\begin{array}{lccccccc}E_{n} \mathrm{MeV} & \mathrm{K}_{\mathrm{\theta}} & \mathrm{K}_{\mathrm{in}} & \mathrm{K}_{\mathrm{n}, \alpha} & \mathrm{K}_{\mathrm{n}, \mathrm{n}^{\prime} 3 \alpha} & \mathrm{K}_{\mathrm{n}, \mathrm{p}} & \mathrm{K}_{\mathrm{t}} & \Delta \mathrm{K}_{\mathrm{t}} \\ 14.5530 & .580 & .204 & .479 & .906 & .000 & 2.170 & .108 \\ 14.5660 & .579 & .204 & .472 & .909 & .000 & 2.165 & .108 \\ 14.6530 & .590 & .205 & .441 & .950 & .001 & 2.187 & .101 \\ 14.6940 & .596 & .206 & .424 & .952 & .001 & 2.181 & .098 \\ 14.7500 & .595 & .202 & .404 & .994 & .001 & 2.196 & .102 \\ 14.7670 & .592 & .200 & .398 & 1.006 & .001 & 2.198 & .105 \\ 14.8070 & .592 & .197 & .388 & 1.058 & .001 & 2.236 & .111 \\ 14.8120 & .593 & .197 & .388 & 1.061 & .001 & 2.241 & .110 \\ 14.8370 & .593 & .194 & .387 & 1.045 & .001 & 2.221 & .105 \\ 14.8630 & .593 & .192 & .385 & 1.030 & .001 & 2.203 & .102 \\ 14.8880 & .593 & .190 & .383 & 1.020 & .001 & 2.188 & .100 \\ 14.8920 & .596 & .190 & .384 & 1.029 & .001 & 2.202 & .100 \\ 14.9060 & .596 & .189 & .383 & 1.028 & .002 & 2.199 & .102 \\ 14.9090 & .596 & .188 & .383 & 1.029 & .002 & 2.199 & .101 \\ 14.9270 & .594 & .186 & .382 & 1.023 & .002 & 2.187 & .103 \\ 14.9540 & .591 & .186 & .382 & 1.044 & .002 & 2.204 & .107 \\ 14.9620 & .590 & .186 & .381 & 1.050 & .002 & 2.210 & .108 \\ 14.9960 & .590 & .186 & .382 & 1.107 & .002 & 2.267 & .116 \\ 15.0000 & .586 & .185 & .381 & 1.083 & .002 & 2.237 & .117 \\ 15.0060 & .587 & .185 & .381 & 1.086 & .002 & 2.242 & .114 \\ 15.0450 & .592 & .185 & .382 & 1.075 & .003 & 2.240 & .107 \\ 15.0530 & .595 & .185 & .382 & 1.077 & .003 & 2.244 & .107 \\ 15.0930 & .600 & .185 & .381 & 1.063 & .003 & 2.238 & .105 \\ 15.2480 & .610 & .178 & .385 & 1.097 & .005 & 2.278 & .111 \\ 15.2500 & .610 & .178 & .385 & 1.096 & .006 & 2.277 & .110\end{array}$


Table 35

Kerma Factors and Uncertainties $\left(\mathrm{fGy} \cdot \mathrm{m}^{2}\right.$ )

$\begin{array}{lllllllll}\mathrm{E}_{\mathrm{n}} \mathrm{MeV} & \mathrm{K}_{\mathrm{e}} & \mathrm{K}_{\mathrm{in}} & \mathrm{K}_{\mathrm{n}, \alpha} & \mathrm{K}_{\mathrm{n}, \mathrm{n}^{\prime} 3 \alpha} & \mathrm{K}_{\mathrm{n}, \mathrm{p}} & \mathrm{K}_{\mathrm{n}, \mathrm{d}} & \mathrm{K}_{\mathrm{t}} & \Delta \mathrm{K}_{\mathrm{t}} \\ 15.4480 & .624 & .170 & .385 & 1.117 & .009 & .002 & 2.308 & .131 \\ 15.4770 & .625 & .169 & .382 & 1.121 & .009 & .003 & 2.310 & .123 \\ 15.5530 & .628 & .166 & .374 & 1.141 & .011 & .007 & 2.329 & .137 \\ 15.7310 & .634 & .161 & .320 & 1.213 & .015 & .018 & 2.364 & .132 \\ 15.9660 & .642 & .153 & .297 & 1.265 & .022 & .036 & 2.416 & .152 \\ 15.9700 & .646 & .153 & .296 & 1.280 & .022 & .037 & 2.435 & .155 \\ 15.9900 & .644 & .152 & .289 & 1.272 & .022 & .037 & 2.418 & .168 \\ 16.0000 & .647 & .152 & .286 & 1.286 & .023 & .038 & 2.433 & .176 \\ 16.0530 & .638 & .150 & .294 & 1.281 & .024 & .041 & 2.430 & .144 \\ 16.0680 & .636 & .150 & .302 & 1.288 & .024 & .042 & 2.445 & .142 \\ 16.2560 & .616 & .141 & .288 & 1.339 & .029 & .053 & 2.467 & .144 \\ 16.4400 & .598 & .131 & .351 & 1.376 & .034 & .066 & 2.557 & .152 \\ 16.4430 & .597 & .131 & .348 & 1.370 & .034 & .066 & 2.546 & .150 \\ 16.5320 & .593 & .126 & .313 & 1.391 & .036 & .072 & 2.533 & .150 \\ 16.5530 & .591 & .125 & .321 & 1.400 & .037 & .073 & 2.549 & .156 \\ 16.6950 & .576 & .124 & .359 & 1.413 & .040 & .083 & 2.595 & .145 \\ 16.8200 & .569 & .124 & .356 & 1.456 & .042 & .093 & 2.640 & .161 \\ 16.8240 & .568 & .124 & .356 & 1.447 & .042 & .093 & 2.630 & .160 \\ 16.9740 & .561 & .124 & .381 & 1.451 & .046 & .105 & 2.668 & .164 \\ 17.0530 & .561 & .124 & .391 & 1.477 & .048 & .112 & 2.714 & .159 \\ 17.0740 & .563 & .125 & .397 & 1.485 & .049 & .114 & 2.733 & .157 \\ 17.1380 & .555 & .124 & .411 & 1.473 & .051 & .119 & 2.733 & .155 \\ 17.3000 & .544 & .127 & .403 & 1.610 & .057 & .136 & 2.879 & .151\end{array}$




\section{Table 36}

Kerma Factors and Uncertainties $\left(f G y \cdot m^{2}\right.$ )

\begin{tabular}{|c|c|c|c|c|c|c|c|c|c|}
\hline$E_{n} \mathrm{MeV}$ & $\mathrm{K}_{\Theta}$ & $\mathrm{K}_{\text {in }}$ & $K_{n, \alpha}$ & $K_{n, n^{\prime} 3 \alpha}$ & $\mathrm{K}_{\mathrm{n}, \mathrm{p}}$ & $K_{n, d}$ & $K_{n, n p}$ & $K_{t}$ & $\Delta K_{t}$ \\
\hline 17.301 & .553 & .127 & .402 & 1.570 & .057 & .135 & .000 & 2.844 & .200 \\
\hline 17.467 & .545 & .128 & .354 & 1.629 & .063 & .152 & .000 & 2.872 & .205 \\
\hline 17.553 & .549 & .129 & .326 & 1.652 & .066 & .162 & .000 & 2.885 & .208 \\
\hline 17.616 & .553 & .127 & .309 & 1.669 & .069 & .169 & .000 & 2.897 & .210 \\
\hline 17.687 & .554 & .123 & .301 & 1.680 & .072 & .177 & .000 & 2.909 & .213 \\
\hline 17.900 & .563 & .113 & .286 & 1.726 & .081 & .203 & .002 & 2.975 & .220 \\
\hline 17.901 & .565 & .113 & .286 & 1.730 & .081 & .203 & .002 & 2.981 & .220 \\
\hline 18.000 & .570 & .108 & .284 & 1.753 & .083 & .214 & .004 & 3.017 & .223 \\
\hline 18.053 & .577 & .106 & .272 & 1.774 & .084 & .221 & .005 & 3.039 & .225 \\
\hline 18.087 & .573 & .106 & .263 & 1.768 & .084 & .224 & .006 & 3.024 & .225 \\
\hline 18.158 & .580 & .115 & .246 & 1.790 & .085 & .233 & .008 & 3.058 & .227 \\
\hline 18.273 & .575 & .121 & .217 & 1.799 & .087 & .246 & .012 & 3.058 & .230 \\
\hline 18.460 & .570 & .119 & .197 & 1.795 & .090 & .266 & .017 & 3.054 & .236 \\
\hline 18.553 & .575 & .120 & .199 & 1.820 & .090 & .271 & .019 & 3.094 & .239 \\
\hline 18.632 & .583 & .118 & .201 & 1.848 & .091 & .275 & .020 & 3.136 & .242 \\
\hline 18.700 & .586 & .113 & .210 & 1.866 & .091 & .278 & .022 & 3.166 & .245 \\
\hline 18.833 & .587 & .104 & .230 & 1.885 & .092 & .283 & .025 & 3.206 & .250 \\
\hline 19.030 & .595 & .091 & .233 & 1.911 & .093 & .290 & .030 & 3.243 & .258 \\
\hline 19.034 & .602 & .091 & .233 & 1.927 & .093 & .291 & .030 & 3.267 & .258 \\
\hline 19.053 & .603 & .090 & .232 & 1.930 & .093 & .290 & .030 & 3.269 & .259 \\
\hline 19.185 & .612 & .088 & .245 & 1.950 & .090 & .287 & .034 & 3.306 & .265 \\
\hline 19.346 & .626 & .089 & .268 & 1.975 & .087 & .283 & .038 & 3.366 & .272 \\
\hline 19.511 & .639 & .090 & .307 & 2.013 & .084 & .279 & .043 & 3.455 & .280 \\
\hline 19.553 & .641 & .091 & .327 & 2.022 & .083 & .279 & .044 & 3.487 & .283 \\
\hline 19.660 & .641 & .092 & .377 & 2.036 & .082 & .276 & .047 & 3.551 & .291 \\
\hline 19.661 & .644 & .092 & .378 & 2.043 & .082 & .277 & .047 & 3.562 & .292 \\
\hline 19.794 & .634 & .092 & .374 & 2.037 & .080 & .272 & .051 & 3.542 & .301 \\
\hline 19.892 & .634 & .093 & .334 & 2.050 & .079 & .270 & .055 & 3.516 & .309 \\
\hline 20.000 & .626 & .094 & .481 & 2.067 & .077 & .267 & .059 & 3.671 & .305 \\
\hline 20.100 & .602 & .095 & .532 & 2.081 & .077 & .265 & .063 & 3.714 & .312 \\
\hline 20.200 & .591 & .096 & .455 & 2.109 & .076 & .264 & .067 & 3.658 & .325 \\
\hline 20.300 & .569 & .098 & .387 & 2.123 & .075 & .263 & .071 & 3.585 & .338 \\
\hline 20.400 & .549 & .099 & .361 & 2.139 & .074 & .261 & .074 & 3.556 & .348 \\
\hline 20.500 & .534 & .100 & .335 & 2.163 & .073 & .259 & .078 & 3.541 & .357 \\
\hline
\end{tabular}


Table 37

Kerma Factors and Uncertainties $\left(\mathrm{fGy} \cdot \mathrm{m}^{2}\right)$

$E_{n} \mathrm{MeV} \quad K_{e} \quad K_{i n} \quad K_{n, \alpha} \quad K_{n, n^{\prime} 3 \alpha} \quad K_{n, p} \quad K_{n, d} \quad K_{n, n p} \quad K_{n, 2 n} \quad K_{n, t} \quad K_{t} \quad \Delta K_{t}$

$\begin{array}{llllllllllll}20.600 & .511 & .101 & .305 & 2.181 & .071 & .257 & .082 & .000 & .000 & 3.509 & .364\end{array}$

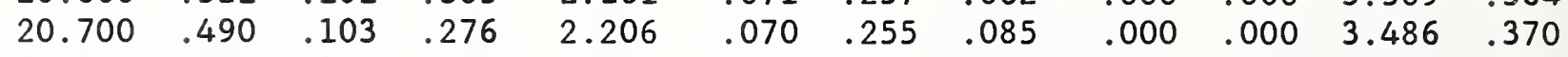

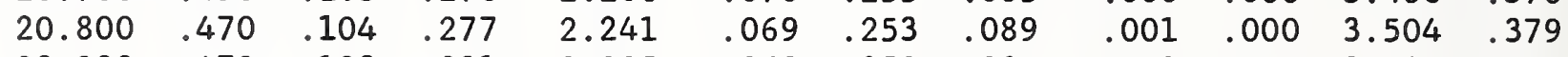

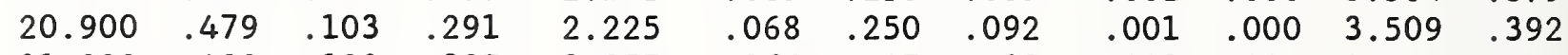

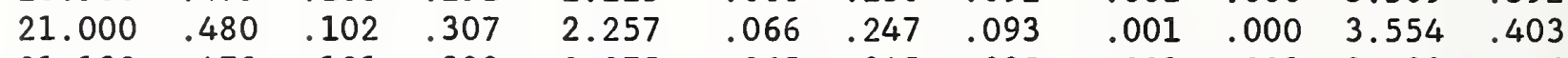

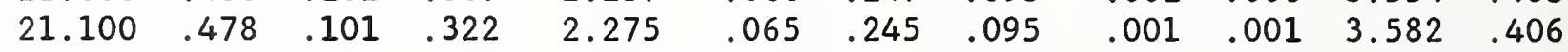

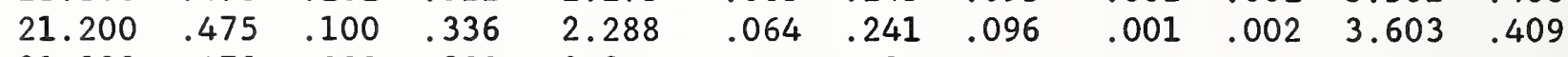

$\begin{array}{llllllllllll}21.300 & .478 & .099 & .380 & 2.320 & .062 & .238 & .097 & .001 & .004 & 3.680 & .416\end{array}$

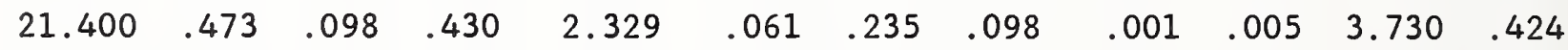

$\begin{array}{llllllllllll}21.500 & .470 & .097 & .444 & 2.342 & .059 & .231 & .098 & .002 & .006 & 3.749 & .428\end{array}$

$\begin{array}{llllllllllll}21.600 & .473 & .096 & .402 & 2.378 & .057 & .228 & .097 & .002 & .008 & 3.741 & .424\end{array}$

$\begin{array}{llllllllllll}21.700 & .473 & .095 & .359 & 2.406 & .056 & .224 & .097 & .002 & .009 & 3.720 & .420\end{array}$

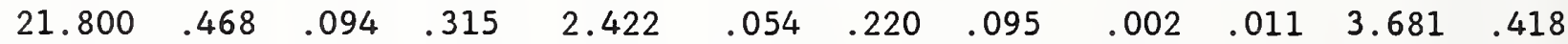

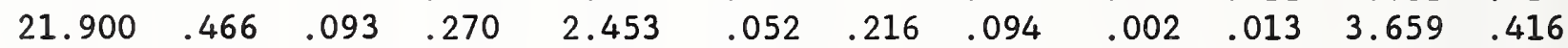

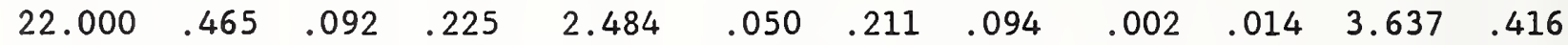

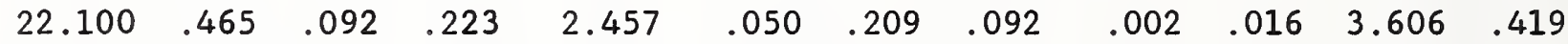

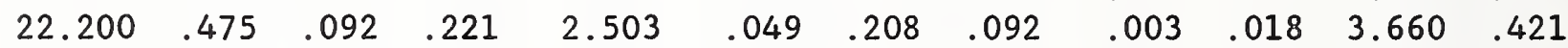

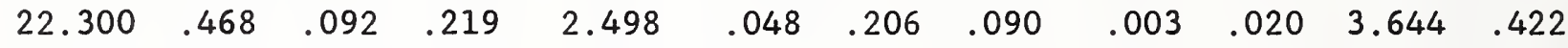

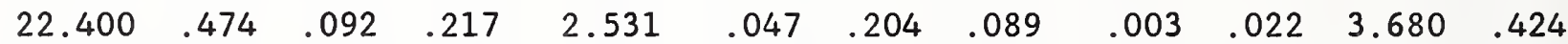

$\begin{array}{llllllllllll}22.500 & .474 & .093 & .215 & 2.547 & .046 & .202 & .089 & .003 & .025 & 3.694 & .425\end{array}$

$\begin{array}{llllllllllll}22.600 & .475 & .093 & .213 & 2.563 & .046 & .199 & .088 & .004 & .027 & 3.707 & .427\end{array}$

$\begin{array}{llllllllllll}22.700 & .480 & .093 & .211 & 2.595 & .045 & .197 & .088 & .004 & .029 & 3.741 & .428\end{array}$

$\begin{array}{llllllllllll}22.800 & .481 & .093 & .208 & 2.615 & .044 & .195 & .087 & .004 & .031 & 3.759 & .430\end{array}$

$\begin{array}{llllllllllll}22.900 & .482 & .093 & .206 & 2.632 & .043 & .192 & .086 & .004 & .034 & 3.773 & .432\end{array}$

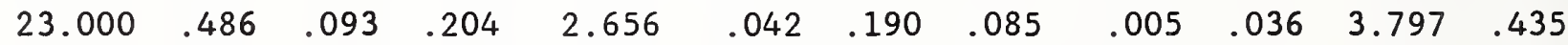

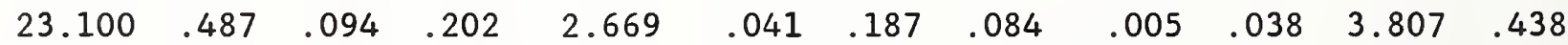

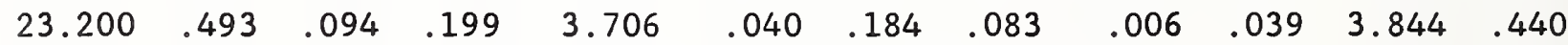

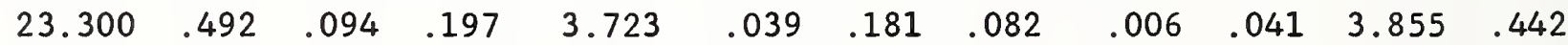

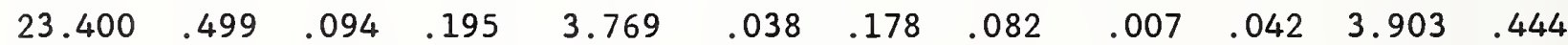

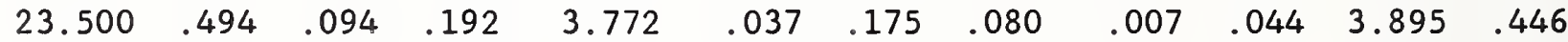

$\begin{array}{llllllllllll}23.600 & .502 & .094 & .189 & 3.781 & .036 & .171 & .079 & .008 & .045 & 3.906 & .448\end{array}$ 
Table 38

Kerma Factors and Uncertainties $\left(f G y \cdot m^{2}\right)$

$\begin{array}{lcccccccccccc}\mathrm{E}_{\mathrm{n}} \mathrm{MeV} & \mathrm{K}_{\boldsymbol{\theta}} & \mathrm{K}_{\mathrm{in}} & \mathrm{K}_{\mathrm{n}, \alpha} & \mathrm{K}_{\mathrm{n}, \mathrm{n}^{\prime} 3 \alpha} & \mathrm{K}_{\mathrm{n}, \mathrm{p}} & \mathrm{K}_{\mathrm{n}, \mathrm{d}} & \mathrm{K}_{\mathrm{n}, \mathrm{np}} & \mathrm{K}_{\mathrm{n}, 2 \mathrm{n}} & \mathrm{K}_{\mathrm{n}, \mathrm{t}} & \mathrm{K}_{\mathrm{n}, \mathrm{G}_{\mathrm{I} i}} & \mathrm{~K}_{\mathrm{t}} & \Delta \mathrm{K}_{\mathrm{t}} \\ 23.700 & .499 & .095 & .187 & 2.741 & .035 & .168 & .078 & .008 & .047 & .015 & 3.872 & .450 \\ 23.800 & .502 & .095 & .184 & 2.721 & .034 & .164 & .076 & .009 & .048 & .021 & 3.853 & .452 \\ 23.900 & .502 & .095 & .181 & 2.697 & .032 & .160 & .075 & .009 & .049 & .028 & 3.829 & .453 \\ 24.000 & .508 & .095 & .178 & 2.693 & .031 & .157 & .074 & .010 & .049 & .035 & 3.830 & .455 \\ 24.100 & .489 & .094 & .177 & 2.808 & .031 & .155 & .073 & .011 & .049 & .047 & 3.934 & .453 \\ 24.200 & .483 & .094 & .175 & 2.797 & .030 & .153 & .071 & .012 & .050 & .060 & 3.925 & .456 \\ 24.300 & .493 & .093 & .174 & 2.843 & .030 & .152 & .070 & .012 & .050 & .074 & 3.990 & .460 \\ 24.400 & .484 & .092 & .172 & 2.820 & .029 & .150 & .068 & .013 & .050 & .088 & 3.966 & .463 \\ 24.500 & .489 & .092 & .170 & 2.849 & .029 & .148 & .067 & .014 & .050 & .104 & 4.011 & .466 \\ 24.600 & .482 & .091 & .168 & 2.826 & .028 & .146 & .066 & .015 & .050 & .120 & 3.991 & .468\end{array}$




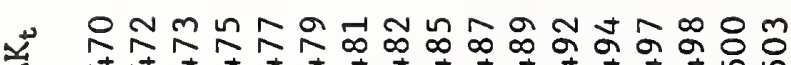

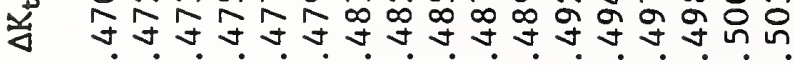

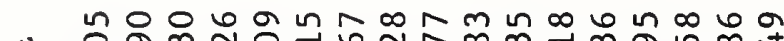

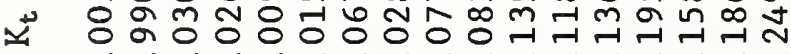

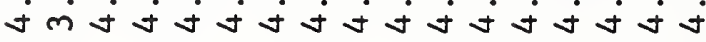

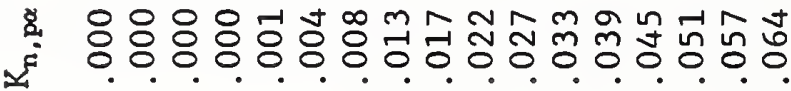

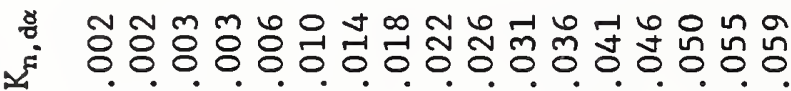

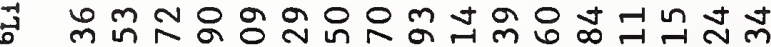

₹

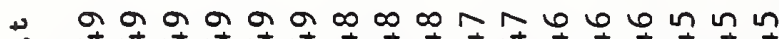

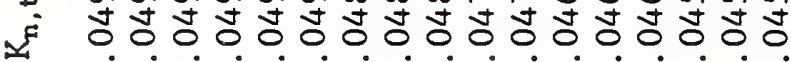

贸

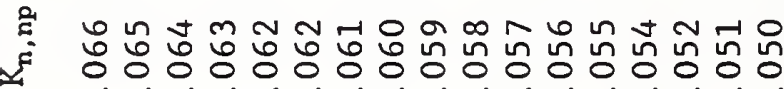

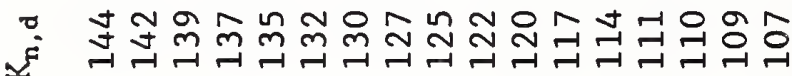

a

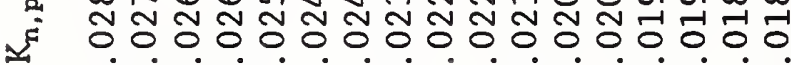

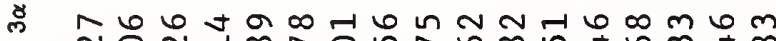

:

₹ กั่ง

ఈ

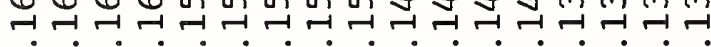

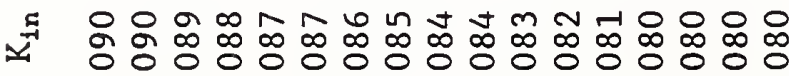

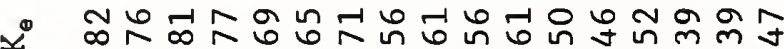

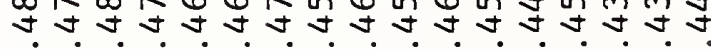

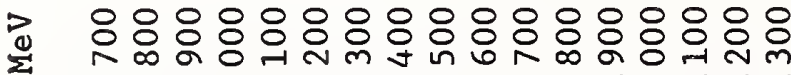

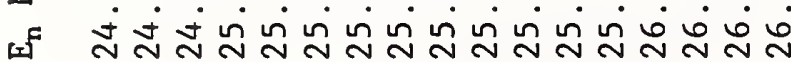


붕ㅇㅇㅇㅇㅢ

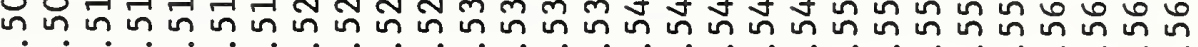

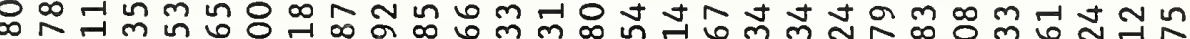
শี ㅊำm m

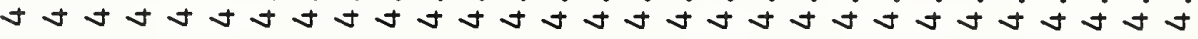

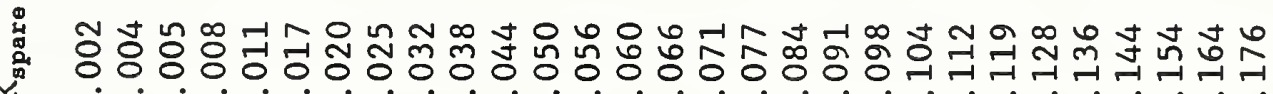

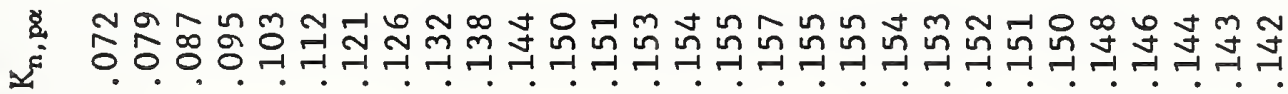

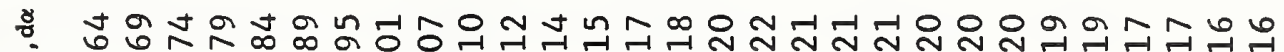
₹

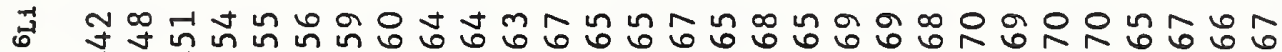

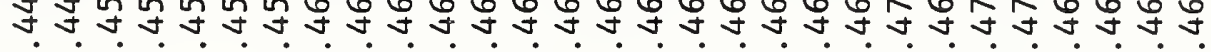

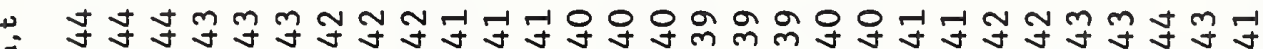

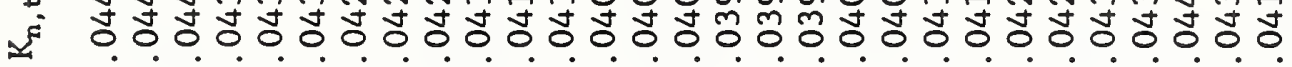

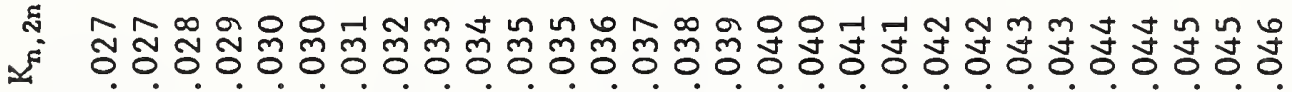

aำ

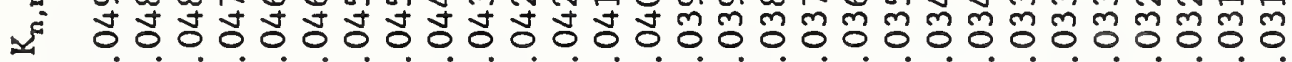

-

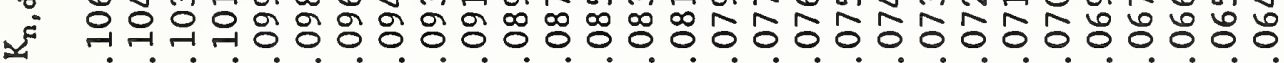

a $\quad \infty N \wedge 0$ un 0 n

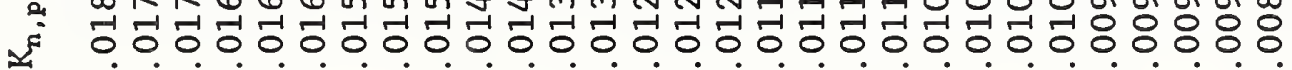

ㅁํำ 낫요

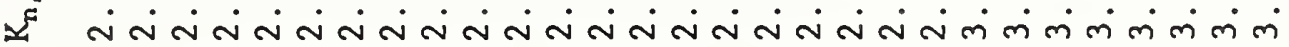

함

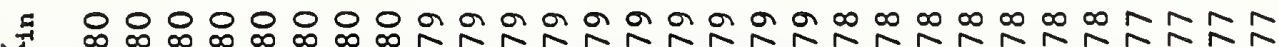
至 :

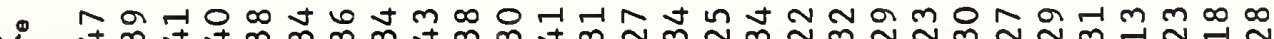
ษ

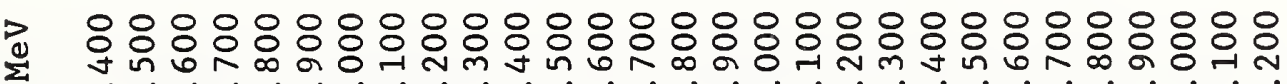
प 
艺

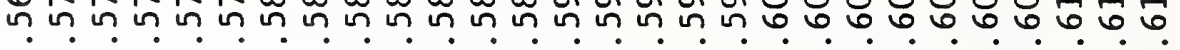

ํํำก ^

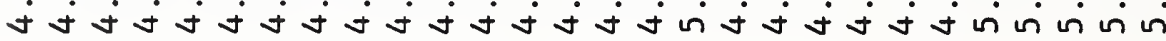

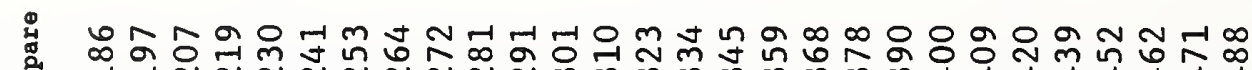
花

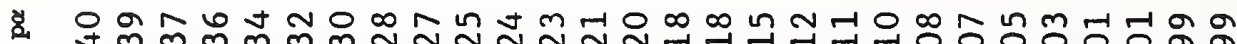

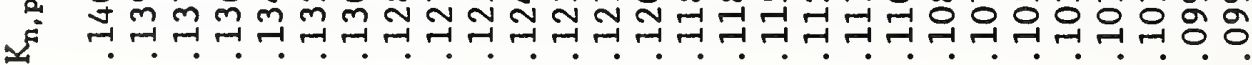

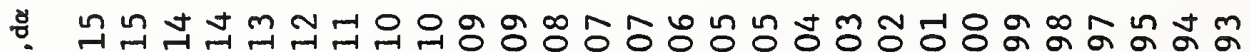

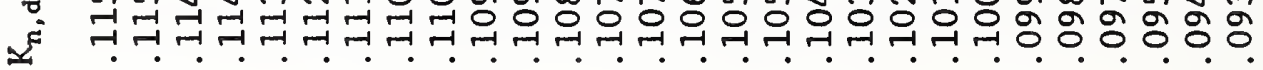

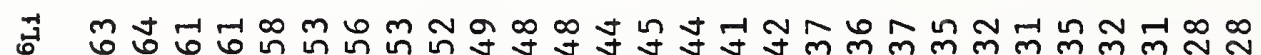
每

- 운ำn ๘

ㄷำ

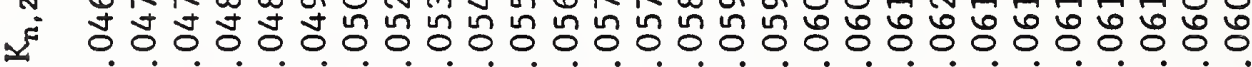

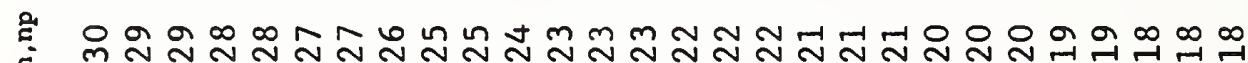
雨

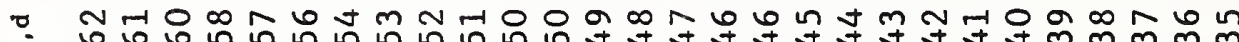

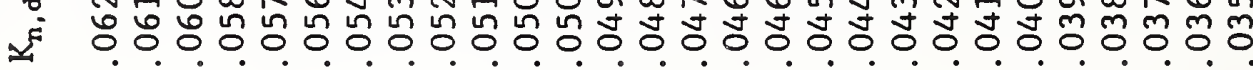

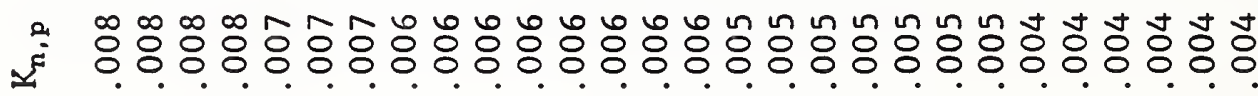

8 结

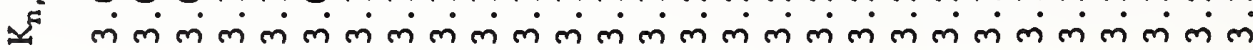

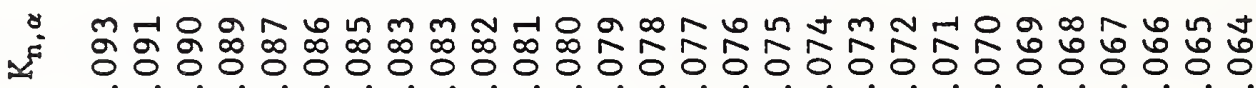

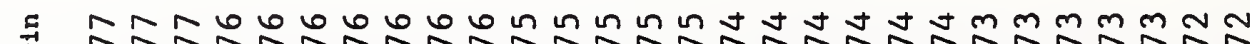

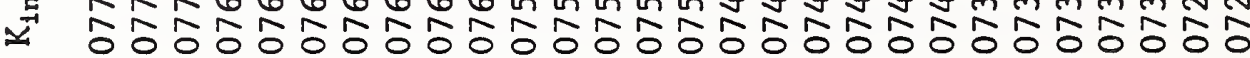

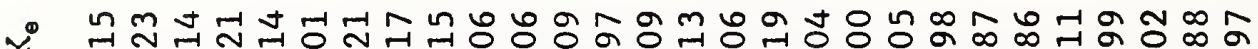

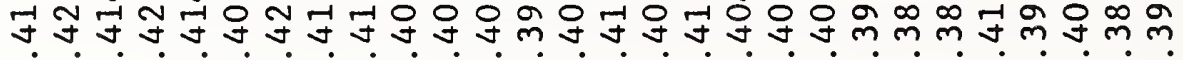

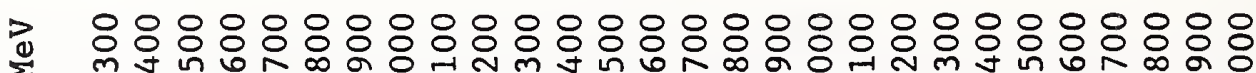
ज 
Table 42

Table of Input Data and Fitted Values for Simultaneous Fit

\begin{tabular}{|c|c|c|c|c|c|c|}
\hline Reference & $\begin{array}{l}\text { Measured } \\
\text { Quantity }\end{array}$ & $\begin{array}{c}\text { Measured } \\
\text { Value }\end{array}$ & Uncertainty & $\begin{array}{c}\text { Fitted } \\
\text { Value }\end{array}$ & Residual & $\begin{array}{l}\text { Weighted } \\
\text { Residual }\end{array}$ \\
\hline This work & gp [1] & 1.000 & .015 & .997 & .003 & .211 \\
\hline This work & $g P[2]$ & 1.000 & .039 & .999 & .001 & .036 \\
\hline This work & gp [3] & 1.000 & .076 & 1.031 & -.031 & -.409 \\
\hline This work & $\mathrm{gp}[4]$ & 1.000 & .130 & 1.013 & -.013 & -.097 \\
\hline This work & $g P[5]$ & 1.000 & .190 & .997 & .003 & .015 \\
\hline This work & gp [6] & 1.000 & .190 & .995 & .005 & .025 \\
\hline This work & $g p[7]$ & 1.000 & .050 & 1.024 & -.024 & -.474 \\
\hline This work & $g p[8]$ & 1.000 & .150 & 1.013 & -.013 & -.089 \\
\hline This work & $\operatorname{gP}[9]$ & 1.000 & .250 & 1.008 & -.008 & -.033 \\
\hline This work & $\operatorname{gp}[10]$ & 1.000 & .250 & 1.029 & -.029 & -.115 \\
\hline De84 & 1 fk 14.1 & 1.780 & .110 & 1.958 & -.178 & -1.616 \\
\hline De85 & $3 \mathrm{fk} 15$ & 2.100 & .160 & 2.184 & -.084 & -.523 \\
\hline Bu85 & $3 \mathrm{fk} 15$ & 2.350 & .210 & 2.184 & .166 & .792 \\
\hline Bu85 & $4 \mathrm{fk} 17$ & 2.460 & .240 & 2.622 & -.162 & -.677 \\
\hline De86 & $5 \mathrm{fk} 17.8$ & 2.920 & .220 & 2.877 & .043 & .197 \\
\hline $\operatorname{De} 85$ & 6 fk 17.9 & 2.970 & .300 & 2.907 & .063 & .210 \\
\hline $\operatorname{De} 86$ & $7 \mathrm{fk} 19.8$ & 3.550 & .280 & 3.408 & .142 & .508 \\
\hline Ho 76 & csta 14.4 & 654.0 & 92.0 & 662.550 & -8.540 & -.093 \\
\hline $\mathrm{Fa} 78$ & csta 14.8 & 900.0 & 70.0 & 798.446 & 101.554 & 1.451 \\
\hline Kn86 & csta 14.8 & 894.0 & 60.0 & 798.446 & 95.554 & 1.593 \\
\hline Ho76 & csta 14.9 & 744.0 & 60.0 & 771.419 & -27.423 & -.457 \\
\hline $\mathrm{Ha} 84$ & fka 14.1 & .490 & .060 & .478 & .012 & .198 \\
\hline $\mathrm{Ha} 84$ & $\mathrm{fk} 3 \mathrm{a} 14.1$ & .560 & .080 & .718 & -.157 & -1.969 \\
\hline An84 & feb3a 10.91 & 3.010 & 1.260 & 2.471 & .539 & .428 \\
\hline An84 & feb3a 12.93 & 4.020 & 1.110 & 3.760 & .260 & .234 \\
\hline An84 & feb3a 14.95 & 5.630 & 1.130 & 5.179 & .451 & .399 \\
\hline An84 & feb $3 a 16.87$ & 5.940 & 1.210 & 6.349 & -.409 & -.338 \\
\hline An84 & feb3a 18.94 & 7.690 & 1.190 & 7.870 & -.180 & -.151 \\
\hline
\end{tabular}


Table 43

Kerma Factors from Simultaneous Fit $\left(\mathrm{fGy} \cdot \mathrm{m}^{2}\right)$

\begin{tabular}{|c|c|c|c|c|c|c|c|c|}
\hline $\mathrm{E}_{\mathrm{n}} \mathrm{MeV}$ & $\mathrm{K}_{\theta}$ & $\mathrm{K}_{\text {in }}$ & $K_{n, \alpha}$ & $K_{n, p}$ & $K_{n, d}$ & $K_{n, n p}$ & $K_{n, n^{\prime} 3 \alpha}$ & $\mathrm{k}_{\mathrm{t}}$ \\
\hline 11.800 & .510 & .220 & .469 & .000 & .000 & .000 & .284 & 1.484 \\
\hline 12.000 & .554 & .216 & .552 & .000 & .000 & .000 & .371 & 1.693 \\
\hline 12.200 & .561 & .216 & .596 & .000 & .000 & .000 & .437 & 1.811 \\
\hline 12.400 & .564 & .214 & .557 & .000 & .000 & .000 & .444 & 1.779 \\
\hline 12.600 & .584 & .223 & .539 & .000 & .000 & .000 & .436 & 1.781 \\
\hline 12.800 & .580 & .241 & .519 & .000 & .000 & .000 & .435 & 1.774 \\
\hline 13.000 & .571 & .249 & .506 & .000 & .000 & .000 & .453 & 1.780 \\
\hline 13.200 & .578 & .254 & .489 & .000 & .000 & .000 & .499 & 1.820 \\
\hline 13.400 & .581 & .256 & .472 & .000 & .000 & .000 & .553 & 1.862 \\
\hline 13.600 & .581 & .262 & .459 & .000 & .000 & .000 & .602 & 1.904 \\
\hline 13.800 & .547 & .256 & .452 & .000 & .000 & .000 & .575 & 1.830 \\
\hline 14.000 & .508 & .244 & .421 & .000 & .000 & .000 & .728 & 1.900 \\
\hline 14.200 & .530 & .241 & .500 & .000 & .000 & .000 & .720 & 1.991 \\
\hline 14.400 & .538 & .227 & .485 & .000 & .000 & .000 & .756 & 2.007 \\
\hline 14.600 & .562 & .210 & .466 & .000 & .000 & .000 & .886 & 2.125 \\
\hline 14.800 & .569 & .203 & .394 & .001 & .000 & .000 & 1.010 & 2.177 \\
\hline 15.000 & .561 & .191 & .386 & .002 & .000 & .000 & 1.044 & 2.184 \\
\hline 15.200 & .581 & .189 & .388 & .005 & .000 & .000 & 1.047 & 2.210 \\
\hline 15.400 & .594 & .178 & .389 & .008 & .000 & .000 & 1.079 & 2.248 \\
\hline 15.600 & .601 & .171 & .365 & .012 & .010 & .000 & 1.121 & 2.280 \\
\hline 15.800 & .607 & .164 & .317 & .017 & .023 & .000 & 1.190 & 2.319 \\
\hline 16.000 & .616 & .157 & .290 & .023 & .038 & .000 & 1.248 & 2.371 \\
\hline 16.200 & .592 & .149 & .296 & .028 & .050 & .000 & 1.286 & 2.399 \\
\hline 16.400 & .572 & .137 & .341 & .033 & .063 & .000 & 1.329 & 2.476 \\
\hline 16.600 & .556 & .129 & .338 & .037 & .076 & .000 & 1.368 & 2.505 \\
\hline 16.800 & .541 & .127 & .361 & .042 & .091 & .000 & 1.412 & 2.574 \\
\hline 17.000 & .532 & .127 & .389 & .047 & .106 & .000 & 1.421 & 2.622 \\
\hline 17.200 & .522 & .129 & .413 & .053 & .125 & .000 & 1.486 & 2.727 \\
\hline 17.400 & .519 & .131 & .378 & .060 & .144 & .000 & 1.564 & 2.796 \\
\hline 17.600 & .522 & .130 & .317 & .068 & .166 & .000 & 1.624 & 2.828 \\
\hline 17.800 & .528 & .120 & .297 & .077 & .190 & .001 & 1.665 & 2.877 \\
\hline 18.000 & .538 & .110 & .288 & .083 & .213 & .003 & 1.714 & 2.948 \\
\hline 18.200 & .545 & .119 & .238 & .086 & .237 & .007 & 1.751 & 2.982 \\
\hline 18.400 & .538 & .122 & .206 & .089 & .259 & .010 & 1.753 & 2.976 \\
\hline 18.600 & .545 & .121 & .203 & .091 & .272 & .013 & 1.792 & 3.036 \\
\hline 18.800 & .551 & .108 & .228 & .092 & .280 & .015 & 1.836 & 3.111 \\
\hline 19.000 & .556 & .094 & .236 & .093 & .287 & .018 & 1.865 & 3.149 \\
\hline 19.200 & .575 & .089 & .250 & .090 & .286 & .020 & 1.909 & 3.219 \\
\hline 19.400 & .590 & .091 & .284 & .086 & .281 & .023 & 1.943 & 3.297 \\
\hline 19.600 & .600 & .093 & .353 & .082 & .276 & .025 & 1.980 & 3.409 \\
\hline 19.800 & .593 & .094 & .376 & .080 & .271 & .028 & 1.990 & 3.432 \\
\hline 20.000 & .585 & .096 & .486 & .077 & .265 & .031 & 2.016 & 3.558 \\
\hline
\end{tabular}




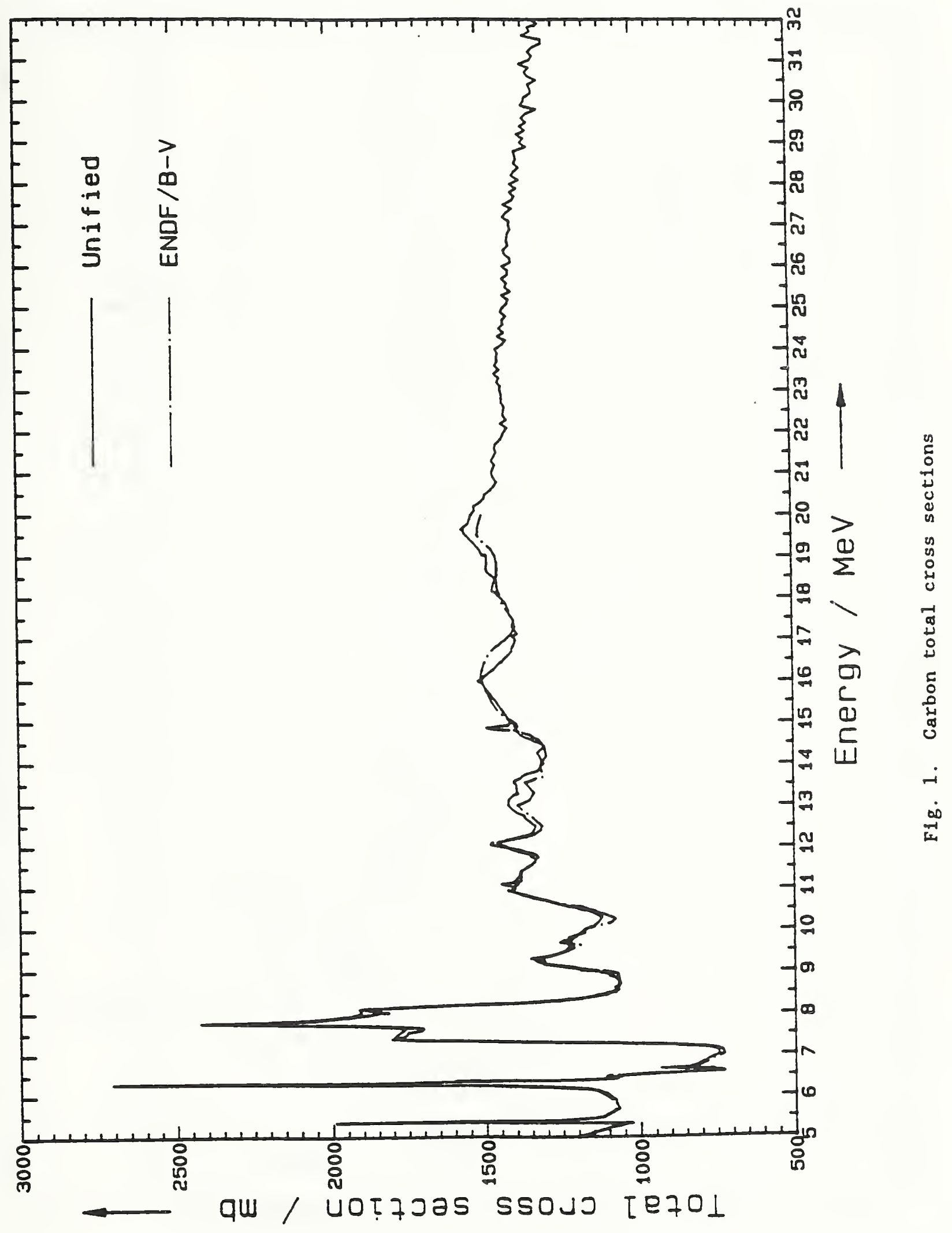




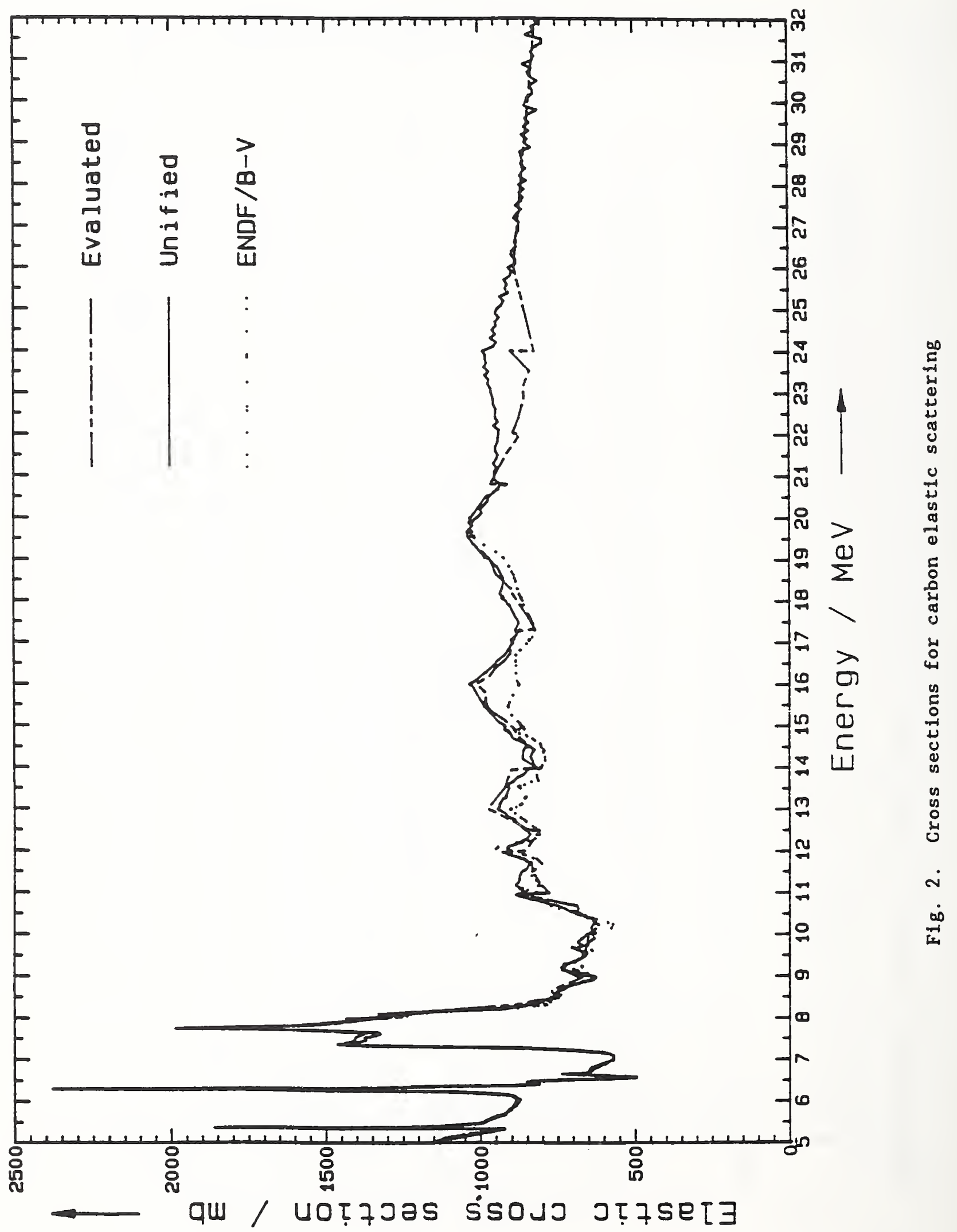




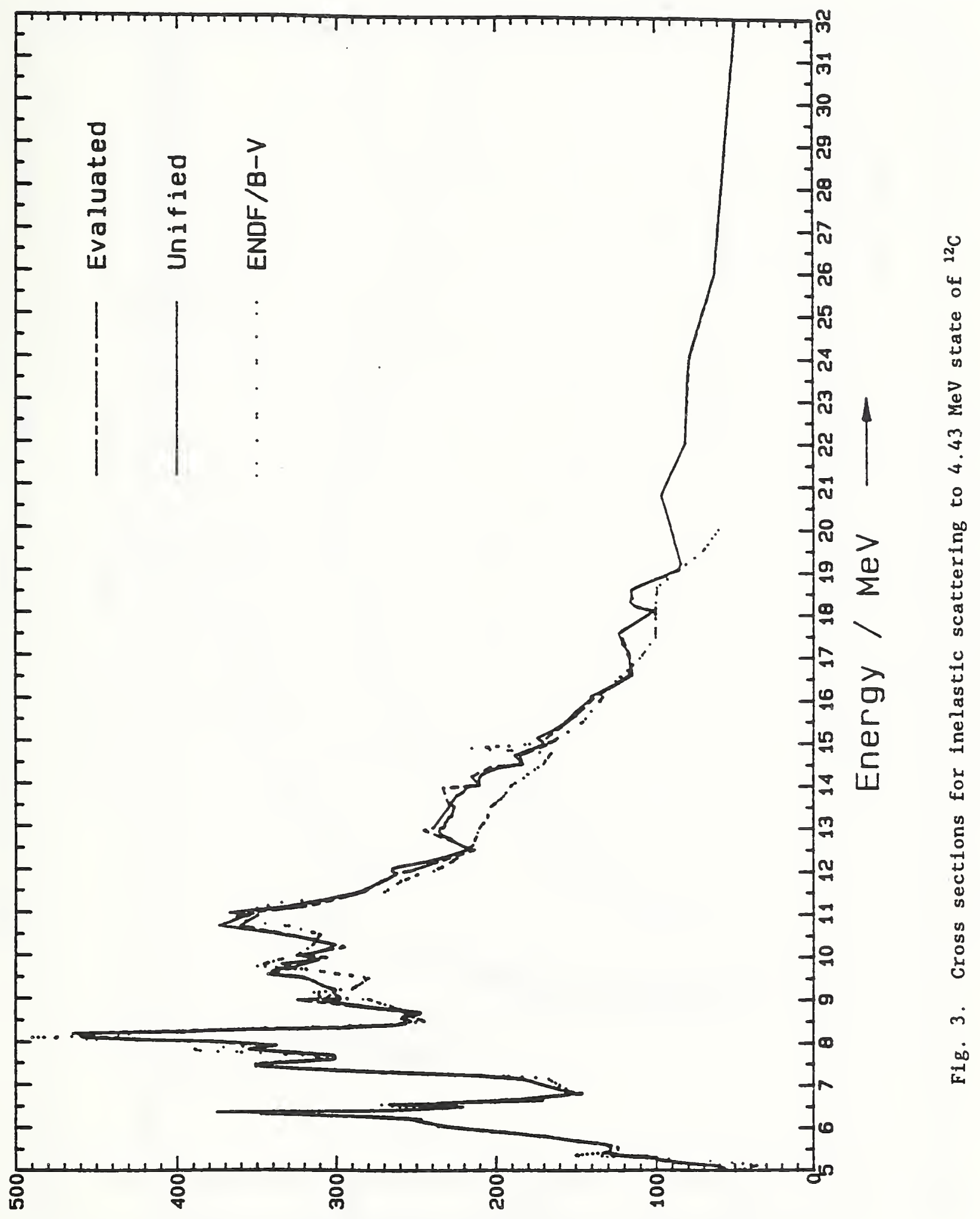

— qu / vot7Jas ssouJ JT7setauI 


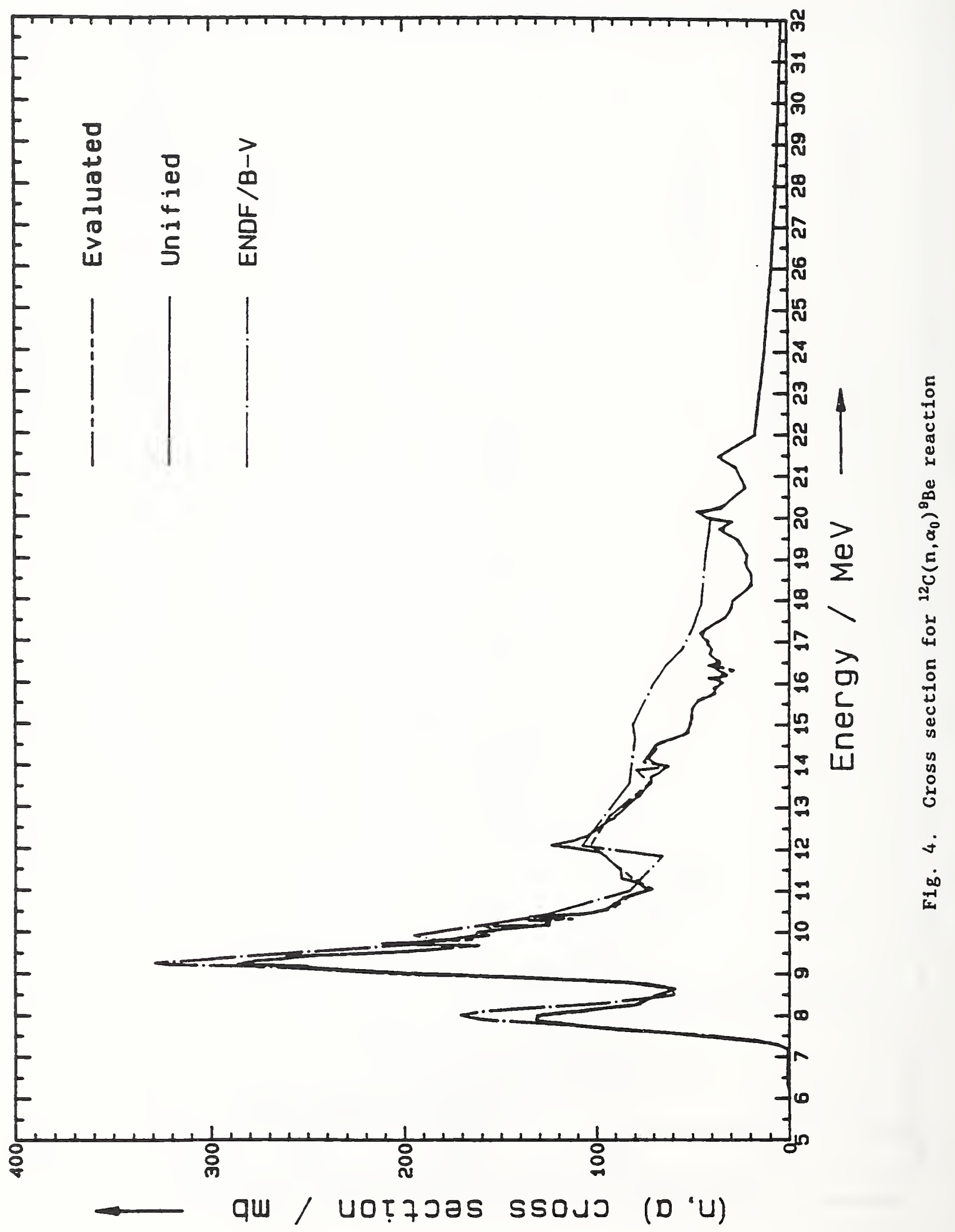




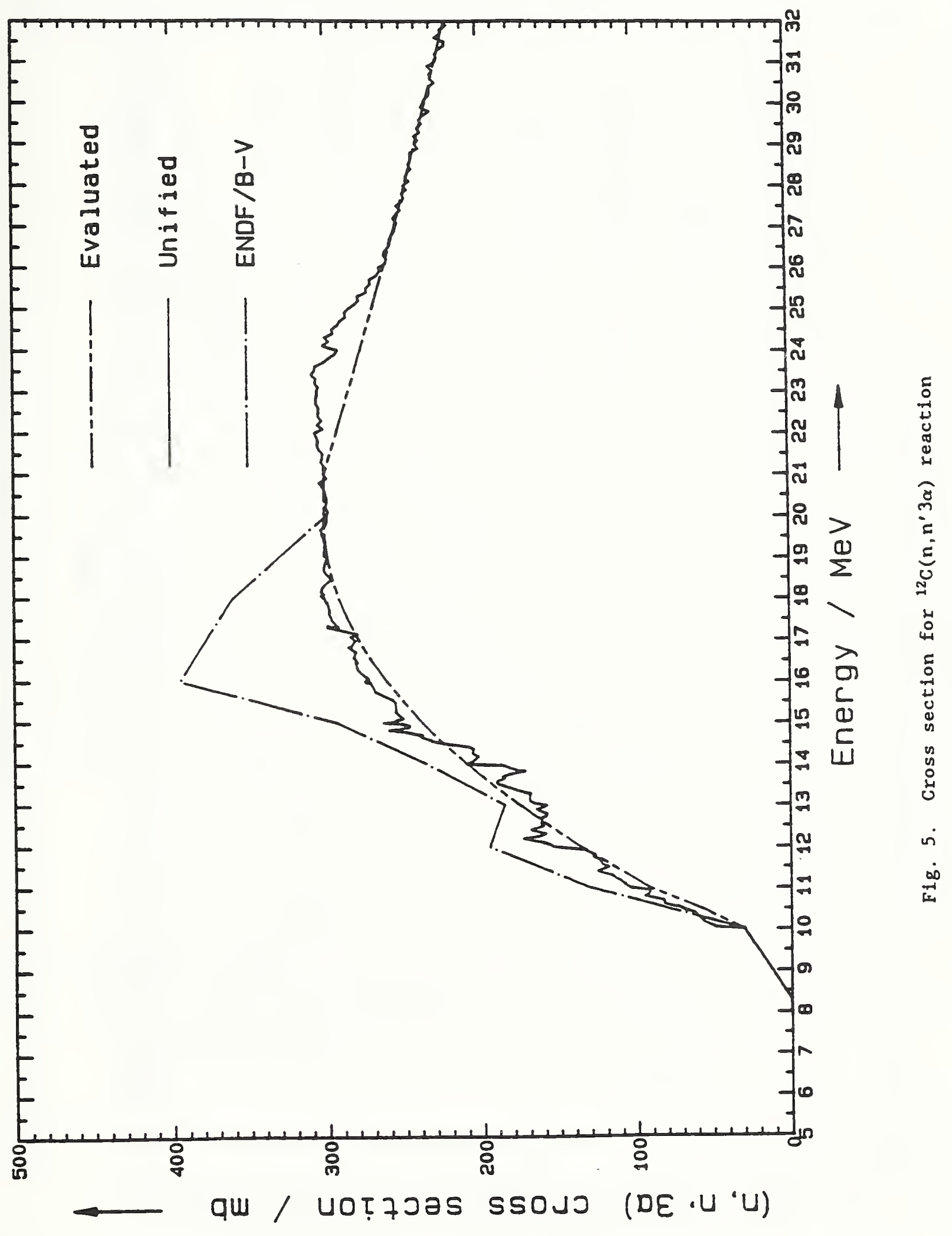




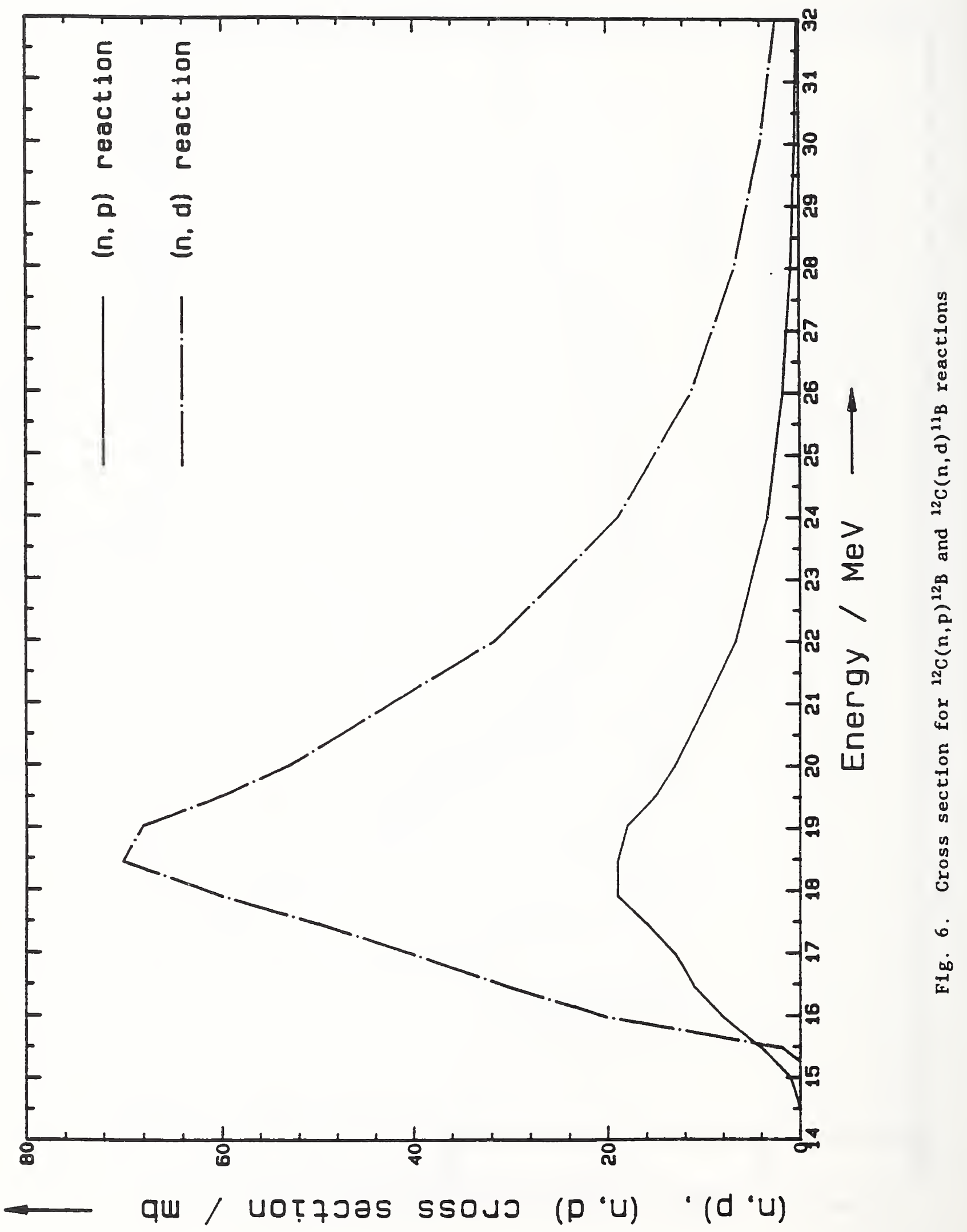




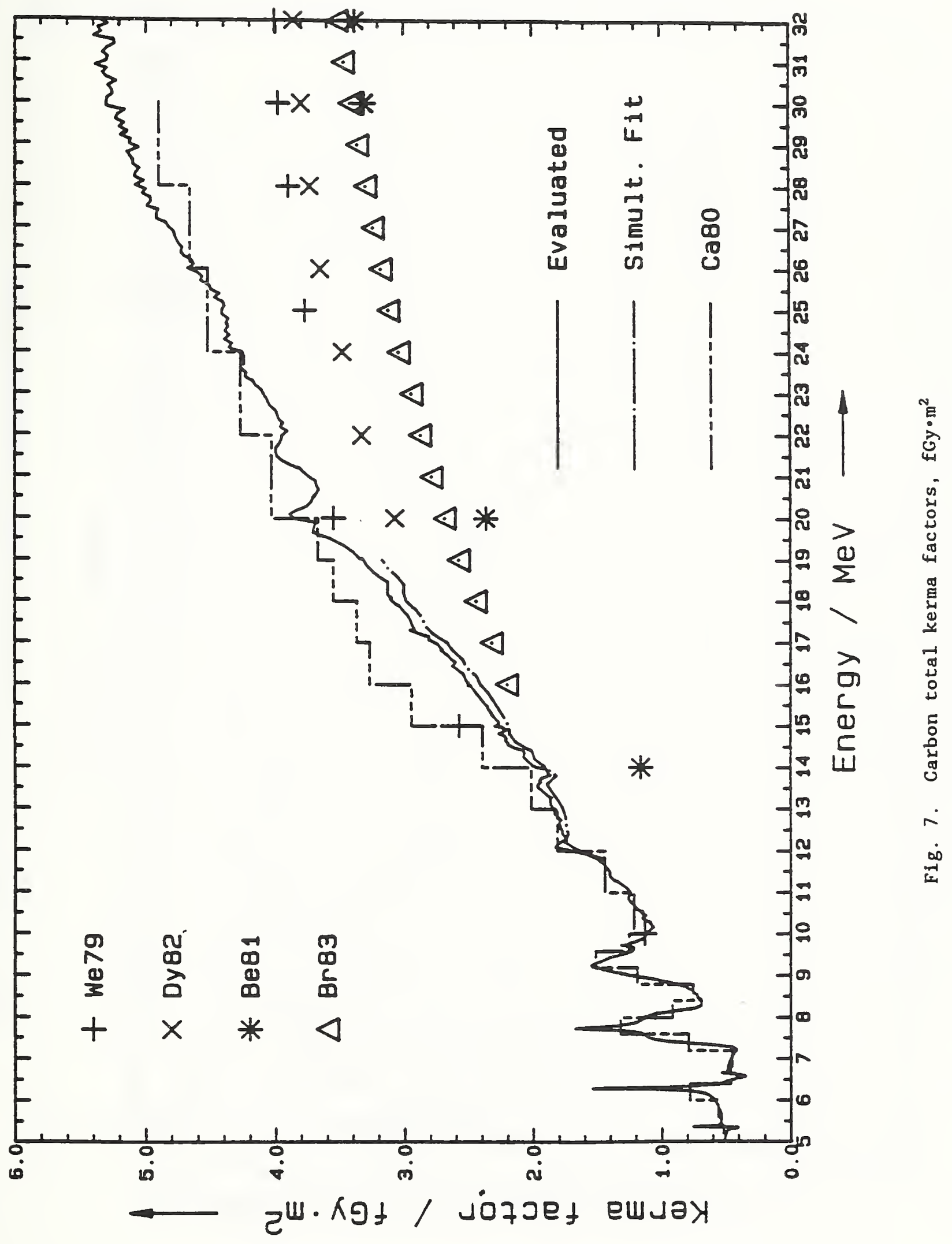




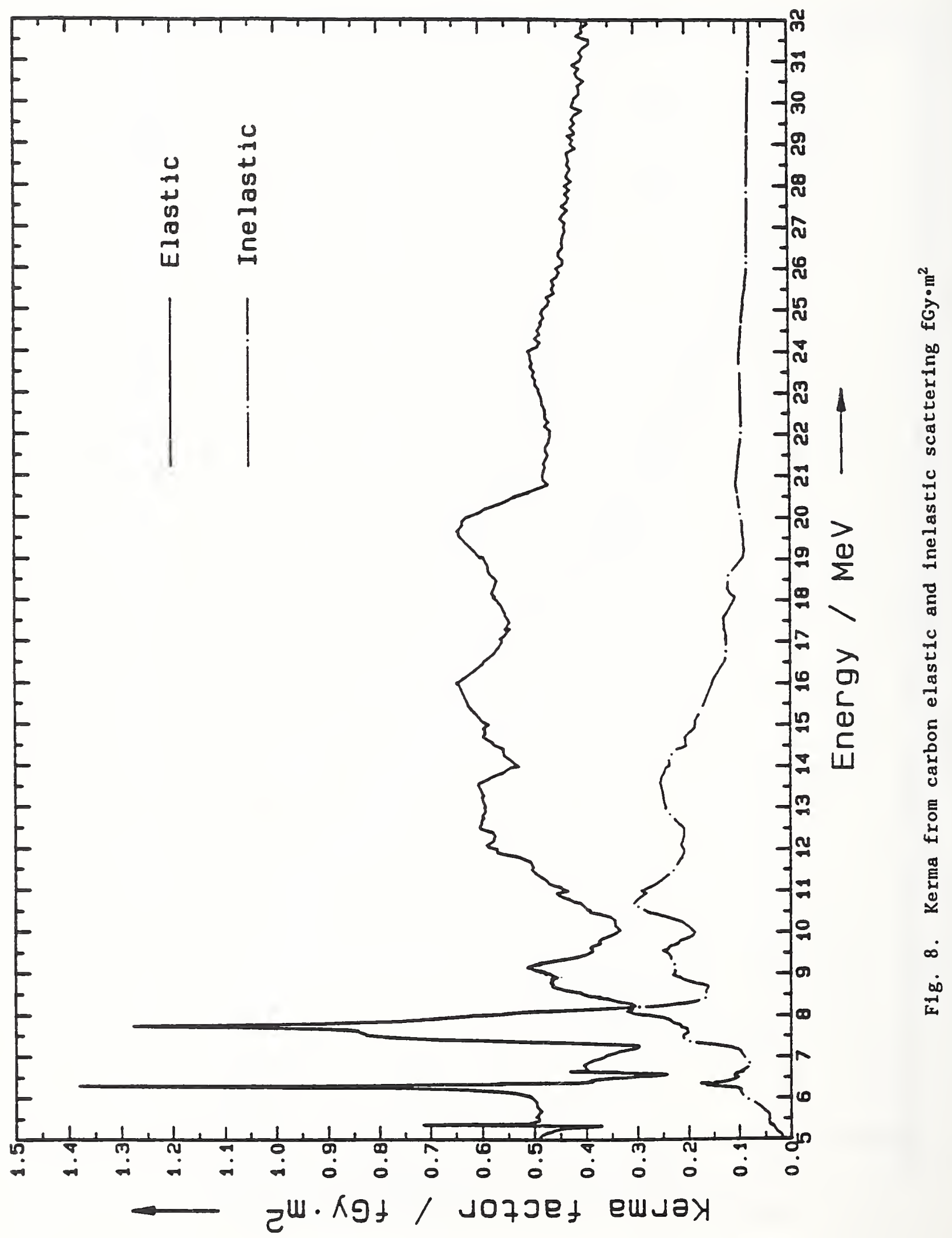




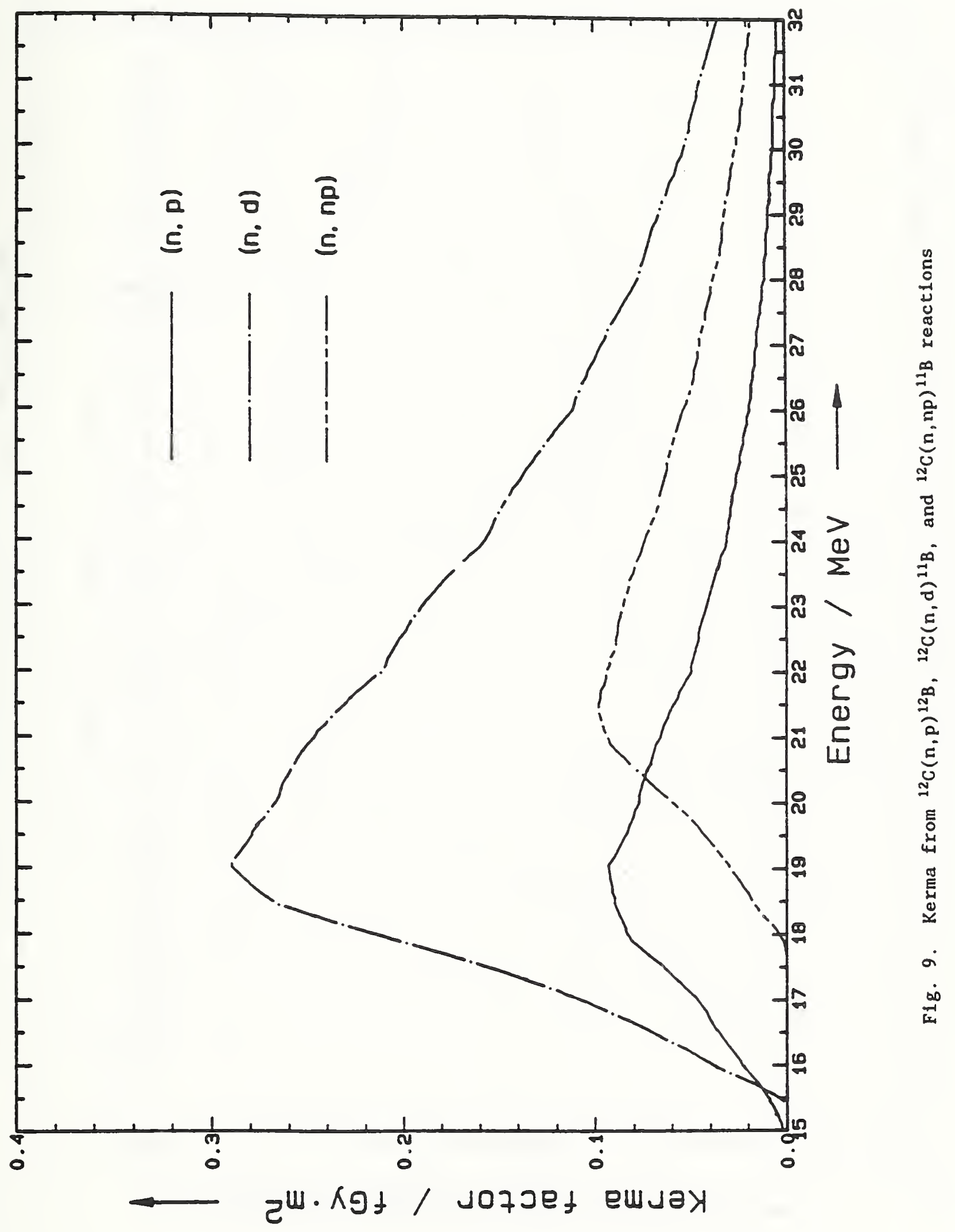




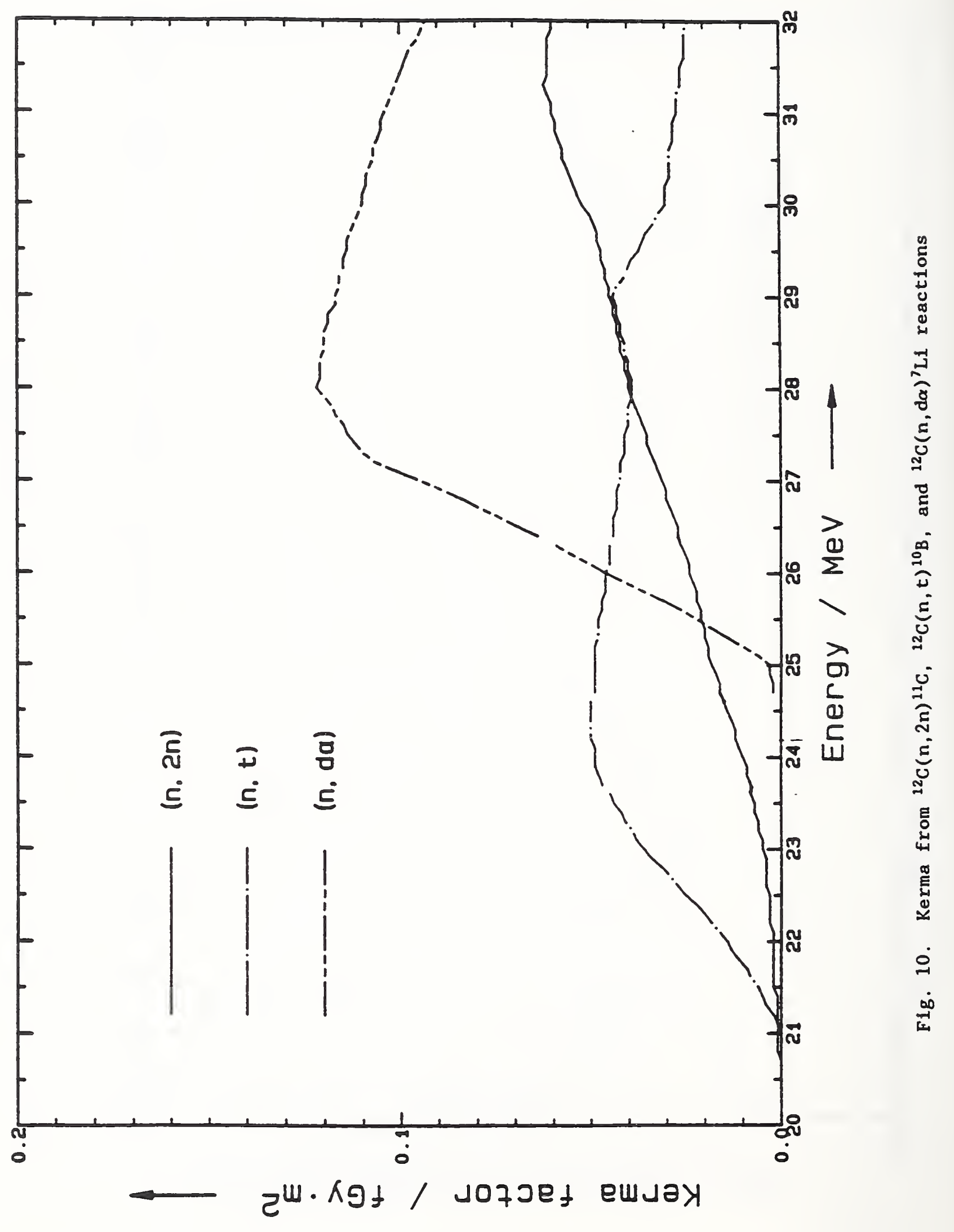




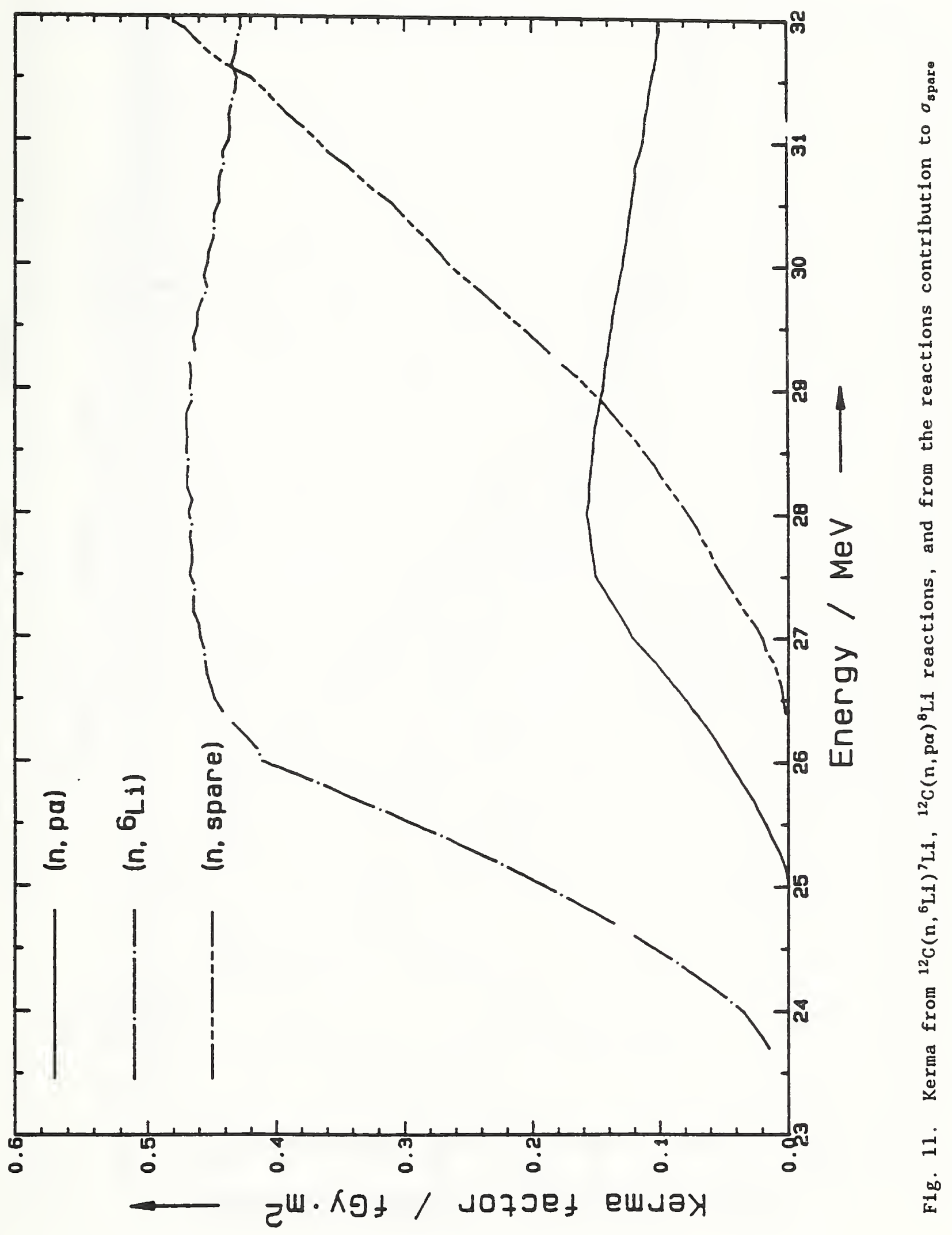




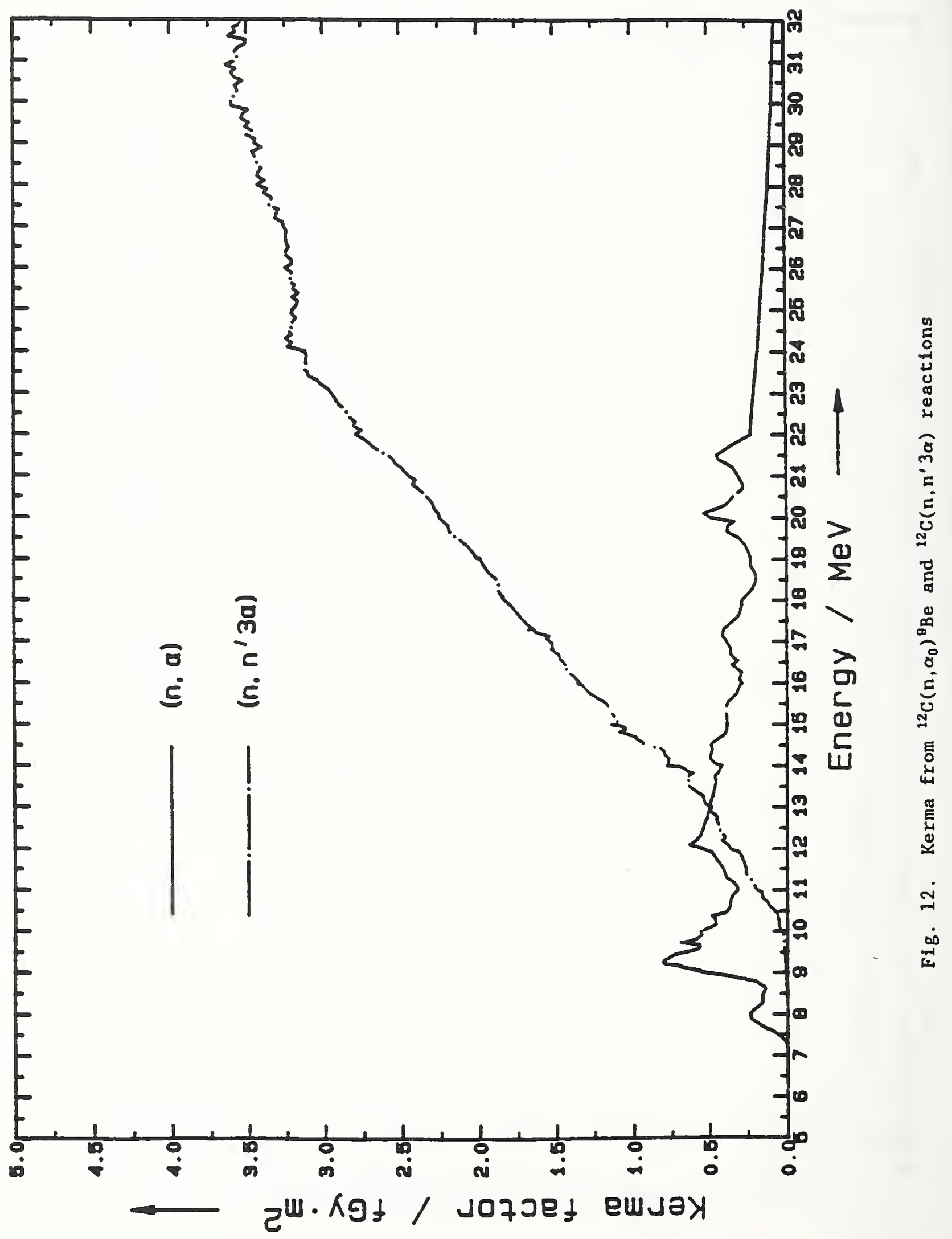




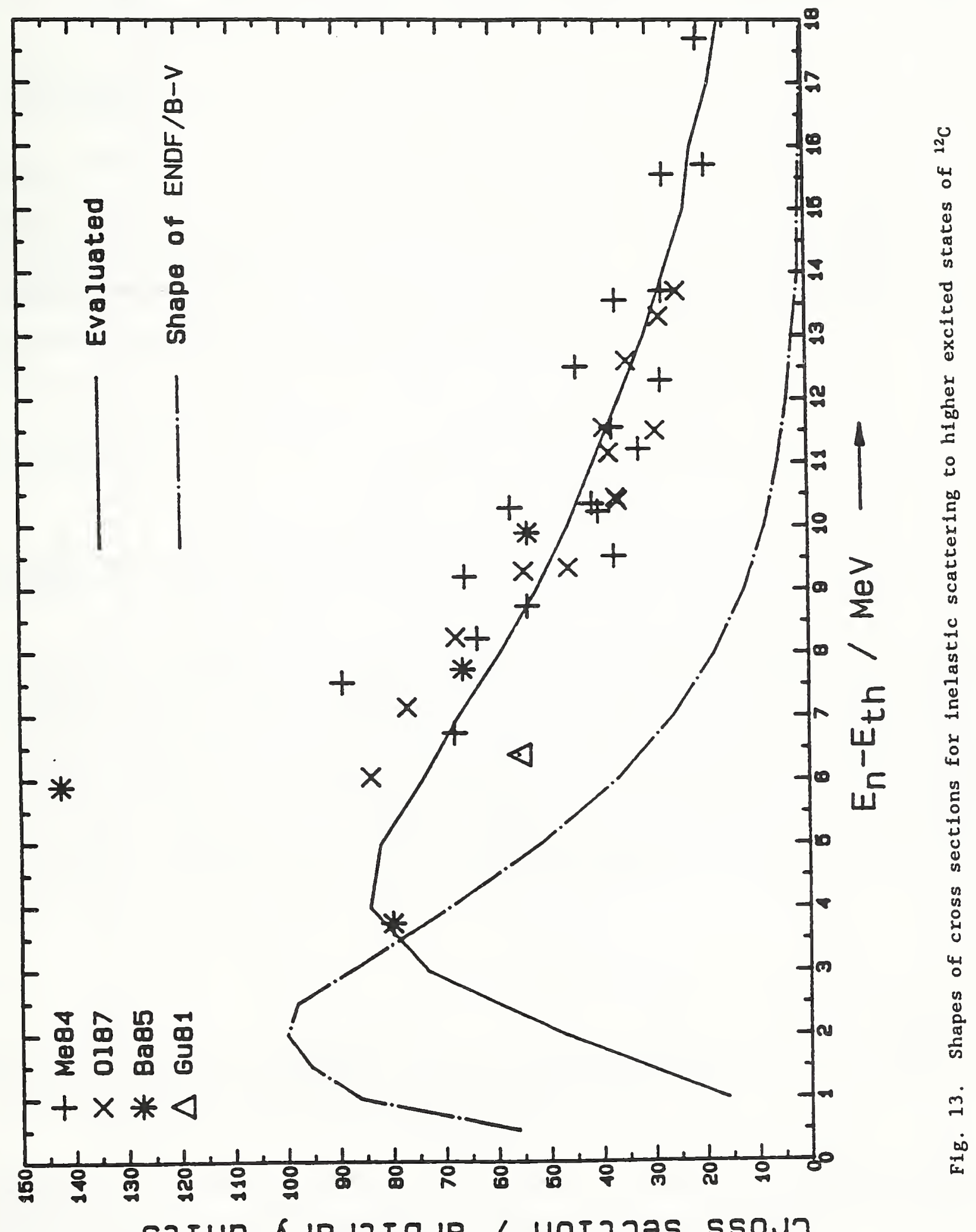

sqiun KJej7tque / voțzos ssojJ 


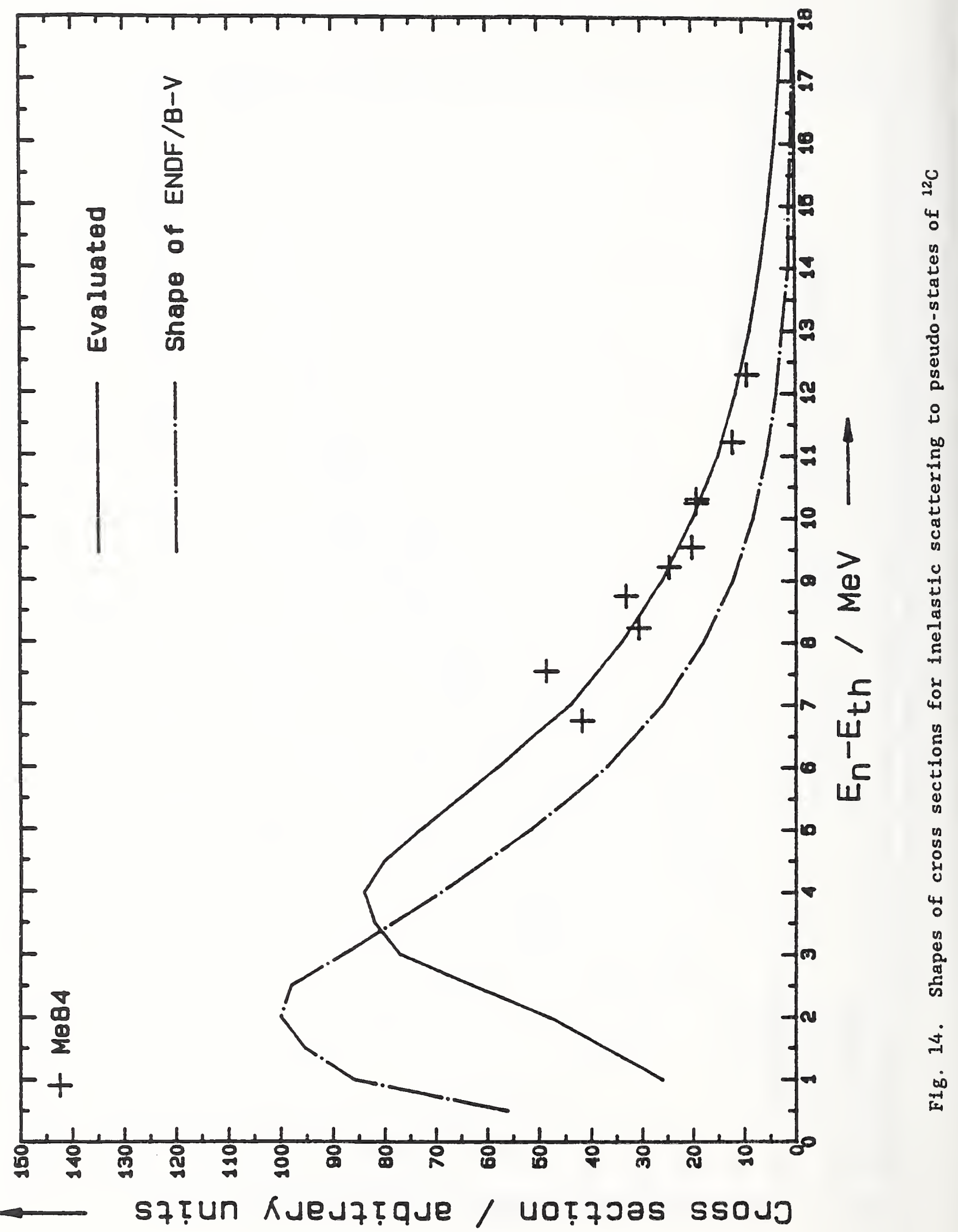




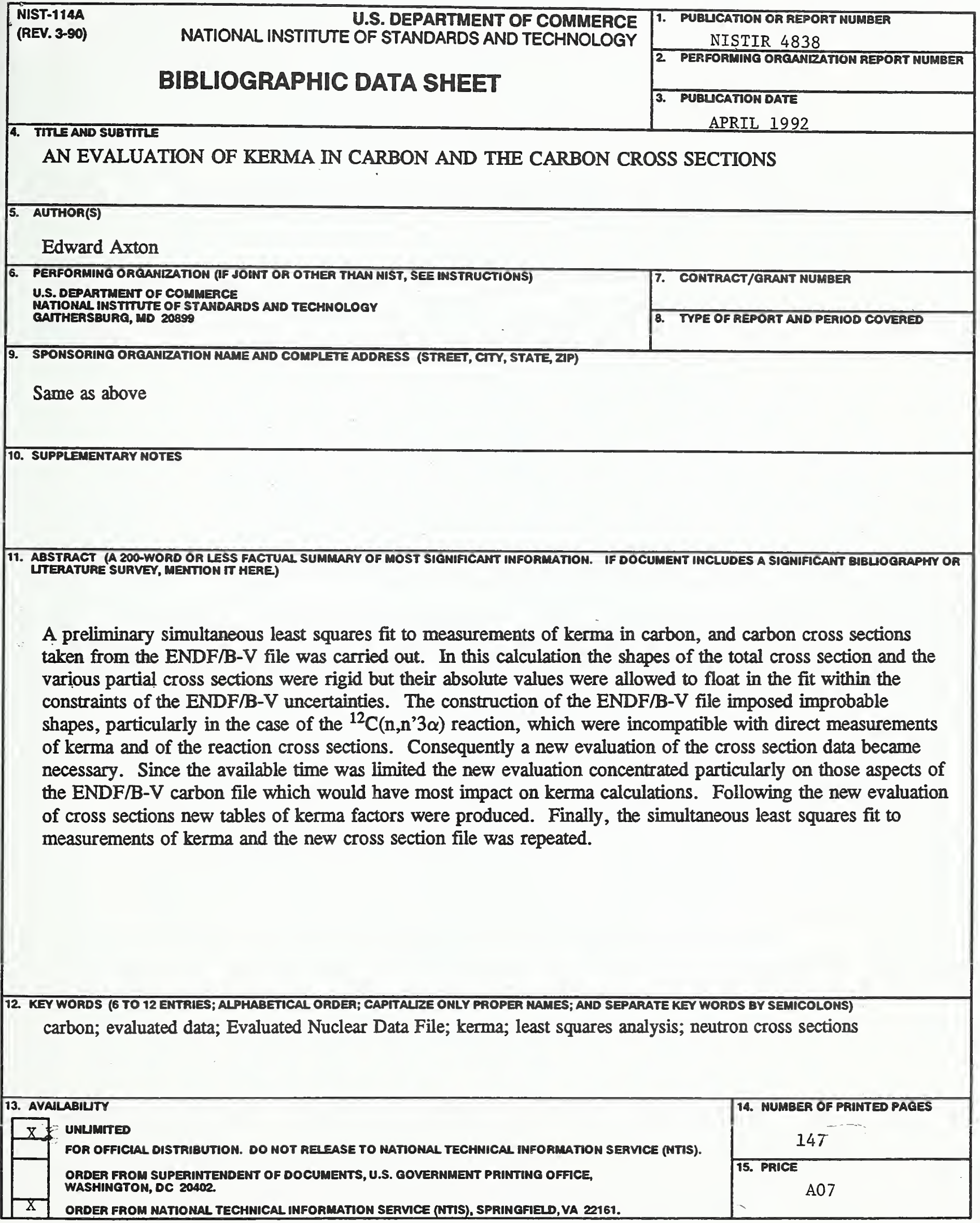




